Universidad de Lima

Facultad de Ingeniería y Arquitectura

Carrera de Ingeniería Industrial

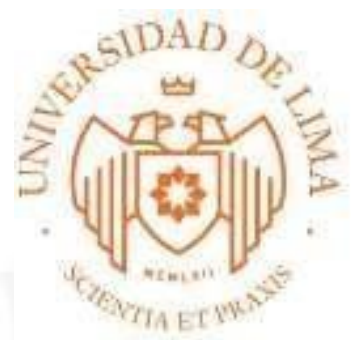

\title{
PROPUESTA DE MEJORA DEL PROCESO PRODUCTIVO DE LA LÍNEA DE PLANCHA DE FIBROCEMENTO DE LA FÁBRICA PERUANA ETERNIT S.A
}

Trabajo de investigación para optar el Título Profesional de Ingeniero Industrial

Marco Antonio Garcia Quispe

Código 20052644

Paul Anthony Acuña Chipana

Código 20051454

Asesor

Nicolás Salazar Medina

Lima - Perú

Diciembre del 2019 


\section{PROPOSAL FOR IMPROVEMENT OF THE PRODUCTION PROCESS OF THE FIBROCEMENT IRON LINE OF LA FÁBRICA PERUANA ETERNIT S.A}




\section{TABLA DE CONTENIDO}

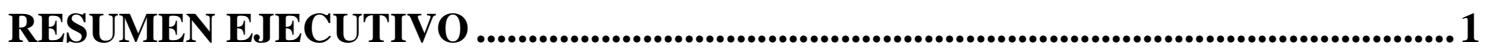

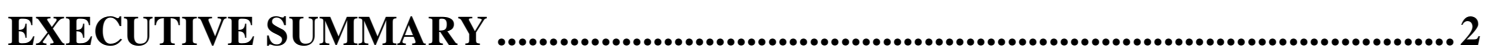

\section{CAPÍTULO I: CONSIDERACIONES GENERALES DE LA INVESTIGACIÓN 3}

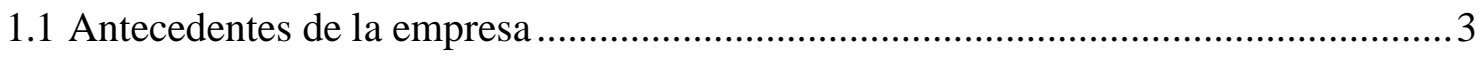

1.1.1 Breve descripción de la empresa y reseña histórica............................................

1.1.2 Descripción de los productos o servicios ofrecidos ......................................... 4

1.1.3 Descripción del mercado objetivo de la empresa ............................................. 10

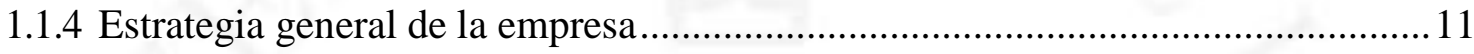

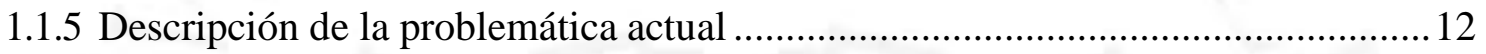

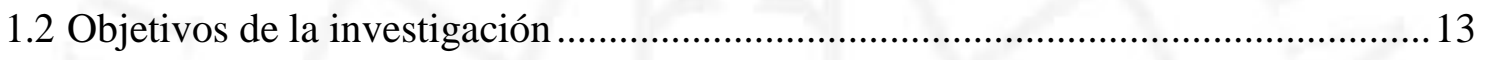

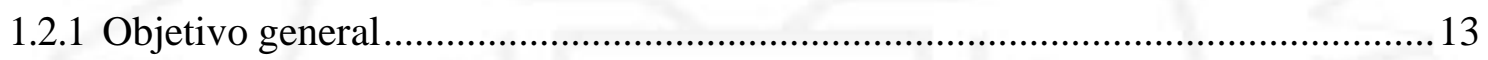

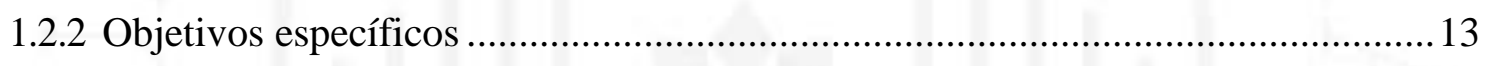

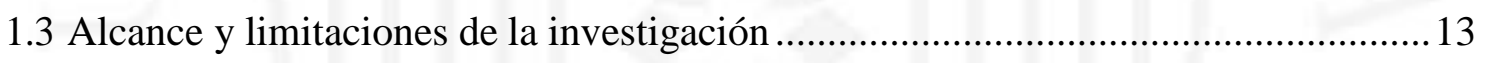

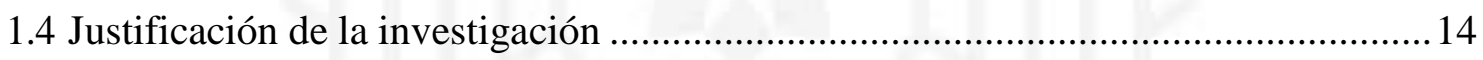

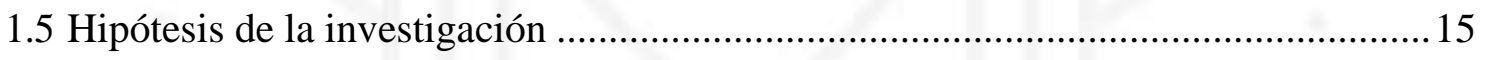

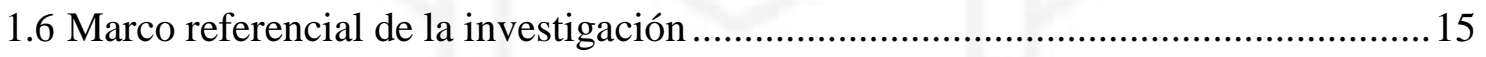

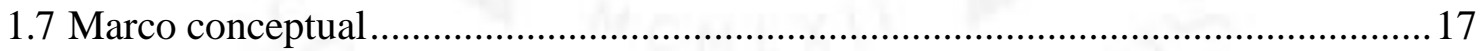

CAPITULO II: ANÁLISIS SITUACIONAL DE LA EMPRESA Y SELECCIÓN DEL SISTEMA O PROCESO A SER MEJORADO ............................................... 21

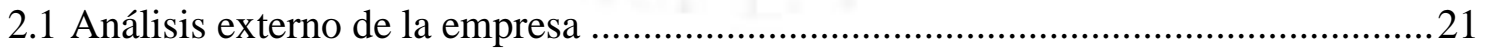

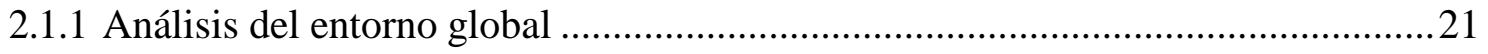

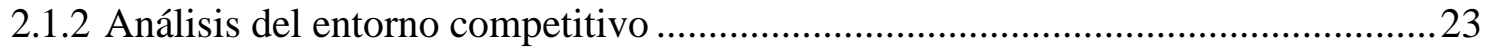

2.1.3 Identificación y evaluación de las oportunidades y amenazas del entorno.............25

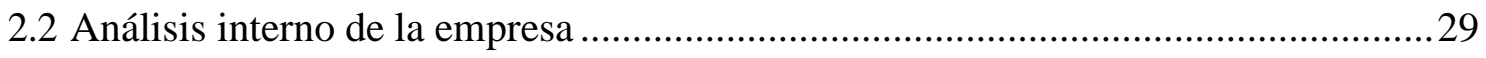

2.2.1 Análisis del direccionamiento estratégico: visión, misión y objetivos 
organizacionales

2.2.2 Análisis de la estructura organizacional .30

2.2.3 Identificación y descripción general de los procesos claves. .31

2.2.4 Análisis de los indicadores generales de desempeño de los procesos claves-línea base (metas, resultados actuales, tendencias, brechas, comparativos).... 32

2.2.5 Determinación de posibles oportunidades de mejora (hallazgo de problemas)......35

2.2.6 Identificación y evaluación de las fortalezas y debilidades de la empresa .............36

2.2.7 Selección del sistema o proceso a mejorar 40

\section{CAPÍTULO III: DIAGNÓSTICO DEL SISTEMA O PROCESO OBJETO DE ESTUDIO} 48

3.1 Análisis del sistema o proceso objeto de estudio .48

3.1.1 Descripción detallada del sistema o proceso objeto de estudio .48

3.1.2 Capacidad instalada .58

3.1.2 Análisis de los indicadores específicos de desempeño del sistema o proceso (metas, resultados actuales, tendencias, brechas, comparativos) .59

3.2 Determinación de las causas raíces de los problemas hallados .59

\section{CAPITULO IV: DETERMINACIÓN DE LA SOLUCIÓN PARA LOS}

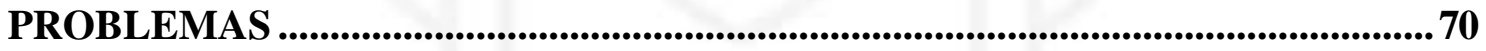

4.1 Planteamiento de alternativas de solución ......................................................... 70

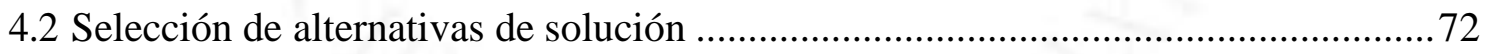

4.2.1 Determinación y ponderación de criterios de evaluación de las alternativas .........72

4.2.2 Evaluación cualitativa de las soluciones propuestas...........................................78

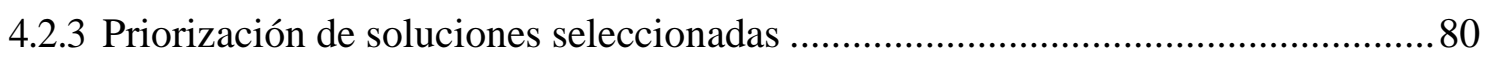

\section{CAPITULO V: IMPLEMENTACIÓN DE LAS SOLUCIONES PROPUESTAS. 84}

5.1 Ingeniería de la solución .84

5.2 Plan de implementación de la solución. 105

5.2.1 Objetivos y metas 105

5.2.2 Elaboración del presupuesto general requerido para la ejecución de la solución 106 


\section{CAPITULO VI: EVALUACIÓN ECONÓMICA FINANCIERA DE LA}

6.1 Determinación de escenarios para las soluciones propuestas .....

6.2 Estimación de los resultados de la implementación

6.2.1 Costos de la línea antes de la mejora 109

6.2.2 Costos de la línea después de la mejora 116

CONCLUSIONES 137

RECOMENDACIONES 138

REFERENCIAS. 140

BIBLIOGRAFIA 141 ANEXOS. 142 


\section{ÍNDICE DE TABLAS}

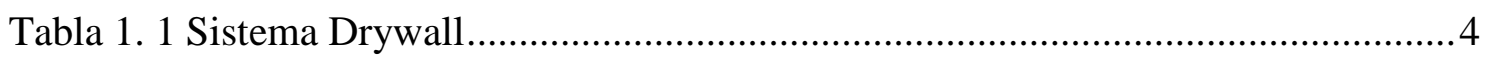

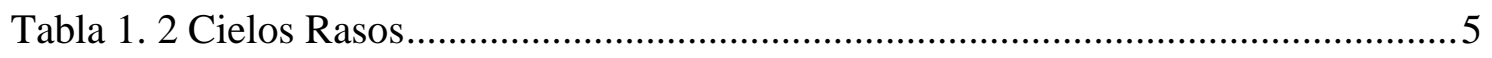

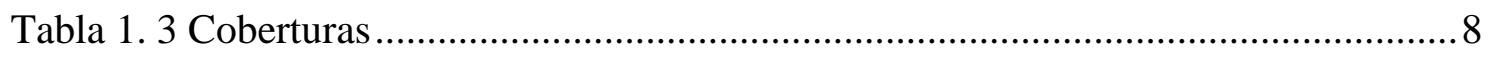

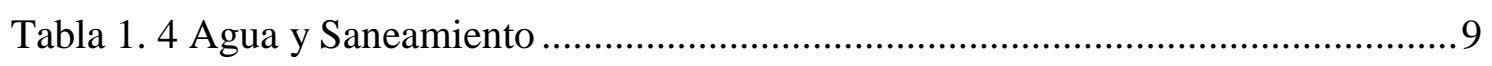

Tabla 1. 5 Principales Constructoras en el Perú 2017 ................................................... 11

Tabla 2. 1 Matriz de enfrentamiento de oportunidades ..................................................26

Tabla 2. 2 Matriz de enfrentamiento de amenazas ....................................................... 27

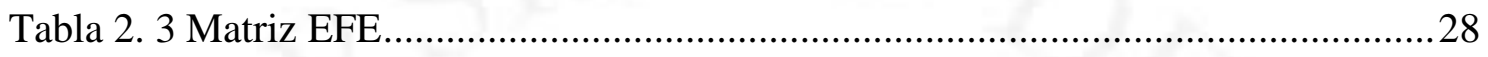

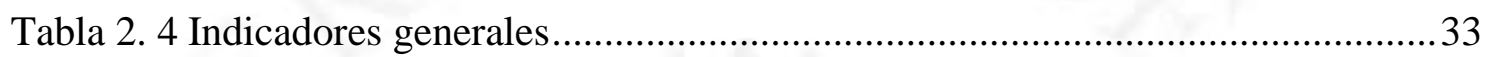

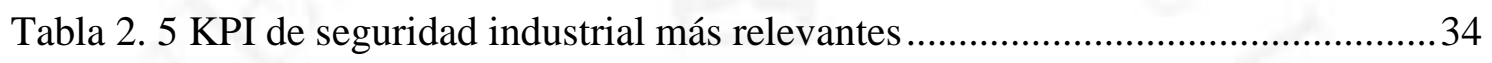

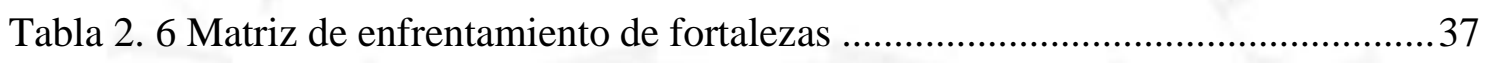

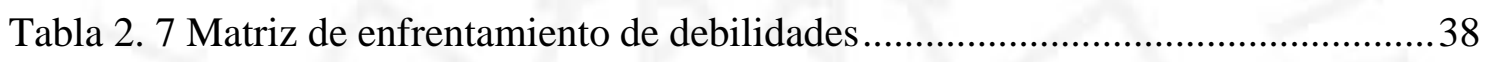

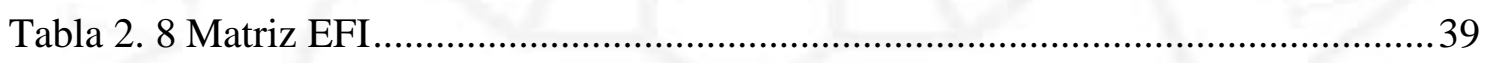

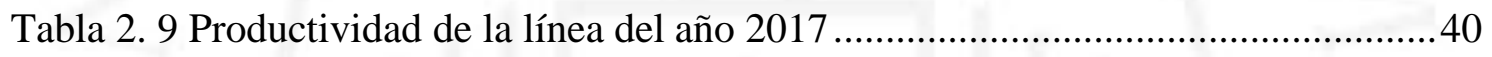

Tabla 2. 10 Paretto de los problemas que ocasionan paradas no programadas y/o baja

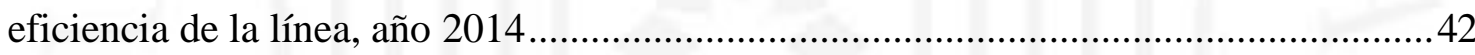

Tabla 2. 11 Paretto de los problemas que ocasionan paradas no programadas y/o baja eficiencia de la línea, año 2015.

Tabla 2. 12 Pareto de los problemas que ocasionan paradas no programadas y/o baja eficiencia de la línea, año 2016.

Tabla 2. 13 Pareto de los problemas que ocasionaron paradas no programadas y/o baja

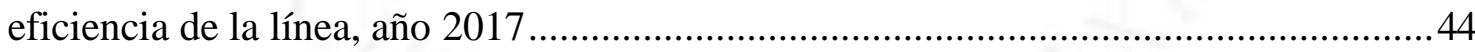

Tabla 2. 14 Cuadro comparativo del rendimiento de materia prima del 2014 al 2018...45

Tabla 2. 15 Accidentes e incidentes ocurridos del 2014 al 2018 ..................................46

Tabla 3. 1 Tiempo de ciclo por equipo para identificar el cuello de botella...................56

Tabla 3. 2 Capacidad de producción por equipo...........................................................58

Tabla 3. 3 Indicadores específicos de desempeño ...................................................59

Tabla 3. 4 Ranking de factores de retrasos en los mantenimientos programados ..........60

Tabla 3. 5 Ranking de factores de bajo rendimiento de la materia prima ......................61

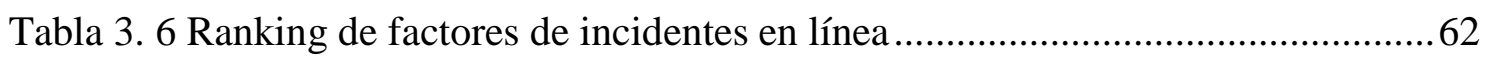

Tabla 3. 7 Ranking de factores de baja productividad en la línea ................................63 
Tabla 4. 1 Matriz de enfrentamiento de factores

Tabla 5. 1 Actividades de mantenimiento programado

Tabla 5. 2 Tiempo estándar de duración de las actividades de mantenimiento programado

Tabla 5. 3 Actividades de mantenimiento programado del Gantt de la primera semana87

Tabla 5. 4 Actividades de mantenimiento programado del Gantt de la segunda semana

Tabla 5. 5 Propuestas de solución para eliminar tiempos muertos .................................91

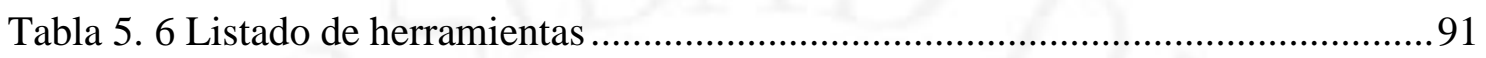

Tabla 5.7 Lista de repuestos y materiales más usados en los mantenimientos programados .92

Tabla 5. 8 Lista de objetos necesarios e innecesarios dentro de la línea .......................92

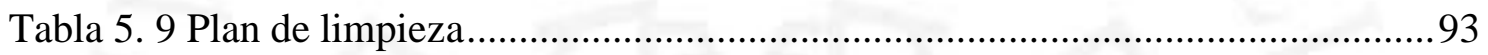

Tabla 5. 10 Distribución Actual....................................................................................94

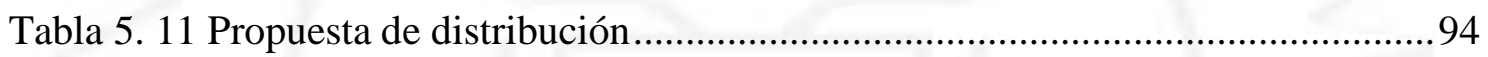

Tabla 5. 12 Capacitación de Programa de bloqueo y etiquetado ....................................98

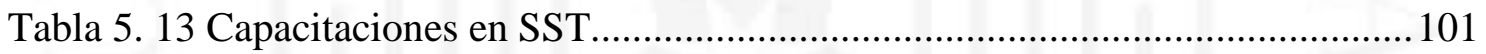

Tabla 5. 14 Mejoras en el equipo cuello de botella - desalojadora .............................. 104

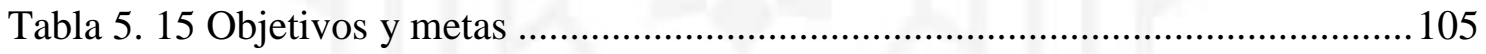

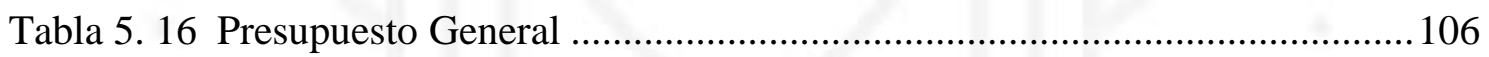

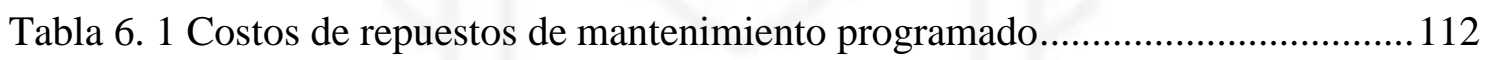

Tabla 6. 2 Costos de mantenimiento y seguridad en la línea de planchas de fibrocemento

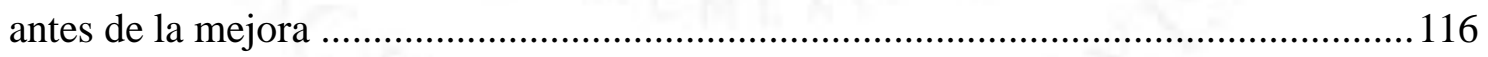

Tabla 6. 3 Materiales adicionales que se necesitan para la mejora............................. 119

Tabla 6. 4 Costos de repuestos con la mejora planteada...............................................119

Tabla 6. 5 Costo para eliminar el cuello de botella........................................................... 121

Tabla 6. 6 Costos de la línea de plancha de fibrocemento con las mejoras planteadas 122

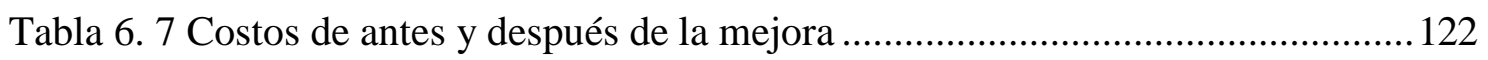

Tabla 6. 8 Variable dependiente del análisis de sensibilidad....................................... 123

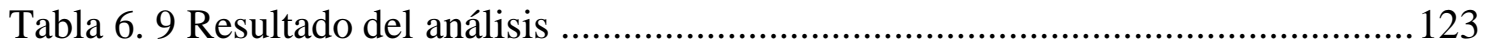

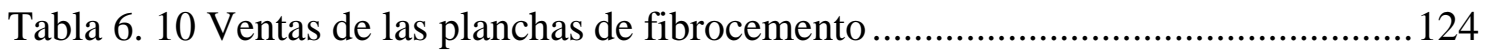

Tabla 6. 11 Costo de venta de las planchas de fibrocemento ........................................ 124 


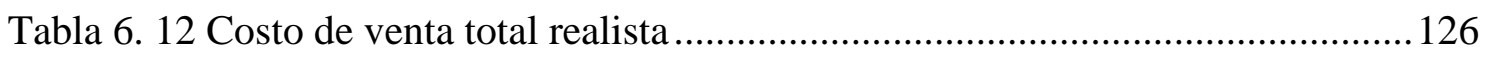

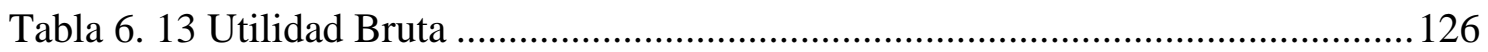

Tabla 6. 14 Análisis Económico en el escenario realista............................................... 127

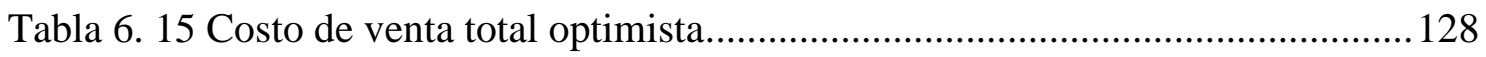

Tabla 6. 16 Análisis Económico en el escenario optimista ........................................ 129

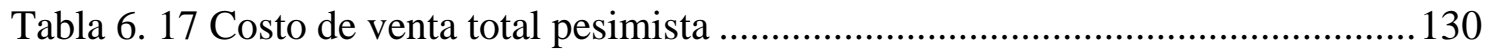

Tabla 6. 18 Análisis Económico en el escenario pesimista ......................................... 131

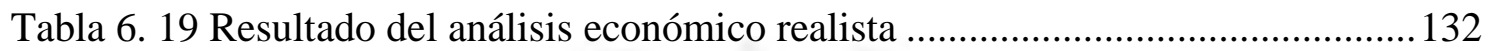

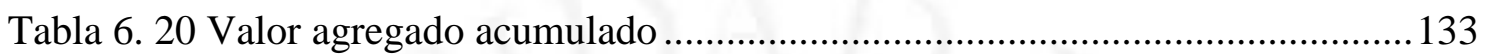




\section{ÍNDICE DE FIGURAS}

Figura 1. 1 Evolución Mensual de la Actividad del Sector Construcción 2015 - 2017.10

Figura 2. 1 Estructura organizacional de la línea de producción de planchas onduladas de

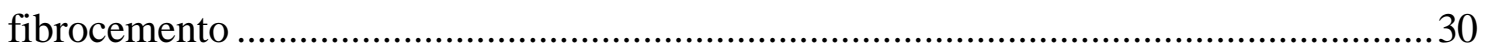

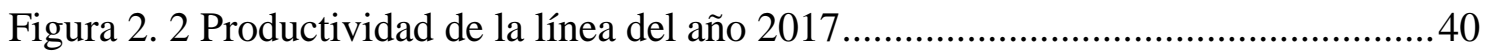

Figura 2. 3 Pareto de los problemas que ocasionan paradas no programadas y/o baja eficiencia de la línea, año 2014.

Figura 2. 4 Pareto de los problemas que ocasionan paradas no programadas y/o baja eficiencia de la línea, año 2015.

Figura 2. 5 Pareto de los problemas que ocasionan paradas no programadas y/o baja eficiencia de la línea, año 2016.

Figura 2. 6 Pareto de los problemas que ocasionan paradas no programadas y/o baja eficiencia de la línea, año 2017.

Figura 2. 7 Tendencia del rendimiento de materia prima del 2014 al 2018

Figura 2. 8 Accidentes e incidentes ocurridos del 2014 al 2018

Figura 3. 1 Mezclador. .48

Figura 3. 2 Máquina Hatschek. 49

Figura 3. 3 Ventosa Ondulada .... .50

Figura 3. 4 Cabina Precuadrado. .51

Figura 3. 5 Máquina Desalojadora. .52

Figura 3. 6 Diagrama de operaciones del proceso de fabricación de planchas de fibrocemento (DOP) .53

Figura 3. 7 Diagrama de Balance de materia .55

Figura 3. 8 Diagrama de Ishikawa de retrasos en los mantenimientos programados .....65

Figura 3. 9 Diagrama de Ishikawa de bajo rendimientode la materia prima .66

Figura 3. 10 Diagrama de Ishikawa de incidentes en la línea. 67

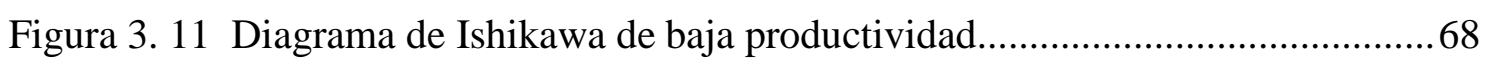

Figura 4. 1 Escalas para evaluar las propuestas de solución.......................................... 73

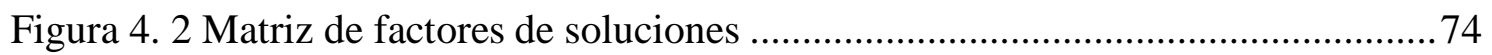

Figura 5. 1 Gannt de primera semana de mantenimiento programado ........................... 88

Figura 5. 2 Gannt de segunda semana de mantenimiento programado .......................... 90

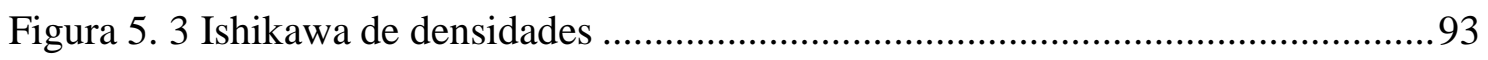




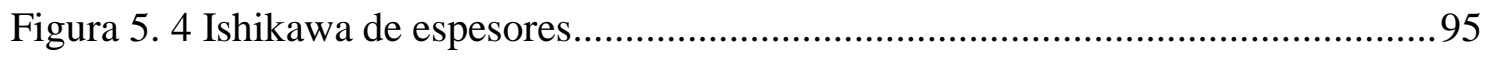

Figura 5. 5 Cronograma de Implementación .............................................................. 108

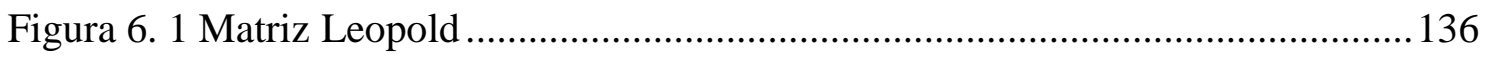




\section{INDICE DE ANEXOS}

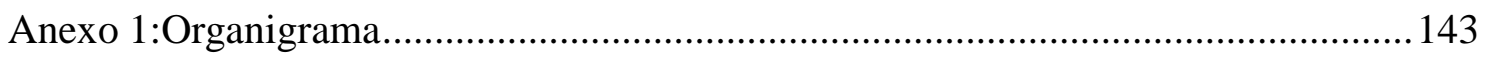

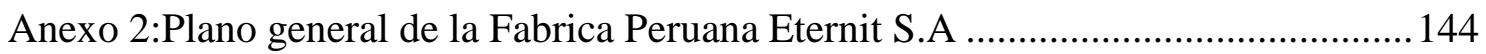

Anexo 3:Determinación del tiempo estándar de las actividades de mantenimiento

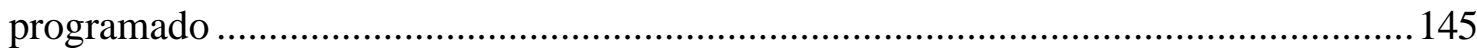

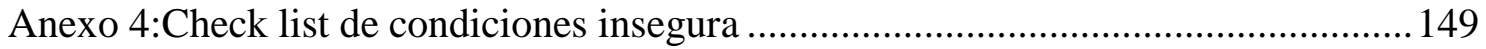

Anexo 5:Criterios de evaluación para la clasificación de condiciones inseguras por

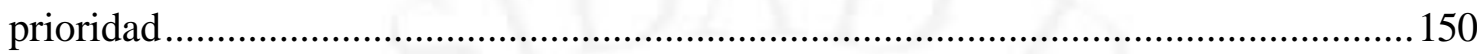

Anexo 6: Matriz de clasificación de condiciones inseguras por prioridad .................... 151

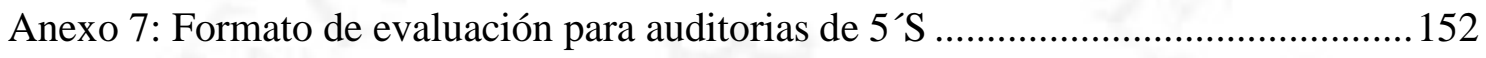

Anexo 8: Formato de observaciones encontradas en auditorias de 5'S ........................ 153

Anexo 9:Formato de control de tarjetas rojas de 5’S ............................................... 155

Anexo 10:Formato de control de tarjetas rojas de 5’S-Herramientas ............................. 156

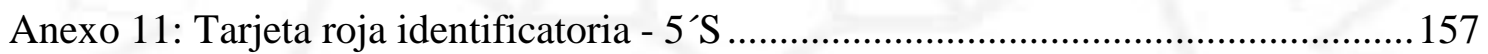

Anexo 12: Zona de acopio del material sustraído de los mantenimientos programados 158

Anexo 13:Cálculo del OEE de los meses de junio, julio, agosto y setiembre del 2018, de la línea de planchas de fibrocemento 159

Anexo 14: Análisis SMED para reducción de tiempos de cambios ............................... 160

Anexo 15:Trabajo de mantenimiento programado .................................................. 161

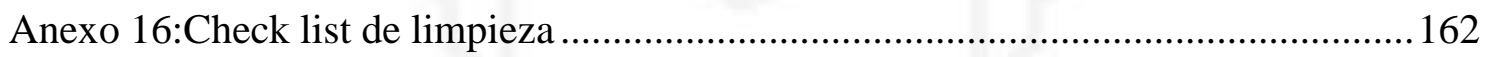

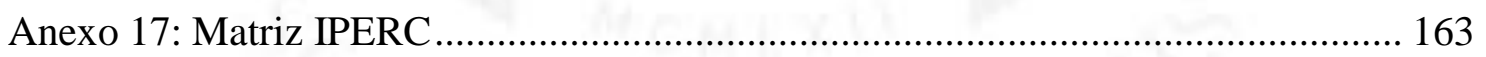




\section{RESUMEN EJECUTIVO}

La presente tesis tiene como objetivo general demostrar que es factible mejorar el proceso productivo de la línea de planchas de fibrocemento de la Fábrica Peruana Eternit aplicando ingeniería y empleando herramientas de ingeniería industrial. Mediante justificaciones técnicas, económicas y sociales se determinó que es factible cumplir con el objetivo general planteado.

Luego de elaborar un análisis interno y externo de Eternit S.A, se determinó que la línea con mejores oportunidades para realizar la mejora es la de planchas de fibrocemento, ya que, es allí donde existe mayor cantidad de problemas que afectan la productividad de la línea y de la empresa.

Por ello, se propuso utilizar las herramientas de ingeniería industrial para la mejora del proceso de la línea de plancha de fibrocemento de la Fábrica Peruana Eternit los cuales fueron 5`S, SMED, OEE, Diagrama de Ishikawa, Diagrama de Pareto para proponer distintas soluciones.

Finalmente, se evaluó los beneficios cuantitativos y cualitavos de la mejora obteniendo resultados positivos para la línea y empresa como un VANE de S/9 935929 y un TIRE de $205 \%$. Así mismo, mediante la matriz de Leopold se concluyó que la implementación de mejora no generará un impacto ambiental dañino para la sociedad.

Palabras Clave: Proceso, plancha de fibrocemento, herramientas de ingeniería industrial. 


\section{EXECUTIVE SUMMARY}

The thesis has as a general objective to demonstrate that it is feasible to improve the production process of the fiber cement sheet line of the Peruvian Eternit Factory using industrial engineering tools. Through technical, economic and social justifications it was determined that it is feasible to comply with the general objective set.

After elaborating an internal and external analysis of Eternit SA, it was determined that the line with the best opportunities to carry out the improvement is that of fiber cement sheets, since that is where there are the greatest number of problems that affect the productivity of the line and of the company.

Therefore, it was proposed to use industrial engineering tools to improve the process of the fiber cement sheet line of the Peruvian Eternit Factory which were 5'S, SMED, OEE, Ishikawa diagram, Paretto diagram to propose different solutions .

Finally, the quantitative and qualitative benefits of the improvement were evaluated, obtaining positive results for the line and company, such as a NPV of S / 9935 929 and a TIR of $205 \%$. Likewise, through the Leopold matrix, it was concluded that the implementation of improvement will not generate an environmental impact harmful to society.

Keywords: Process, fiber cement sheet, industrial engineering tools. 


\section{CAPÍTULO I: CONSIDERACIONES GENERALES DE LA INVESTIGACIÓN}

\subsection{Antecedentes de la empresa}

\subsubsection{Breve descripción de la empresa y reseña histórica}

Fábrica Peruana Eternit S.A con RUC 20100051240 y domicilio legal en Jirón República del Ecuador $N^{\circ} 448$ avenida Argentina (Entre las cuadras 10 y 11) - Lima, representada por su Titular - Gerente Sr. Manzur Fegale.

Es una empresa líder en la fabricación de productos de fibrocemento que opera desde 1940 en la zona industrial de Lima. Dicha empresa está conformada por las áreas de Administración y Recursos Humanos, Finanzas y Contabilidad, Logística, Marketing y Publicidad, Ventas, Sistemas e Informática, Producción, Planeamiento y Control de la producción, Calidad, Mantenimiento. Así mismo, forma parte del Grupo Etex, importante Holding Industrial Belga con presencia en los cinco continentes. Toda la producción se realiza bajo estrictas normas técnicas nacionales e internacionales, esto certifica un alto nivel de calidad en cada uno de los productos. Así mismo, cuenta con innovación constante para brindar nuevas soluciones y opciones creativas para la industria de la construcción.

Cuenta con tres plantas de producción localizadas en Lima, Huachipa y Chiclayo. Por otro lado, cuenta con líneas especializadas como protección pasiva contra incendios y fachadas arquitectónicas. 


\subsubsection{Descripción de los productos o servicios ofrecidos}

Tabla 1. 1

Sistema Drywall

PRODUCTO DESCRIPCION

GYPLAC ST 1/2" - EXTRALIVIANA

Placa de yeso, con menor peso.

FICHA GYPLAC ST

La placa de yeso standard GYPLAC ST, sirve para paredes y cielos rasos interiores. No apto para su uso en exteriores. Es $100 \%$ reciclado.

GYPLAC RH

GYPLAC RF
La placa de yeso GYPLAC RH es resistente a la humedad e ideal para su uso en baños y cocinas. Es una base para la aplicación de todo tipo de enchapes u otros acabados. Es $100 \%$ reciclado.

La placa de yeso GYPLAC RF es resistente al fuego. Es utilizada para ambientes que necesiten resistencia hacia el fuego tales como cocinas, salidas de emergencia, escuelas, hospitales, universidades, etc.

FICHA GYPLAC EXSOUND

La placa de yeso GYPLAC EXSOUND tiene un diseño con perforaciones cuadradas o circulares las cuales le dan características fonoabsorbentes y estéticas

PLACA DE YESO GYPLAC CIEL $7,0 \mathrm{~mm}$
La placa GYPLAC CIEL 7,0 mm. Fue diseñada para falsos cielos rasos del Sistema Drywall.

Fuente: Fábrica Peruana Eternit (2019)

Elaboración Propia

Tal como se puede observar en la Tabla 1.1, se muestras los distintos productos del

Sistema Drywall de la Fábrica Peruana Eternit S.A los cuales están conformados por 6. 
Tabla 1.2

Cielos Rasos

PRODUCTO DESCRIPCION

FICHA TECNICA-VANTAGE 10.PDF

Es resistente a la humedad con aspecto clásico de cielos acústicos minerales. Libre de formaldehido.

FINE FISSURED

Es $100 \%$ fisurado, con variedad de detalles y tamaños.

SAND MICRO

Es un cielo raso cuenta con una ligera textura brindando un mejor reflejo de la luz.

VINYL SHIEL A

Fue diseñado para aplicaciones sanitarias y para salas amplias.

Es ideal para ambientes de alto tránsito y que requieran una limpieza constante.

VINYL ROCK

SYMPHONY M



TACLA 0

CONSTELLATION 3

PLAIN
No contienen asbesto.

Es un cielo raso de la línea DecoAcustic, se caracteriza por tener una fina textura y sin micro perforaciones, cuenta con una alta densidad que permite un buen aislamiento acústico.

Cuenta con un alto nivel de asepsia, soportando hasta 500 ciclos de lavado; con su acabado microperforado garantiza un alto nivel de confort acústica.

Cuenta con un alto nivel de asepsia, soportando hasta 500 ciclos de lavado; tiene un acabado 100\% liso. 
(continuación)

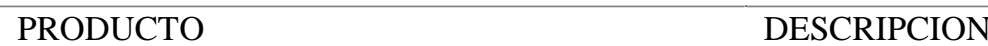

COSMO 68N

Cuenta con un acabado microperforado elegante y moderno, con alto nivel de absorción y atenuación acústica.

BAMBOO DARK

Cuenta con un acabado de Bamboo oscuro con micro perforaciones simétricas ofreciendo un toque exclusivo de lujo y calidez

BAMBOO LIGHT

AQUACOSMOS

SERENE

SIRUS

DECO ASTRAL

LOS PANELES METÁLICOS OWATECTA
Cuenta con un acabado de Bamboo claro con micro perforaciones simétricas ofreciendo un toque exclusivo de lujo y calidez, con alta absorción de ruido.
Tiene un alto nivel de resistencia a la humedad y se puede utilizar externamente y en otras áreas húmedas, donde los techos se encuentren en exposición de hasta $100 \%$ de humedad relativa.

Es una baldosa para cielo raso, líder en el mercado, que combina un excelente acabado fisurado con un buen desempeño acústico, además de un precio económico

Es un sistema deco que ofrece soluciones completas para tu cielo raso. Es ideal para oficinas, salas de reuniones y gerencia, salas de música y aulas.

Es una baldosa para cielo raso de la línea DecoBasic que combina un excelente acabado con un precio muy accesible.

Son unos de los favoritos de los diseñadores porque ofrecen a los especificadores, arquitectos y contratistas variedad de opciones y soluciones creativas para todo tipo de proyectos

(continúa) 
(continuación)

PRODUCTO

DESCRIPCION

DURACUSTIC CIROCO

Cielo Raso con funciones de aislamiento acústico y térmico compuesto por una lámina rígida de fibra de vidrio, recubierta en una de sus caras por una película de PVC.

LAS BALDOSAS BOLERO

Oculta detrás de tanta delicadeza óptica una alta absorción del sonido. Combina perfectamente la suavidad y fineza de la estructura de la superficie con una excelente absorción del sonido.

SINFONIA

Fue desarrollado con el fin de trabajar en un campo operativo de gran alcance. Las baldosas son adecuadas para zonas acústicamente sensibles.

\section{MULTIPLACA CIELO}

Es un sistema de cielo raso especialmente desarrollado para brindar una solución práctica y económica de óptimo desempeño.

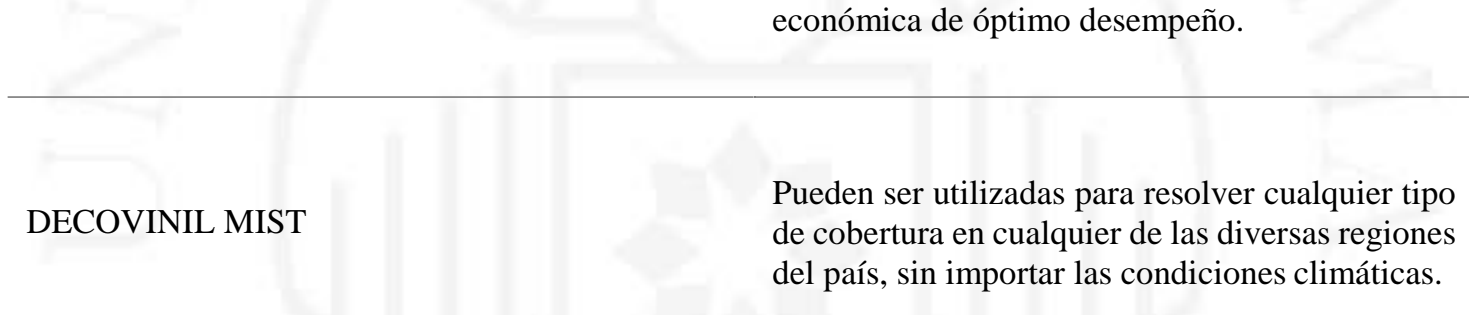

DECOMETAL

Es la línea de cielos modulare en aluminio. Combina durabilidad con un diseño moderno y elegante y está compuesta por bandejas de $0.61 \mathrm{x}$ $0.61 \mathrm{~m}$. con perforaciones simétricas.

Fuente: Fábrica Peruana Eternit (2019)

Elaboración Propia

Tal como se puede observar en la Tabla 1.2, se puede apreciar los tipos de cielos rasos que produce la Fábrica Peruana Eternit S.A los cuales están conformados por 23. 
Tabla 1.3

Coberturas

PRODUCTO DESCRIPCION

PERFIL 4

Es la plancha ondulada de fibrocemento para coberturas. Las planchas están fabricadas con una mezcla homogénea de cemento, fibras sintéticas y agua, materiales con los cuales se logra un producto de gran resistencia.

GRAN ONDA

Es la plancha ondulada de fibrocemento para coberturas. Las planchas están fabricadas con una mezcla homogénea de cemento, fibras sintéticas y agua, materiales con los cuales se logra un producto de gran resistencia.

TEJA ANDINA
Es una plancha decorativa de fibrocemento para coberturas. Las planchas están fabricadas con una mezcla homogénea de cemento, fibras sintéticas y agua, materiales con los cuales se logra un producto de gran resistencia.

Fuente: Fábrica Peruana Eternit (2019)

Elaboración Propia

Tal como se puede observar en la Tabla 1.3, se puede apreciar los tipos de coberturas (planchas) que produce la Fábrica Peruana Eternit S.A los cuales están conformados por 3 , los cuales a pesar de las condiciones climáticas de distintas provincias del país, los techos que ofrece Eternit S.A cuentan con alta resistencia a la humedad, intensas lluvias, nieve o granizo. 
Tabla 1.4

Agua y Saneamiento

PRODUCTO DESCRIPCION

LOS TANQUES DOMÉSTICOS

Están fabricados con materia prima de alta calidad y bajos altos estándares de seguridad para asegurar un almacenamiento totalmente seguro e higiénico.

EL TANQUE CISTERNA

EL BIODIGESTOR
Se instala bajo tierra y almacena agua limpia proveniente de la red pública. Es parte del sistema de tanque elevado. Su diseño con hombros y anillos le otorga mayor resistencia para instalarse enterrada.

Es la solución para zonas donde no se encuentra red pública de desagüe o drenaje. Reemplaza de manera eficiente los pozos sépticos. Es autolimpiable, lo que ahorra costos de mantenimiento. Funciona de forma segura y es muy económico.

Los tanques para almacenamiento de pisco y vino, son especialmente diseñados para la industria vitivinícola ya que mantiene las propiedades físicas, químicas y organolépticas del Pisco y Vino.

Los tanques para almacenamiento industrial de agua tienen una capa interior $\mathrm{A}+$ antimicrobiana que impide el crecimiento y reproducción de bacterias. Son altamente resistentes.

TANQUE PARA ALMACENAMIENTO DE AGUA

Los tanques para almacenamiento de químicos, permite almacenar diversos compuestos químicos utilizados en procesos industriales. Mantiene las propiedades físicas y químicas de los productos sin transferir color, sabor y olor.

Fuente: Fábrica Peruana Eternit (2019)

Elaboración Propia

Tal como se puede observar en la Tabla 1.4 se puede apreciar los distintos tanques producidos para el almacenamiento del agua y saneamiento los cuales están conformados por 6. 


\subsubsection{Descripción del mercado objetivo de la empresa}

El sector construcción es un impulsor para la economía peruana. Genera mayores oportunidades de empleo y tiene gran cobertura dentro de la inversión privada y pública.

En el año 2017, el sector Construcción ha presentado un gran incremento a comparación de otros años alcanzando la más alta tasa en el mes de agosto 2017.

(El diario de Economia y Negocios del Perú, 2017) "el Informe Técnico Avance Coyuntural de la Actividad Económica, este comportamiento positivo se explica por el crecimiento del consumo interno de cemento $(3,52 \%)$ y el mayor gasto en inversión de obras públicas $(9,60 \%)$ ”

Figura 1. 1

Evolución Mensual de la Actividad del Sector Construcción 2015 - 2017

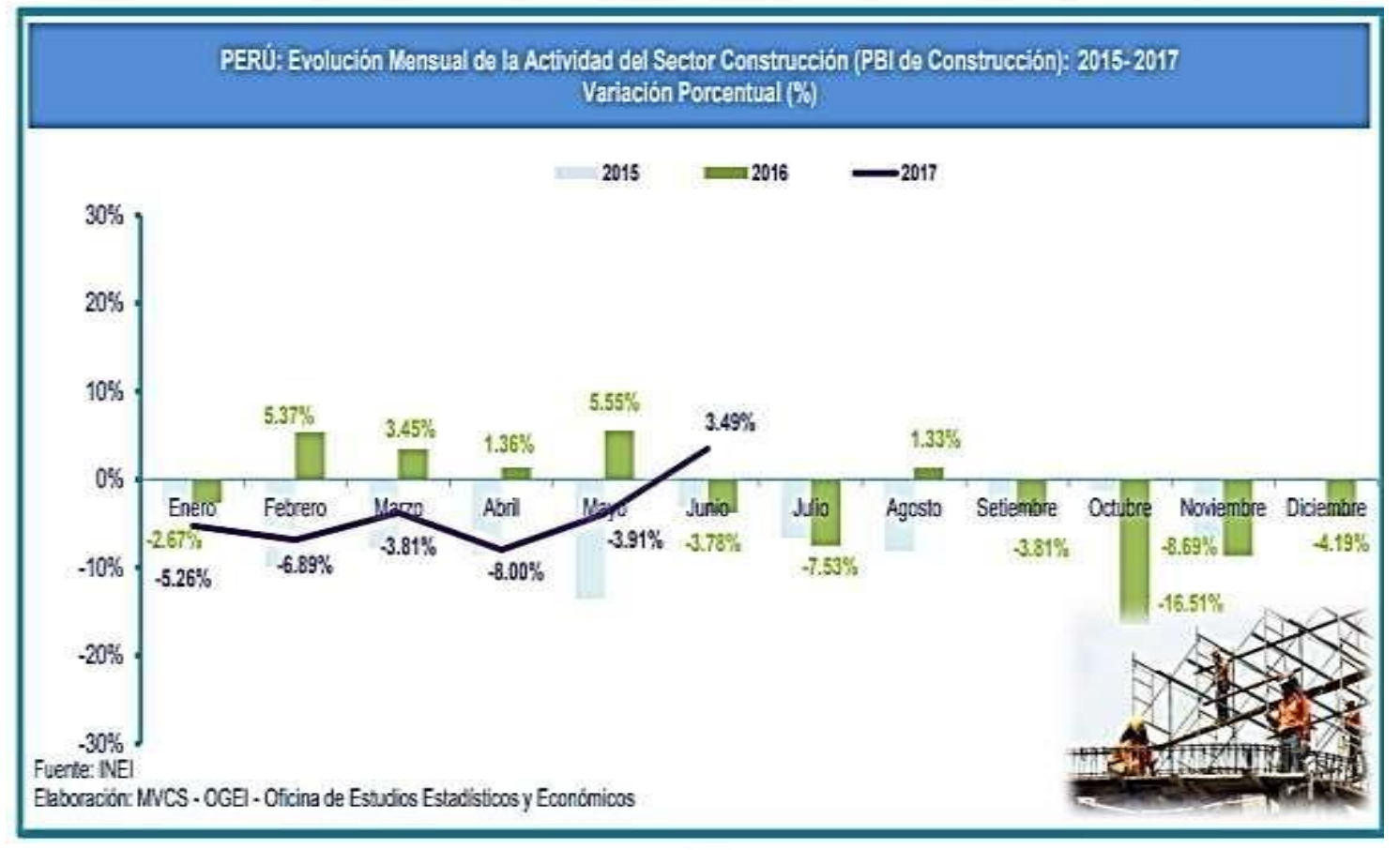

Fuente: Instituto Nacional de Estadística e Informática (2019)

Como se puede apreciar en la Figura 1.1, la evolución mensual del sector construcción entre los años 2015-217 presenta una mejora, lo cual es favorable para la Fábrica Peruana Eternit S.A ya que el sector construcción es su principal mercado objetivo. 
Tabla 1.5

Principales Constructoras en el Perú 2017

\begin{tabular}{ll}
\hline EMPRESA & DESCRIPCIÓN \\
\hline COSAPI & COSAPI ofrece al mercado \\
& servicios de ingeniería y \\
construcción, servicios mineros, \\
negocios en concesiones de \\
infraestructura y desarrollos
\end{tabular}

Fuente: Cámara Peruana de la Construcción (2019)

Elaboración Propia

Como se puede observar en la Tabla 1.5, se presentan las tres principales empresas constructoras en el Perú, las cuales compran los productos ofrecidos por la Fábrica Peruana Eternit S.A.

\subsubsection{Estrategia general de la empresa}

La estrategia de la empresa Eternit es usar su competitividad en el mercado como fabricantes de materiales de fibrocemento, yeso y polietileno en el sector de la construcción. Contando con mayor presencia en las zonas de comercialización del país teniendo un eficiente y eficaz servicio al cliente.

Mantener la calidad del producto a precios competitivos que cubran las necesidades del mercado de la construcción.

Ampliar la red de distribuidores con empresas líderes en trayectoria comercial y crediticia.

Mantener la participación en ferias y eventos en el interior del país contribuyendo y obteniendo contactos con profesionales de los gremios de la construcción. 


\subsubsection{Descripción de la problemática actual}

En la actualidad, de todas las líneas que maneja la Fabrica Peruana Eternit S.A la línea que presenta mayor problema y dificultad de producción es la línea de planchas de fibrocemento. Esto es debido a diferentes factores tales como:

Retrasos en los mantenimientos programados ya que actualmente tiene una duración de 12 horas cuando debería ser de 8 horas (meta establecida por la empresa). Esto es debido a la falta de una planificación previa de los trabajos a ejecutarse y una carencia de supervisión al personal que las ejecuta, existen tiempos muertos por búsqueda de herramientas, materiales y repuestos, además, la línea se encuentra sucia y desordenada, no existe un programa de orden y limpieza.

Bajo rendimiento de materia prima y esto se genera por que los parámetros de control que impactan directamente al rendimiento de la materia prima resultan fuera de los límites de aceptación, las propiedades de algunas materias primas están fuera de especificación, hay fuga de material, el personal no opera correctamente los equipos y la línea se encuentra sucia y desordenada, no existe un programa de orden y limpieza.

Incidentes en la línea, esto es debido a que no hay un seguimiento de condiciones inseguras reportadas, se han encontrado equipos sin sistema de seguridad integrado, falta de compromiso del personal técnico y operario con la seguridad, y la línea se encuentra sucia y desordenada, no existe un programa de orden y limpieza.

La baja productividad de la línea de planchas, esta no alcanza al indicador meta establecido por la empresa $\left(962 \mathrm{~m}^{2} \mathrm{n}^{1} / \mathrm{hc}\right)$ y esto debido a que no se mide la eficiencia productiva por cada equipo, no se plantean y se ejecutan acciones para "eliminar" el cuello de botella, ineficientes trabajos en los mantenimientos programados, paradas no programadas, demoras en los cambios de producción y la línea se encuentra sucia y desordenada, no existe un programa de orden y limpieza.

Es por ello, que se ha determinado el uso de ingeniería y de las herramientas de ingeniería industrial para disminuir los problemas encontrados en la línea.

\footnotetext{
${ }^{1}$ Metros cuadros normales: Se calcula multiplicando largo (mts) x ancho (mts) x espesor (mm)/5 de las planchas. $\left(1 \mathrm{~m}^{3}=200 \mathrm{~m}^{2} \mathrm{n}\right)$
} 


\subsection{Objetivos de la investigación}

\subsubsection{Objetivo general}

Demostrar que es factible mejorar el proceso productivo de la línea de planchas de fibrocemento de la Fábrica Peruana Eternit S.A aplicando ingeniería y empleando herramientas de ingeniería industrial.

\subsubsection{Objetivos específicos}

- Definir como disminuir los retrasos en los mantenimientos programados en la línea de planchas de fibrocemento de la Fábrica Peruana Eternit S.A.

- Identificar como mejorar el bajo rendimiento de materia prima en la línea de planchas de fibrocemento de la Fábrica Peruana Eternit S.A.

- Identificar como reducir los incidentes en la línea de planchas de fibrocemento de la Fábrica Peruana Eternit S.A

- Evaluar de qué manera se incrementará la baja productividad en la línea de planchas de fibrocemento de la Fábrica Peruana Eternit S.A.

\subsection{Alcance y limitaciones de la investigación}

A continuación se define el alcance y limitaciones que se presentan en el trabajo de investigación:

La presente investigación se realiza como proyecto de mejora de ingeniería a nivel de propuesta validada desarrollado en el proceso productivo de la línea de planchas de fibrocemento de la Fábrica Peruana Eternit y se elaboró durante el año 2017 al 2018.

Como limitaciones se tiene la disponibilidad de información por lo que ha sido necesario realizar visitas de observación a la planta productiva. Por otro lado, se tiene el tiempo reducido por lo que se ha cumplido con el tiempo límite de orden de un cronograma de trabajo. 


\subsection{Justificación de la investigación}

\section{Técnica}

Técnicamente es viable realizar la mejora del proceso productivo de la línea de plancha de fibrocemento de la Fábrica Peruana Eternit S.A utilizando las herramientas de ingeniería industrial como SMED que tiene como objetivo la reducción del tiempo de cambio (setup), OEE ( Eficiencia global de los equipos) que sirve para medir la eficiencia a medida que se introducen mejoras , 5 $\mathrm{S}$ que abarcan una serie de actividades para eliminar los despilfarros que contribuyen a errores, defectos y accidentes en el trabajo y para apoyar el proceso de mejora se utilizará diagramas de distintos tipos como Pareto, Ishikawa.

Asimismo, es factible aplicar ingeniería en el equipo cuello de botella (desalojadora) disminuyendo su tiempo de ciclo.

\section{Económica}

- Incrementando la productividad de la empresa equivale a obtener menores costos utilizando las herramientas de mejora continua.

- Eliminando las horas muertas en el mantenimiento programado de las máquinas equivale a un aumento de la eficiencia en base a la máxima disponibilidad de las máquinas.

- Eliminando las fuentes de suciedad, que causan un mal funcionamiento en las máquinas y por ende un costo por pérdida de tiempo en la operación.

- Eliminando el despilfarro que conlleva a incrementar la competitividad de la empresa y por ende aumentar sus ganancias.

\section{Social}

- Al mantener la zona de trabajo limpia y ordenada se logrará motivar a los operarios a que se sigan esforzando, sintiéndose a gusto y cómodos trabajando.

- Al utilizar los equipos de protección al personal los trabajadores podrán trabajar con menor riesgo laboral.

- Así mismo al mantener la zona de trabajo limpia y ordenada se logrará reducir los incidentes, accidentes y se mejorará la salud ocupacional de los trabajadores. 
- Al reducir las fallas de los equipos se logrará reducir el estrés laboral.

\subsection{Hipótesis de la investigación}

La mejora en el proceso productivo de la línea de plancha de fibrocemento de la Fábrica Peruana Eternit S.A es factible a partir de la aplicación de ingeniería y haciendo uso de las herramientas de ingeniería industrial.

\subsection{Marco referencial de la investigación}

\section{Marco Referencial}

Actualmente el mayor problema de la línea de planchas de fibrocemento es la baja productividad atribuida a varios factores siendo los más relevantes:

- $\quad$ No se mide la eficiencia productiva por cada equipo.

- El mantenimiento programado excede al presupuestado por el grupo donde el excedente de tiempo se imputa como parada no programada.

- Demoras en los cambios de producción.

- Se tiene constantes paradas no programadas por el equipo cuello de botella, tiempo de ciclo mucho mayor en comparación con los demás equipos de la línea.

- La línea se encuentra sucia y desordenada.

Aquello que no se mide, no se puede mejorar, por lo que la presente investigación propone medir el desempeño de los equipos, implementando el SMED para reducir los cambios de producción, eliminando el excedente de tiempo de los mantenimientos programados, etc. Aplicando herramientas de mejora continua y reingeniería en el equipo cuello de botella (desalojadora) a fin de aumentar la productividad de la línea.

Se visitó en varias ocasiones la Biblioteca de la Universidad de Lima no encontrándose trabajos semejantes, la gran mayoría de investigaciones proponen mejoras en el área de Logística, Comercial o Seguridad Industrial. 
Por lo que se visitó bibliotecas de otras universidades encontrándose investigaciones semejantes, los cuales servirán de referencia y aplicación para la investigación:

Título: Mejora de la Productividad en el área de Confecciones de la empresa Best Group Textil S.A.C mediante la aplicación de la metodología PHVA. Escuela Profesional de Ingeniería Industrial de la Universidad San Martin de Porres.

Cabrejos, D. y Mejia,K (2013) nos dice al respecto:

La deficiencia principal que tiene la empresa es la baja productividad a causa de una inadecuada gestión de la producción, mantenimiento inapropiado de maquinarias, inadecuado manejo del personal y una falta de revisión y control de prendas.

Semejanza: La semejanza que hay con esta empresa es que tampoco cuenta con una política de mantenimiento preventivo de los equipos, carencia de orden y limpieza.

Diferencia: Best Group Textil S.A.C es una empresa dedicada íntegramente a la confección de prendas de vestir de punto y está constituido únicamente por las áreas de Comercial, Producción y Ventas. Mientras que Fabrica Peruana Eternit S.A está constituido por más de 3 áreas y se dedica al rubro de la construcción.

Título: Propuesta de mejora del proceso productivo de una línea de confecciones de ropa interior en una empresa textil mediante el uso de herramientas de Manufactura Esbelta. Escuela Profesional de Ingeniería Industrial de la Universidad Católica del Perú.

Mejia Carrera (2013) nos dice al respecto:

El objetivo de esta investigación es mejorar la competitividad de la empresa en el mercado, haciendo que adopte nuevas técnicas y una de estas es la aplicación de las herramientas de manufactura esbelta.

Semejanza: Dicha investigación se asemeja a la investigación ya que aplica herramientas de mejora continua tales como 5’S, SMED, TPM, etc., por lo tanto, servirá como guía y referencia para la investigación.

Diferencia: La propuesta de mejora de la tesis es del rubro textil mientras que la tesis a desarrollar es del rubro de la construcción. 
Título: La mejora continúa en las organizaciones. Análisis de su implementación en 30 empresas.

Autor: Mari Carmen Jaca Garcia /Javier Santos Garcia

Garcia y Santos Garcia (2009) nos comentan lo siguiente:

Este estudio pretende analizar la implantación de distintas formas de participación en la mejora, en un conjunto de 30 empresas. Este artículo identifica las experiencias de mejora comunes en las distintas empresas y además presenta algunas originales prácticas detectadas en algunas de las organizaciones. Por último, se dan algunas ideas sobre elementos a potenciar en la implantación de la mejora continua.

Semejanza: Dicho artículo se asemeja a la investigación en que se aplica las herramientas de mejora continua como 5'S, SMED, TPM, etc. a empresas del rubro de la construcción como es el caso de la Fábrica Peruana Eternit S.A

Diferencia: El artículo abarca más temas de mejora continua de los que se tomará en cuenta en la investigación.

Título: Mejora continua de los procesos herramientas y técnicas.

Bonilla,E.; Diaz, B.; Kleeberg,F.; Noriega,M (2014) nos comentan lo siguiente:

Este libro trata sobre las más difundidas técnicas de mejora continua con una especial mención y detallada explicación de la metodología Kaizen.

Semejanza: La semejanza en este libro es que cuenta con un caso real de mejora en una empresa del sector de la construcción como es el caso de Aceros Arequipa. Eternit S.A también pertenece a este sector.

Diferencia: En el caso real que se plantea en el libro Aceros Arequipa no cuenta con una línea de planchas de fibrocemento. La mejora que se pretende hacer es en dicha línea.

\subsection{Marco conceptual}

Este proyecto es un proceso de diagnóstico y mejora de producción de la línea de planchas de fibrocemento de la Fábrica Peruana Eternit S.A. Para ello, se identificaron 4 problemas que son retrasos en los mantenimientos programados, bajo rendimiento de materia prima, 
incidentes en línea y baja productividad. Debido a estos problemas los indicadores que cuenta la línea no llegan a la meta establecida.

En el caso de los mantenimientos programados, estos tienen una duración de 12 horas cuando la meta asignada por la empresa es de 8 horas, el excedente de 4 horas son imputadas como paradas no programadas. Esto sucede del mismo modo con los cambios de producción, que según la meta asignada por la compañía deberían durar 1 hora pero actualmente están durando aproximadamente 1.5 horas, el excedente de 0.5 horas son imputadas como paradas no programadas. Estos excedentes de tiempos impactan negativamente al indicador de productividad de la línea.

En el año 2017, el indicador de rendimiento de materia prima fue de $(158,27$ $\left.\mathrm{m}^{2} \mathrm{n}^{2} / \mathrm{tn}\right)$ y en el año $2018\left(156,42 \mathrm{~m}^{2} \mathrm{n} / \mathrm{tn}\right)$ fue menor a la meta $\left(159 \mathrm{~m}^{2} \mathrm{n} / \mathrm{tn}\right)$, por lo que el objetivo de este proyecto es que siempre se mantenga por encima.

En relación a los incidentes en línea, es ya que se evidencia falta de compromiso con la seguridad, los equipos no tienen un sistema de seguridad integrado y la línea casi siempre se encuentra sucia y desordenada.

Por otro lado, en el caso de la baja productividad en el año 2017 solo en los meses de marzo $\left(967 \mathrm{~m}^{2} \mathrm{n} / \mathrm{hc}\right)$, abril $\left(963 \mathrm{~m}^{2} \mathrm{n} / \mathrm{hc}\right)$, junio $\left(964 \mathrm{~m}^{2} \mathrm{n} / \mathrm{hc}\right)$ y setiembre $\left(970 \mathrm{~m}^{2} \mathrm{n} / \mathrm{hc}\right)$ la productividad obtenida fue mayor a la meta $\left(962 \mathrm{~m}^{2} \mathrm{n} / \mathrm{hc}\right)$. Los demás meses la productividad fue de $928 \mathrm{~m}^{2} \mathrm{n} / \mathrm{hc}$ a $961 \mathrm{~m}^{2} \mathrm{n} / \mathrm{hc}$.

Para encontrar las causas raíces de estos problemas se utilizó herramientas de ingeniería industrial como el Diagrama de Ishikawa y un ranking de factores para seleccionar las causas raíces más importantes de cada problema.

1. Retrasos en los mantenimientos programados.

- Ineficiente programación de trabajos.

- No se supervisan los trabajos.

- Línea sucia y desordenada.

- Demora en retiro de materiales y repuestos.

- Retraso en la ejecución de trabajos.

- Demora en la búsqueda de herramientas.

\footnotetext{
${ }^{2}$ Metros cuadros normales: Se calcula multiplicando largo (mts) x ancho (mts) x espesor (mm)/5 de las planchas. $\left(1 \mathrm{~m}^{3}=200 \mathrm{~m}^{2} \mathrm{n}\right)$
} 
- No hay la cantidad ni las herramientas necesarias.

2. Bajo rendimiento de materia prima.

- Línea sucia y desordenada, no permite detectar fugas de material.

- El personal opera de una forma inadecuada los equipos.

- Pruebas con nuevas materias primas.

- Parámetros de control del proceso fuera del rango de aceptación.

- Inadecuada dosificación de las materias primas o insumos.

- No se cuenta con residuos húmedos3 para consumir en la mezcla.

3. Incidentes en la línea.

- No se hace seguimiento a las condiciones inseguras.

- No hay un supervisor de campo de seguridad industrial.

- Falta de compromiso del personal técnico y operario con la seguridad.

- La línea se encuentra sucia y desordenada.

- Los equipos no cuentan con sistema de seguridad integrado.

4. Baja productividad

- No se mide la eficiencia productiva por cada equipo.

- Se postergan constantemente los mantenimientos programados.

- Demoras en los cambios de producción.

- Ineficientes trabajos realizados en los mantenimientos programados.

- La máquina Hatschek se encuentra demasiado sucia.

- El fieltro y los tamices se encuentran colmatados.

- Fallas de equipos.

- La línea se encuentra sucia y desordenada.

- Insatisfacción y falta de motivación por parte del personal técnico y operario.

- Falta de compromiso de operarios.

- Demoras en el tiempo de atención de fallas de equipos por parte de los mecánicos y electricistas.

- Pruebas con nuevas materias primas.

- Parámetros de aceptación de materias primas fuera de rango.

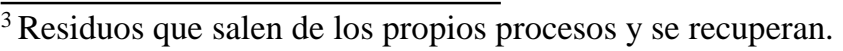


- Tiempo de ciclo de la desalojadora, mucho mayor a comparación de los demás equipos de la línea, equipo cuello de botella.

Así mismo, se propuso alternativas de solución para cada problema encontrado como encontrar el tiempo estándar de ejecución de cada trabajo realizado en los mantenimientos programados, elaborar un indicador de cumplimiento de los trabajos, elaborar un Gantt de los mantenimientos programados, implementar la metodología 5`S, asignar un área para almacenar material sustraído de limpieza, elaborar un check list de las condiciones en las que se recibe el turno, creación de una matriz de condiciones inseguras, adquirir dispositivos de bloqueo, implementar el OEE (Eficiencia global de los equipos), adquirir equipos modernos, aplicar SMED (Single minute Exchange of die o cambio de matriz en menos de 10 minutos), etc.

Después de las posibles soluciones, mediante un ranking de factores se seleccionó la mejor solución para cada problema como por ejemplo determinar frecuencias de limpieza de cada equipo y tubería, así mismo determinar el tiempo estándar de ejecución de cada actividad, implementar la metodología 5`S, asignar una zona de los productos sustraídos de mantenimiento programado, fabricación de canaleta para recuperación de material, implementación del OEE y aplicar SMED, creación de una matriz de condiciones inseguras, capacitación al personal en temas de seguridad industrial y salud en el trabajo, etc.

Por último, para validar las soluciones se determinó metas para cada problema encontrado en la línea de planchas de fibrocementos de la Fábrica Peruana Eternit. 


\section{CAPITULO II: ANÁLISIS SITUACIONAL DE LA EMPRESA Y SELECCIÓN DEL SISTEMA O PROCESO A SER MEJORADO}

\subsection{Análisis externo de la empresa}

\subsubsection{Análisis del entorno global}

\section{- Entorno Económico}

Si bien el sector de la construcción tuvo un leve decrecimiento en el primer bimestre del 2017 debido a la desaceleración económica que hubo en el Perú y al impacto negativo que hubo en el sector inmobiliario. Además, el gobierno tomó la decisión de eliminar subsidios de crédito del "Programa Mí vivienda" con precio entre 39 y 70 UIT’S las empresas de construcción tienen confianza que esta situación se remontará ya que, se espera una relativa estabilidad de los precios y una mejora económica en los próximos años.

\section{- Entorno Social}

El sector de la construcción ha ido en constante crecimiento, por lo que tiene un rol importante en el desarrollo del país. El crecimiento del sector de construcción trajo consigo un aumento de la demanda de profesionales en dicho sector. Por lo que el factor humano ha cobrado bastante relevancia en las empresas públicas y privadas que operan en el interior del país. Sin embargo, los principales problemas que tiene la empresa con el entorno social son los asuntos de gobierno local, demarcación territorial y socio ambiental que impiden o retrasan el funcionamiento de los proyectos que tiene la empresa.

Por esta razón, la mayoría de las empresas de dicho sector dentro de su organización han implementado áreas de responsabilidad social donde junto con las comunidades adyacentes y autoridades nacionales trabajan en conjunto para prevenir conflictos sociales. Un ejemplo de actividades que realiza Eternit en responsabilidad social son la capacitación a jóvenes de bajos recursos económicos en técnicas de construcción colaborando así, a que puedan contar con mayores posibilidades de trabajo 
brindándoles una opción para su sustento y el de sus familias. También, Eternit ha venido trabajando en la construcción de capillas en poblaciones de pocos recursos.

\section{- Entorno demográfico}

El crecimiento constante de la población peruana y de sus ingresos; así como la expansión de crédito para viviendas ha incrementado la demanda de las familias peruanas para la construcción y obtención de viviendas. Así mismo, el sector de la construcción en Perú es uno de los sectores de mayor productividad en el trabajo.

En al año 2014, hubo 916000 trabajadores de construcción los cuáles 95,8\% eran hombres y de este porcentaje el 74,5\% alcanzó secundaria completa y solo el 8,3\% se capacitó en algún curso técnico. A esto se le agrega que en dicho sector hay preferencia en contratar al sexo masculino y los sueldos oscilan entre S/ 850 y S/1 200 sin contar los beneficios del trabajo nocturno el cual incrementa el sueldo en $20 \%$ a $25 \%$ y sin tomar en cuenta los beneficios por asignación escolar. Por último, para los trabajos de construcción no hay distinción de raza, religión y condición económica.

\section{- Entorno Legal}

El rol del Estado peruano es de suma importancia para crear condiciones seguras de inversión. La política tiene un rol crucial en las empresas del sector de la construcción, ya que, depende del estado peruano poner en marcha las inversiones y proyectos que tienen a futuro. El país ha experimentado un crecimiento económico considerable los últimos 15 años por lo que se ha conseguido la continuidad de políticas económicas.

Según el Marco Macroeconómico Multianual 2015 - 2017 las políticas más relevantes son las siguientes: Frey Morote, Juan Carlos y Vela Ruiz, Jessica Paola (2016)

$>$ Política Fiscal ordenada: Tiene bajos niveles de deuda internacional, por lo que, hace posible una mayor inversión pública agregando liquidez a la económica interna.

$>$ Política Social y de lucha contra la pobreza: Incluye la implementación de programas de ayuda social en los sectores menos favorecidos de la sociedad.

El inicio de la descentralización política y económica del estado brinda a las entidades regionales cierto poder para decidir en la inversión de los recursos públicos 
asignados, de esta manera, esto permite ampliar mercados y estar acorde a los avances de la globalización.

Respecto a los factores legales el sector de la construcción está regulado por la ley $\mathrm{N}^{\circ} 30156$ cuyo título es "Ley de organización y funciones del ministerio de vivienda, construcción y saneamiento". Esta ley tiene como objetivo regular el ámbito de competencia, así como formular, planear, dirigir, coordinar, ejecutar, supervisar y evaluar la política nacional y sectorial.

\section{- Entorno Tecnológico}

Con el avance de la tecnología en estos últimos años el sector de la construcción se ha beneficiado, ya que, la mayoría de las empresas proveedoras de materia prima para construcción tienen maquinarias sofisticadas las cuales brindan al cliente un producto de calidad. Eternit S.A no es la excepción, ya que, cuenta con maquinarias sofisticadas como el equipo Hatschek que da inicio a la formación de la plancha de fibrocemento y la Onduladora que es la que finalmente le da el ondulado a las planchas. Adicional a esto las líneas de Eternit S.A manejan un circuito cerrado, es decir que todo material se reaprovecha, no teniendo así costos por desperdicios o problemas en la producción. Así mismo, se cuenta con un sistema de gestión de procesos llamado BIM (Building Information Modeling) la cual permite compartir información en línea, discutirla y plantear sugerencias.

Esta herramienta mayormente se usa en los proyectos de ingeniería y construcción. Además, se cuenta con sistemas de información en línea denominados eprocurement que permiten la integración con proveedores y el manejo eficiente de inventarios, reduciendo costos.

\subsubsection{Análisis del entorno competitivo}

Porter (2017) Se presenta las 5 fuerzas de Porter las cuales se dividen de la siguiente manera:

\section{Amenaza de nuevos entrantes}

La primera fuerza de Porter trata sobre qué tan fácil o difícil puede ser para alguien empezar a operar en una industria. En este tipo de industria su alto costo de inversión, hacen que la entrada de nuevos competidores sea baja. 


\section{$\underline{\text { Amenaza de productos o servicios sustitutos }}$}

La segunda fuerza de Porter se refiere a un comprador que puede sustituir el producto o servicio por otro. Lo sustituto se convierte en amenaza cuando comienzan a ser reales, eficaces y más baratos que el que vende la empresa inicial. El producto de calamina de fibrocemento que ofrece Eternit puede ser sustituido por otros similares y otros que cumplen su misma función, pero de menor calidad. Ejemplo: Calaminas de plástico, tripleys. La amenaza de productos o servicios sustitutos es alta.

\section{$\underline{\text { Poder de negociación de los compradores }}$}

Por ser una empresa de prestigio y que la marca ya se encuentra posicionada en el mercado los compradores tienen bajo poder de negociación, ya que, el producto al serde calidad tiene sus precios fijos.

\section{$\underline{\text { Poder de negociación de los proveedores }}$}

La cuarta fuerza competitiva se refiere al poder que tienen los proveedores, cuyas herramientas sirven para alcanzar los objetivos de la empresa. En este caso para la materia prima que emplea Eternit, en la elaboración de las Planchas de fibrocemento, existen muchos proveedores por lo que el poder de negociación es bajo.

\section{$\underline{\text { Intensidad de la rivalidad }}$}

La competitividad en una industria viene marcada por el grado de rivalidad entre los competidores. En el caso de Eternit, si bien tiene un producto diferenciado del resto (planchas de fibrocemento) hay varias empresas que compiten por la misma función del producto, ya que, existen empresas que producen calaminas de plástico y tripleys, como es el caso de la empresa Fibraforte que producen calaminas en polipropileno opaco y traslúcido. Por lo que la rivalidad es alta. 


\subsubsection{Identificación y evaluación de las oportunidades y amenazas del entorno}

\section{Oportunidades}

- Aumento de demanda en el sector de construcción.

- Cuenta con la posibilidad de obtener acceso a créditos.

- Cuenta con una red amplia de distribuidores a nivel nacional.

- Excelente relación laboral con empresas líderes en el sector de la construcción.

- Construcción Eco-amigable.

\section{$\underline{\text { Amenazas }}$}

- Aparición de productos sustitutos en el mercado.

- Desaceleración económica.

- Aparición de nuevos competidores.

- Abaratamiento de precios en el mercado.

- $\quad$ Escaza mano de obra calificada en el mercado.

Tomando en cuenta las oportunidades y amenazas de la empresa Fabrica Peruana Eternit S.A se observa en la Tabla 2.3, que el resultado total de la matriz EFE es 2,52 lo que quiere decir que las estrategias de la empresa están aprovechando con eficacia de las oportunidades existentes y minimizando los posibles efectos negativos de las amenazas externas. Zacarias (2014) 
Tabla 2. 1

Matriz de enfrentamiento de oportunidades

\begin{tabular}{|c|c|c|c|c|c|c|c|}
\hline Factor & $\begin{array}{l}\text { Aumento de demanda } \\
\text { en sector de la } \\
\text { construcción }\end{array}$ & $\begin{array}{l}\text { Cuenta con la } \\
\text { posibilidad de } \\
\text { obtener accesos a } \\
\text { créditos }\end{array}$ & $\begin{array}{l}\text { Cuenta con una red } \\
\text { amplia de } \\
\text { distribuidores a } \\
\text { nivel nacional }\end{array}$ & $\begin{array}{l}\text { Excelente relación } \\
\text { laboral con } \\
\text { empresas líderes } \\
\text { en el sector de la } \\
\text { construcción }\end{array}$ & $\begin{array}{l}\text { Construcción } \\
\text { Eco - amigable }\end{array}$ & Peso & $\begin{array}{c}\text { Porcentaje } \\
\text { al } 50 \%\end{array}$ \\
\hline $\begin{array}{l}\text { Aumento de demanda } \\
\text { en sector de la } \\
\text { construcción }\end{array}$ & & 0 & 1 & 1 & 1 & 3 & $13,64 \%$ \\
\hline $\begin{array}{l}\text { Cuenta con la } \\
\text { posibilidad de obtener } \\
\text { accesos a créditos }\end{array}$ & 1 & & 1 & 0 & 0 & 2 & $9,09 \%$ \\
\hline $\begin{array}{l}\text { Cuenta con una red } \\
\text { amplia de } \\
\text { distribuidores a nivel } \\
\text { nacional }\end{array}$ & 0 & 0 & & 1 & 0 & 1 & $4,55 \%$ \\
\hline $\begin{array}{l}\text { Excelente relación } \\
\text { laboral con empresas } \\
\text { líderes en el sector de } \\
\text { la construcción }\end{array}$ & 0 & 0 & 1 & & 0 & 1 & $4,55 \%$ \\
\hline $\begin{array}{l}\text { Construcción Eco - } \\
\text { Amigable }\end{array}$ & 1 & 1 & 1 & 1 & & 4 & $18,18 \%$ \\
\hline Total & & & & & & 11 & $50,00 \%$ \\
\hline
\end{tabular}


Tabla 2. 2

Matriz de enfrentamiento de amenazas

\begin{tabular}{|c|c|c|c|c|c|c|c|}
\hline Factor & $\begin{array}{l}\text { Aparición de } \\
\text { productos sustitutos } \\
\text { en el mercado }\end{array}$ & $\begin{array}{l}\text { Desaceleración } \\
\text { económica }\end{array}$ & $\begin{array}{l}\text { Aparición de } \\
\text { nuevos } \\
\text { competidores }\end{array}$ & $\begin{array}{l}\text { Abaratamiento de } \\
\text { precios en el } \\
\text { mercado }\end{array}$ & $\begin{array}{l}\text { Escaza mano de } \\
\text { obra calificada } \\
\text { en el mercado }\end{array}$ & Peso & $\begin{array}{l}\text { Porcentaje } \\
\text { al } 50 \%\end{array}$ \\
\hline $\begin{array}{l}\text { Aparición de productos } \\
\text { sustitutos en el } \\
\text { mercado }\end{array}$ & & 0 & 1 & 1 & 1 & 3 & $11,54 \%$ \\
\hline $\begin{array}{l}\text { Desaceleración } \\
\text { económica }\end{array}$ & 1 & & 1 & 1 & 1 & 4 & $15,38 \%$ \\
\hline $\begin{array}{l}\text { Aparición de nuevos } \\
\text { competidores }\end{array}$ & 1 & 0 & & 1 & 1 & 3 & $11,54 \%$ \\
\hline $\begin{array}{l}\text { Abaratamiento de } \\
\text { precios en el mercado }\end{array}$ & 1 & 0 & 1 & & 1 & 3 & $11,54 \%$ \\
\hline $\begin{array}{l}\text { Escaza mano de obra } \\
\text { calificada en el } \\
\text { mercado }\end{array}$ & 1 & 0 & 0 & 0 & & 0 & $0,00 \%$ \\
\hline Total & & & & & & 13 & $50,00 \%$ \\
\hline
\end{tabular}


Tabla 2. 3

\section{Matriz EFE}

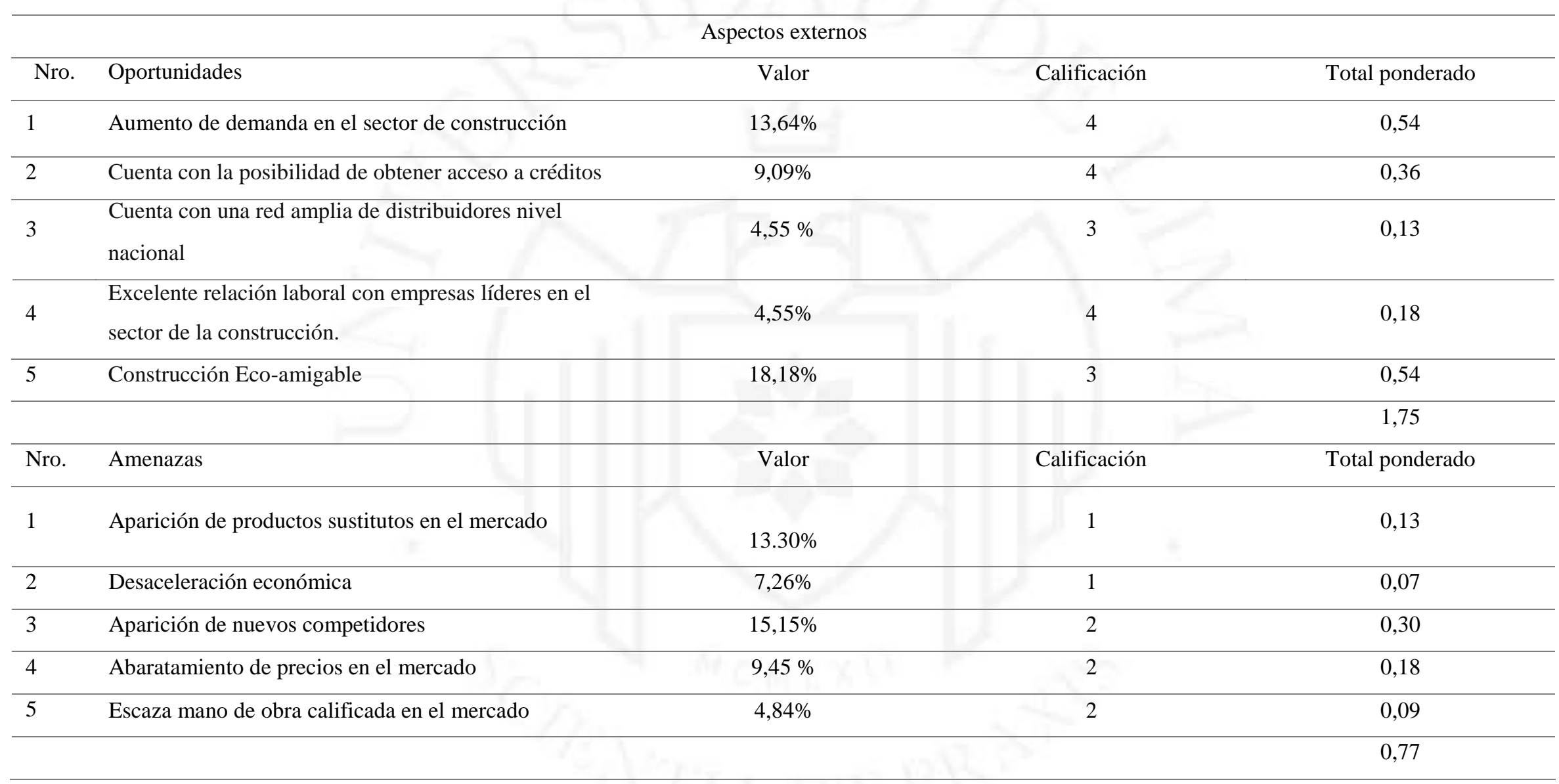

Elaboración Propia 


\subsection{Análisis interno de la empresa}

\subsubsection{Análisis del direccionamiento estratégico: visión, misión y objetivos organizacionales}

A continuación, se detalla la misión y visión que indica tener la Empresa Eternit. Eternit Construimos Confianza (2017)

\section{Visión}

Ser la alternativa preferida para quien tenga una necesidad de productos para la construcción.

\section{Misión}

Brindar productos y soluciones en la actividad de la construcción, que mejoren la calidad de vida de los usuarios, manteniendo un espíritu de mejora continua en nuestra organización.

\section{Objetivos Organizacionales}

- Controlar los objetivos y desempeño de cada empleado para desarrollar y aplicar acciones correctivas.

- Lograr el más alto estándar de satisfacción al cliente a través de productos y servicios innovadores.

- Realizar constantemente estudios de mercado para analizar la oferta y demanda existente.

- Ampliar el portafolio de productos ofrecidos a nivel global.

- Conseguir que los empleados de todos los niveles conozcan que tareas deben realizar y quienes deben hacerlo para de esta manera integrarlos a la empresa. 
Figura 2. 1

Estructura organizacional de la línea de producción de planchas onduladas de fibrocemento

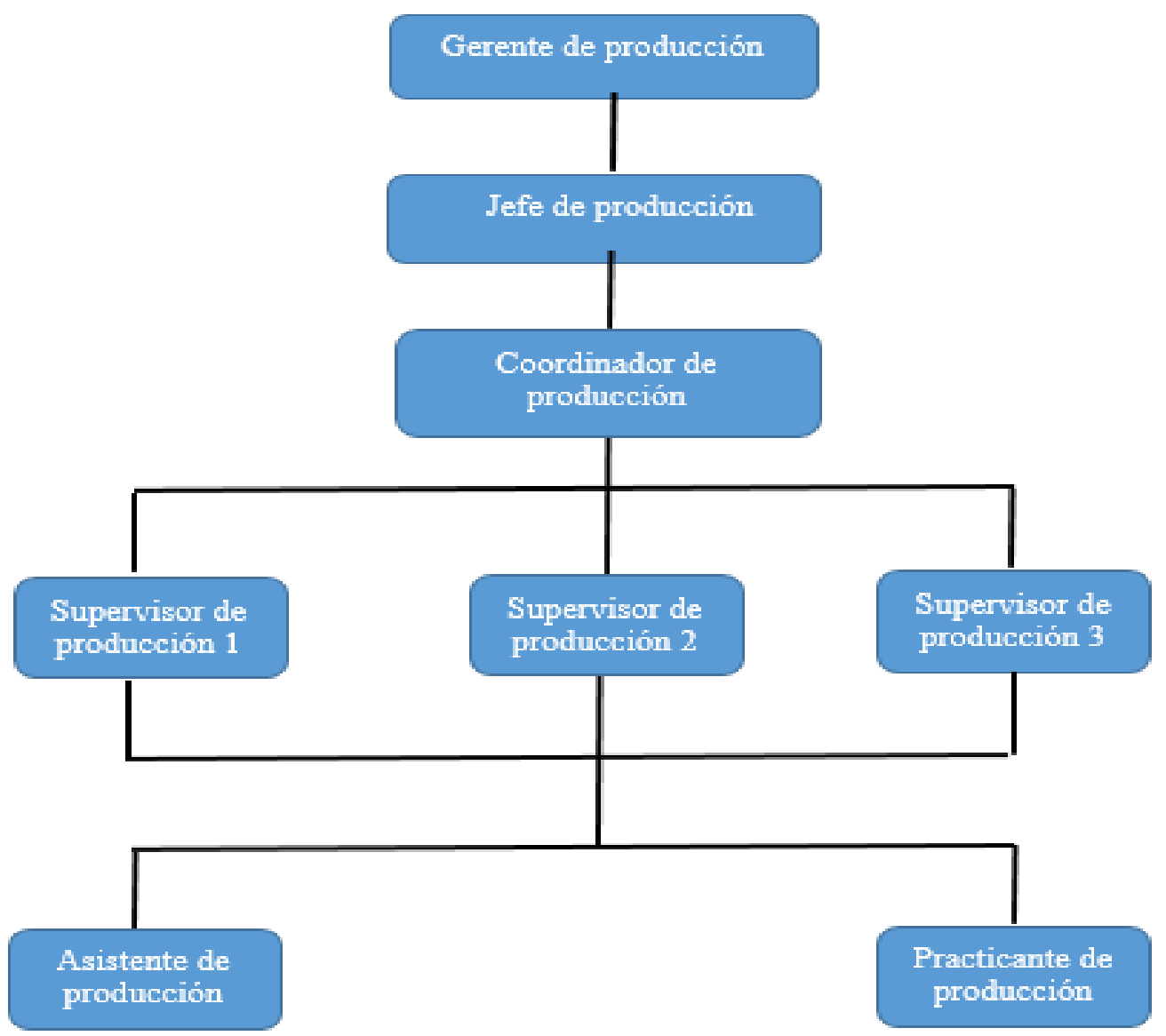

Elaboración propia

Ver Anexo 1 (Organigrama)

\subsubsection{Análisis de la estructura organizacional}

Fabrica Peruana Eternit S.A es una empresa que viene operando desde 1940 y pertenece al grupo ETEX, su mercado objetivo es la construcción de edificaciones de los segmentos de vivienda, comercial, institucional, educación, salud e industria, a través de la fabricación de materiales de fibrocemento, yeso y polietileno. Ver anexo 2 (Plano general de la empresa Fabrica Peruana Eternit)

Es una organización con fines de lucro y descentralizada, la toma de decisiones se delega en la cadena de mando. 
Actualmente la empresa viene experimentando un proceso de grandes cambios con miras a la mejora continua, si bien es cierto anteriormente solo estaban enfocados en producir a grandes volúmenes pero ahora la empresa se ha dado cuenta que el mundo está evolucionando y con ello las industrias cada vez se vuelven más competitivas por lo que ahora están prestando más atención a la calidad del producto terminado, a reducir el índice de reclamos por productos defectuosos, a reducir el costo unitario de los productos y esto mediante mejoras en los equipos, automatización de las líneas, mejoras aprovechamientos de los recursos, entre otras cosas más.

Ya que este proyecto se basa en mejoras en la línea de producción de planchas de fibrocemento, se detallará la estructura organizacional de dicha área.

El área cuenta con un gerente de producción, el cual es responsable no solo de la línea de fabricación de planchas de fibrocemento, sino que también es responsable de las demás líneas de la planta de Lima (línea de producción de tanque de polietileno,pintura, moldeados y planchas planas), así como también de las plantas de Huachipa y Chiclayo. El jefe de producción es quien reporta directamente al gerente de producción, es responsable de igual manera de las tres plantas y de las líneas que contienen cada una, él a su vez cuenta con un coordinador de producción y con tres supervisores de producción a su cargo, que son los encargados de administrar la línea. se cuenta también con un asistente y un practicante de producción quienes son el soporte en cuanto a temas de gestión, procesamiento de data, digitación, solicitudes de pedidos, avisos de mantenimiento, etc.

\subsubsection{Identificación y descripción general de los procesos claves}

Como los procesos más importantes se están considerando la preparación de la materia prima, la formación del producto, el ondulado del producto, la etapa de curado y el proceso de desapilado. Estos procesos se consideran los más importantes, ya que, en estos procesos el producto va adquiriendo todas las características que por especificaciones técnicas debe contener.

- Preparación de la mezcla: Aquí es donde se prepara y mezclan las materias primas que va a contener el producto terminado.

- Formación del producto: En esta etapa del proceso es donde se forma el producto plano y se le otorga características de espesor, densidad y humedad. 
- Ondulado: Aquí el producto plano se convierte en producto ondulado y se le otorga características de largo y ancho.

- Curado: A esta parte del proceso es donde el producto llega con contenido de humedad y entran a unas cabinas donde se le suministra vapor, con la finalidad de que el cemento fragüe.

- Desapilado: Es donde se arman los paquetes para que posteriormente sean derivados al almacén de producto terminado.

\subsubsection{Análisis de los indicadores generales de desempeño de los procesos claves-línea base (metas, resultados actuales, tendencias, brechas, comparativos)}

Los indicadores de gestión en los cuales el grupo ETEX pone más énfasis y los considera los más relevantes son los siguientes:

- Rendimiento de materia prima: Este indicador es el más importante de todos ya que refleja cuan eficientes se ha sido en el aprovechamiento de la materia prima, el cual representa el $70 \%$ del costo del producto. Es la relación entre la producción total y el peso de materia prima utilizada.

- Eficiencia de máquina: Es la relación que hay entre la producción total y las horas programadas menos las horas de mantenimiento programado.

- Porcentaje de rechazos: No es más que la relación entre la cantidad de producto defectuoso y la producción total.

- Índice de Frecuencia (IF): Deben considerarse las horas reales de trabajo, descontando todas las ausencias en el trabajo por permiso, vacaciones, baja por enfermedad, accidentes, etc.

(\# Accidentes incapacitantes en el mes x 1000000) / HH trabajadas en el mes

- Índice de Gravedad (IG): Este índice representa el número de jornadas pérdidas por cada millón de horas trabajadas.

(\# Días perdidos por accidentes incapacitantes en el mes x 1000000) / HH trabajadas en el mes. 
Tabla 2.4

Indicadores generales

\begin{tabular}{|c|c|c|c|c|}
\hline $\begin{array}{l}\text { Indicadores } \\
\text { generales }\end{array}$ & Unidades & Valor Actual & Valor Meta & Responsable \\
\hline $\begin{array}{l}\text { Rendimiento de } \\
\text { materia prima }\end{array}$ & $\mathrm{m}^{2} \mathrm{n} / \mathrm{TN}$ & 158 & 159 & $\begin{array}{l}\text { Coordinador de } \\
\text { producción }\end{array}$ \\
\hline $\begin{array}{l}\text { Eficiencia de } \\
\text { máquina }\end{array}$ & $\mathrm{m}^{2} \mathrm{n} / \mathrm{HC}$ & 953 & 962 & $\begin{array}{l}\text { Coordinador de } \\
\text { producción }\end{array}$ \\
\hline $\begin{array}{l}\text { Porcentaje de } \\
\text { rechazos }\end{array}$ & $\%$ & $31 \%$ & $50 \%$ & $\begin{array}{l}\text { Coordinador de } \\
\text { producción }\end{array}$ \\
\hline $\begin{array}{l}\text { Indice de } \\
\text { frecuencia (IF) }\end{array}$ & $\frac{\text { Accidentes }}{\mathrm{H}-\mathrm{H}}$ & 1,02 & 1,7 & $\begin{array}{l}\text { Coordinador de } \\
\text { producción }\end{array}$ \\
\hline $\begin{array}{l}\text { Indice de } \\
\text { gravedad (IG) }\end{array}$ & $\frac{\text { Dias perdidos }}{\mathrm{H}-\mathrm{H}}$ & 0,12 & 0,13 & $\begin{array}{l}\text { Coordinador de } \\
\text { producción }\end{array}$ \\
\hline
\end{tabular}

Elaboración propia

Cabe mencionar que la organización para poder agregar diferentes productos juntos creó una unidad de medida que denominó metros cuadrados normales $\left(\mathrm{m}^{2} \mathrm{n}\right)$. Esto se calcula multiplicando el largo (mts) x ancho (mts) x espesor $(\mathrm{mm}) / 5$. Para términos de referencia $200 \mathrm{~m}^{2} \mathrm{n}=$ son iguales a $1 \mathrm{~m}^{3}$.

Como se puede observar en la Tabla 2.4, se puede decir que en cuanto al KPI de eficiencia de máquina en el 2017, se encuentra por debajo de la meta y esto se debe principalmente a que el $\%$ de paradas de la máquina se encuentra fuera de la meta ${ }^{4}$. El cálculo de la eficiencia de máquina es la división del total producido en $\mathrm{m}^{2} \mathrm{n}$ (metros cuadros normales) entre las horas consumidas. Las horas consumidas es la resta del total de horas programadas menos las paradas programadas.

Con respecto al KPI rendimiento de materia prima muestra que en el 2017 el indicador se encuentra un punto por debajo de la meta, a diferencia del 2016 que se pudo alcanzar la meta. Este indicador es el más importante ya que la materia prima representa el $70 \%$ del costo del producto y por lo tanto un buen aprovechamiento de la materia prima te da como resultado reducción de costos. 
El KPI \% de rechazos se encuentra dentro del objetivo, pero como parte de la mejora continua se apunta a reducir al mínimo la merma del proceso, lo cual se traduce también en una reducción de costos.

Tabla 2. 5

KPI de seguridad industrial más relevantes

\begin{tabular}{ccccc}
\hline KPI & Resultados 2016 & Meta & $\begin{array}{c}\text { Resultados } \\
2017\end{array}$ & Meta \\
\hline IF & 0,51 & $<=2,7$ & 1,02 & $<=1,7$ \\
\hline IG & 0,18 & $<=0,14$ & 0,12 & $<=0,13$ \\
\hline
\end{tabular}

Elaboración propia

Se puede observar en la Tabla 2.5, que en el año 2017, la meta del IF se hizo más estricta llegando a ser de 1,7 en comparación al año 2016 que fue de 2,7.

En el año 2016 se tuvo un IF de 0,51 y en el 2017 el IF fue de 1,02, siendo mayor ese año que el anterior y esto se debió a que en el año 2017 hubo dos accidentes y en el año 2016 tan solo hubo un accidente.

En el año 2017, se presentó un accidente ocasionando la fractura de hombro de un trabajador, en este caso un electricista de turno se encontraba revisando la grúa puente de APT5 cuando el operador de la grúa puente hace una mala maniobra y con el gancho de la grúa impacta en el hombro del electricista. El segundo accidente, se dio por un corte profundo en la mano de un trabajador, un mecánico interviene los rodillos de una fajaen movimiento, este introduce un desarmador con la intención de remover material que se había adherido a un rodillo, cuando de un momento a otro el rodillo atrapa la mano del mecánico ocasionándole el corte en la mano.

En el año 2016, el único accidente ocurrido fue por una fractura en el brazo derecho a un operador, esto debido a que un equipo presentó una falla y el operador decidió ingresar para ver a que se debía, pero no bloqueo el equipo, cuando de repente el equipo empieza a operar y una estructura del equipo impacta con su brazo derecho provocándole una fractura.

\footnotetext{
${ }_{5}^{5}$ Almacén de productos terminados.
} 


\subsubsection{Determinación de posibles oportunidades de mejora (hallazgo de problemas)}

Luego de realizar el análisis respectivo, se identificó que una de las líneas de producción que presenta mayor parte de problemas para cumplir con su proceso correctamente es la línea encargada de la fabricación de planchas de fibrocemento la cual representa una venta alta para la empresa.

Se identificó distintos problemas dentro de su proceso productivo como lo es los retrasos en los mantenimientos programados, ya que no se cuenta con los tiempos estándar de ejecución de los trabajos, a la misma vez no cuenta con una previa planificación de estos, que pueda asegurar que se hagan de una forma correcta y dentro del tiempo establecido. La línea se encuentra sucia y desordenada, se tiene varios tiempos muertos por búsqueda de herramientas, materiales y repuestos.

Además, presenta un bajo rendimiento de materia prima ya que no se logra detectar a que deben las desviaciones y pérdidas del material que ocasionan un no adecuado aprovechamiento de las materias primas. De igual forma, no cuentan con un área donde cumpla la función de almacenar el material sustraído de la limpieza realizada en los mantenimientos programados, por lo que aproximadamente solo el $20 \%$ se reaprovecha y el otro $80 \%$ se manda al relleno sanitario.

Igualmente se han dado varios accidentes en la línea y esto debido a que no se realiza un seguimiento adecuado de las condiciones inseguras reportadas, se evidencia una falta de conocimiento y de compromiso por parte del personal técnico y operario con la seguridad, los equipos no cuentan con sistemas de seguridad integrada y la línea generalmente se encuentra sucia y desordenada aumentando la probabilidad de que ocurra un accidente.

Por último, la línea presenta baja productividad debido a que no se mide la productividad por cada equipo, demoras en los cambios de producción, avería de los equipos, cuentan con paradas no programadas por su cuello de botella pero no plantean acciones para "eliminarlo", conviven con el problema. 


\subsubsection{Identificación y evaluación de las fortalezas y debilidades de la empresa}

\section{Fortalezas}

- Reaprovechamiento de la materia prima.

- Calidad del producto final.

- Facilidad de innovación de los productos.

- Alta fidelidad de los clientes.

- Recursos financieros.

\section{Debilidades}

- Accidentes imprevistos dentro de la planta.

- Carencia de formación técnica en la mano de obra.

- Pérdida de personal calificado.

- Falta de cumplimiento de procedimientos de trabajo.

- Falta de una cultura laboral enfocada a buenas prácticas.

Tomando en cuenta las fortalezas y debilidades de la empresa Fabrica Peruana Eternit S.A se observa en la Tabla 2.8, que el resultado total de la matriz EFI es 2,58 que indica que la empresa cuenta con una posición interna muy fuerte ya que si fuera menos a 2,5 indicaría que tiene una posición interna muy débil. García (2013) 
Tabla 2. 6

Matriz de enfrentamiento de fortalezas

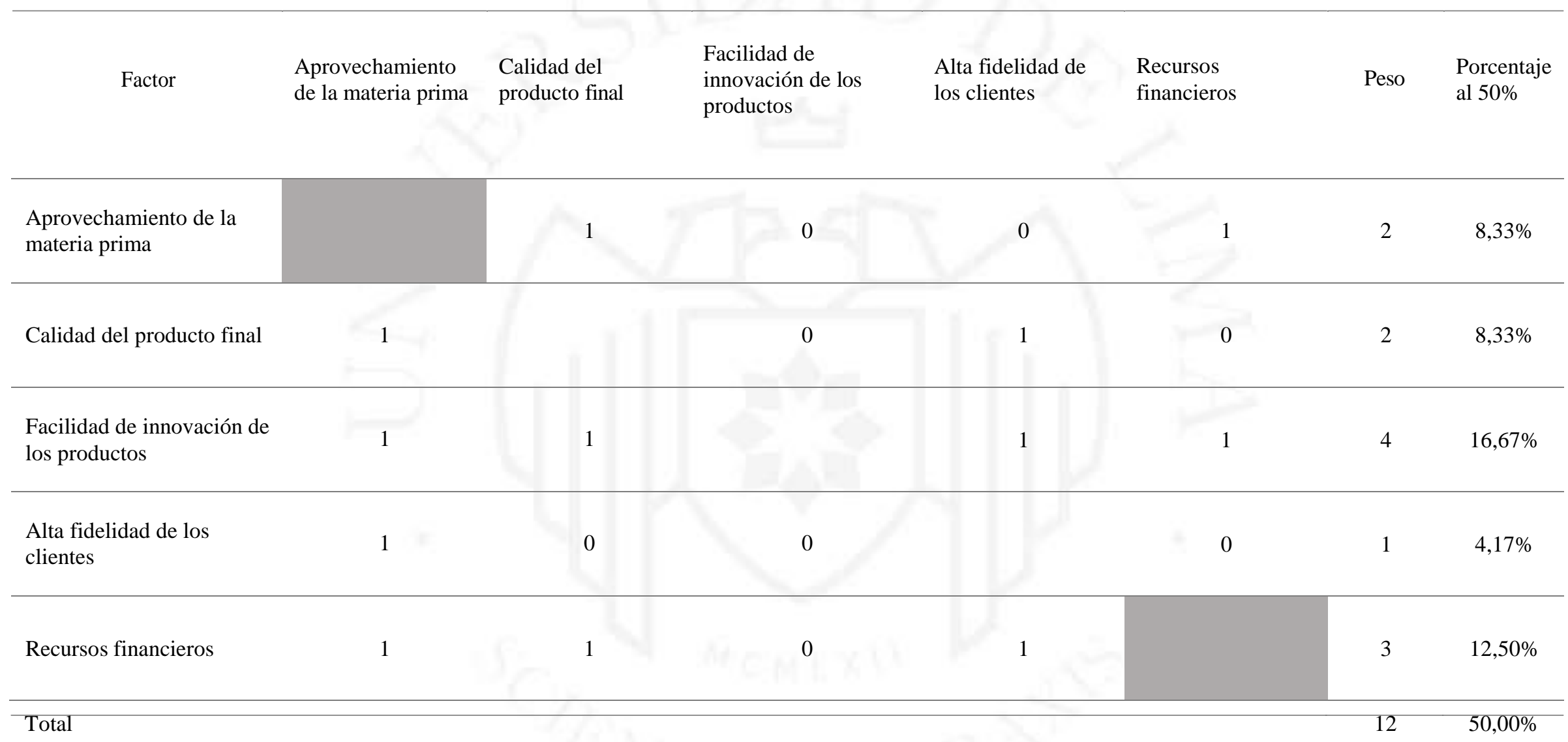

Elaboración Propia 
Tabla 2.7

Matriz de enfrentamiento de debilidades

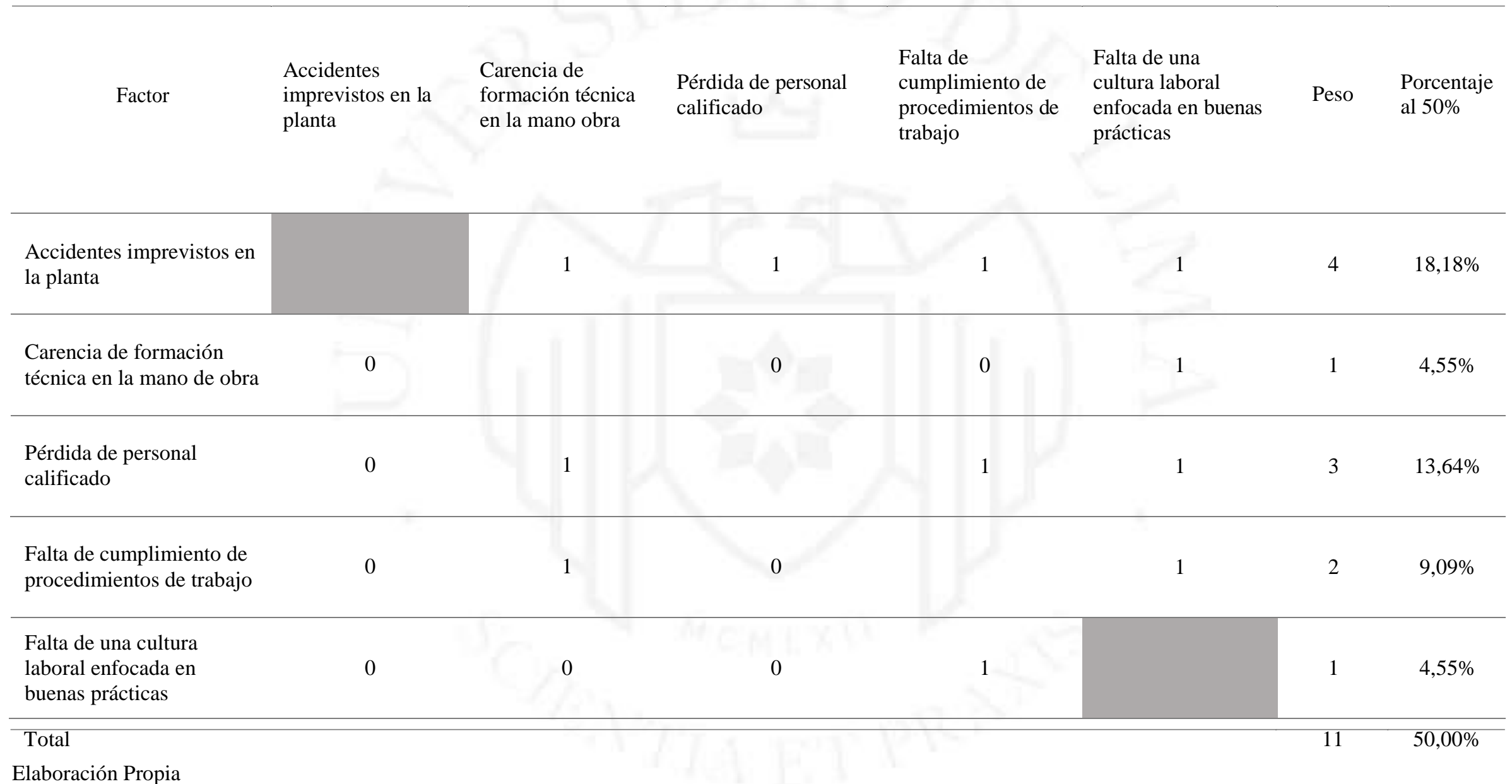


Tabla 2.8

Matriz EFI

Aspectos internos

\begin{tabular}{llccc}
\hline Nro. & Fortalezas & Valor & Calificación & Total ponderado \\
\hline 1 & Aprovechamiento de la materia prima & $8,33 \%$ & 4 & 4,33 \\
\hline 2 & Calidad del producto final & $8,33 \%$ & 3 & 0,33 \\
\hline 3 & Facilidad de innovación de los productos & $16,67 \%$ & 4 & 0,50 \\
\hline 4 & Alta fidelidad de los clientes & $4,17 \%$ & 4 & 0,16 \\
\hline 5 & Recursos financieros & $12,50 \%$ & Calificación & 1,82 \\
\hline & & & 1 & 2 \\
\hline Nro. & Debilidades & Valor & 0,18 \\
\hline 1 & Accidentes imprevistos dentro de la planta & $18,18 \%$ & 0,09 \\
\hline 2 & Carencia de formación técnica en la mano de obra & $4,55 \%$ & 2 & 0,27 \\
\hline 3 & Pérdida de personal calificado & $13,64 \%$ & 2 & 0,18 \\
\hline 4 & Falta de cumplimiento de procedimientos de trabajo & $9,09 \%$ & 1 & 0,04 \\
\hline 5 & Falta de una cultura laboral enfocada a buenas & & $4,55 \%$ & 0,76
\end{tabular}

Elaboración Propia 


\subsubsection{Selección del sistema o proceso a mejorar}

A continuación, se presenta la productividad de la línea obtenida en el año 2017. Tabla 2.9

Productividad de la línea del año 2017

\begin{tabular}{lll}
\hline 2017 & \multicolumn{2}{l}{ EMQ $\left(\mathrm{m}^{2} \mathrm{n} / \mathrm{hc}\right)$} \\
\hline MESES & REAL & TARGET \\
\hline ENERO & 928 & 962 \\
\hline FEBRERO & 950 & 962 \\
\hline MARZO & 967 & 962 \\
\hline ABRIL & 963 & 962 \\
\hline MAYO & 958 & 962 \\
\hline JUNIO & 964 & 962 \\
\hline JULIO & 957 & 962 \\
\hline AGOSTO & 932 & 962 \\
\hline SETIEMBRE & 970 & 962 \\
\hline OCTUBRE & 961 & 962 \\
\hline NOVIEMBRE & 954 & 962 \\
\hline DICIEMBRE & 937 & 962 \\
\hline PROMEDIO & 953 & 962
\end{tabular}

Elaboración Propia

Figura 2. 2

Productividad de la línea del año 2017

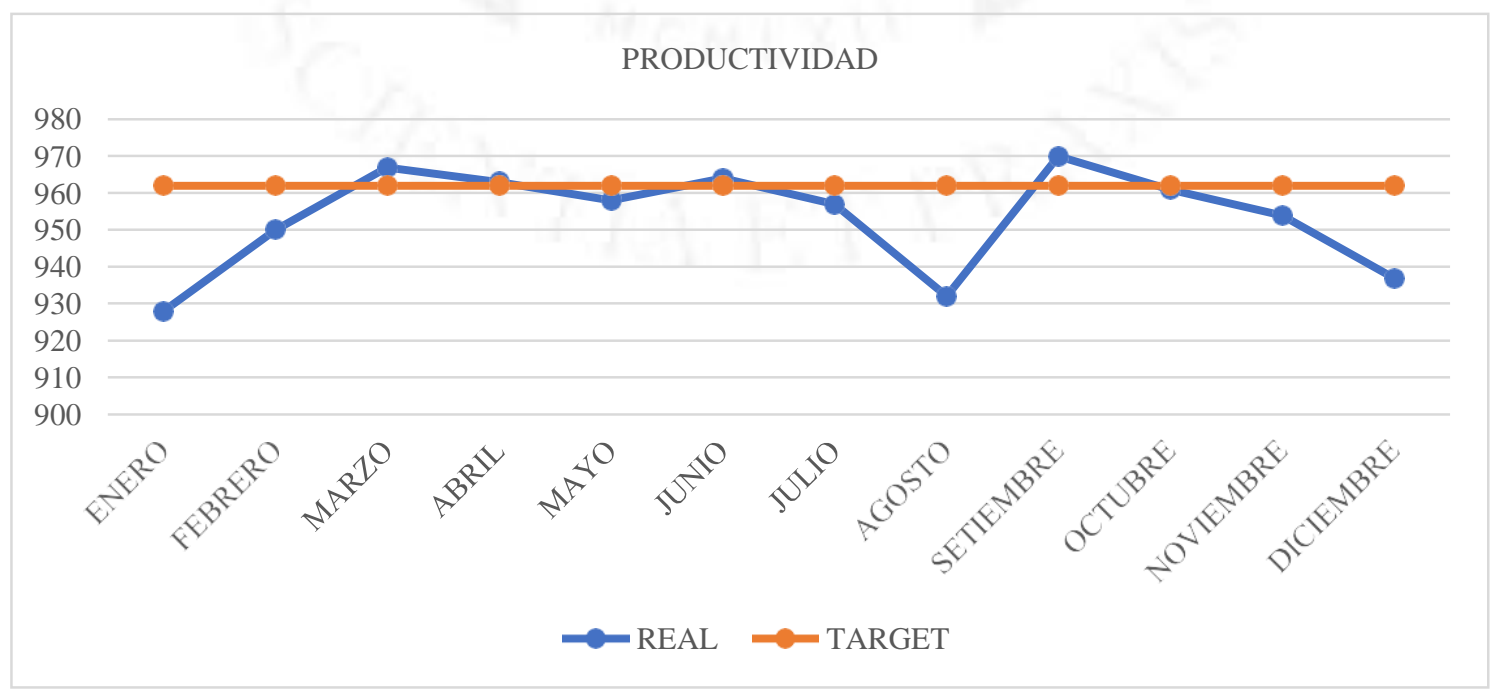

Elaboración Propia 
Tal como se observa en la Tabla 2.9 y Figura 2.2 , se recopilo data en cuanto a la productividad de la línea de los meses del año 2017 y se pudo observar que solo en los meses de marzo, abril, junio y setiembre, la productividad obtenida fue mayor a la meta, mientras que en los demás meses estuvo por debajo. La productividad alcanzada en el año 2017 fue de 953 resultando por debajo de la meta presupuestada para ese año.

Se recopiló información desde el año 2014 al 2018, de los problemas del proceso productivo de la línea. En las gráficas de Pareto se puede observar que el problema de "Retrasos en los mantenimientos programados" genera el $80 \%$ de las horas pérdidas (pérdida de productividad).

También se va a buscar disminuir el bajo rendimiento de materia prima, mejorando el indicador o por lo menos mantenerlo dentro del presupuesto. En este punto la compañía pone bastante énfasis debido a que como ya se mencionó la materia prima representa el $70 \%$ del costo del producto.

Finalmente, se abordará un tema muy importante que es la seguridad y esto con la finalidad de reducir el número de incidentes y accidentes. Analizando la Tabla 2.15 y Figura 2.8 de accidentes e incidentes se puede llegar a la conclusión que los incidentes son una alerta que indica que se debe tomar acción inmediata antes de que ocurra un accidente, esto mediante medidas correctivas y preventivas.

Se hará uso de una herramienta de mejora continua, un Pareto, para poder encontrar los problemas más relevantes que tiene la línea de planchas de fibrocemento. En cuanto a producción, cabe mencionar que se está sumando el total de horas pérdidas en el año por cada problema y se está calculando cuanto porcentaje representa cada tipo de problema del total de estas horas pérdidas. En cuanto a los problemas que no ocasionaron una parada no programada pero si una baja eficiencia de la línea se le bajo la velocidad presupuestada al equipo, por lo que se está traduciendo esta pérdida de eficiencia en horas pérdidas por baja velocidad con la finalidad de poder armar el diagrama de Pareto de los problemas que ocasionaron paradas no programadas y/o baja eficiencia de la línea. 
A continuación, se presentan Paretos de las paradas no programadas del año 2014 al 2017. Las paradas se han agrupado por tipo, indicando el total de horas acumuladas que se dejó de producir por cada uno. Esta información fue obtenida del SAP y fue proporcionada por la empresa.

Tabla 2. 10

Paretto de los problemas que ocasionan paradas no programadas y/o baja eficiencia de la línea, año 2014

\begin{tabular}{|l|c|c|c|}
\hline \multicolumn{1}{|c|}{ Problema } & $\begin{array}{c}\text { Horas perdidas } \\
\text { en el año }\end{array}$ & \% Total & \% Total acumulado \\
\hline Retrasos en los mantenimientos programados & 227.47 & $41 \%$ & $41 \%$ \\
\hline Avería de equipos & 146.15 & $26 \%$ & $67 \%$ \\
\hline Fieltro colmatado & 64.89 & $12 \%$ & $79 \%$ \\
\hline Arranques de máquina & 57.78 & $10 \%$ & $89 \%$ \\
\hline Recirculación & 34.72 & $6 \%$ & $95 \%$ \\
\hline Personal ausente & 25.44 & $5 \%$ & $100 \%$ \\
\hline
\end{tabular}

Elaboración propia

Figura 2. 3

Pareto de los problemas que ocasionan paradas no programadas y/o baja eficiencia de la línea, año 2014

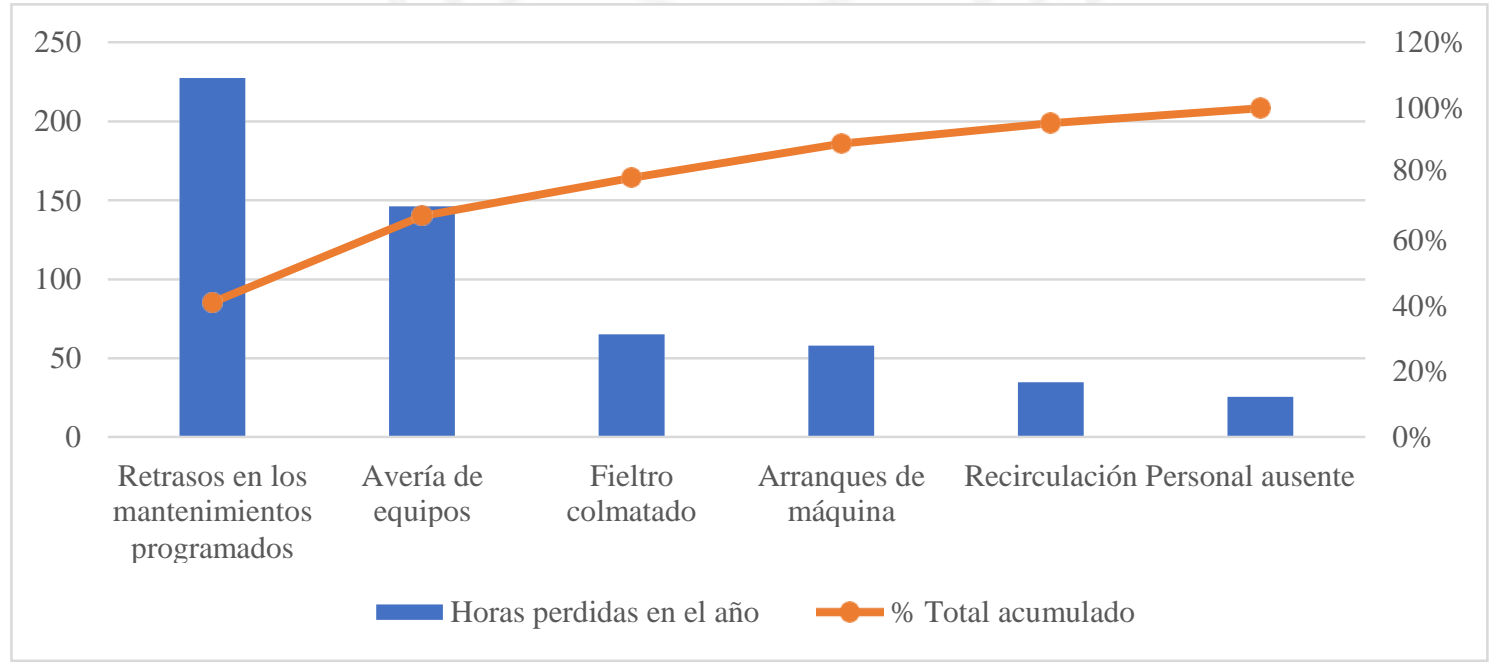

Elaboración propia 
Tabla 2. 11

Paretto de los problemas que ocasionan paradas no programadas y/o baja eficiencia de la línea, año 2015

\begin{tabular}{|l|c|c|c|}
\hline \multicolumn{1}{|c|}{ Problema } & $\begin{array}{c}\text { Horas perdidas } \\
\text { en el año }\end{array}$ & \% Total & \% Total acumulado \\
\hline Retrasos en los mantenimientos programados & 191.13 & $43 \%$ & $43 \%$ \\
\hline Avería de equipos & 113.31 & $26 \%$ & $69 \%$ \\
\hline Arranques de máquina & 55.1 & $12 \%$ & $81 \%$ \\
\hline Fieltro colmatado & 40.88 & $9 \%$ & $91 \%$ \\
\hline Recirculación & 22.24 & $5 \%$ & $96 \%$ \\
\hline Personal ausente & 18.88 & $4 \%$ & $100 \%$ \\
\hline
\end{tabular}

Elaboración propia

Figura 2. 4

Pareto de los problemas que ocasionan paradas no programadas y/o baja eficiencia de la línea, año 2015

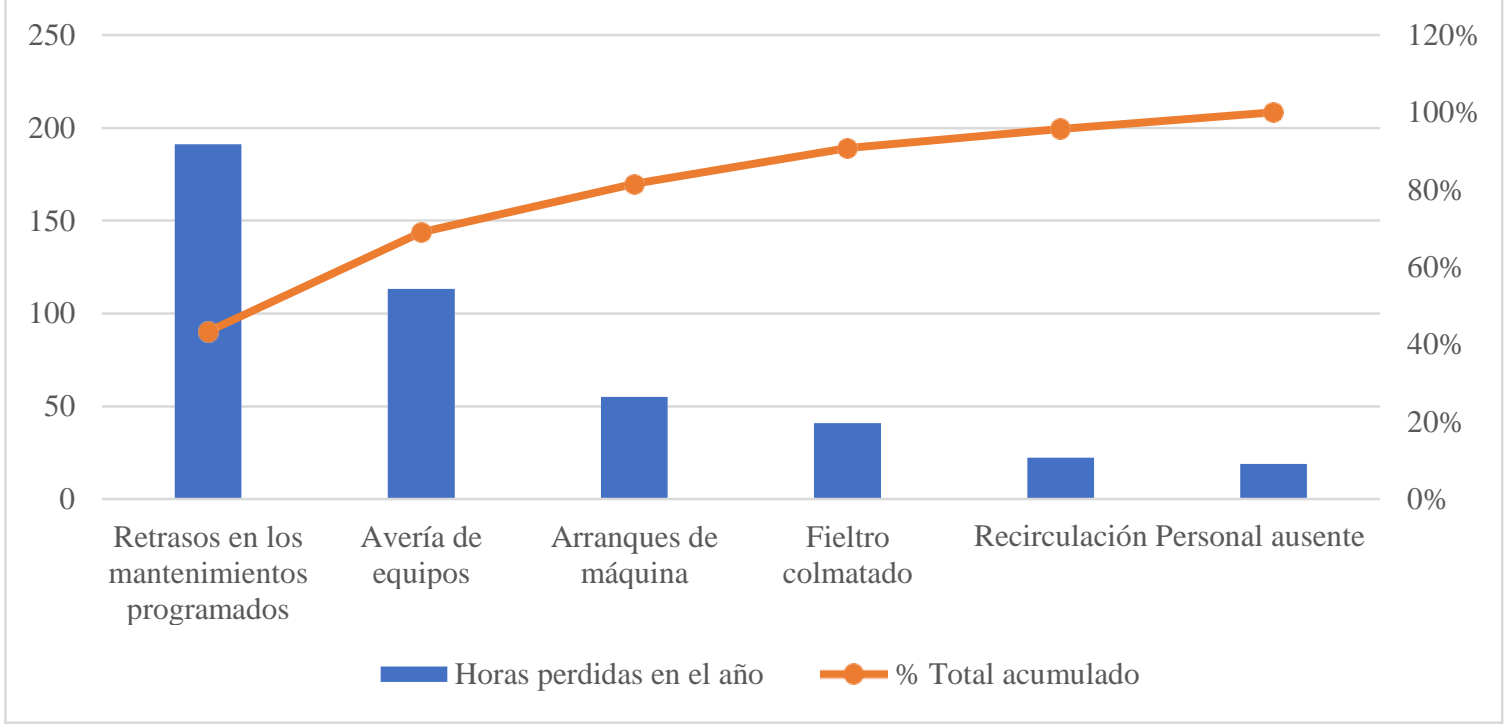

Elaboración propia 
Tabla 2.12

Pareto de los problemas que ocasionan paradas no programadas y/o baja eficiencia de la línea, año 2016

\begin{tabular}{|l|c|c|c|}
\hline \multicolumn{1}{|c|}{ Problema } & $\begin{array}{c}\text { Horas perdidas } \\
\text { en el año }\end{array}$ & \% Total & \% Total acumulado \\
\hline Retrasos en los mantenimientos programados & 256.96 & $38 \%$ & $38 \%$ \\
\hline Avería de equipos & 176.21 & $26 \%$ & $64 \%$ \\
\hline Coyuntura con el sindicato & 82.00 & $12 \%$ & $77 \%$ \\
\hline Arranques de máquina & 64.2 & $10 \%$ & $86 \%$ \\
\hline Fieltro colmatado & 67.7 & $10 \%$ & $96 \%$ \\
\hline Recirculación & 19.4 & $3 \%$ & $99 \%$ \\
\hline Personal ausente & 6.7 & $1 \%$ & $100 \%$ \\
\hline
\end{tabular}

Elaboración propia

Figura 2.5

Pareto de los problemas que ocasionan paradas no programadas y/o baja eficiencia de la línea, año 2016

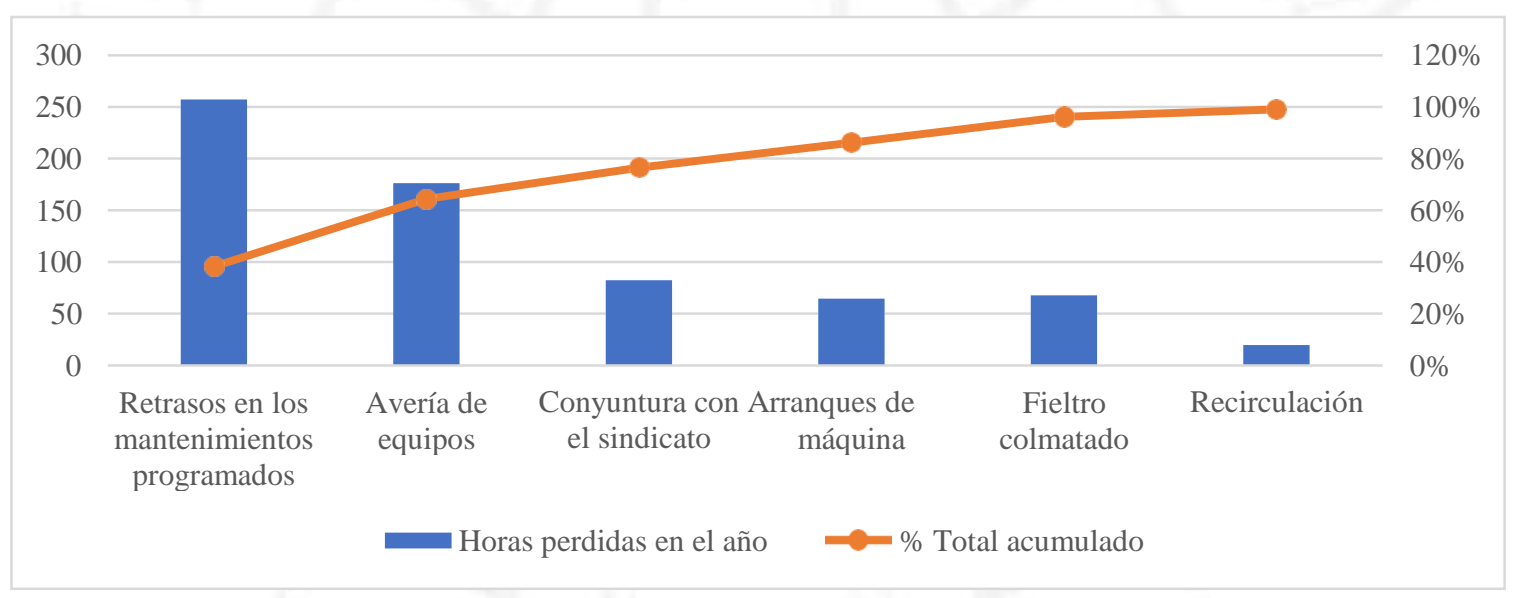

Elaboración propia

Tabla 2. 13

Pareto de los problemas que ocasionaron paradas no programadas y/o baja eficiencia de la línea, año 2017

\begin{tabular}{|l|c|c|c|}
\hline \multicolumn{1}{|c|}{ Problema } & $\begin{array}{c}\text { Horas perdidas } \\
\text { en el año }\end{array}$ & $\%$ Total & $\%$ Total acumulado \\
\hline Retrasos en los mantenimientos programados & 187.68 & $46 \%$ & $46 \%$ \\
\hline Avería de equipos & 100.87 & $25 \%$ & $71 \%$ \\
\hline Arranques de máquina & 37.35 & $9 \%$ & $81 \%$ \\
\hline Fieltro colmatado & 35.55 & $9 \%$ & $90 \%$ \\
\hline Recirculación & 42.21 & $10 \%$ & $100 \%$ \\
\hline
\end{tabular}

Elaboración propia 
Figura 2. 6

Pareto de los problemas que ocasionan paradas no programadas y/o baja eficiencia de la línea, año 2017

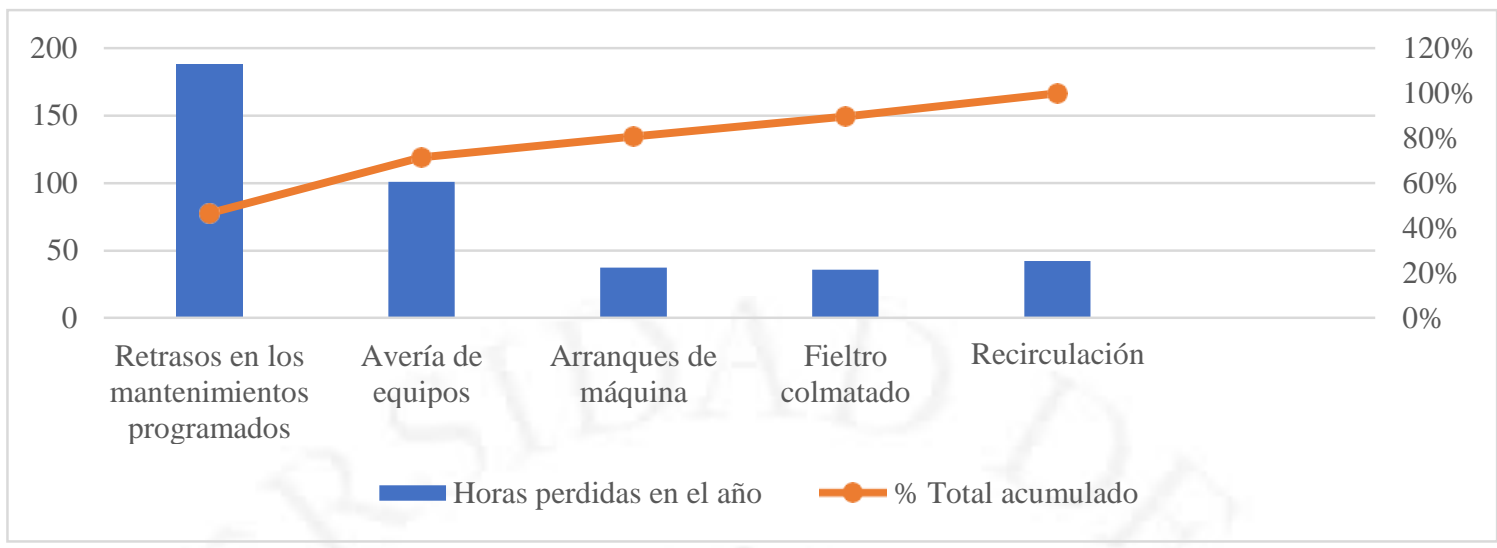

Elaboración propia

Tabla 2. 14

Cuadro comparativo del rendimiento de materia prima del 2014 al 2018

\begin{tabular}{|c|c|c|}
\hline Año & RMP $\left(\mathrm{m}^{2} \mathrm{n} / \mathrm{tn}\right)$ & Presupuesto $\left(\mathrm{m}^{2} \mathrm{n} / \mathrm{tn}\right)$ \\
\hline 2014 & 160.34 & 159 \\
\hline 2015 & 159.11 & 159 \\
\hline 2016 & 157.86 & 159 \\
\hline 2017 & 158.27 & 159 \\
\hline 2018 & 156.42 & 159 \\
\hline
\end{tabular}

Elaboración propia

Figura 2.7

Tendencia del rendimiento de materia prima del 2014 al 2018

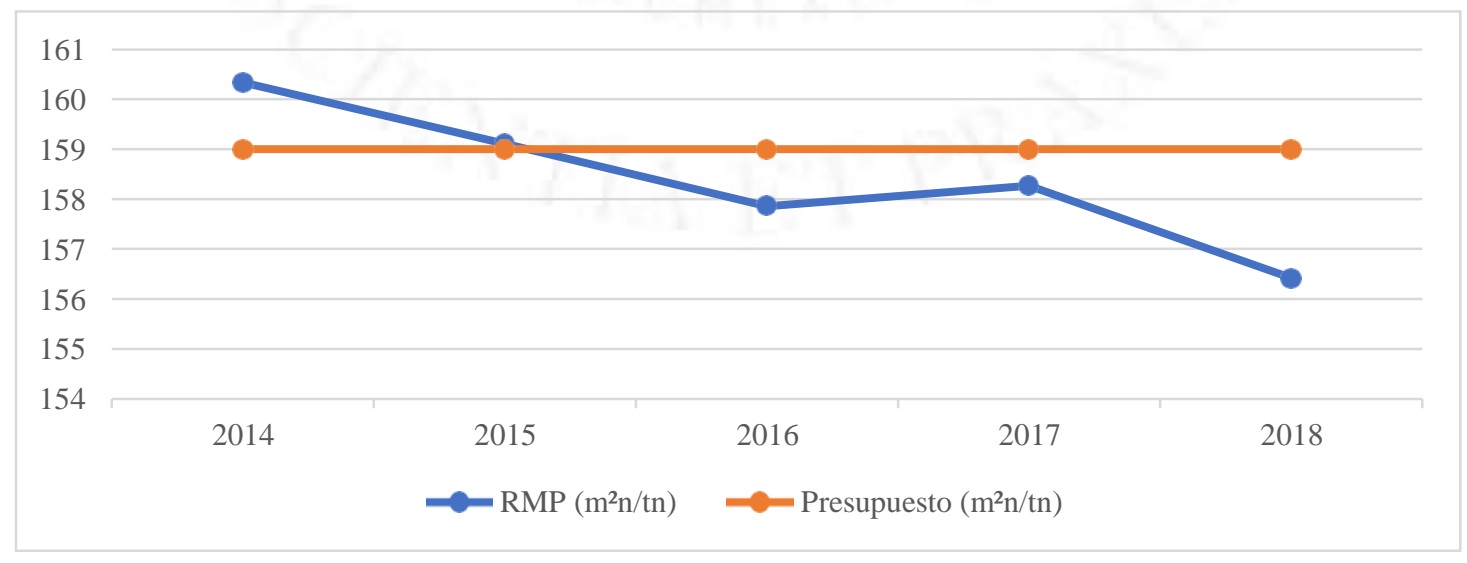

Elaboración propia 
En la Tabla 2.14 y Figura 2.7, se puede observar que, en los años 2014 al 2018 el indicador de rendimiento de materia prima salió del presupuesto y con tendencia a bajar cada año por lo que se deja en evidencia que la compañía tiene un problema con el correcto aprovechamiento de la materia prima, por lo que en este proyecto propone la mejora con el objetivo de que este indicador siempre se mantenga por encima del presupuesto y con esto se logrará una reducción en el costo del producto.

Tabla 2. 15

Accidentes e incidentes ocurridos del 2014 al 2018

\begin{tabular}{ccc}
\hline Año & Accidentes & Incidentes \\
\hline 2014 & 1 & 3 \\
\hline 2015 & 2 & 4 \\
\hline 2016 & 1 & 2 \\
\hline 2017 & 2 & 3
\end{tabular}

Elaboración propia

Figura 2.8

Accidentes e incidentes ocurridos del 2014 al 2018

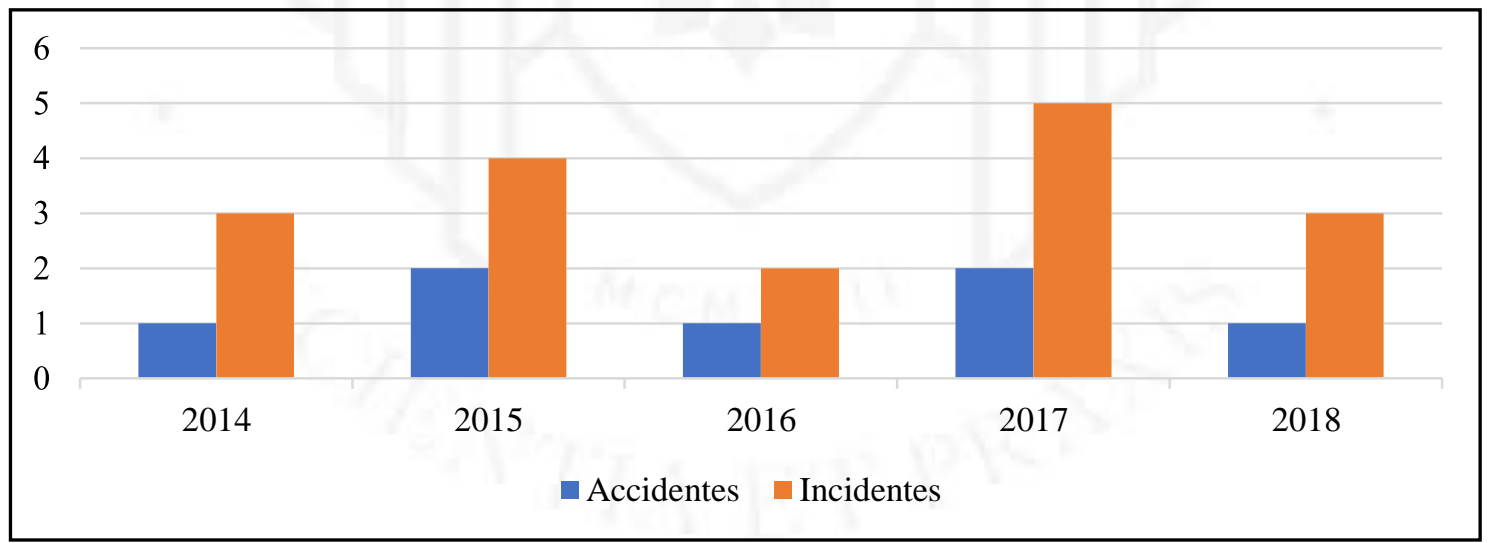

Elaboración propia

En la Tabla 2.15 y Figura 2.8, nos permite observar lo siguiente:

En el año 2014, ocurrió un accidente en el área de moldeados (procesos manuales), un operador estaba trasladando producción en un coche, en el trayecto pasa por una intersección y es embestido por un montacarga, que no lo vio cruzar debido a ello el operador sufrió una fractura en la pierna izquierda. 
En el año 2015, ocurrieron dos accidentes, los dos sucedieron en PL6, línea que fabrica planchas lisas, un operador se encontraba desarmando una tubería para limpiarla, pero se olvidó de cerrar la válvula de pase de material y el material le cayó en los ojos ocasionándole una infección. El otro accidente, se dio en un mantenimiento programado de la línea, dos operadores se encontraban desarmando una tubería, cuando a uno de ellos se le resbala de las manos un tramo de tubería, impactando está en la canilla del otro operador, causando una fuerte contusión.

En el año 2016, ocurrió un accidente en PL5, línea donde se va a realizar el proyecto de mejora, este accidente sucedió cuando un operador ingresó a la máquina que operaba para revisarla, debido a que esta presentaba una falla, pero se olvidó de bloquear el equipo cuando de repente la máquina empezó a operar y parte de un equipo impacta con el operador ocasionándole una fractura en el brazo derecho.

En el año 2017, un accidente ocurrió en el área de almacén de productos terminados; el electricista de turno se encontraba revisando la grúa puente, ya que esta había presentado una falla. Cuando el eléctrico termina de intervenir la grúa puente le indica al operador que opere para verificar que el problema fue resuelto pero eloperador realiza una mala maniobra generando que el gancho de la grúa puente impacte en el hombro del electricista ocasionado una fractura. El otro accidente ocurrió en PL5; un mecánico interviene los rodillos de una faja en movimiento, este introduce un desarmador en el rodillo con la intención de remover material que se había adherido al rodillo, cuando el rodillo atrapa la mano del mecánico generándole un corte profundo en su mano derecha.

En el año 2018, ocurrió un accidente en PL5, un operador que se encontraba enganchando los paquetes para que posteriormente la grúa puente se los llevase, no se percata que una rejilla de la canaleta de paso de vapor condensado de las cabinas de curado se encontraba doblada, dejando un hueco grande, por lo que, al pasar, su pie derecho se introduce en el hueco generándole quemaduras de segundo grado. Según la investigación final, el peso de los paquetes había generado que la rejilla se doblase, esto sucedió en el turno anterior. El turno que le continuaba retira el paquete, pero como se comenta líneas arriba, el operador que estaba enganchando los paquetes no se diocuenta del mal estado de la rejilla, ocasionándole que luego al volver a pasar por esa zona sufra el accidente. 


\section{CAPÍTULO III: DIAGNÓSTICO DEL SISTEMA O PROCESO OBJETO DE ESTUDIO}

\subsection{Análisis del sistema o proceso objeto de estudio}

\subsubsection{Descripción detallada del sistema o proceso objeto de estudio}

- Preparación de la mezcla:

Es muy importante controlar la cantidad de cada materia prima que ingresará a la mezcla; ya que, el suministrar más o menos de algún componente traería consecuencias perjudiciales en el proceso productivo, así como en la calidad del producto. Las materias primas como el agua, caolín, carbonato de calcio, celulosa y cemento ingresan automáticamente a un mezclador, a excepción de la Fibras sintéticas que el operador del mezclador tiene que ingresarlas manualmente (la fibra C66 viene en bolsas de 19,88 kg, la fibra U30 en bolsas de 7,64 kg y el residuo seco en bolsas de 15,28 kg). Aquí se obtiene una mezcla homogénea.

Figura 3. 1

Mezclador

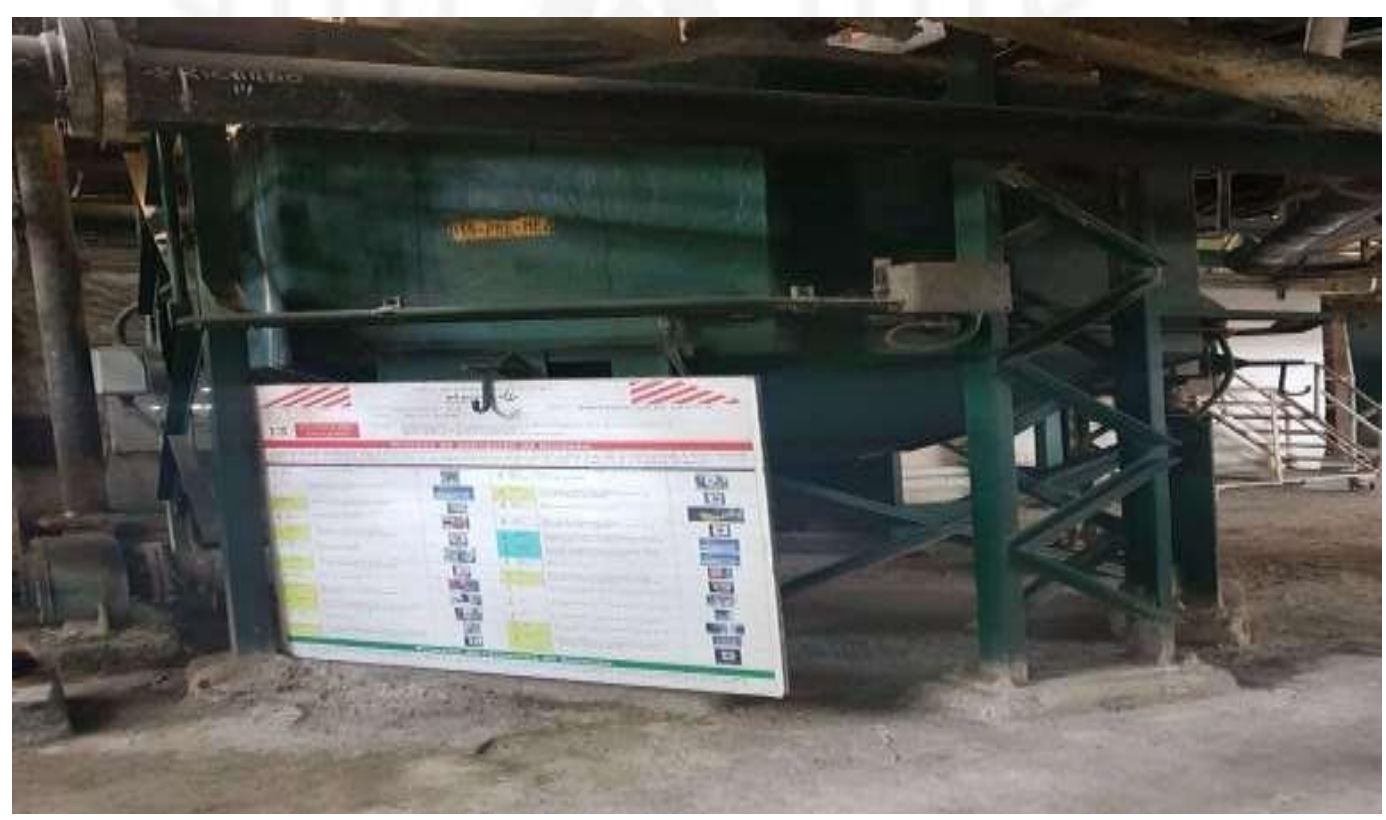

Fuente: Fábrica Peruana Eternit S.A (2019) 
- Formación del producto:

La mezcla ingresa a la máquina "Hatschek" donde se da inicio a la formación de la plancha de fibrocemento, previamente se le agrega un floculante que tiene como función aglomerar las partículas pequeñas y convertirlas en partículas más grandes para que de esta manera sea factible que los tamices recojan el material y lo transfieran al fieltro. Junto con el floculante se le agrega un antiespumante para vencer la tensión superficial y evitar de esta manera que entre capa y capa se formen burbujas de aire, lo que sería perjudicial para la calidad de la plancha en el proceso de ondulado. La máquina "Hatschek" cuenta al inicio con 2 "mesas de vacío secundarias" que tienen como función hacer que la lámina de material que aun contiene un exceso de humedad de $70-80 \%$ y un espesor de $0,33-0,66 \mathrm{~mm}$ no se desprenda del fieltro y esto lo logra mediante un sistema de succión. También se cuenta con 2 "mesas de vacío principales" las cuales retiran el agua de la lámina, esto también se logra mediante un sistema de succión. La lamina luego de haber pasado por las "mesas de vacío principales" pasan por el rodillo formador donde se van formando las capas de material y una vez completadas el número de capas (4 capas de material con un espesor de $0,99 \mathrm{~mm}$ cada una) una cuchilla de corte automática corta la lámina (6,25 mts de largo cada lamina) y el proceso se vuelve a repetir.

Figura 3. 2

Máquina Hatschek

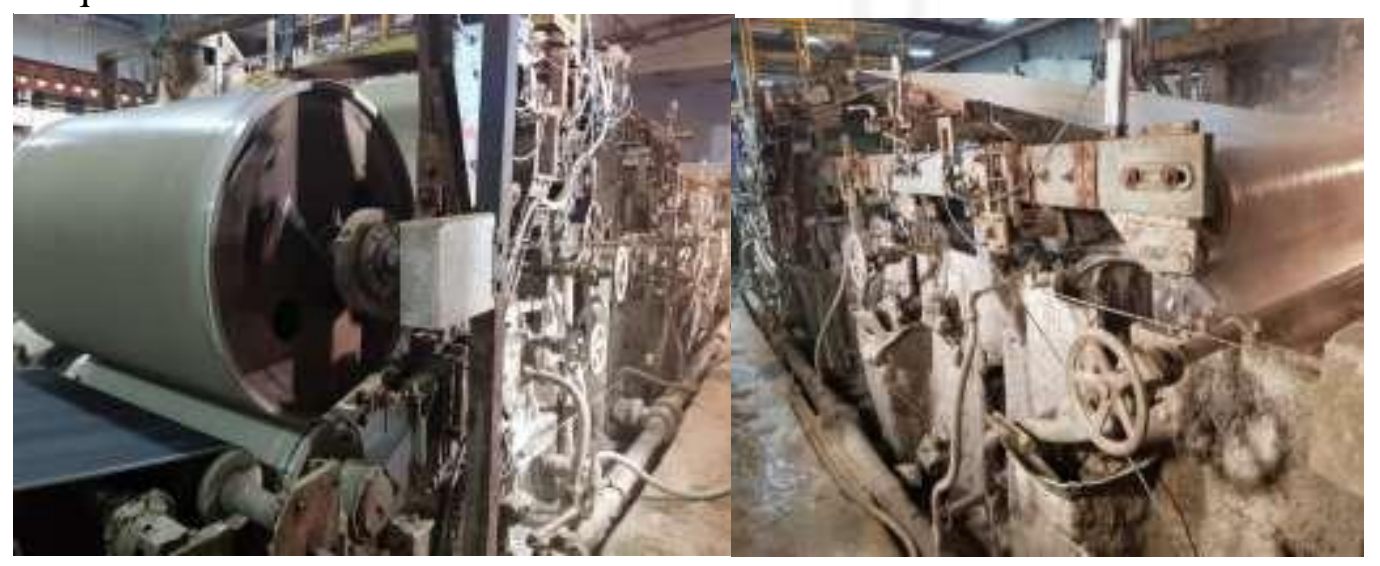

Fuente: Fábrica Peruana Eternit S.A (2019) 
- Ondulado:

Luego de que la lámina lisa de 6,25 x 1,20 mts, sale de la máquina "Hatschek" pasa por 2 discos de corte longitudinales que corta la lámina a ambos extremos, medida acorde a la medida del ancho del producto terminado (1,10 mts). Después de que lamina lisa haya sido cortada longitudinalmente es cortada transversalmente por 3 discos de corte, 2 ubicados a los extremos y 1 en el centro, cabe mencionar que estos retazos no se pierden sino que son trasladados por una faja transportadora, hacia un equipo que desintegra lo retazos y por bombeo vuelven a retornar al proceso para ser reaprovechados como parte de la mezcla. De estos cortes se obtienen dos planchas lisas de 3,05 x 1,10 mts cada una. Finalmente, una "ventosa" recoge las dos planchas lisas y las ondula (el ondulado es similar a un acordeón), luego de haberlas ondulado las deja en un molde de acero inoxidable, el proceso se vuelve a repetir. En el ondulado se forman paquetes de 46 planchas con sus 46 moldes respectivos.

Figura 3.3

Ventosa Ondulada

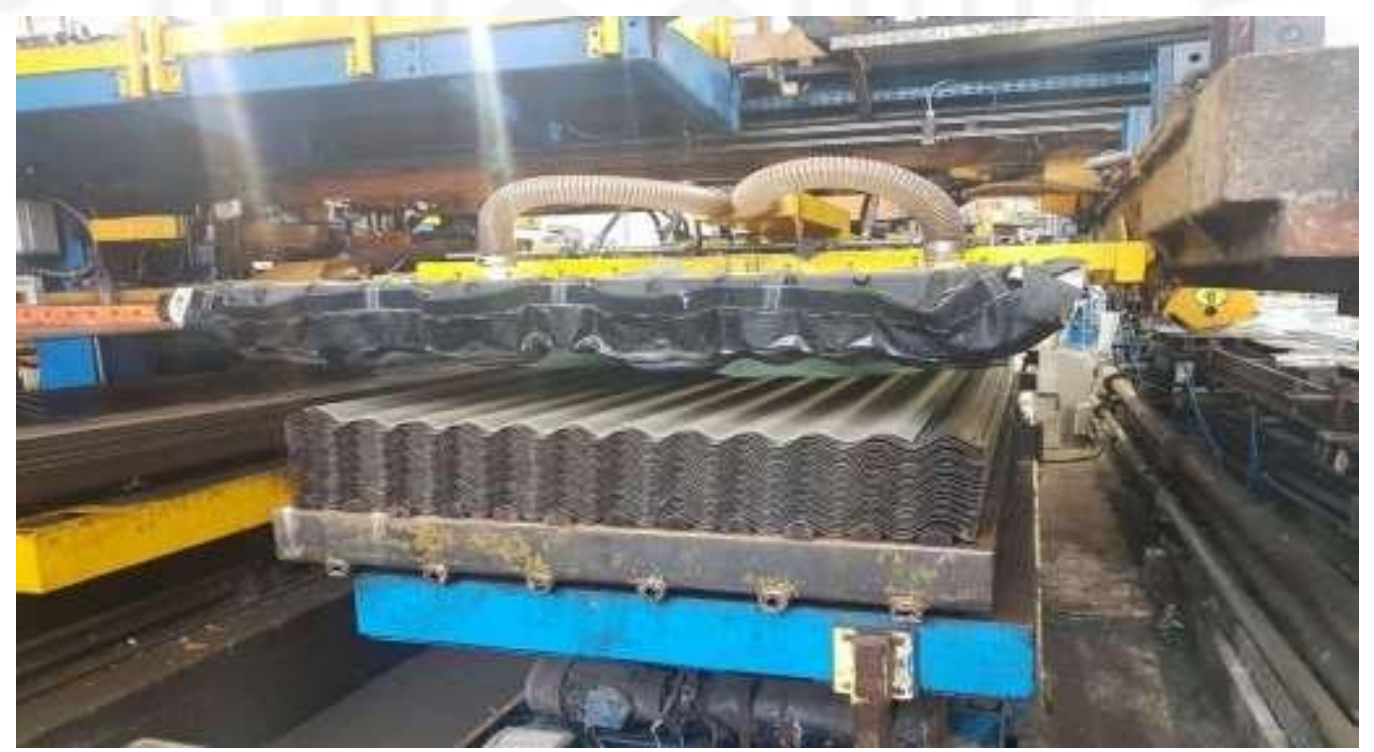

Fuente: Fábrica Peruana Eternit S.A (2019) 
- Pre - curado:

Los paquetes formados en el ondulado son trasladados mediante una grúa puente a las cabinas de pre - curado, aquí los paquetes permanecen entre 3,5 a 4 hrs, a una temperatura entre 60 a $65{ }^{\circ} \mathrm{C}$, esto con el fin de acelerar el fraguado de las planchas de fibrocemento.

Figura 3.4

Cabina Precuadrado

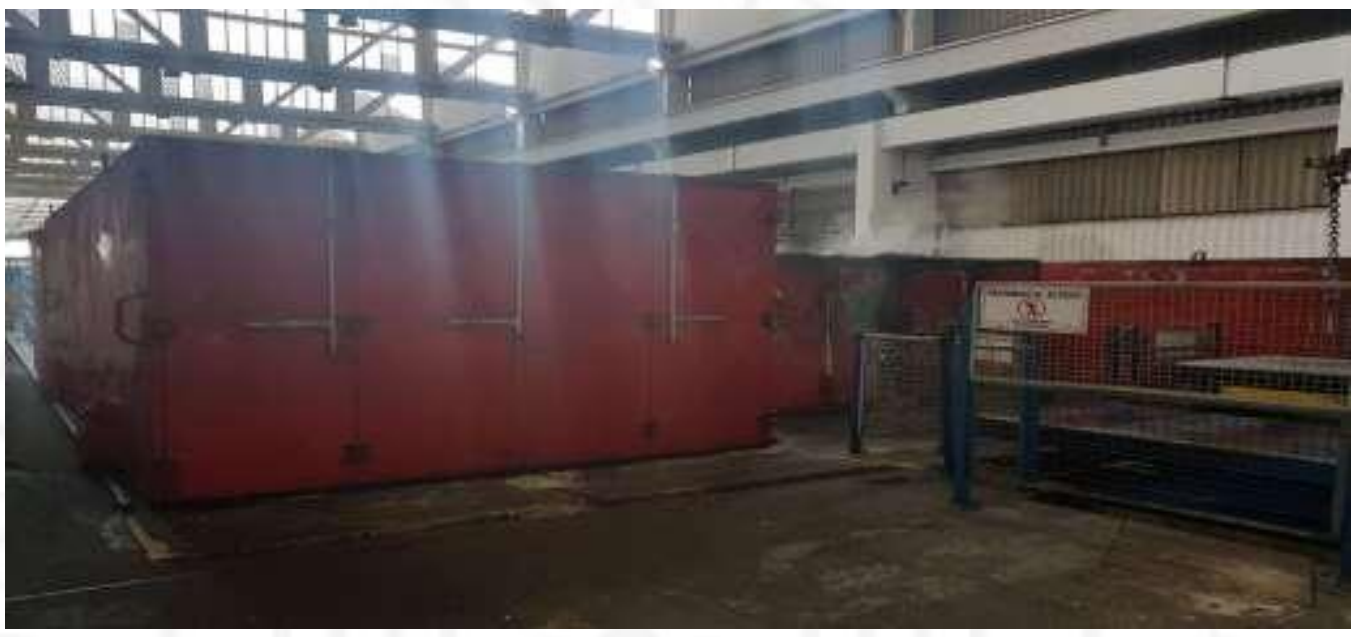

Fuente: Fábrica Peruana Eternit S.A (2019)

- Proceso de desapilado

Como etapa final del proceso de producción, los paquetes ya fraguados en las cabinas de pre - curado son trasladados a zona de desapilado para separar los moldes de las planchas. Aquí se forman paquetes de 130 planchas y los moldes son trasladados nuevamente a la zona de ondulado, pero previamente son lubricados con aceite con el fin de evitar que las planchas se peguen al molde y al momento de separarlos, estas se quiebren. Los paquetes de 130 planchas son derivadas al APT. 
Figura 3.5

Máquina Desalojadora

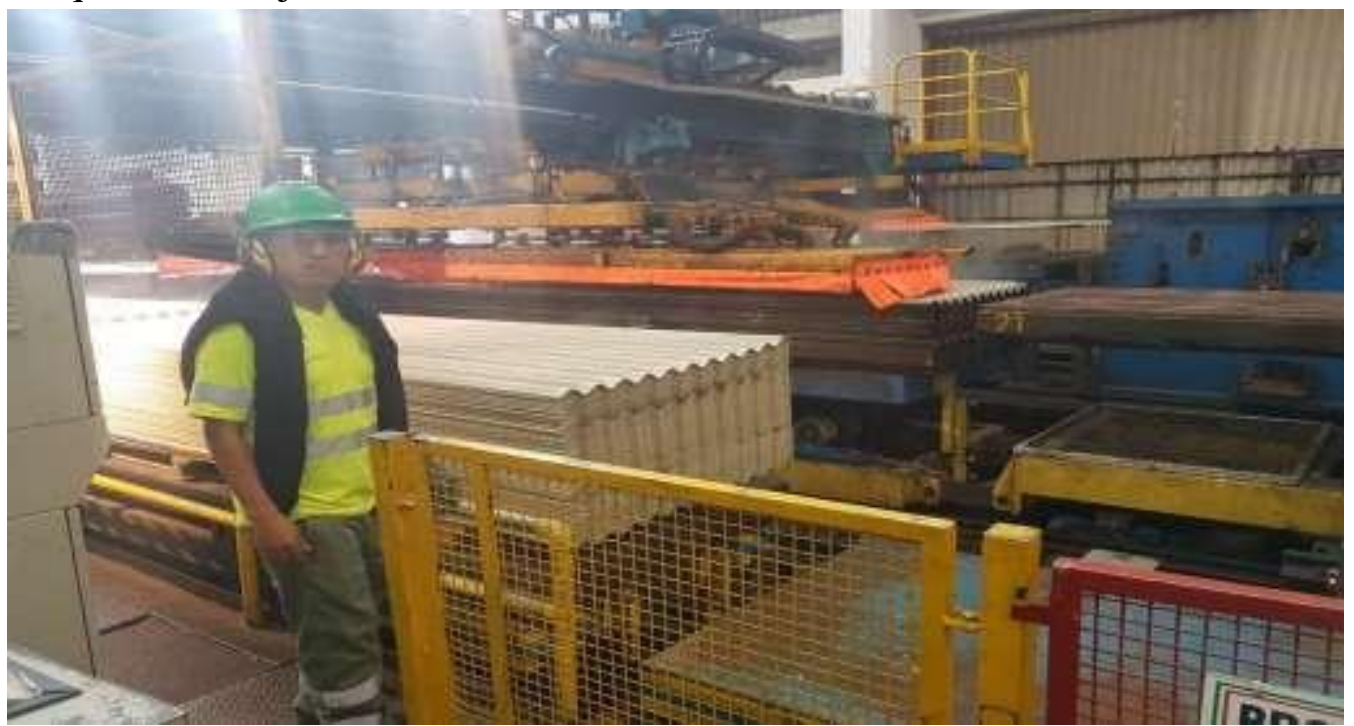

Fuente: Fábrica Peruana Eternit S.A (2019) 
Figura 3.6

Diagrama de operaciones del proceso de fabricación de planchas de fibrocemento (DOP)

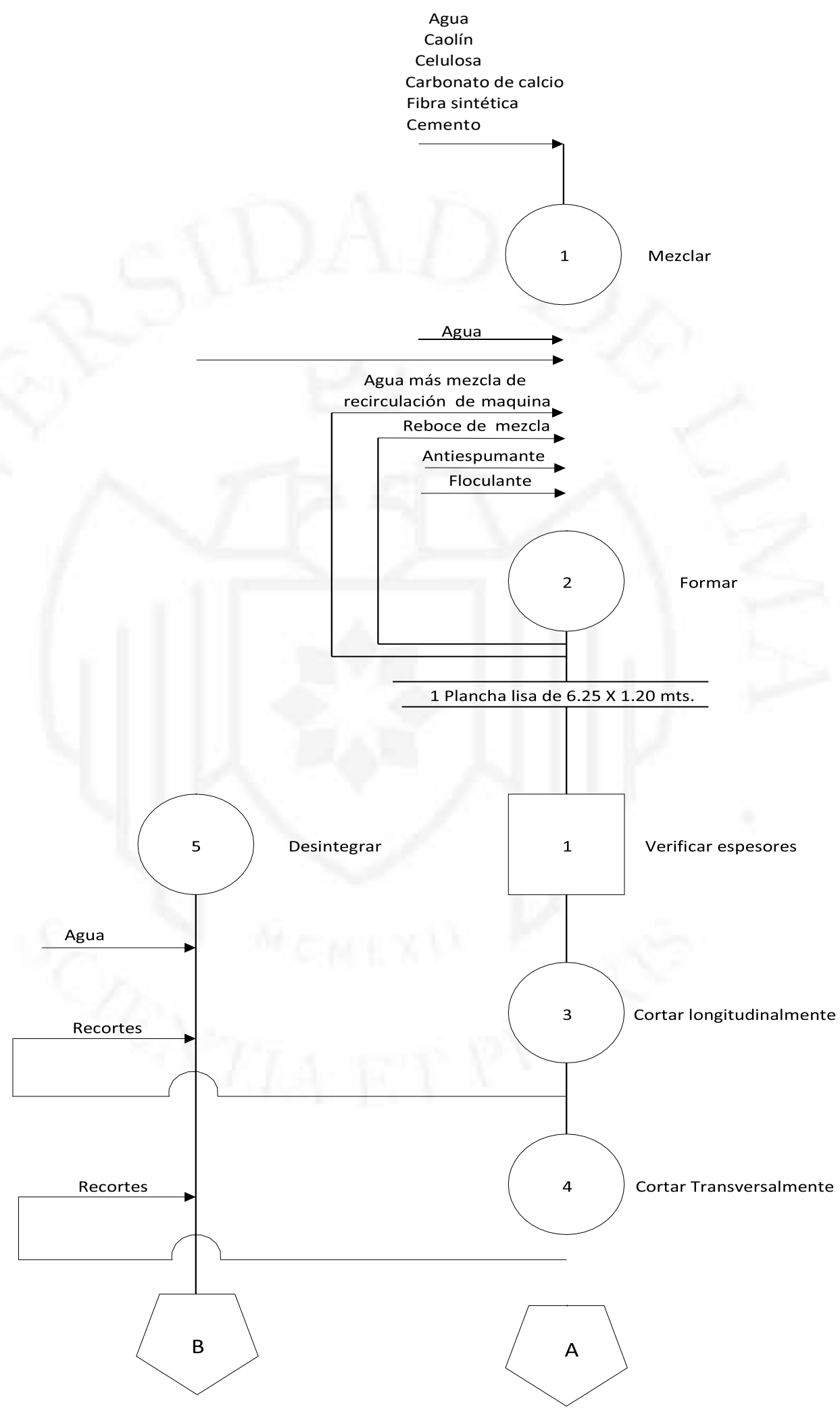

(continúa) 
(continuación)
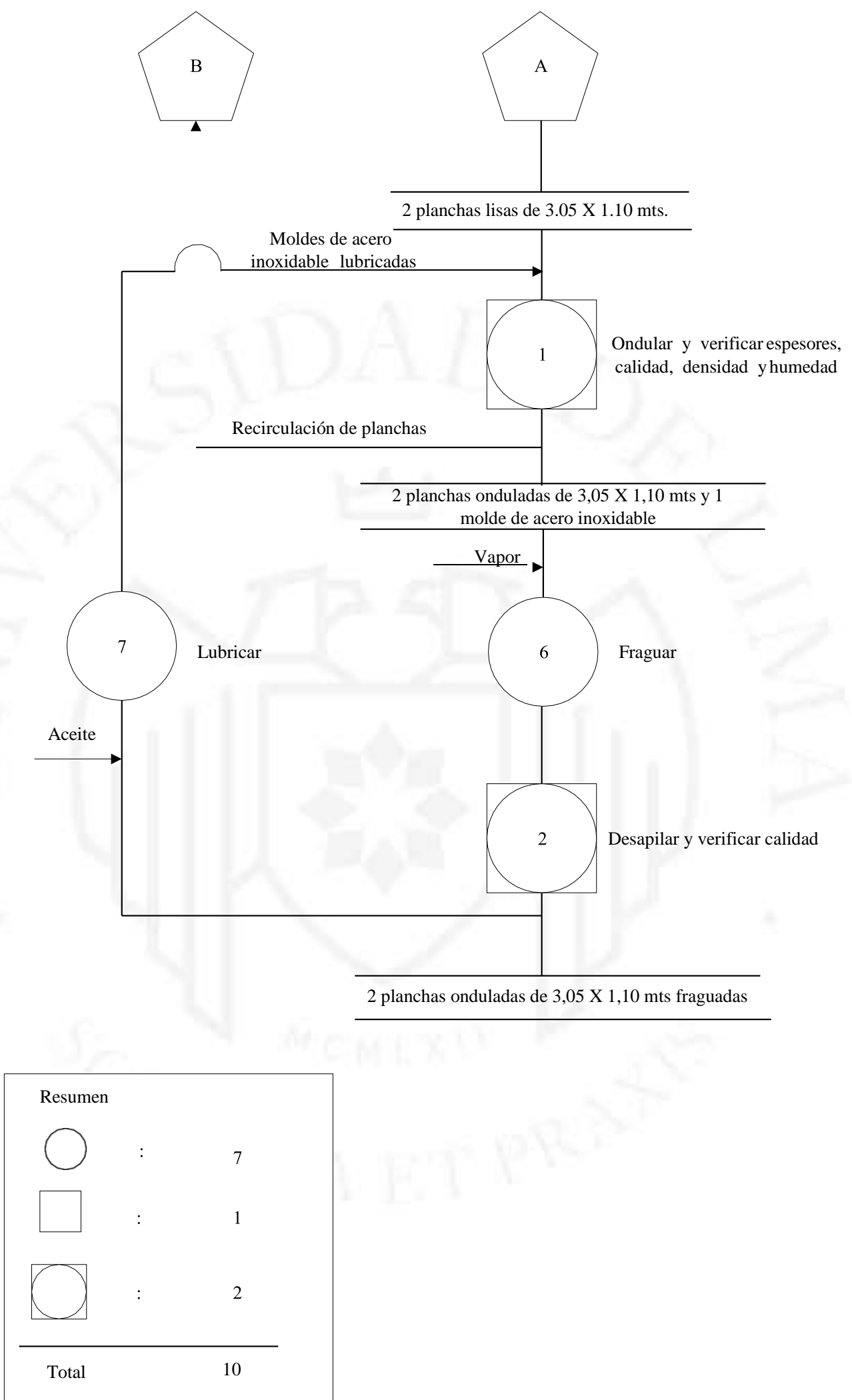

Elaboración Propia 
Figura 3.7

Diagrama de Balance de materia

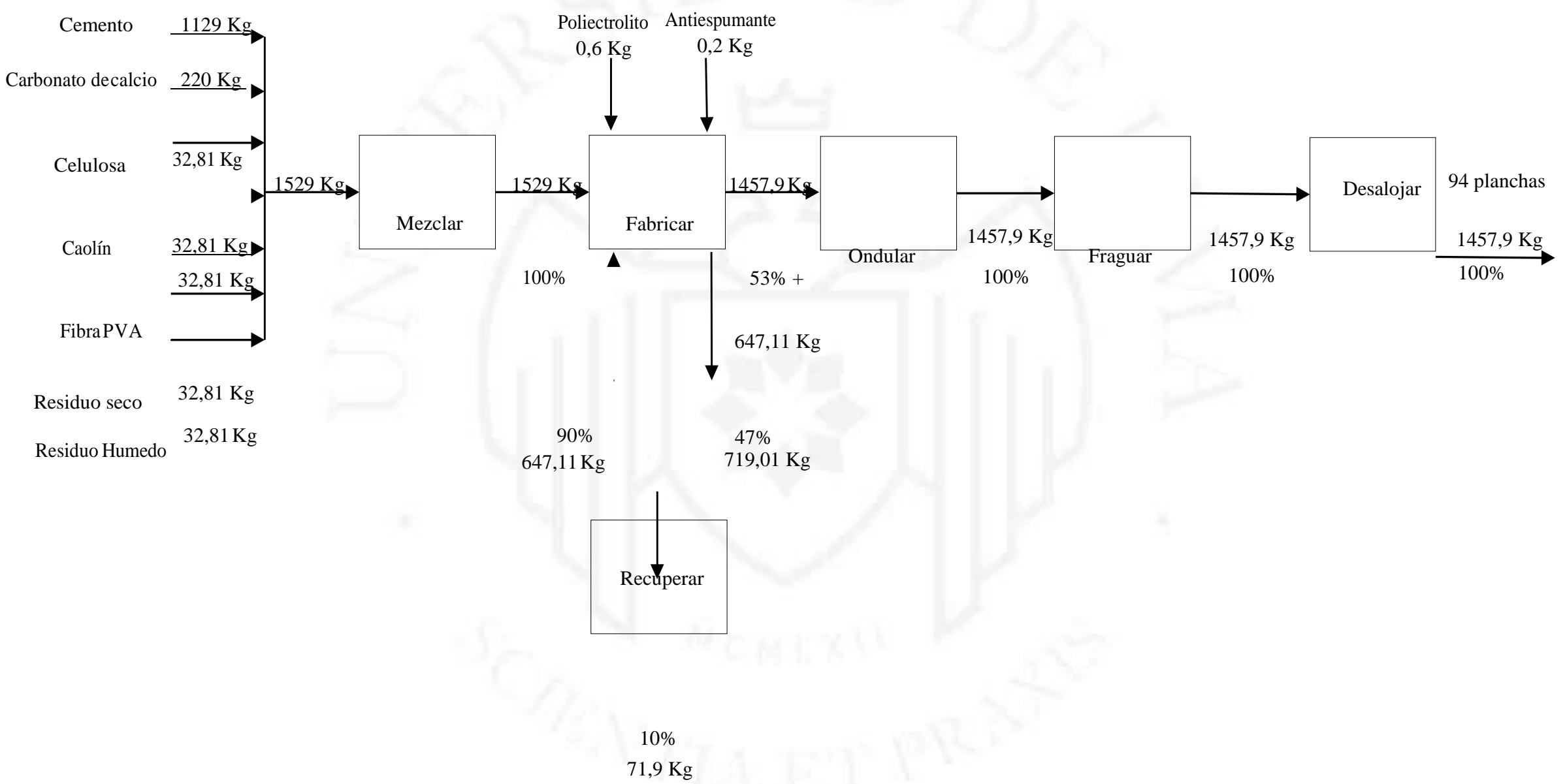

Elaboración Propia

Como se puede observar en la Figura 3.7, el diagrama de flujo representa el balance de material. 
Tabla 3. 1

Tiempo de ciclo por equipo para identificar el cuello de botella

\begin{tabular}{|c|c|c|c|c|c|c|c|c|c|c|c|}
\hline Equipo & Elemento & OBS DIA1 & OBS DIA2 & OBS DIA3 & OBS DIA4 & OBS DIA5 & OBS DIA6 & OBS DIA7 & OBS DIA8 & OBS DIA9 & OBS DIA10 \\
\hline \multirow{2}{*}{ Hatschek } & \multirow{2}{*}{ Formación de pasta } & 18.38 & 18.18 & 18.4 & 18.41 & 18.28 & 18.5 & 18.14 & 18.32 & 18.31 & 18.34 \\
\hline & & & & & & & & & & & \\
\hline \multirow{2}{*}{ Fajas transportadoras } & \multirow{2}{*}{ Transporte de pasta } & 18.31 & 18.29 & 18.32 & 18.28 & 18.29 & 18.31 & 18.31 & 18.3 & 18.28 & 18.29 \\
\hline & & & & & & & & & & & \\
\hline \multirow{2}{*}{ Onduladora } & \multirow{2}{*}{$\begin{array}{l}\text { Corte, ondulado y apilado de } \\
\text { pasta }\end{array}$} & 18.72 & 18.39 & 18.63 & 18.55 & 18.79 & 23.26 & 31.14 & 18.53 & 18.52 & 18.41 \\
\hline & & & & & & & CEP & D & & & \\
\hline \multirow[b]{2}{*}{ Desalojadora } & \multirow[b]{2}{*}{ Separación de pasta y molde } & 20.36 & 21.31 & 20.19 & 20.78 & 21.75 & 20.48 & 21.12 & 20.15 & 20.71 & 21.16 \\
\hline & & & & & & & & 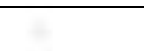 & & & \\
\hline \multirow{3}{*}{ Grúa Puente } & \multirow{3}{*}{ Traslación de paquetes } & 17.96 & 18.71 & 17.79 & 18.18 & 18.98 & 17.88 & 18.72 & 17.55 & 18.31 & 18.56 \\
\hline & & & & & & & & & & & \\
\hline & & & & & & & & & & & \\
\hline
\end{tabular}


(continuación)

\begin{tabular}{|c|c|c|c|c|c|c|c|c|c|c|c|c|c|c|}
\hline Equipo & Elemento & $\begin{array}{l}\text { OBS } \\
\text { DIA11 }\end{array}$ & $\begin{array}{l}\text { OBS } \\
\text { DIA12 }\end{array}$ & $\begin{array}{l}\text { OBS } \\
\text { DIA13 }\end{array}$ & $\begin{array}{c}\text { OBS } \\
\text { DIA14 }\end{array}$ & $\begin{array}{l}\text { OBS } \\
\text { DIA15 }\end{array}$ & $\begin{array}{l}\text { OBS } \\
\text { DIA16 }\end{array}$ & $\begin{array}{l}\text { OBS } \\
\text { DIA17 }\end{array}$ & $\begin{array}{c}\text { OBS } \\
\text { DIA18 }\end{array}$ & $\begin{array}{l}\text { OBS } \\
\text { DIA19 }\end{array}$ & $\begin{array}{l}\text { OBS } \\
\text { DIA20 }\end{array}$ & $\begin{array}{l}\text { Tiempo } \\
\text { promedio } \\
\text { (seg.) }\end{array}$ & Suplementos & $\begin{array}{c}\text { Tiempo } \\
\text { estándar } \\
\text { (seg./pasta) }\end{array}$ \\
\hline \multirow{2}{*}{ Hatschek } & \multirow{2}{*}{ Formación de pasta } & 18.41 & 18.55 & 18.25 & 18.33 & 18.17 & 31.36 & 18.51 & 18.62 & 18.66 & 18.14 & \multirow{2}{*}{18.36} & \multirow{2}{*}{-} & \multirow{2}{*}{9.18} \\
\hline & & & & & & & $\mathrm{D}$ & & 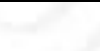 & & & & & \\
\hline \multirow{2}{*}{ Fajas transportadoras } & \multirow{2}{*}{ Transporte de pasta } & 18.29 & 18.31 & 18.3 & 18.32 & 18.32 & 18.31 & 18.27 & 18.29 & 18.32 & 18.3 & \multirow{2}{*}{18.30} & \multirow{2}{*}{-} & \multirow{2}{*}{9.15} \\
\hline & & & & & & & & & & & & & & \\
\hline \multirow{2}{*}{ Onduladora } & \multirow{2}{*}{$\begin{array}{l}\text { Corte, ondulado y } \\
\text { apilado de pasta }\end{array}$} & 18.6 & 24.12 & 18.88 & 18.55 & 18.34 & 18.41 & 18.77 & 18.82 & 18.58 & 18.6 & \multirow{2}{*}{18.59} & \multirow{2}{*}{0.22} & \multirow{2}{*}{9.41} \\
\hline & & & CEM & & & & & & & & & & & \\
\hline \multirow{2}{*}{ Desalojadora } & \multirow{2}{*}{$\begin{array}{l}\text { Separación de pasta y } \\
\text { molde }\end{array}$} & 28.19 & 19.39 & 20.79 & 20.26 & 20.45 & 34.76 & 20.16 & 20.67 & 21.13 & 31.65 & \multirow{2}{*}{20.64} & \multirow{2}{*}{0.71} & \multirow{2}{*}{10.67} \\
\hline & & CEMP & & & & & CEPT & & & & REM & & & \\
\hline \multirow{2}{*}{ Grúa Puente } & \multirow{2}{*}{$\begin{array}{l}\text { Traslación de } \\
\text { paquetes }\end{array}$} & 18.15 & 18.23 & 18.39 & 17.88 & 18.05 & 18.1 & 18.16 & 18.07 & 18.73 & 17.93 & \multirow{2}{*}{18.22} & & \multirow{2}{*}{9.11} \\
\hline & & & & & & & & & & & & & & \\
\hline
\end{tabular}

\begin{tabular}{|l|c|c|}
\hline \multicolumn{1}{|c|}{ Elementos extraños } & $\begin{array}{c}\text { Tiempo promedio } \\
\text { (seg.) }\end{array}$ & Códigos \\
\hline $\begin{array}{l}\text { Cambio de estantes } \\
\text { de pastas }\end{array}$ & 4.67 & CEP \\
\hline $\begin{array}{l}\text { Cambio de estante } \\
\text { de moldes }\end{array}$ & 5.53 & CEM \\
\hline $\begin{array}{l}\text { Cambio de estante } \\
\text { de moldes y pastas }\end{array}$ & 7.55 & CEMP \\
\hline $\begin{array}{l}\text { Cambio de estantes } \\
\text { de Producto } \\
\text { terminado }\end{array}$ & 14.12 & CEPT \\
\hline $\begin{array}{l}\text { Recojo de estantes } \\
\text { de moldes }\end{array}$ & 11.01 & REM \\
\hline Demora & & D \\
\hline
\end{tabular}

\begin{tabular}{|c|c|}
\hline Cabinas de curado & pastas / cabina \\
\hline 1 & 368 \\
\hline 2 & 552 \\
\hline 3 & 552 \\
\hline 4 & 276 \\
\hline Total & 1748 \\
\hline
\end{tabular}

Elaboración Propia 
Tal como se puede apreciar en la Tabla 3.1, para obtener la toma de tiempo de la máquinas se hizo que los equipos operasen a su máxima capacidad para que de esta manera se pueda identificar cual es el cuello de botella. Luego de los cálculos obtenidos se identificó que el cuello de botella es la desalojadora, ya que tiene el mayor tiempo de ciclo (10,67 seg. /pasta)

\subsubsection{Capacidad instalada}

Tabla 3.2

Capacidad de producción por equipo

\begin{tabular}{lcccccc}
\hline \multicolumn{7}{c}{ Capacidad de producción por equipo } \\
\hline Equipo & Pastas/hora & $\begin{array}{c}\text { Factor de } \\
\text { rtilizanión }\end{array}$ & $\begin{array}{c}\text { Factor de } \\
\text { ofiniannin }\end{array}$ & $\begin{array}{c}\text { Capacidad } \\
\text { instalada } \\
\text { pastas/hora) }\end{array}$ & $\begin{array}{c}\text { Coeficiente } \\
\text { de } \\
\text { conversión }\end{array}$ & $\begin{array}{c}\text { Capacidad } \\
\text { instalada } \\
\left(\mathrm{m}^{2} \mathrm{n} / \mathrm{hora}\right)\end{array}$ \\
\hline Hatschek & 392 & 0,9 & 0,96 & 339 & 3,16 & 1071 \\
\hline Onduladora & 383 & 0,9 & 0,96 & 331 & 3,16 & 1046 \\
\hline Desalojadora & 337 & 0,9 & 0,96 & 291 & 3,16 & 920 \\
\hline $\begin{array}{l}\text { Cabina de } \\
\text { Curado }\end{array}$ & 437 & 0,9 & 0,96 & 378 & 3,16 & 1195 \\
\hline
\end{tabular}

Elaboración Propia

Como se puede observar en la Tabla 3.2, para el cálculo de la capacidad instalada se ha considerado 0,9 como factor de utilización. Considerando un tiempo disponible real por turno de 8 horas y un tiempo promedio de paro de 0,8 horas.

Tiempo efectivo utilizado por producir $=8 \mathrm{Hrs}-0,8 \mathrm{Hrs}=7,2 \mathrm{Hrs}$

Factor de Utilización $=$ Tiempo efectivo utilizado por producir X 100

Tiempo disponible real

Factor de Utilización $=7,2$ Hrs X $100=90 \%$

\section{$8 \mathrm{Hrs}$}

En cuanto al factor de eficiencia se está considerando 0,96, ya que la producción potencial de la línea es de 400 pastas/hora mientras que la producción real es de 383 pastas/hora.

Según los cálculos obtenidos la capacidad instalada es de 291 pastas/hora y se toma en cuenta esta capacidad, la del cuello de botella. 


\subsubsection{Análisis de los indicadores específicos de desempeño del sistema o proceso (metas, resultados actuales, tendencias, brechas, comparativos)}

Tabla 3.3

Indicadores específicos de desempeño

\begin{tabular}{ll}
\hline Indicadores generales & \multicolumn{1}{c}{ Indicadores específicos } \\
\hline \multirow{3}{*}{ Rendimiento de materia prima } & $\begin{array}{l}\text { \% de eficiencia de bateas } \\
\text { Promedio de densidades de las planchas }\end{array}$ \\
\hline \multirow{2}{*}{ Eficiencia de máquina } & $\begin{array}{l}\text { Promedio de espesores de las planchas } \\
\text { \% de recirculación }\end{array}$ \\
\hline \% de rechazos & $\begin{array}{l}\text { Tiempo de formación promedio de la plancha(con las } \\
\text { velocidades de la máquina) }\end{array}$ \\
\hline Índice de frecuencia (IF) & Cumplimiento de los estándares de calidad \\
\hline Cantidad de SOP ${ }^{6}$ registrados \\
\hline Índice de gravedad (IG) & Cantidad de conversaciones de seguridad ${ }^{7}$ registradas \\
\cline { 2 - 2 } & Cantidad de accidentes incapacitantes \\
\hline
\end{tabular}

Elaboración Propia

\subsection{Determinación de las causas raíces de los problemas hallados}

Para poder elegir los puntos en los cuales la investigación se enfocará, se realizará una comparación entre los factores que originan los problemas más relevantes de la línea de fabricación de planchas de fibrocemento. De esta manera se determinará los que son más importantes con respecto a los otros. Si un factor es más o igual de importante que el otro se colocará un 1 y si es menos importante se colocar 0 .

Cabe resaltar que esta calificación es desde el punto de vista de los autores de esta investigación y puede variar dependiendo de quién la realice.

\footnotetext{
${ }^{6}$ SOP: Sistema de observación preventiva. Loa actos inseguros cometidos por una persona son registrados en una base de datos, previamente se le hace la observación a la persona y se le explican los riesgos de ese acto inseguro.

${ }^{7}$ Se le comunica al personal y se trata de crear en ellos una cultura de seguridad, estas conversaciones son registradas en una base de datos.
} 
Tabla 3. 4

Ranking de factores de retrasos en los mantenimientos programados

\begin{tabular}{|c|c|c|c|c|c|c|c|c|c|c|}
\hline $\begin{array}{l}\text { Retrasos en los } \\
\text { mantenimientos } \\
\text { programados }\end{array}$ & $\begin{array}{l}\text { Ineficiente } \\
\text { programación } \\
\text { de trabajos }\end{array}$ & $\begin{array}{l}\text { No se } \\
\text { supervisan } \\
\text { los trabajos }\end{array}$ & $\begin{array}{c}\text { Línea sucia } \\
\text { y } \\
\text { desordenada }\end{array}$ & $\begin{array}{l}\text { Demora en } \\
\text { retiro de } \\
\text { materiales y } \\
\text { repuestos }\end{array}$ & $\begin{array}{c}\text { Retraso en } \\
\text { la } \\
\text { ejecución } \\
\text { de trabajos }\end{array}$ & $\begin{array}{c}\text { Demora en } \\
\text { la búsqueda } \\
\text { de } \\
\text { herramientas }\end{array}$ & $\begin{array}{c}\text { No hay la } \\
\text { cantidad ni } \\
\text { las } \\
\text { herramientas } \\
\text { necesarias }\end{array}$ & Puntaje & $\begin{array}{c}\text { Real } \\
\%\end{array}$ & Ponderación \\
\hline
\end{tabular}

\begin{tabular}{|c|c|c|c|c|c|c|c|c|c|c|}
\hline $\begin{array}{l}\text { Ineficiente programación } \\
\text { de trabajos }\end{array}$ & & 1 & 0 & 1 & 1 & 1 & 1 & 5 & 13,89 & 14 \\
\hline $\begin{array}{l}\text { No se supervisan los } \\
\text { Trabajos }\end{array}$ & 1 & & 0 & 1 & 1 & 1 & 1 & 5 & 13,89 & 14 \\
\hline Línea sucia y desordenada & 1 & 1 & & 1 & 1 & 1 & 1 & 6 & 16,67 & 16 \\
\hline $\begin{array}{l}\text { Demora en retiro de } \\
\text { materiales y repuestos }\end{array}$ & 1 & 1 & 0 & & 1 & 1 & 1 & 5 & 13,89 & 14 \\
\hline $\begin{array}{l}\text { Retraso en la ejecución de } \\
\text { Trabajos }\end{array}$ & 1 & 1 & 0 & 1 & & 1 & 1 & 5 & 13,89 & 14 \\
\hline $\begin{array}{l}\text { Demora en la búsqueda de } \\
\text { Herramientas }\end{array}$ & 1 & 1 & 0 & 1 & 1 & & 1 & 5 & 13,89 & 14 \\
\hline $\begin{array}{l}\text { No hay la cantidad ni las } \\
\text { herramientas necesarias }\end{array}$ & 1 & 1 & 0 & 1 & 1 & 1 & & 5 & 13,89 & 14 \\
\hline
\end{tabular}


Tabla 3. 5

Ranking de factores de bajo rendimiento de la materia prima

\begin{tabular}{|c|c|c|c|c|c|c|c|c|c|}
\hline $\begin{array}{l}\text { Bajo rendimiento } \\
\text { de la materia prima }\end{array}$ & $\begin{array}{l}\text { Línea sucia y } \\
\text { desordenada, } \\
\text { evita detectar } \\
\text { fuga de } \\
\text { material }\end{array}$ & $\begin{array}{l}\text { Personal } \\
\text { opera mal } \\
\text { los equipos }\end{array}$ & $\begin{array}{l}\text { Pruebas con } \\
\text { nuevas } \\
\text { materias } \\
\text { primas }\end{array}$ & $\begin{array}{l}\text { Parámetros de } \\
\text { control fuera del } \\
\text { rango de } \\
\text { aceptación. }\end{array}$ & $\begin{array}{l}\text { Inadecuada } \\
\text { dosificación de las } \\
\text { materias primas o } \\
\text { insumos }\end{array}$ & $\begin{array}{l}\text { No hay } \\
\text { residuos } \\
\text { húmedos }\end{array}$ & Puntaje & Real \% & Ponderación \\
\hline $\begin{array}{l}\text { Línea sucia y } \\
\text { desordenada, evita } \\
\text { detectar fugas de } \\
\text { material }\end{array}$ & & 1 & 1 & 1 & 1 & 1 & 5 & 26,32 & 26 \\
\hline $\begin{array}{l}\text { Personal opera mal } \\
\text { los equipos }\end{array}$ & 0 & & 1 & 0 & 1 & 0 & 2 & 10,53 & 11 \\
\hline $\begin{array}{l}\text { Pruebas con nuevas } \\
\text { materias primas }\end{array}$ & 0 & 0 & & 0 & 1 & 0 & 1 & 5,26 & 5 \\
\hline $\begin{array}{lr}\text { Parámetros } & \text { de } \\
\text { control fuera } & \text { del } \\
\text { rango } & \text { de } \\
\text { aceptación. } & \\
\end{array}$ & 1 & 1 & 1 & & 1 & 1 & 5 & 26,32 & 26 \\
\hline $\begin{array}{l}\text { Inadecuada } \\
\text { dosificación de las } \\
\text { materias primas o } \\
\text { insumos }\end{array}$ & 0 & 1 & 0 & 0 & & 0 & 1 & 5,26 & 5 \\
\hline $\begin{array}{l}\text { No hay residuos } \\
\text { húmedos }\end{array}$ & 1 & 1 & 1 & 1 & 1 & & 5 & 26,32 & 26 \\
\hline
\end{tabular}

Elaboración Propia 
Tabla 3. 6

Ranking de factores de incidentes en línea

\begin{tabular}{|c|c|c|c|c|c|c|c|c|}
\hline Incidentes en línea & $\begin{array}{l}\text { No se hace } \\
\text { seguimiento a } \\
\text { las condiciones } \\
\text { inseguras }\end{array}$ & $\begin{array}{l}\text { Falta un } \\
\text { supervisor de } \\
\text { campo de } \\
\text { seguridad } \\
\text { industrial }\end{array}$ & $\begin{array}{l}\text { Falta de compromiso } \\
\text { del personal técnico y } \\
\text { operario con la } \\
\text { seguridad }\end{array}$ & $\begin{array}{c}\text { La línea se } \\
\text { encuentra sucia y } \\
\text { desordenada }\end{array}$ & $\begin{array}{l}\text { Equipos no } \\
\text { cuentan con } \\
\text { sistema de } \\
\text { seguridad } \\
\text { integrado }\end{array}$ & Puntaje & $\begin{array}{c}\text { Real } \\
\%\end{array}$ & Ponderación \\
\hline $\begin{array}{l}\text { No se hace seguimiento a } \\
\text { las condiciones inseguras }\end{array}$ & & 1 & 1 & 1 & 1 & 4 & 26,67 & 27 \\
\hline $\begin{array}{l}\text { Falta un supervisor de } \\
\text { campo de seguridad } \\
\text { industrial }\end{array}$ & 0 & & 0 & 0 & 0 & 0 & 0,00 & 0 \\
\hline $\begin{array}{l}\text { Falta de compromiso del } \\
\text { personal técnico y operario } \\
\text { con la seguridad }\end{array}$ & 1 & 0 & & 1 & 1 & 3 & 20,00 & 20 \\
\hline $\begin{array}{l}\text { La línea se encuentra sucia } \\
\text { y desordenada }\end{array}$ & 1 & 1 & 1 & & 1 & 4 & 26,67 & 27 \\
\hline $\begin{array}{l}\text { Equipos no encuentran con } \\
\text { sistema de seguridad } \\
\text { integrado }\end{array}$ & 1 & 1 & 1 & 1 & & 4 & 26,67 & 27 \\
\hline
\end{tabular}

Elaboración Propia 
Tabla 3.7

Ranking de factores de baja productividad en la línea

\begin{tabular}{|c|c|c|c|c|c|c|c|c|c|c|c|c|c|c|c|c|}
\hline $\begin{array}{l}\text { Baja productividad } \\
\text { en la línea }\end{array}$ & $\begin{array}{l}\text { No se mide } \\
\text { la eficiencia } \\
\text { productiva } \\
\text { por equipo }\end{array}$ & $\begin{array}{l}\text { Postergan el } \\
\text { mantenimie } \\
\text { nto } \\
\text { programado }\end{array}$ & $\begin{array}{l}\text { Demoras en } \\
\text { cambios de } \\
\text { producción }\end{array}$ & $\begin{array}{l}\text { Inef } \\
\text { los t } \\
\text { mar } \\
\text { pro }\end{array}$ & $\begin{array}{l}\text { cia de } \\
\text { jos en } \\
\text { mient } \\
\text { ados }\end{array}$ & $\begin{array}{l}\text { Fieltro y } \\
\text { tamices } \\
\text { colmatad } \\
\text { os }\end{array}$ & $\begin{array}{l}\text { Avería } \\
\text { de } \\
\text { equipo } \\
\mathrm{s}\end{array}$ & $\begin{array}{l}\text { Máquina } \\
\text { sucia }\end{array}$ & $\begin{array}{l}\text { Línea sucia } \\
\text { y desordena }\end{array}$ & $\begin{array}{l}\text { Insatisfacc } \\
\text { ión del } \\
\text { personal }\end{array}$ & & $\begin{array}{l}\text { ta de } \\
\text { romiso } \\
\text { ersonal }\end{array}$ & $\begin{array}{l}\text { Demora } \\
\text { del } \\
\text { personal } \\
\text { técnico }\end{array}$ & $\begin{array}{c}\text { Prue } \\
\text { bas } \\
\text { con } \\
\text { nuev } \\
\text { as } \\
\text { MP }\end{array}$ & $\begin{array}{l}\text { MP } \\
\text { fuer } \\
\text { a de } \\
\text { espe } \\
\text { cific } \\
\text { ació } \\
n\end{array}$ & $\begin{array}{c}\text { Desa } \\
\text { lojad } \\
\text { ora } \\
\text { cuell } \\
\text { o de } \\
\text { botel } \\
\text { la }\end{array}$ \\
\hline $\begin{array}{l}\text { No se mide la } \\
\text { eficiencia } \\
\text { productiva por } \\
\text { equipo }\end{array}$ & & 1 & 1 & 1 & 1 & & 1 & 1 & 1 & 1 & 1 & 1 & 1 & 1 & & 1 \\
\hline $\begin{array}{l}\text { Postergan el } \\
\text { mantenimiento } \\
\text { programado }\end{array}$ & 0 & & 1 & 1 & 1 & & 1 & 1 & 1 & 1 & 1 & 1 & 1 & 1 & & 1 \\
\hline $\begin{array}{l}\text { Demoras en } \\
\text { cambios de } \\
\text { producción }\end{array}$ & 0 & 1 & & 1 & 1 & & 1 & 1 & 1 & 1 & 1 & 1 & 1 & 1 & & 1 \\
\hline $\begin{array}{l}\text { Ineficiencia de los } \\
\text { trabajos en los } \\
\text { mantenimientos } \\
\text { programados }\end{array}$ & 0 & 1 & 1 & & 1 & & 1 & 1 & 1 & 1 & 1 & 1 & 1 & 1 & & 1 \\
\hline $\begin{array}{l}\text { Fieltro y tamices } \\
\text { Colmatados }\end{array}$ & 0 & 0 & 0 & 0 & & & 0 & 1 & 1 & 1 & 1 & 1 & 1 & 1 & & 1 \\
\hline Avería de equipos & 0 & 0 & 0 & 0 & 1 & & & 1 & 1 & 1 & 1 & 1 & 1 & 1 & & 1 \\
\hline Máquina sucia & 0 & 1 & 1 & 1 & 1 & 1 & 1 & & 1 & 1 & 1 & 1 & 1 & 1 & & 1 \\
\hline
\end{tabular}


(continuación)

\begin{tabular}{|c|c|c|c|c|c|c|c|c|c|c|c|c|c|c|}
\hline $\begin{array}{l}\text { La línea sucia } \\
\text { y desordenada }\end{array}$ & 0 & 1 & 1 & 1 & 1 & 1 & 1 & & 1 & 1 & 1 & 1 & 1 & 0 \\
\hline $\begin{array}{l}\text { Insatisfacción } \\
\text { del personal }\end{array}$ & 0 & 0 & 0 & 0 & 0 & 0 & 0 & 0 & & 1 & 0 & 0 & 0 & 0 \\
\hline $\begin{array}{l}\text { Falta de } \\
\text { compromiso } \\
\text { del personal }\end{array}$ & 0 & 0 & 0 & 0 & 0 & 0 & 0 & 0 & 1 & & 0 & 0 & 0 & 0 \\
\hline $\begin{array}{l}\text { Demora del } \\
\text { personal } \\
\text { técnico }\end{array}$ & 0 & 0 & 0 & 0 & 0 & 0 & 0 & 0 & 1 & 1 & & 0 & 0 & 0 \\
\hline $\begin{array}{l}\text { Pruebas con } \\
\text { nuevas MP }\end{array}$ & 0 & 0 & 0 & 0 & 0 & 0 & 0 & 0 & 1 & 1 & 1 & & 0 & 0 \\
\hline $\begin{array}{l}\text { MP fuera de } \\
\text { Especificación }\end{array}$ & 0 & 0 & 0 & 0 & 0 & 0 & 0 & 0 & 1 & 1 & 1 & 1 & & 0 \\
\hline $\begin{array}{l}\text { Desalojadora } \\
\text { cuello de } \\
\text { botella }\end{array}$ & 1 & 1 & 1 & 1 & 1 & 1 & 1 & 1 & 1 & 1 & 1 & 1 & 1 & \\
\hline Puntaje & 13 & 4 & 3 & 2 & 1 & 1 & 11 & 12 & 9 & 8 & 12 & 12 & 12 & 13 \\
\hline$\%$ Real & $11,5 \%$ & $3,54 \%$ & $2,65 \%$ & $1,77 \%$ & $0,88 \%$ & $0,88 \%$ & $9.73 \%$ & $10,6 \%$ & $7,96 \%$ & $7,08 \%$ & $10,6 \%$ & $10,6 \%$ & $10,6 \%$ & $11,5 \%$ \\
\hline Ponderación & 12 & 4 & 3 & 2 & 1 & 1 & 10 & 11 & 8 & 7 & 11 & 11 & 11 & 12 \\
\hline
\end{tabular}

Elaboración Propia 
Figura 3.8

Diagrama de Ishikawa de retrasos en los mantenimientos programados

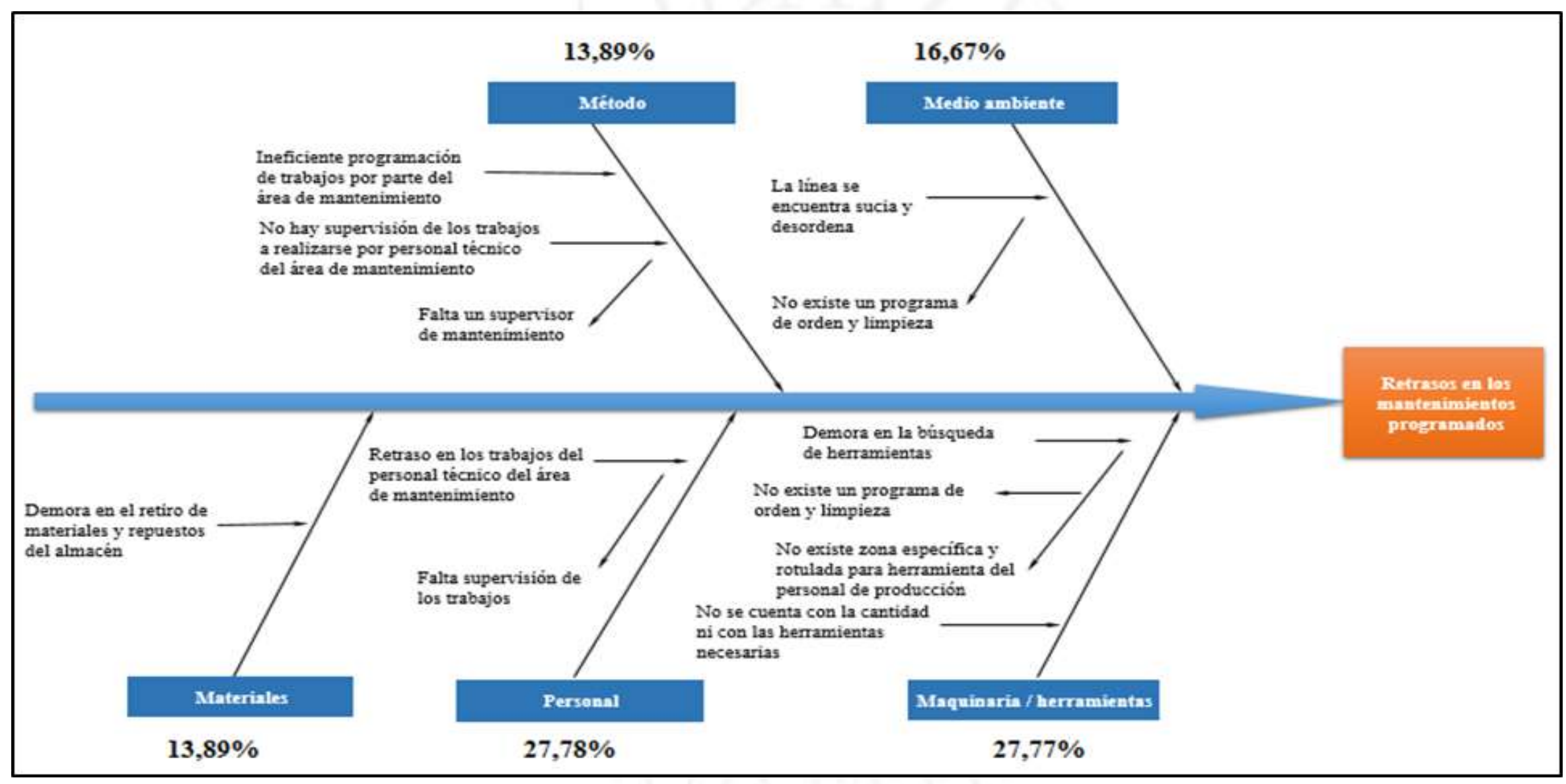

Elaboración Propia 
Figura 3.9

Diagrama de Ishikawa de bajo rendimientode la materia prima

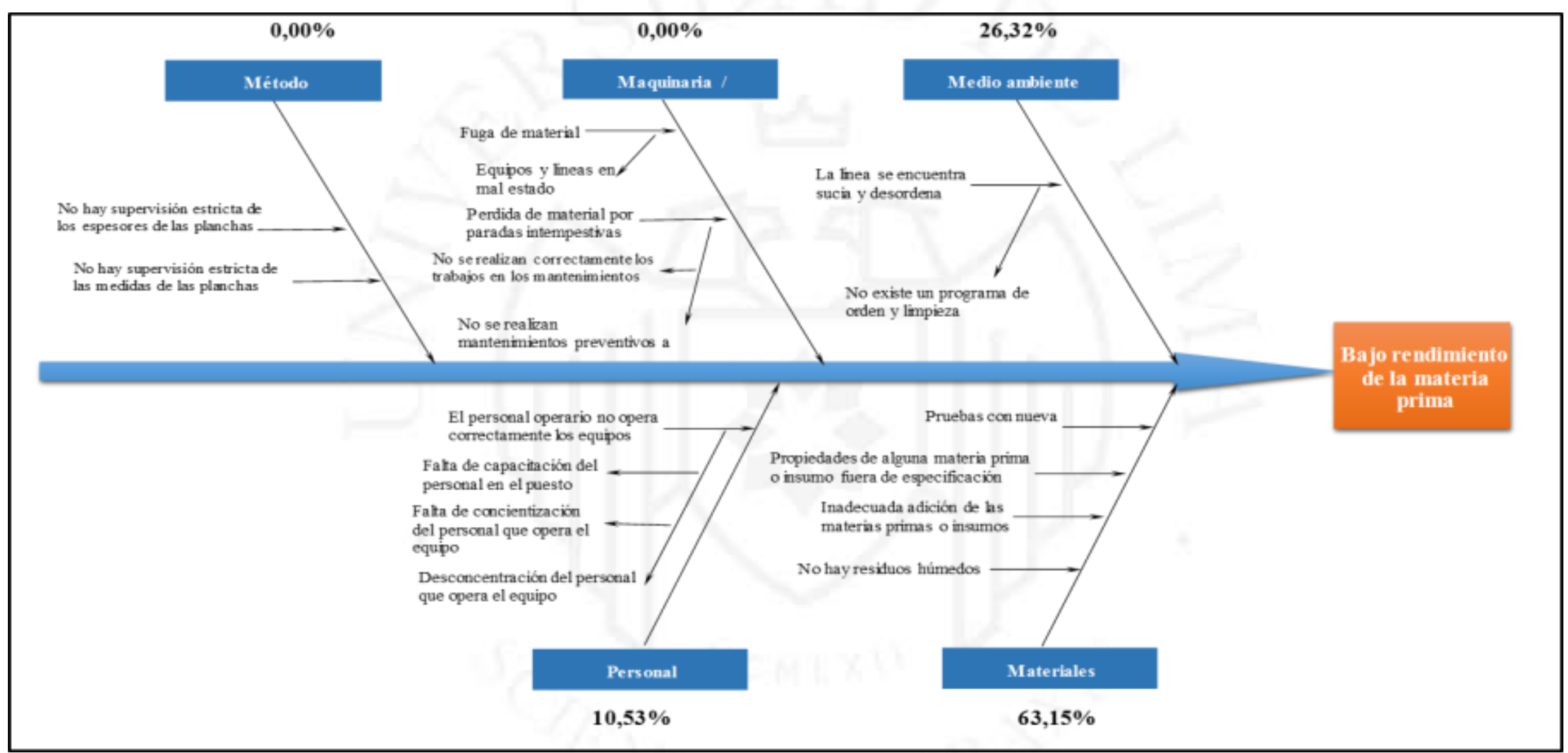

Elaboración Propia 
Figura 3. 10

Diagrama de Ishikawa de incidentes en la línea

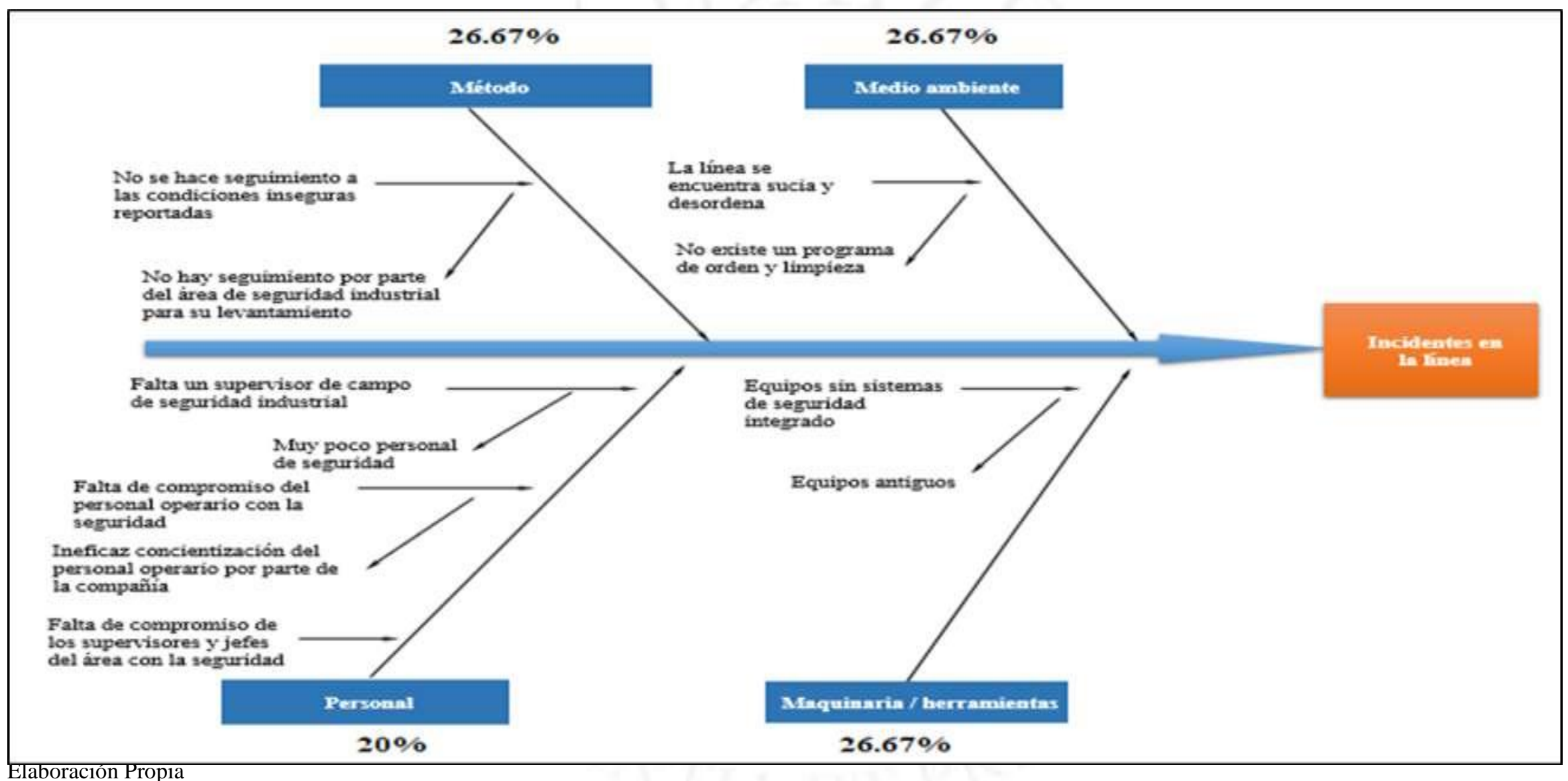


Figura 3. 11

Diagrama de Ishikawa de baja productividad

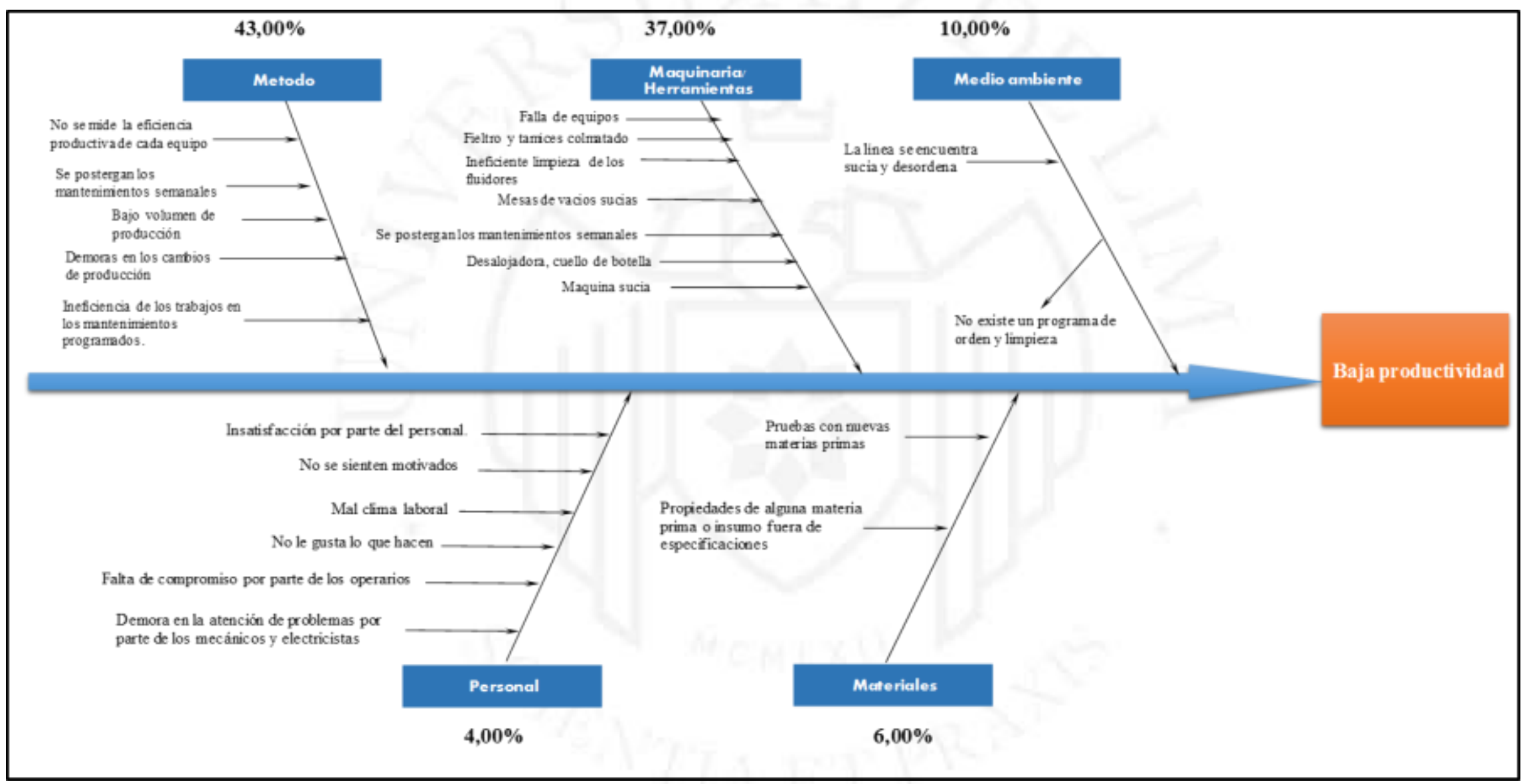

Elaboración Propia 
Como se puede observar en la Figura 3.8, mantenimiento programado la causa principal del problema está en el factor personal representada con un $27,78 \%$, que implica retrasos en los trabajos del personal técnico del área de mantenimiento y la falta de supervisión.

Tal como se observa en la Figura 3.9, bajo rendimiento de materia prima la principal causa del problema está en el factor material representada con un $63,15 \%$, que implica pruebas con una nueva materia prima, propiedades de alguna materia prima o insumo fuera de especificación, inadecuada adición de las materias primas o insumos, no hay residuos húmedos.

Tal como se observa en la Figura 3.10, incidentes en seguridad de la línea las causas principales del problema están en el factor método, medio ambiente, maquinaria/herramientas representadas con un $26,67 \%$.

Tal como se observa en la Figura 3.11, baja productividad las causas principales del problema están en el factor método representada con un $43 \%$, que implica insatisfacción en el ámbito laboral, falta de compromiso y demora en la atención de problemas. 


\section{CAPITULO IV: DETERMINACIÓN DE LA SOLUCIÓN PARA LOS PROBLEMAS}

\subsection{Planteamiento de alternativas de solución}

Los problemas estudiados para el presente trabajo de investigación son aquellos que tienen mayor repercusión en la situación actual de la línea de fabricación de planchas de fibrocemento. Para ello, se consultó a profesionales que vienen laborando en la línea hace ya varios años, los cuales expusieron propuestas de solución para dichos problemas.

Con las diferentes propuestas de solución, se pudo plantear los siguientes mecanismos de mejoras:

\section{Retrasos en los mantenimientos programados}

- Determinar el tiempo estándar de cada actividad que involucre el mantenimiento programado y determinar las frecuencias de limpieza decada equipo y tubería

- Elaborar un Gantt de los mantenimientos programados donde se refleje la duración, cantidad de personas involucradas y responsable para cada trabajo a ejecutarse.

- Elaborar un indicador que refleje el porcentaje de cumplimiento de los trabajos planificados para los mantenimientos programados. Luego de cada mantenimiento el resultado del indicador se compartirá con las áreas involucradas y con la gerencia.

- Implementar la metodología de las 5’S en la línea.

\section{Bajo rendimiento de la materia prima}

- Elaborar un diagrama de causa - efecto (Ishikawa) de que cosas ocasionan que los parámetros de control que impactan directamente al rendimiento de materia prima (densidad y espesor de las planchas) resulten fuera de los parámetros de aceptación y presentar acciones correctivas para cada una.

- Asignar un área donde se almacene el material sustraído de la limpieza de los equipos en los mantenimientos programados para que luego sea molido y reutilizado en la mezcla como residuos húmedos. 
- Fabricar una canaleta que recupere el material que se pierde por la salida de los tamices.

- Implementar la metodología de las 5’S en la línea.

\section{Incidentes en la línea}

- Identificar los equipos que no cuentan con botoneras de paradas de emergencia y/o sistemas de interruptores de carga eléctrica. Instalarles a los equipos que no cuentan con esto.

- Adquirir dispositivos de bloqueo.

- Capacitar al personal operario y técnico en temas de seguridad industrial y salud en el trabajo.

- Creación de una matriz de clasificación de condiciones inseguras por prioridad. Luego de lo obtenido de esta matriz se fijarán fechas de ejecución, las cuales deberá ser comunicadas a todo el personal de la línea.

- Elaborar un check list simple, que los mismos operarios llenarán, de las condiciones en las que están recibiendo el turno, ya que este check list será el input para la matriz de clasificación de condiciones inseguras por prioridad. Si se detectan condiciones inseguras, estas deben de ser reportadas de inmediato, delimitando la zona y comunicando a todo el personal de la línea para que todos tengan conocimiento y estén alertas.

- Elaborar un indicador mensual de cuantas condiciones inseguras fueron resueltas entre las que se tenían definidas con fecha de ejecución en ese mes.

- Implementar la metodología de las 5’S en la línea.

\section{Baja productividad}

- Implementar el indicador OEE (Overall Equipment Effectiveness o Eficiencia General de los Equipos). De esta manera se podrá medir y cuantificar los procesos. Si mido puedo controlar y si controló puedo mejorar.

- Implementar la metodología de las 5’S en la línea. Con ello se podrá obtener menos averías de equipos, menos movimientos y traslados inútiles, etc.

- Hacer mejoras en el equipo cuello de botella, reduciendo así su tiempo de ciclo. 
- Aplicar la herramienta de mejora continua SMED (Single Minute Exchange of Die o cambio de matriz en menos de 10 minutos) para reducir los tiempos de cambios de producción.

\subsection{Selección de alternativas de solución}

\subsubsection{Determinación y ponderación de criterios de evaluación de las alternativas}

Para escoger una solución, antes se necesita elaborar una matriz de enfrentamiento de factores que cuantifique la ponderación de cada uno de los criterios escogidos.

Tabla 4. 1

Matriz de enfrentamiento de factores

\begin{tabular}{|c|c|c|c|c|c|c|c|}
\hline Criterios & Complejidad & Factibilidad & Inversión & $\begin{array}{l}\text { Inmediatez } \\
\text { en } \\
\text { resultados }\end{array}$ & $\begin{array}{l}\text { Impacto en } \\
\text { problemas }\end{array}$ & Conteo & Ponderado \\
\hline Complejidad & & 1 & 0 & 0 & 0 & 1 & $10 \%$ \\
\hline Factibilidad & 0 & & 0 & 1 & 0 & 1 & $10 \%$ \\
\hline Inversión & 1 & 1 & & 0 & 0 & 2 & $20 \%$ \\
\hline $\begin{array}{l}\text { Inmediatez } \\
\text { en resultados }\end{array}$ & 1 & 0 & 1 & & 0 & 2 & $20 \%$ \\
\hline \multirow[t]{2}{*}{ Impacto } & 1 & 1 & 1 & 1 & & 4 & $40 \%$ \\
\hline & & & & & Total & 10 & $100 \%$ \\
\hline
\end{tabular}

Elaboración propia

De la Tabla 4.1, se obtiene como conclusión que los criterios más relevantes son “inversión”, "inmediatez en resultados" e "impacto en problemas".

Los puntajes utilizados para medir cada una de las propuestas son los siguientes: 
Figura 4. 1

Escalas para evaluar las propuestas de solución

\begin{tabular}{|c|c|}
\hline Estado de Complejidad & Puntaje \\
\hline Alta & 10 \\
\hline Media & 20 \\
\hline Baja & 30 \\
\hline
\end{tabular}

\begin{tabular}{|c|c|}
\hline Inmediatez en resultados & Puntaje \\
\hline Largo plazo & 10 \\
\hline Mediano plazo & 20 \\
\hline Corto plazo & 30 \\
\hline
\end{tabular}

\begin{tabular}{|c|c|}
\hline Factibilidad & Puntaje \\
\hline Muy Factible & 30 \\
\hline Factible & 20 \\
\hline Poco factible & 10 \\
\hline No existe factibilidad & 0 \\
\hline
\end{tabular}

\begin{tabular}{|c|c|}
\hline Impacto en problemas & Puntaje \\
\hline Alto & 30 \\
\hline Medio & 20 \\
\hline Bajo & 10 \\
\hline
\end{tabular}

\begin{tabular}{|c|c|}
\hline Inversión & Puntaje \\
\hline Alta & 10 \\
\hline Media & 20 \\
\hline Baja & 30 \\
\hline
\end{tabular}

Fuente: Pastor,Elsie (2010)

Para poder decidir cuales alternativas de solución, para cada problema, son las más relevantes se empleará la matriz de ranking de factores. 
Figura 4. 2

Matriz de factores de soluciones

\begin{tabular}{|c|c|c|c|c|c|c|c|c|}
\hline \multirow{2}{*}{\multicolumn{3}{|c|}{ 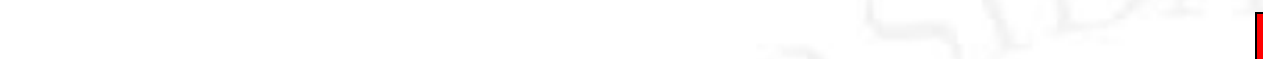 }} & \multirow{3}{*}{$\begin{array}{c}10 \% \\
\text { Escala de } \\
\text { complejidad }\end{array}$} & & & & & \\
\hline & & & & \multirow{2}{*}{$\begin{array}{c}10 \% \\
\text { Factibilidad }\end{array}$} & \multirow{2}{*}{\begin{tabular}{|c|}
$20 \%$ \\
Inversión
\end{tabular}} & \multirow{2}{*}{\begin{tabular}{|c|}
$20 \%$ \\
$\begin{array}{c}\text { Inmediatez en } \\
\text { resultados }\end{array}$
\end{tabular}} & \multirow{2}{*}{$\begin{array}{c}40 \% \\
\text { Impacto en } \\
\text { problemas }\end{array}$} & \multirow[b]{2}{*}{ Total } \\
\hline Causas raíces & Problemas & Alternativas de solución & & & & & & \\
\hline $\begin{array}{l}\text { Ineficiente programación } \\
\text { de trabajos }\end{array}$ & \multirow{7}{*}{$\begin{array}{c}\text { Retrasos en los } \\
\text { mantenimientos } \\
\text { programados }\end{array}$} & \multirow{3}{*}{$\begin{array}{l}\text { Determinar frecuencias de } \\
\text { limpieza de cada equipo y tubería, } \\
\text { así mismo determinar tiempos } \\
\text { promedios de duración. }\end{array}$} & \multirow{3}{*}{30} & \multirow{3}{*}{30} & \multirow{3}{*}{30} & \multirow{3}{*}{30} & \multirow{3}{*}{30} & \multirow{3}{*}{30} \\
\hline $\begin{array}{l}\text { No se supervisan los } \\
\text { trabajos }\end{array}$ & & & & & & & & \\
\hline $\begin{array}{l}\text { Retraso en la ejecución de } \\
\text { trabajos }\end{array}$ & & & & & & & & \\
\hline Línea sucia y desordena & & \multirow{2}{*}{$\begin{array}{l}\text { Elaborar Gantt previo a los } \\
\text { mantenimientos programados } \\
\text { (duración, cantidad de personas } \\
\text { involucradas y responsables). }\end{array}$} & \multirow{2}{*}{30} & \multirow{2}{*}{30} & \multirow{2}{*}{30} & \multirow{2}{*}{30} & \multirow{2}{*}{30} & \multirow{2}{*}{30} \\
\hline $\begin{array}{l}\text { Demora en retiro de } \\
\text { materiales y repuestos }\end{array}$ & & & & & & & & \\
\hline $\begin{array}{l}\text { Demora en la búsqueda de } \\
\text { herramientas }\end{array}$ & & $\begin{array}{l}\text { Elaborar KPI de \% de } \\
\text { cumplimiento de trabajos } \\
\text { ejecutados. }\end{array}$ & 30 & 30 & 30 & 30 & 10 & 22 \\
\hline Falta de herramientas & & $\begin{array}{l}\text { Implementar la metodología de las } \\
\text { 5'S. }\end{array}$ & 20 & 30 & 30 & 30 & 30 & 29 \\
\hline
\end{tabular}

(continúa) 


\section{(continuación)}

\begin{tabular}{|c|c|c|c|c|c|c|c|c|}
\hline & & & & & & $20 \%$ & $40 \%$ & \\
\hline Causas raíces & & & & & & $\begin{array}{l}\text { Inmediatez } \\
\text { en } \\
\text { resultados }\end{array}$ & $\begin{array}{l}\text { Impacto en } \\
\text { problemas }\end{array}$ & Total \\
\hline $\begin{array}{l}\text { Línea sucia y desordenada, } \\
\text { evita detectar fuga de material }\end{array}$ & \multirow{4}{*}{$\begin{array}{l}\text { Bajo rendimiento de la } \\
\text { materia prima }\end{array}$} & $\begin{array}{l}\text { Elaborar un diagrama de } \\
\text { causa - efecto (Ishikawa) de } \\
\text { que cosas ocasionan que los } \\
\text { parámetros de control que } \\
\text { impactan directamente al } \\
\text { rendimiento de materia prima } \\
\text { resulten fuera de los rangos de } \\
\text { aceptación. }\end{array}$ & 30 & 30 & 30 & 30 & 30 & 30 \\
\hline \multirow[t]{2}{*}{$\begin{array}{l}\text { Parámetros de control fuera del } \\
\text { rango de aceptación. }\end{array}$} & & $\begin{array}{l}\text { Ubicar zona para material } \\
\text { sustraído de los } \\
\text { mantenimientos } \\
\text { programados. }\end{array}$ & 30 & 10 & 30 & 30 & 30 & 28 \\
\hline & & $\begin{array}{ll}\text { Fabricar canaleta } & \text { de } \\
\text { recuperación de material. } & \end{array}$ & 30 & 30 & 20 & 30 & 30 & 28 \\
\hline $\begin{array}{l}\text { No hay residuos húmedos para } \\
\text { consumir }\end{array}$ & & $\begin{array}{l}\text { Implementar la metodología } \\
\text { de las 5'S. Crear un programa } \\
\text { de limpieza. }\end{array}$ & 20 & 30 & 30 & 30 & 20 & 25 \\
\hline
\end{tabular}


(continuación)

\begin{tabular}{|c|c|c|c|c|c|c|c|c|}
\hline \multirow[b]{2}{*}{ Causas raíces } & & & & & & $20 \%$ & $40 \%$ & \\
\hline & & & & & & $\begin{array}{l}\text { Inmediatez } \\
\text { en } \\
\text { resultados }\end{array}$ & $\begin{array}{l}\text { Impacto en } \\
\text { problemas }\end{array}$ & Total \\
\hline \multirow[t]{2}{*}{$\begin{array}{l}\text { Falta de seguimiento a las } \\
\text { condiciones inseguras }\end{array}$} & \multirow{8}{*}{ Incidentes en la línea } & $\begin{array}{l}\text { Instalar botoneras de parada de } \\
\text { emergencia y/o interruptores } \\
\text { de carga eléctrica a los equipos } \\
\text { que no cuentan con esto. }\end{array}$ & 30 & 20 & 20 & 30 & 30 & 27 \\
\hline & & \begin{tabular}{|lll}
$\begin{array}{l}\text { Adquirir dispositivos de } \\
\text { bloqueo. }\end{array}$ & \\
\end{tabular} & 30 & 30 & 20 & 30 & 30 & 28 \\
\hline \multirow{2}{*}{$\begin{array}{l}\text { Falta de compromiso del } \\
\text { personal técnico y operario con } \\
\text { la seguridad }\end{array}$} & & $\begin{array}{l}\text { Capacitación al personal en } \\
\text { temas de seguridad y salud en } \\
\text { el trabajo. }\end{array}$ & 30 & 30 & 20 & 30 & 30 & 28 \\
\hline & & $\begin{array}{l}\text { Elaborar un check list de las } \\
\text { condiciones en las que se } \\
\text { recibe el turno. }\end{array}$ & 30 & 30 & 30 & 30 & 30 & 30 \\
\hline \multirow{2}{*}{ Línea sucia y desordena } & & $\begin{array}{l}\text { Clasificar las condiciones } \\
\text { inseguras por prioridad y } \\
\text { establecer fechas de ejecución. }\end{array}$ & 30 & 30 & 30 & 30 & 30 & 30 \\
\hline & & 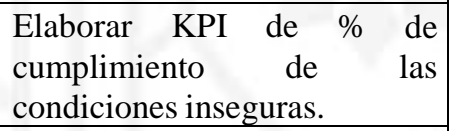 & 30 & 30 & 30 & 30 & 10 & 22 \\
\hline \multirow{2}{*}{$\begin{array}{l}\text { Equipos no cuentan con sistema } \\
\text { de seguridad integrado }\end{array}$} & & $\begin{array}{l}\text { Ronda por la línea por parte } \\
\text { del supervisor de seguridad, } \\
\text { una vez por turno. }\end{array}$ & 30 & 30 & 30 & 30 & 10 & 22 \\
\hline & & $\begin{array}{l}\text { Implementar la metodología } \\
\text { de las 5’S. }\end{array}$ & 20 & 30 & 30 & 30 & 20 & 25 \\
\hline
\end{tabular}


(continuación)

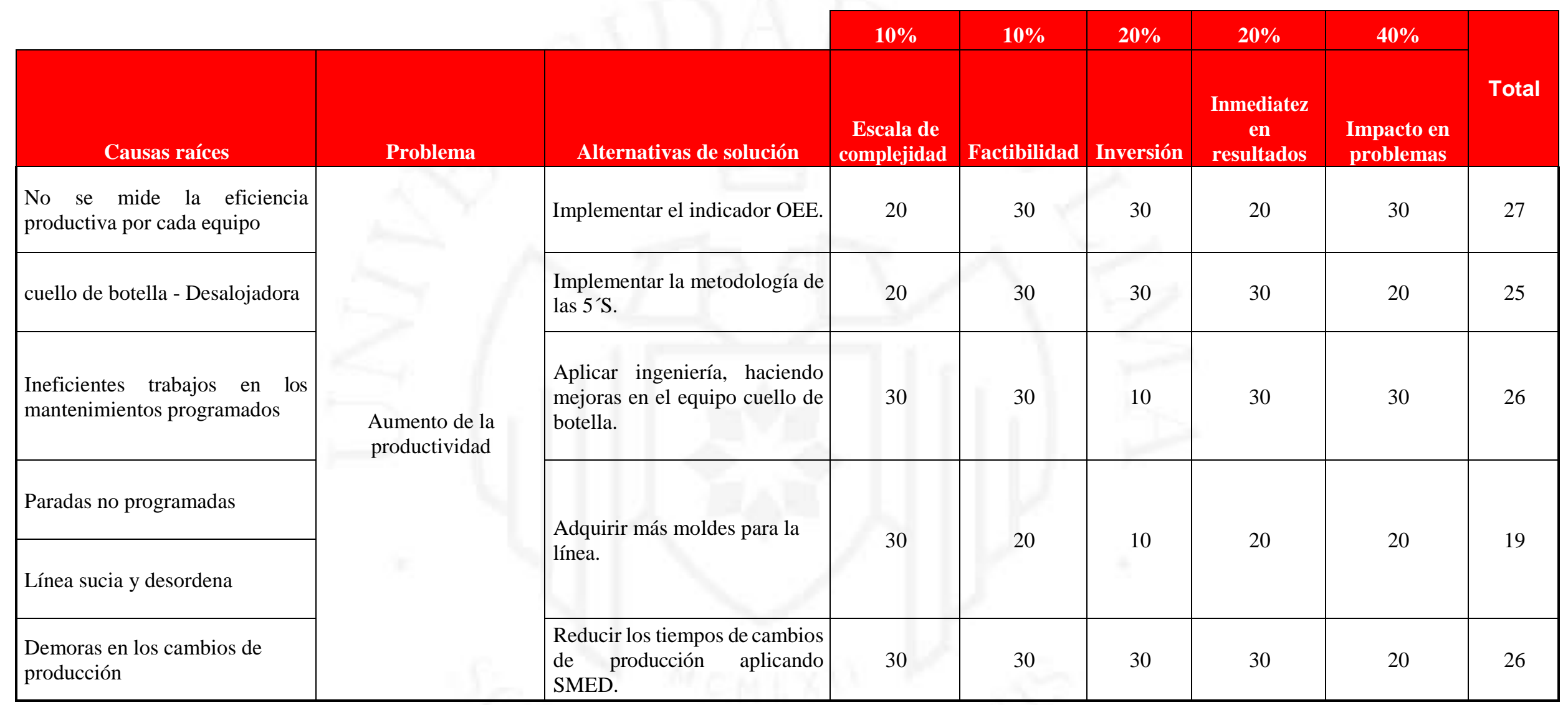

Elaboración propia 
Luego de realizar el ranking de factores se eligen las soluciones propuestas que obtienen el mayor puntaje, las demás propuestas de solución que por su poca inmediatez en los resultados o por su poco impacto tienen menos puntaje, pasarían a ser soluciones secundarias y que se pueden ejecutar después de haberse ejecutado las principales.

\subsubsection{Evaluación cualitativa de las soluciones propuestas}

Los beneficios cualitativos que se esperan una vez que las propuestas de solución sean implementadas son las siguientes:

\section{Reducción del mantenimiento programado}

- Al calcular los tiempos estándar de ejecución de cada actividad realizada en los mantenimientos programados, así como la frecuencia de limpieza de cada equipo y tubería, se va a poder planificar eficientemente las actividades, tener una mejor asignación de recursos y esto traerá como consecuencia que los mantenimientos no se extiendan más del tiempo presupuestado, lo que se traduce en tener más tiempo disponible los equipos para producir.

- Implementando la metodología de las 5’S vamos a lograr eliminar los tiempos muertos que se tienen por búsqueda de herramientas, materiales y repuestos.

\section{Aumento del rendimiento de materia prima}

- Fabricando una canaleta que recupere el material que sale del fondo de los tamices se logrará un mejor aprovechamiento de la materia prima ya que el material no iría al cono, adhiriéndose gran parte de este material en las paredes del cono y en el de las tuberías, ya que con esta propuesta de solución el material reingresaría directamente a la máquina.

- Recuperando todo el material que se sustrae de la limpieza de los equipos y tuberías en los mantenimientos programados y asignando una zona para almacenar este material para que posteriormente sea reutilizado en la mezcla, se conseguirá incrementar el volumen por mezcla y con ello aumentar también el rendimiento de materia prima.

- Empleando la herramienta de mejora continua, Ishikawa, para encontrar las causas raíces que ocasionan que los parámetros de control que impactan directamente al rendimiento de materia prima resulten fuera de los rangos de 
aceptación, podremos plantear acciones para eliminarlas y que estas no se vuelvan a presentar a futuro.

- Implementando las 5’S también se va a conseguir tener un mejor aprovechamiento de la materia ya que al tener limpio los equipos y la zona de trabajo, se va a lograr detectar a tiempo cualquier fuga de material.

\section{Disminución de accidentes}

- Se elaborará un check list de las condiciones con las que el operador recibe el turno, la cual lo tiene que llenar el mismo operador al inicio de sus actividades. Se logrará con esto que los operadores estén alertas a lo que sucede y está presente en su entorno de trabajo, evitando así que ocurra un accidente por algo que no se detectó a tiempo.

- Es posible que en una semana o en un mes se detecten varias condiciones inseguras y el problema aquí también sea ¿qué condición insegura se debe levantar primero?, ya que, por el tiempo y los recursos limitados, todas las condiciones inseguras no pueden ser levantadas en un mismo día es por eso que se ha elaborado una matriz de clasificación de condiciones inseguras con la que se va a poder clasificarlas por prioridad.

- Realizando capacitaciones en temas de seguridad como peligros y riesgos, primeros auxilios, procedimientos contra todo tipo de emergencias, Lototo,etc., se conseguirá que todo el personal de la línea esté preparado para identificar los peligros y riesgos de cada trabajo que va a realizar, que sepa en qué puntos debe realizar el bloqueo de seguridad, como debe de proceder ante cualquier tipo de emergencia, identificar en qué estado se encuentran antes de iniciar su jornada de trabajo y también como brindar primero auxilios. Con todo esto se va a conseguir evitar que ocurran accidentes ya que todo el personal de la línea estará capacitado y comprometido con la seguridad.

- Implementando las 5`S también se logrará evitar que ocurra un accidente por motivos de que no se detectó a tiempo una condición insegura ya que la zona se encontraba sucia y desordenada. 


\section{Aumento de la productividad}

- Implementando el OEE (Overall Equipment Effectiveness) vamos a conseguir optimizar los procesos, identificando cuales son las perdidas y los cuellos de botella. Hansen (2001)

- Implementando la metodología de las 5’S se va a poder conseguir una mejor visibilidad para identificar algunas fallas antes que se vuelvan críticas ocasionando una parada no programada, ya que al tener los equipos y tu zona de trabajo limpia, ordenada y sin ningún objeto en desuso, por ejemplo las fugas de aceite, fugas de aire, pernos flojos, etc., van a poder ser detectados con facilidad y antes de que el equipo falle. Se va a reducir el tiempo de las paradas por cambios de producción ${ }^{8}$, ya que, las herramientas a utilizarse estarán clasificadas, ordenadas y al alcance de la mano, se eliminará los movimientos y traslados inútiles. Aldavert, Vidal y Lorente (2016)

- Aplicando ingeniería, mejoras en el equipo cuello de botella, vamos a lograr reducir su tiempo de ciclo y por consiguiente vamos a lograr un aumento en la productividad de la línea.

- Aplicando SMED para los cambios de producción vamos a lograr acortar el tiempo que dura hacer estos cambios, haciendo que actividades internas (se ejecutan con máquina detenida) pasen a ser actividades externas (se pueden ejecutar con máquina en funcionamiento) $)^{9}$. Méndez (2003)

\subsubsection{Priorización de soluciones seleccionadas}

De la matriz de factores de soluciones se escogió las propuestas más relevantes para proponerlas como mejoras a implementarse en la línea de fabricación de planchas de fibrocemento.

\footnotetext{
${ }^{8}$ Esto se complementará con la implementación del SMED.

${ }^{9}$ Contemplando que toda actividad debe ser totalmente segura para quien la ejecuta. Se debe garantizar la seguridad del trabajador.
} 


\section{Retrasos de mantenimientos programados}

- Determinar frecuencias de limpieza de cada equipo y tubería, así mismo determinar tiempos estándar de ejecución.

- Elaborar Gantt de los mantenimientos programados (duración, cantidad de personas involucradas y responsables)

- Se implementará la metodología de las 5’S. Se realizará una presentación a los trabajadores de la línea, explicándoles en que consiste las 5’S, cuáles son los pasos a seguir y cuáles son los beneficios de implementar esta metodología.

\section{Bajo rendimiento de la materia prima}

- Elaborar un diagrama de causa - efecto (Ishikawa) de que cosas ocasionan que los parámetros de control que impactan directamente al rendimiento de materia prima resulten fuera de los rangos de aceptación.

- Asignar una zona para el producto sustraído de los mantenimientos programados. Se separará y delimitará una zona para el almacenamiento del material sustraído de los mantenimientos para que posteriormente sea reutilizado en la mezcla, para la fabricación de las planchas de fibrocemento, como residuos. El material antes de ingresar a la mezcla será molido y disuelto en agua para que luego sea almacenado en una cisterna y por bombeo ingrese a la mezcla.

- Fabricar canaleta de recuperación de material

De la mezcla que ingresa a la máquina, aproximadamente un 55\% se "aprovecha", el otro $45 \%$ se va por el fondo y por bombeo este material es trasladado a un cono (reservorio) para que luego vuelva a ingresar a la máquina. Como ya se mencionó anteriormente, la línea cuenta con un circuito cerrado, todo se reaprovecha por lo que sería lógico que el rendimiento de materia prima este muy bien pero estadísticamente no resulta así y esto se debe a que la mezcla que se va por el fondo de la máquina se adhiere a las paredes de los equipos, de las tuberías y del cono por lo que es allí donde se pierde materia prima. Por tal motivo, se fabricará una canaleta para que en vez de que la mezcla se vaya por el fondo de la máquina, se vaya por esta canaleta y automáticamente, por bombeo, ingrese nuevamente a la máquina y de esta manera no se pierda materia prima. Cabe mencionar que este material que reingresa nuevamente a la máquina no va a causar ningún problema 
al proceso ya que solamente se está acortando el recorrido que sufre este, para que en lugar que vaya al cono (reservorio) y luego reingrese a la máquina, lo haga de manera casi inmediata, logrando que no se pierda material en el largo del recorrido.

- Implementación de la metodología 5 S', con esto lograremos detectar cualquier fuga de material por tuberías y/o equipos, evitando perdidas de materia prima.

\section{Incidentes de la línea}

- Instalar botoneras de parada de emergencia y/o interruptores de carga eléctrica a los equipos que no cuentan con esto.

- Adquirir dispositivos de bloqueo.

- Creación de una matriz de clasificación de condiciones inseguras por prioridad. Elaborar un check list de las condiciones inseguras existentes, clasificándolas por prioridad y estableciendo fechas de ejecución. Actualmente las fechas que se asignan a las condiciones inseguras son por disponibilidad de recursos y no por prioridad, no se realiza un previo análisis, como un IPERC, de cada condición insegura para recién establecer las fechas de ejecución de cada una. Se creará una matriz de clasificación de condiciones inseguras por prioridad, esta matriz para su clasificación tendrá en consideración el puntaje obtenido del IPERC paracada condición insegura, la frecuencia de tránsito por esa zona y la gravedad del riesgo que pueda ocasionar. El input para está matriz serán las condiciones inseguras detectadas en el check list, cabe mencionar que las condiciones inseguras que puedan ser levantadas inmediatamente no entran como input para la matriz, por obvias razones.

- Se creará un check list simple para que los mismos operadores lo llenen, una vez por turno y este se hará siempre al inicio de cada turno. Este check list contemplará las condiciones en las que se está recibiendo el turno, si hay algo en la línea que pueda significar un riesgo para él, para los demás trabajadores o para cualquiera que visite la línea. Este check list debe ser revisado por el supervisor de turno y por el supervisor del área de seguridad industrial.

- Capacitaciones en temas de seguridad y salud en el trabajo tales como: cursos en salud ocupacional, higiene industrial, ergonomía, gestión y salud ocupacional y planes y respuestas ante emergencias. Estos cursos serán dictados por AGS 
Consulting S.A.C, especialistas en el tema. Además se realizará un capacitación de bloqueo y etiquetado Loto. Esta capacitación será llevado en Tecsup.

- Implementación de la metodología 5 S', con esto evitaremos que por temas de suciedad y desorden en la línea no se pueda detectar a tiempo una condición insegura o que el mismo desorden se vuelva una condición insegura.

\section{Aumento de productividad}

- Implementar el indicador OEE (Ver anexo 13: cálculo del OEE de los meses de junio, julio, agosto y setiembre del 2018, de la línea de planchas de fibrocemento)

- Reducir los tiempos de cambios de producción aplicando SMED. Se identificará, elaborando una lista de todas las actividades que conlleva un cambio de producción y las herramientas necesarias para esto. Las actividades se clasificarán en actividades internas (máquina trabajando y operario trabajando) y externas (máquina apagada y operario trabajando). Posterior a esto, se examinará que actividades que se ejecutan con máquina detenida podrían ejecutarse con maquina en funcionamiento. Antes de realizar un cambio de producción se debe tener listo todas las herramientas necesarias identificadas con anterioridad en la lista, así mismo se debe tener un juego extra por si alguna herramienta se dañe durante la ejecución de la tarea y estas deben estar cerca de la zona del trabajo. Se buscará siempre mejorar los tiempos obtenidos en cada cambio de producción anterior.

- Reducir el tiempo de ciclo del equipo de botella aplicando ingeniería, mejoras en el equipo logrando aumentar la eficiencia de la línea.

- Implementar la metodología de las 5’S. Con esto lograremos eliminar los tiempos muertos y reprocesos. 


\section{CAPITULO V: IMPLEMENTACIÓN DE LAS SOLUCIONES PROPUESTAS}

\subsection{Ingeniería de la solución}

El presente trabajo busca detectar los principales problemas de la línea de fabricación de planchas de fibrocemento mediante la recopilación de información y entrevistas al personal involucrado en el proceso productivo. En base a ello establecer su grado de relevancia y si trae consigo una solución ejecutable.

\section{Problema 1: Retrasos de los mantenimientos programados}

Alternativa de solución 1: Determinar frecuencias de limpieza de cada equipo y tubería, así mismo determinar tiempos promedios de duración y la cantidad de personas necesarias para ejecutar cada actividad.

Tabla 5. 1

Actividades de mantenimiento programado

\begin{tabular}{|c|l|}
\hline \# & \\
\hline E1 & Limpieza de Cisterna Principal Actividades \\
\hline E2 & Limpieza de Línea de Agua de Arrastre \\
\hline E3 & Limpieza de Línea de recuperación de 6' \\
\hline E4 & Limpieza de Mezclador \\
\hline E5 & Limpieza de canaletas de rebose de bateas + Caja rebose \\
\hline E6 & Limpieza de Premixer + Timones reguladores de alimentación a bateas \\
\hline E7 & Limpieza de Selectifier + Caja de desconche \\
\hline E8 & Limpieza de Canaletas de alimentación a bateas \\
\hline E9 & Limpieza de Kanaflex's de succión de vacíos \\
\hline E10 & Limpieza de Bateas 1, 2 y 3 \\
\hline E11 & Limpieza de Mesas de lavado y secado de Fieltro \\
\hline E12 & Limpieza de Mesas principales de vacío \\
\hline E13 & Limpieza de Mesas tubulares de fijación \\
\hline E14 & Limpieza de Desintegrador de recortes \\
\hline E15 & Limpieza de Línea "Y" y Codo adyacente al desintegrador de pasta+ caída a cisterna principal \\
\hline E16 & Limpieza de Línea de subida a torre de enfriamiento \\
\hline
\end{tabular}




\section{(continuación)}

\begin{tabular}{|l|l|}
\hline \# & \\
\hline E18 & Actividades \\
\hline E19 & Lubricación de la caja de rodamientos de la bomba de descarga de mezclador \\
\hline E20 & Mantenimiento de los ejes de los agitadores de la hatschek \\
\hline E21 & Mantenimiento de los orientadores de la hatschek \\
\hline E22 & Lubricación de chumaceras de los rolos prensapastas \\
\hline E23 & Lubricación de chumaceras de los tamices \\
\hline E24 & Lubricación de chumaceras del rolo templador de fieltro \\
\hline E25 & $\begin{array}{l}\text { Lubricar los rodamientos del motor de la bomba del sistema de traslación de la } \\
\text { onduladora }\end{array}$ \\
\hline E26 & Lubricar los rodamientos del motor del agitador del mezclador \\
\hline E27 & Lubricación de chumaceras de los rodillos de las fajas transportadoras \\
\hline E28 & Mantenimiento a los tableros eléctricos \\
\hline E29 & Limpieza de Cono \\
\hline E30 & Limpieza de Poza de recuperación \\
\hline E31 & Limpieza de Canaletas alrededor de máquina \\
\hline E32 & Limpieza de Línea de recuperación de 8' \\
\hline E33 & Limpieza de Línea de bajada a torre de enfriamiento \\
\hline E34 & Limpieza de Línea de fluidores alrededor de máquina \\
\hline E35 & Limpieza de Línea de Cisterna principal a Desintegrador de recortes \\
\hline Elaborán \\
\hline Propia de \\
\hline
\end{tabular}

Elaboración Propia

Tabla 5. 2

Tiempo estándar de duración de las actividades de mantenimiento programado

\begin{tabular}{|c|c|c|c|c|}
\hline$\#$ & $\begin{array}{c}\text { Cantidad de } \\
\text { personas }\end{array}$ & Tipo de trabajo & $\begin{array}{c}\text { Frecuencia de } \\
\text { intervención (días) }\end{array}$ & $\begin{array}{c}\text { Tiempo estándar } \\
\text { (Hrs.) }\end{array}$ \\
\hline E1 & 3 & Operacional & 15 & 2,60 \\
\hline E2 & 4 & Operacional & 15 & 3,20 \\
\hline E3 & 4 & Operacional & 15 & 2,90 \\
\hline E4 & 1 & Operacional & 15 & 2,60 \\
\hline E5 & 1 & Operacional & 7 & 1,40 \\
\hline E6 & 1 & Operacional & 7 & 1,30 \\
\hline E7 & 1 & Operacional & 7 & 0,80 \\
\hline E8 & 1 & Operacional & 7 & 1,90 \\
\hline E9 & 2 & Operacional & 7 & 1,20 \\
\hline E10 & 3 & Operacional & 7 & 1,50 \\
\hline E11 & 1 & Operacional & 7 & 1,50 \\
\hline E12 & 1 & Operacional & 7 & 1,50 \\
\hline E13 & 2 & Operacional & 7 & $(\mathrm{continúa)}$ \\
\hline
\end{tabular}

(continúa) 
(continuación)

\begin{tabular}{|c|c|c|c|c|}
\hline$\#$ & $\begin{array}{c}\text { Cantidad de } \\
\text { personas }\end{array}$ & Tipo de trabajo & $\begin{array}{c}\text { Frecuencia de } \\
\text { intervención (días) }\end{array}$ & $\begin{array}{c}\text { Tiempo estándar } \\
\text { (Hrs.) }\end{array}$ \\
\hline E15 & 2 & Operacional & 15 & 1,10 \\
\hline E16 & 3 & Operacional & 15 & 2,59 \\
\hline E17 & 6 & Operacional & 15 & 3,96 \\
\hline E18 & 1 & Mecánico & 7 & 1,00 \\
\hline E19 & 1 & Mecánico & 7 & 0,93 \\
\hline E20 & 2 & Mecánico & 7 & 5,83 \\
\hline E21 & 1 & Mecánico & 7 & 5,83 \\
\hline E22 & 1 & Mecánico & 7 & 1,00 \\
\hline E23 & 1 & Mecánico & 7 & 1,00 \\
\hline E24 & 1 & Mecánico & 7 & 0,50 \\
\hline E25 & 1 & Mecánico & 7 & 1,51 \\
\hline E26 & 1 & Mecánico & 7 & 0,55 \\
\hline E27 & 2 & Mecánico & 7 & 3,47 \\
\hline E28 & 3 & Eléctrico & 7 & 6,50 \\
\hline E29 & 2 & Operacional & 15 & 3,83 \\
\hline E30 & 3 & Operacional & 15 & 4,15 \\
\hline E31 & 2 & Operacional & 15 & 2,42 \\
\hline E32 & 4 & Operacional & 15 & 15 \\
\hline E33 & 3 & Operacional & 15 & 15 \\
\hline E34 & Operacional & Operacional & 73 \\
\hline E35 & 5 & & 7,96 \\
\hline
\end{tabular}

Elaboración Propia

Ver Anexo $N^{\circ} 3$ Determinación del tiempo estándar de las actividades de mantenimiento programado.

Alternativa de solución 2: Elaborar Gantt de los mantenimientos programados (duración, cantidad de personas involucradas y responsables).

Para la elaboración del Gantt se ha considerado lo siguiente:

15 operarios (10 de turno y 5 en sobretiempo).

5 mecánicos (3 de turno y 2 en sobretiempo). 


\section{3 electricistas ( 2 de turno y 1 en sobretiempo).}

\section{SP: Supervisor de producción.}

\section{CE: Coordinador eléctrico.}

\section{CM: Coordinador mécanico.}

Tabla 5.3

Actividades de mantenimiento programado del Gantt de la primera semana

\begin{tabular}{|c|c|}
\hline$\#$ & Actividades de mantenimiento programado en la primera semana \\
\hline E1 & Limpieza de Cisterna Principal \\
\hline E2 & Limpieza de Línea de Agua de Arrastre \\
\hline E3 & Limpieza de Línea de recuperación de 6' \\
\hline E4 & Limpieza de Mezclador \\
\hline E5 & Limpieza de canaletas de rebose de bateas + Caja rebose \\
\hline E6 & Limpieza de Premixer + Timones reguladores de alimentación a bateas \\
\hline E7 & Limpieza de Selectifier + Caja de desconche \\
\hline E8 & Limpieza de Canaletas de alimentación a bateas \\
\hline E9 & Limpieza de Kanaflex’s de succión de vacíos \\
\hline E10 & Limpieza de Bateas 1,2 y 3 \\
\hline E11 & Limpieza de Mesas de lavado y secado de Fieltro \\
\hline E12 & Limpieza de Mesas principales de vacío \\
\hline E13 & Limpieza de Mesas tubulares de fijación \\
\hline E14 & Limpieza de Desintegrador de recortes \\
\hline E15 & $\begin{array}{l}\text { Limpieza de Línea "Y" y Codo adyacente al desintegrador de pasta+ caída a cisterna } \\
\text { principal }\end{array}$ \\
\hline E16 & Limpieza de Línea de subida a torre de enfriamiento \\
\hline E17 & Limpieza de poza de agua de sello \\
\hline E18 & Lubricación de la caja de rodamientos de la bomba de descarga de mezclador \\
\hline E19 & Lubricar de los rodamientos del motor de la bomba de descarga de la cisterna principal \\
\hline E20 & Mantenimiento de los ejes de los agitadores de la hatschek \\
\hline E21 & Mantenimiento de los orientadores de la hatschek \\
\hline E22 & Lubricación de chumaceras de los rolos prensapastas \\
\hline E23 & Lubricación de chumaceras de los tamices \\
\hline E24 & Lubricación de chumaceras del rolo templador de fieltro \\
\hline E25 & $\begin{array}{l}\text { Lubricar los rodamientos del motor de la bomba del sistema de traslación de la } \\
\text { onduladora }\end{array}$ \\
\hline E26 & Lubricar los rodamientos del motor del agitador del mezclador \\
\hline E27 & Lubricación de chumaceras de los rodillos de las fajas transportadoras \\
\hline E28 & Mantenimiento a los tableros eléctricos \\
\hline
\end{tabular}

Elaboración Propia 
Figura 5. 1

Gannt de primera semana de mantenimiento programado

\begin{tabular}{|c|c|c|c|c|c|c|c|c|c|c|c|}
\hline Actividades & $\begin{array}{c}\text { T. de } \\
\text { ejecución } \\
\text { luego de la } \\
\text { mejora } \\
\text { (Hrs.) }\end{array}$ & $\begin{array}{c}\text { Cantidad } \\
\text { de } \\
\text { personas }\end{array}$ & Responsable & $7-8$ & $8-9$ & $9-10$ & $10-11$ & $11-12$ & $12-13$ & $13-14$ & $14-15$ \\
\hline $\mathrm{E} 0$ & 1 & 3 & $\mathrm{SP}$ & & & & & & & & \\
\hline $\mathrm{E} 1$ & 2,6 & 3 & $\mathrm{SP}$ & & & & & & & & \\
\hline E2 & 3,2 & 4 & SP & & & & & & & & \\
\hline E3 & 2,9 & 4 & SP & & & & & & & & \\
\hline E4 & 2,6 & 1 & SP & & & & & & & & \\
\hline E5 & 1,4 & 1 & SP & & & & & & & & \\
\hline E6 & 1,3 & 1 & SP & & & & & & & & \\
\hline E7 & 1,1 & 1 & SP & & & & & & & & \\
\hline ES & 0,8 & 1 & SP & & & & & & & & \\
\hline Eg & 1,9 & 2 & SP & & & & & & & & \\
\hline E10 & 1,2 & 3 & SP & & & & & & & & \\
\hline E11 & 1,5 & 1 & $\mathrm{SP}$ & & & & & & & & \\
\hline E12 & 1,5 & 1 & $\mathrm{SP}$ & & & & & & & & \\
\hline E13 & 1,5 & 2 & $\mathrm{SP}$ & & & & & & & & \\
\hline E14 & 4,2 & 2 & $\mathrm{SP}$ & & & & & & & & \\
\hline E15 & 1,1 & 2 & $\mathrm{SP}$ & & & & & & & & \\
\hline E16 & 2,59 & 3 & $\mathrm{SP}$ & & & & & & & & \\
\hline E17 & 3,96 & 6 & $\mathrm{SP}$ & & & & & & & & \\
\hline E18 & 1,00 & 1 & $\mathrm{CM}$ & & & & & & & & \\
\hline E19 & 0,93 & 1 & $\mathrm{CM}$ & & & & & & & & \\
\hline $\mathrm{E} 20$ & 5,83 & 2 & $\mathrm{CM}$ & & & & & & & & \\
\hline E21 & 5,83 & 1 & $\mathrm{CM}$ & & & & & & & & \\
\hline$E 22$ & 1,00 & 1 & $\mathrm{CM}$ & & & & & & & & \\
\hline E23 & 1,00 & 1 & $\mathrm{CM}$ & & & & & & & & \\
\hline E24 & 0,50 & 1 & $\mathrm{CM}$ & & & & & & & & \\
\hline E25 & 1,51 & 1 & $\mathrm{CM}$ & & & & & & & & \\
\hline E26 & 0,55 & 1 & $\mathrm{CM}$ & & & & & & & & \\
\hline E27 & 3,47 & 2 & $\mathrm{CM}$ & & & & & & & & \\
\hline E28 & 6,50 & 3 & $\mathrm{CE}$ & & & & & & & & \\
\hline
\end{tabular}

\begin{tabular}{|c|l|}
\hline \multicolumn{2}{|c|}{ Leyenda: } \\
\hline SP: & Supervisor de producción \\
\hline CE: & Coordinador eléctrico \\
\hline CM: & Coordinador mécanico \\
\hline
\end{tabular}

Elaboración Propia 
Tabla 5.4

Actividades de mantenimiento programado del Gantt de la segunda semana

\begin{tabular}{|c|c|}
\hline \# & Actividades \\
\hline E1 & Limpieza de Cono \\
\hline $\mathrm{E} 2$ & Limpieza de Poza de recuperación \\
\hline E3 & Limpieza de Canaletas alrededor de máquina \\
\hline E4 & Limpieza de Línea de recuperación de 8' \\
\hline E5 & Limpieza de canaletas de rebose de bateas + Caja rebose \\
\hline E6 & Limpieza de Premixer + Timones reguladores de alimentación a bateas \\
\hline E7 & Limpieza de Selectifier + Caja de desconche \\
\hline E8 & Limpieza de Canaletas de alimentación a bateas \\
\hline E9 & Limpieza de Kanaflex’s de succión de vacíos \\
\hline E10 & Limpieza de Bateas 1,2 y 3 \\
\hline E11 & Limpieza de Mesas de lavado y secado de Fieltro \\
\hline E12 & Limpieza de Mesas principales de vacío \\
\hline E13 & Limpieza de Mesas tubulares de fijación \\
\hline E14 & Limpieza de Línea de bajada a torre de enfriamiento \\
\hline E15 & Limpieza de Línea de fluidores alrededor de máquina \\
\hline E16 & Limpieza de Línea de Cisterna principal a Desintegrador de recortes \\
\hline E17 & Lubricación de la caja de rodamientos de la bomba de descarga de mezclador \\
\hline E18 & Lubricar de los rodamientos del motor de la bomba de descarga de la cisterna principal \\
\hline E19 & Mantenimiento de los ejes de los agitadores de la hatschek \\
\hline E20 & Mantenimiento de los orientadores de la hatschek \\
\hline E21 & Lubricación de chumaceras de los rolos prensapastas \\
\hline E22 & Lubricación de chumaceras de los tamices \\
\hline E23 & Lubricación de chumaceras del rolo templador de fieltro \\
\hline E24 & $\begin{array}{l}\text { Lubricar los rodamientos del motor de la bomba del sistema de traslación de la } \\
\text { onduladora }\end{array}$ \\
\hline E25 & Lubricar los rodamientos del motor del agitador del mezclador \\
\hline E26 & Lubricación de chumaceras de los rodillos de las fajas transportadoras \\
\hline E27 & Mantenimiento a los tableros eléctricos \\
\hline
\end{tabular}

Elaboración Propia 
Figura 5. 2

Gannt de segunda semana de mantenimiento programado

\begin{tabular}{|c|c|c|c|c|c|c|c|c|c|c|c|}
\hline Actividades & $\begin{array}{l}\text { T. de } \\
\text { ejecución } \\
\text { luego de } \\
\text { la mejora } \\
\text { (Hrs.) }\end{array}$ & $\begin{array}{c}\text { Cantidad } \\
\text { de } \\
\text { personas }\end{array}$ & $\begin{array}{c}\text { Responsa } \\
\text { ble }\end{array}$ & $7-8$ & $8-9$ & $9-10$ & $10-11$ & $11-12$ & $12-13$ & $13-14$ & $14-15$ \\
\hline EO & 1,00 & 3 & SP & & & & & & & & \\
\hline E1 & 3,83 & 2 & SP & & & & & & & & \\
\hline E2 & 4,15 & 3 & SP & & & & & & & & \\
\hline E3 & 1,42 & 2 & SP & & & & & & & & \\
\hline E4 & 3,43 & 4 & SP & & & & & & & & \\
\hline E5 & 1,40 & 1 & SP & & & & & & & & \\
\hline E6 & 1,41 & 1 & $S P$ & & & & & & & & \\
\hline E7 & 1,10 & 1 & SP & & & & & & & & \\
\hline E8 & 0,80 & 1 & SP & & & & & & & & \\
\hline E9 & 1,90 & 2 & SP & & & & & & & & \\
\hline E10 & 1,20 & 3 & SP & & & & & & & & \\
\hline E11 & 1,50 & 1 & SP & & & & & & & & \\
\hline E12 & 1,50 & 1 & SP & & & & & & & & \\
\hline E13 & 1,50 & 2 & SP & & & & & & & & \\
\hline E14 & 2,87 & 3 & SP & & & & & & & & \\
\hline E15 & 2,92 & 4 & SP & & & & & & & & \\
\hline E16 & 2,96 & 5 & SP & & & & & & & & \\
\hline E17 & 1,00 & 1 & $\mathrm{CM}$ & & & & & & & & \\
\hline E18 & 0,93 & 1 & $\mathrm{CM}$ & & & & & & & & \\
\hline E19 & 5,83 & 2 & $\mathrm{CM}$ & & & & & & & & \\
\hline $\mathrm{E} 20$ & 5,83 & 1 & $\mathrm{CM}$ & & & & & & & & \\
\hline E21 & 0,75 & 1 & $\mathrm{CM}$ & & & & & & & & \\
\hline E22 & 1,00 & 1 & $\mathrm{CM}$ & & & & & & & & \\
\hline E23 & 0,50 & 1 & $\mathrm{CM}$ & & & & & & & & \\
\hline E24 & 1,51 & 1 & $\mathrm{CM}$ & & & & & & & & \\
\hline E25 & 0,65 & 1 & $\mathrm{CM}$ & & & & & & & & \\
\hline E26 & 3,47 & 2 & $\mathrm{CM}$ & & & & & & & & \\
\hline E27 & 6,50 & 3 & $\mathrm{CE}$ & & & & & & & & \\
\hline
\end{tabular}

\begin{tabular}{|c|l|}
\hline \multicolumn{2}{|c|}{ Leyenda: } \\
\hline SP: & Supervisor de producción \\
\hline CE: & Coordinador eléctrico \\
\hline CM: & Coordinador mécanico \\
\hline
\end{tabular}

Elaboración Propia

Alternativa de solución 3: Implementar la metodología de las 5’S con el objetivo de eliminar los tiempos muertos. Se definirá cuáles son las causas raíces y en base a esto se propondrá alternativas de solución para eliminar cada una.

Líneas abajo se muestra las alternativas de solución para eliminar los tiempos muertos. 
Tabla 5. 5

Propuestas de solución para eliminar tiempos muertos

\begin{tabular}{|l|l|}
\hline \multicolumn{1}{|c|}{ Causa } & \multicolumn{1}{|c|}{ Propuesta de solución } \\
\hline Búsqueda de herramientas & $\begin{array}{l}\text { Implementar las 5'S. Hacer una lista de las herramientas } \\
\text { necesarias y cuantas más se necesitan comprar (Ver Tabla 5.6 } \\
\text { Listado de herramientas). Mandar a fabricar armarios para } \\
\text { colocar las herramientas, estas deben ir clasificadas y rotuladas. }\end{array}$ \\
\hline Búsqueda de repuestos y materiales & $\begin{array}{l}\text { Implementar las 5'S. Tener una zona dentro de la línea donde se } \\
\text { almacene los repuestos y materiales que se usan con frecuencia } \\
\text { en los mantenimientos (Ver Tabla 5.7 lista de repuestos y } \\
\text { materiales más usados en los mantenimientos programados). } \\
\text { Esto luego de los mantenimientos debe reponerse. }\end{array}$ \\
\hline Desorden en la línea & $\begin{array}{l}\text { Implementar las 5'S. Hacer una lista de los objetos innecesarios } \\
\text { que se encuentran dentro de la línea para luego ser reubicados en } \\
\text { otra zona (Ver Tabla 5.6 lista de objetos necesarios e } \\
\text { innecesarios). Elaborar un plan de limpieza, clasificando la línea } \\
\text { por zonas y determinar responsables de mantener estas zonas } \\
\text { limpias y ordenadas (Ver Tabla 5.8 Plan de limpieza). Adicional } \\
\text { a esto, se creará un check list de limpieza el cual debe ser llenado } \\
\text { al inicio de cada turno (Ver Anexo 16 Check list de limpieza). }\end{array}$ \\
\hline $\begin{array}{l}\text { Previo a un mantenimiento, realizar un Gantt para proyectar la } \\
\text { duración de este (Ver Figura 5.1 y 5.2 Gantt mantenimientos } \\
\text { programados). Designar por grupo de actividades, a responsables } \\
\text { que las supervisen y garanticen que se ejecuten dentro del tiempo } \\
\text { estándar establecido para cada actividad. }\end{array}$ \\
\hline
\end{tabular}

Elaboración Propia

Tabla 5. 6

Listado de herramientas

\begin{tabular}{|l|l|c|}
\hline$\#$ & \multicolumn{1}{|c|}{ Actuales } & Por comprar \\
\hline 1 & Llave de boca de 24" (4 unid.) & 5 unid. \\
\hline 2 & Llave de boca de 28" (2 unid.) & 2 unid. \\
\hline 3 & Llave de boca de 32" (1 unid.) & 1 unid. \\
\hline 4 & Llave de boca de 16" (3 unid.) & 2 unid. \\
\hline 5 & Llave francesa de 12" (2 unid.) & 3 unid. \\
\hline 6 & Llave stillson de 24" $(2$ unid. $)$ & 2 unid. \\
\hline 7 & Pistola Neumática $(1$ unid. $)$ & 3 unid. \\
\hline 8 & Rotomartillo neumático $(0$ unid.) & 2 unid. \\
\hline
\end{tabular}

Elaboración Propia 
Tabla 5.7

Lista de repuestos y materiales más usados en los mantenimientos programados

\begin{tabular}{|c|l|l|c|}
\hline$\#$ & \multicolumn{1}{|c|}{ Descripción } & TIPO & $\begin{array}{c}\text { Stock de } \\
\text { seguridad a } \\
\text { mantener dentro } \\
\text { de planta }\end{array}$ \\
\hline 1 & Llave de bola de 1 1/2" & Repuesto & 6 \\
\hline 2 & Llave de bola de 2" & Repuesto & 3 \\
\hline 3 & Conector rápido 5/16" & Repuesto & 4 \\
\hline 4 & Empaquetadura para tubería de 4" & Repuesto & 7 \\
\hline 5 & Empaquetadura para tubería de 6" & Repuesto & 7 \\
\hline 6 & Empaquetadura para tubería de 8" & Repuesto & 4 \\
\hline 7 & Perno, tuerca y arandela M-16 & Repuesto & 22 \\
\hline 8 & Perno, tuerca y arandela M-5 & Repuesto & 30 \\
\hline 9 & Frasco de silicona líquida de 1kg & Material & 4 \\
\hline 10 & Balde de 10 kg de grasa & Material & 2 \\
\hline 11 & Cinta metálica 3M & Material & 5 \\
\hline 12 & Jebe esponjoso de 5 x 1 cm & Material & 6 \\
\hline
\end{tabular}

Elaboración Propia

Tabla 5.8

Lista de objetos necesarios e innecesarios dentro de la línea

\begin{tabular}{|c|c|c|}
\hline \# & Objetos necesarios & Objetos innecesarios \\
\hline 1 & Formato de backup (1 unid.) & Formatos antiguos (2 unid.) \\
\hline 2 & Bombas de vacío de back up (1 unid.) & Líneas de Tuberías en desuso (3 unid.) \\
\hline 3 & $\begin{array}{l}\text { Telas back up para la ventosa onduladora } \\
\text { ( } 2 \text { unid.) }\end{array}$ & Moldes fuera de medidas (350 unid.) \\
\hline 4 & $\begin{array}{l}\text { Armarios de herramientas en buen estado } \\
\text { (1 unid.) }\end{array}$ & $\begin{array}{l}\text { Estantes de moldes fuera de medidas } \\
\text { (10 unid) }\end{array}$ \\
\hline 5 & Tamiz de back up (1 unid.) & $\begin{array}{l}\text { Armario de herramientas en muy mal estado } \\
\text { ( } 3 \text { unid) }\end{array}$ \\
\hline 6 & Mesa tubular de back up (1 unid.) & - \\
\hline 7 & Mesa de vacío de back up & - \\
\hline
\end{tabular}

Elaboración Propia 
Tabla 5. 9

Plan de limpieza

\begin{tabular}{|c|c|c|c|}
\hline Zona & Sub Zonas & Tiempo (min.) & Responsables \\
\hline \multirow{5}{*}{ Mezclador } & Mezclador & 5 & \multirow{5}{*}{$\begin{array}{l}\text { Operador del } \\
\text { mezclador }\end{array}$} \\
\hline & Cono & 10 & \\
\hline & Cisterna principal & 8 & \\
\hline & Cisterna Auxiliar & 5 & \\
\hline & Sala de control & 10 & \\
\hline \multirow{3}{*}{ Formato } & Fajas transportadoras \#1 y \#2 & 8 & \multirow{3}{*}{$\begin{array}{l}\text { Operador del } \\
\text { formato }\end{array}$} \\
\hline & Formato & 5 & \\
\hline & Tablero de control & 5 & \\
\hline \multirow{2}{*}{ Máquina } & Máquina Hatschek & 10 & \multirow{2}{*}{$\begin{array}{c}\text { Operador de la } \\
\text { máquina }\end{array}$} \\
\hline & Zona bombas de vacío & 5 & \\
\hline \multirow{4}{*}{ Onduladora } & Fajas transportadoras \#3 & 5 & \multirow{4}{*}{$\begin{array}{l}\text { Operador de la } \\
\text { onduladora }\end{array}$} \\
\hline & Desintegrador de recortes & 10 & \\
\hline & Tablero de control & 5 & \\
\hline & ventosas y vagonetas & 13 & \\
\hline \multirow{2}{*}{$\begin{array}{c}\text { Cabinas de pre - } \\
\text { curado }\end{array}$} & Cabinas de pre - curado & 13 & \multirow{2}{*}{$\begin{array}{l}\text { Operador del } \\
\text { enzunchado }\end{array}$} \\
\hline & Zona de válvulas reguladoras de vapor & 7 & \\
\hline \multirow{3}{*}{ Desalojadora } & Sistema de lubricación de moldes & 18 & \multirow{3}{*}{$\begin{array}{l}\text { Operador del } \\
\text { desalojo }\end{array}$} \\
\hline & Tablero de control & 5 & \\
\hline & ventosas y vagonetas & 13 & \\
\hline
\end{tabular}

Elaboración Propia

Problema 2: Bajo rendimiento de la materia prima.

Alternativa de solución 1: Elaborar un diagrama de causa - efecto (Ishikawa) de las cosas ocasionan que los parámetros de control que impactan directamente al rendimiento de materia prima resulten fuera de los parámetros de aceptación.

Figura 5.3

Ishikawa de densidades

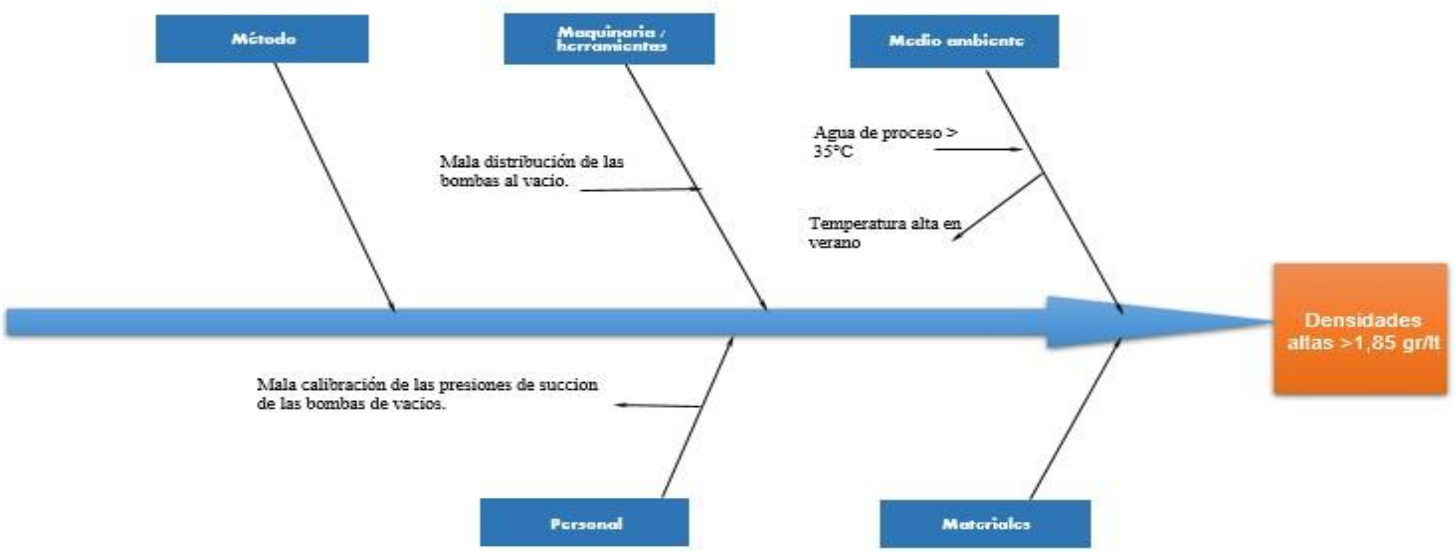

Elaboración Propia 
Propuesta de solución de densidades altas.

1. Mala distribución de las bombas al vacío----- > Modificar la distribución actual.

Tabla 5. 10

Distribución Actual

\begin{tabular}{|l|l|}
\hline Bomba vacío 1 & Mesa de secado \\
\hline Bomba vacío 2 & Mesa de lavado \\
\hline Bomba vacío 2 & Mesa tubular 1 \\
\hline Bomba vacío 2 & Mesa tubular 2 \\
\hline Bomba vacío 3 & Mesa principal 1 \\
\hline Bomba vacío 4 & Mesa principal 2 \\
\hline
\end{tabular}

Elaboración Propia

Tabla 5. 11

Propuesta de distribución

\begin{tabular}{|l|l|}
\hline Bomba vacío 1 & Mesa de secado \\
\hline Bomba vacío 1 & Mesa de lavado \\
\hline Bomba vacío 2 & Mesa tubular 1 \\
\hline Bomba vacío 2 & Mesa tubular 2 \\
\hline Bomba vacío 3 & Mesa principal 1 \\
\hline Bomba vacío 4 & Mesa principal 2 \\
\hline
\end{tabular}

Elaboración Propia 
Figura 5.4

Ishikawa de espesores

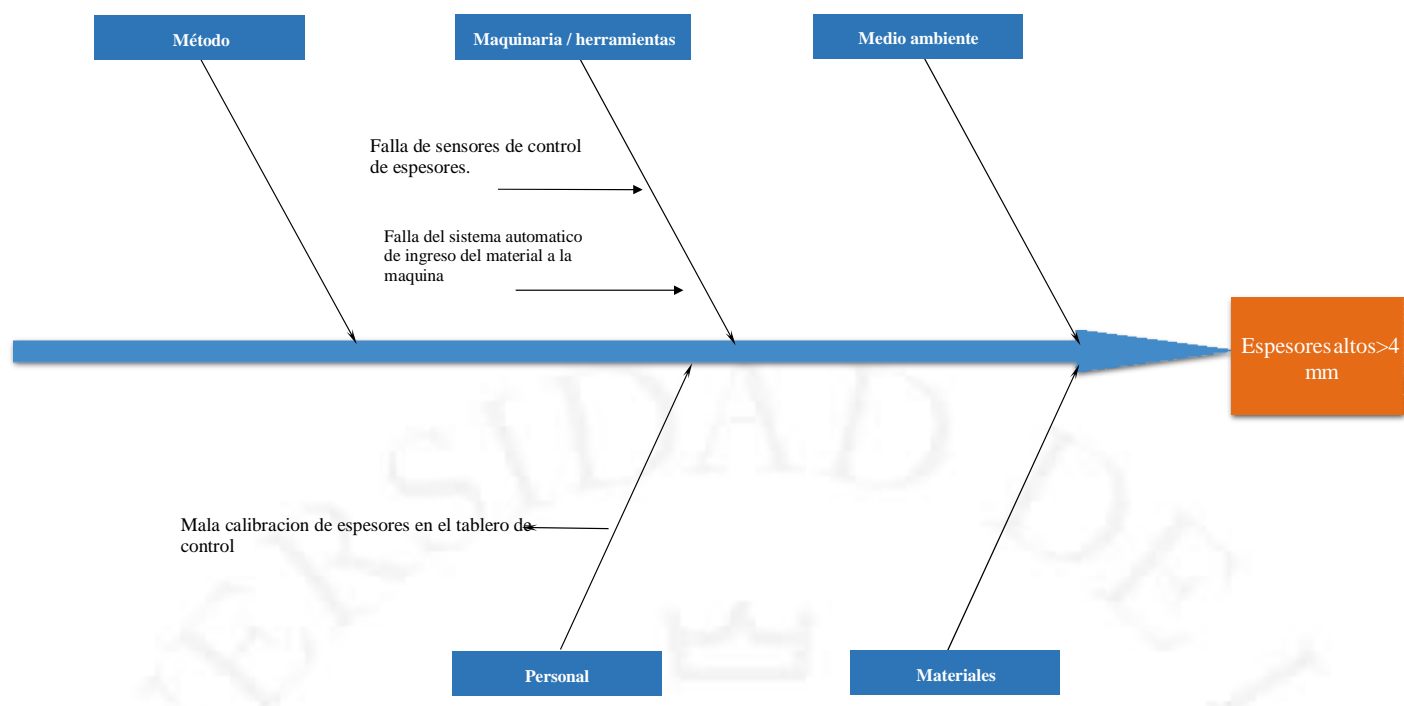

Elaboración Propia

Propuesta de solución para espesores altos

1. Falla de los sensores de control de espesores y del sistema automático de ingreso del material a la maquina ------> Capacitación del personal operario en elproceso productivo.

Alternativa de solución 2: Ubicar zona para material sustraído de los mantenimientos programados.

(Ver Anexo 12 Zona de acopio del material sustraído de los mantenimientos programados)

Alternativa de solución 3: Fabricar canaleta de recuperación de material.

La canaleta se fabricará con material en desuso (chatarra) que se obtiene de la línea de planchas, por lo que el costo será de S/. 0,00. Esta canaleta será fabricada por los mecánicos de la empresa. Su ubicación será a la salida de los tamices.

Alternativa de solución 4: Implementar la metodología de las 5’S.

\section{Seleccionar}

Se realizará una lista de lo que actualmente se tiene dentro de la planta (Ver Tabla 5.8 Lista de objetos necesarios e innecesarios dentro de la línea) 
Se realizará una lista de las herramientas e insumos con las cantidades respectivas necesarias que se manejan o se deben manejar en planta (Ver Tabla 5.7 Lista de repuestos y materiales más usados en los mantenimientos programados) esta información se evaluará en conjunto con la opinión de los técnicos y operarios.

\section{Ordenar}

Los objetos innecesarios se derivan a una zona fuera de planta y los necesarios se reubican y se mantienen dentro planta delimitando una zona.

Se acondiciona un armario para las herramientas y otro armario para los insumos y repuestos que son usados con mayor frecuencia en los mantenimientos.

\section{Limpieza estandarización y disciplina}

Se creará un programa de limpieza, definiendo zonas, tiempo de duración y designando responsables (Ver Tabla 5. 9 Plan de limpieza) y un check list de limpieza que debe ser llenado (Ver Anexo 16 Check list de limpieza).

La empresa tiene que asumir la responsabilidad de estas 3`S, de tal manera que las primeras $2^{`} \mathrm{~S}$, sean sostenibles en el tiempo como, por ejemplo. Los supervisores de la línea deben de asegurar que el armario de herramientas siempre se mantenga clasificado y ordenado. El armario de insumos usados con mayor frecuencia en el mantenimiento programado siempre se mantenga con el stock necesario.

\section{Problema 3: Incidentes en la línea}

Alternativa de solución 1 y 2: Instalar botoneras de parada de emergencia y/o interruptores de carga eléctrica a los equipos que no cuentan con esto y adquirir dispositivos de bloqueo loto

Se tomará en cuenta el programa de bloqueo loto. El bloqueo loto es un procedimiento de emergencia (eléctrica, mecánica e hidráulica) donde se le quita o libera energía a un equipo que puede causar un incidente. Por lo que, la intención es paralizar el trabajo hasta que se controle o elimine el peligro. 
Se planteará la compra de 3 kits de bloqueo loto que incluye:

- 11 dispositivos de bloqueos para válvulas.

- Enchufes.

- Interruptores.

- 1 sensor.

- 10 tarjetas de peligro.

- 2 cerrojos de acero.

- 10 candados.

- 1 manual.

- 1 caja grande de plástico.

El costo de cada kit es de S/ 2000 y se comprará 3 kits, por lo que el costo total es de S/ 6000 .

Así mismo, se tomó en cuenta una capacitación para el personal de la línea en el procedimiento de bloqueo Loto. Para dicha capacitación se toma en cuenta la institución TECSUP. Líneas abajo está el programa a desarrollar.

\section{Curso Especialista en Bloqueo y Etiquetado LOTO}

\section{Programa a desarrollar:}

- Energías peligrosas

- Bloqueo y Etiquetado

- Normas relacionadas (OSHA, ANSI y normas peruanas) Programa de Bloqueo y Etiquetado

- Dispositivos de Bloqueo y Etiquetado

- Pasos para un bloqueo efectivo

- Consecuencias a causa de incumplimiento 
Tabla 5.12

Capacitación de Programa de bloqueo y etiquetado

\begin{tabular}{|c|c|c|c|}
\hline INSTITUCIÓN & CAPACITACIÓN & DURACIÓN & COSTO \\
\hline TECSUP & $\begin{array}{c}\text { Programa de bloqueo y } \\
\text { etiquetado }\end{array}$ & 6 horas & S/ 800 \\
\hline Total & \multicolumn{2}{|r|}{ S/32000 } \\
\hline
\end{tabular}

Elaboración Propia

Para la capacitación de la línea se considera las siguientes personas:

- 3 mecánicos

- 2 electricistas

- 10 operarios por turno. El número de trabajo por día son 3 turnos.

- 1 jefe de producción.

- 1 coordinador de producción.

- 3 supervisores de producción.

Para capacitar a 40 personas el costo total es de 32000 soles.

Alternativa de solución 3: Capacitación al personal en temas de seguridad y salud en el trabajo

Dentro del plan de mejora se ha considerado dar capacitación a la organización en temas relacionados a la prevención de riesgos tomados con la empresa AGS CONSULTING S.A.C.

AGS CONSULTING S.A.C. es una empresa dedicada a servicios varios de asesoría en las principales áreas de seguridad, salud en el trabajo y gestión empresarial. Se escogió esta empresa ya que permite desarrollar soluciones de acuerdo a las necesidades de la empresa.

La capacitación solicitada se dará una vez al año y está conformada por 4 cursos de 8 horas cada curso con un total de 32 horas divididas en 4 días.

Por otro lado, la capacitación se hará abordada en los distintos temas designados líneas debajo de manera general no abarcando puntos específicos ya que se necesita que el personal tenga conocimiento general de cada curso que se dictará. 


\section{Programa a desarrollar:}

\section{Cursos de salud ocupacional}

- Prevención de la hipoacusia inducida por ruido

- Prevención de enfermedades infecciosas ocupacionales

- Prevención de enfermedades al sistema musculo esquelético

- Prevención de enfermedades respiratorias ocupacionales

- Exámenes Médicos Ocupacionales

- Protocolos Médicos Ocupacionales

\section{Higiene industrial}

Agentes Físicos

- Ruido y sus efectos en la salud

- Vibraciones y sus efectos en la salud

- Iluminación y sus efectos en la salud

- Temperaturas extremas y sus efectos en la salud

- Radiaciones ionizantes y no-ionizantes y sus efectos en la salud

Agentes Químicos

- Polvo y sus efectos en la salud

- Gases y vapores y sus efectos en la salud

- Humos y sus efectos en la salud

Agentes biológicos

\section{Cursos de Ergonomía}

- Norma Básica de Ergonomía y Evaluación del Riesgo Disergonómico

- Manejo manual de cargas 
- Carga Postural: caracterización, evaluación y control

- Movimientos repetitivos

- Métodos de evaluación ergonómicas: Ecuación NIOSH, OWAS, REBA, RULA, JSI, OCRA, Tablas de Snook \& Cirello, Renault.

- Ergonomía en oficinas

- Carga Mental

\section{Cursos de Gestión de la Seguridad y Salud Ocupacional}

- Sistema de Gestión de Seguridad y Salud en el Trabajo OHSAS 18001

- Administración del Control de Pérdidas

- Identificación de Peligros, Evaluación y Control de Riesgos (IPERC)

- Estadísticas de Seguridad

- Legislación de Seguridad y Salud en el Trabajo

- Ley 29783 Ley de Seguridad y Salud en el Trabajo.

- Mapping de Procesos

- Programa Anual de Seguridad y Salud en el Trabajo

- Reglamento Interno de Seguridad

- Organización y Funcionamiento del Comité de Seguridad y salud en el trabajo

\section{Cursos de Planes y Respuestas ante Emergencias}

- Seguridad Contraincendios

- Preparación para la emergencia

- Planes de Evacuación

- Capacitación de Brigadas (Primeros auxilios, Evacuación e Incendios)

- Simulacros de evacuación

- Primeros auxilios (teórico - Práctico) 
Tabla 5.13

Capacitaciones en SST

\begin{tabular}{|c|l|c|c|}
\hline INSTITUCIÓN & \multicolumn{1}{|c|}{ CAPACITACIÓN } & DURACION & COSTO S/ \\
\hline AGS CONSULTING & Salud Ocupacional & 8 horas & S/ 500 \\
\hline AGS CONSULTING & $\begin{array}{l}\text { Higiene Industrial y } \\
\text { Ergonomía Ocupacional }\end{array}$ & 800 \\
\hline AGS CONSULTING & $\begin{array}{l}\text { Cursos de Gestión de la } \\
\text { Seguridad y Salud } \\
\text { Ocupacional }\end{array}$ & 8 horas & S/ 1000 \\
\hline AGS CONSULTING & $\begin{array}{l}\text { Cursos de Planes y } \\
\text { Respuestas ante } \\
\text { Emergencias }\end{array}$ & 8 horas & S/ 800 \\
\hline Total & \multicolumn{2}{|l}{} & S/2 800 \\
\hline
\end{tabular}

Elaboración Propia

Para la capacitación de la línea se considera las siguientes personas:

- 3 mecánicos

- 2 electricistas

- 10 operarios por turno. El número de trabajo por día son 3 turnos.

- 1 jefe de producción.

- 1 coordinador de producción.

- 3 supervisores de producción.

Para capacitar a 40 personas el costo total es de 112000 soles.

Alternativa de solución 4: Elaborar un check list de las condiciones en las que se recibe el turno.

(Ver Anexo 4 Check list de condiciones inseguras)

Ver anexo 5 Criterios de evaluación para la clasificación de condiciones inseguras por prioridad.

Alternativa de solución 5: Clasificar las condiciones inseguras por prioridad y establecer fechas de ejecución. 
(Ver Anexo 17 Matriz IPERC)

(Ver Anexo 6 Matriz de clasificación de condiciones inseguras por prioridad)

Alternativa de solución 6: Implementar la metodología de las 5’S

\section{Clasificar}

La primera regla de la 5'S es clasificar los objetos en necesario e innecesario con el objetivo de liberar espacio desechando o reusando (Ver Tabla 5.8 Lista de objetos necesarios e innecesarios dentro de la línea).

Así mismo, se habló con el jefe de producción de la línea para laimplementación de tarjetas rojas (Ver Anexo 11 Tarjeta roja identificatoria - 5'S) en los elementos de poco uso o ningún uso.

\section{Organizar}

El siguiente paso es organizar, con esto se organiza el espacio dentro del área de producción de la línea permitiendo encontrar los objetos necesarios de una manera más rápida, eficaz y sin demoras en el tiempo. Los objetos necesarios se colocan en un armario clasificándolos de acuerdo a su función y los innecesarios se ubicarán en una zona de acopio dentro de la planta (Ver Anexo 12 Zona de acopio del material sustraído de los mantenimientos programados). De esta manera también, se evitará accidentes que perjudican a los operarios de la línea.

\section{Limpieza}

Para el desarrollo de la limpieza se tiene que considerar, que no es una simple actividad de limpieza de equipos y pisos, sino que esto tiene que ir acompañado con la inspección (Ver Anexo 7 Formato de evaluación para auditorias de 5’S y Ver anexo 8. Formato de observaciones encontradas en auditorias 5’S), ya que, se trata de revisar toda el área para evitar accidentes y daños en los equipos. Para ello, se conversó con la gerencia de producción para realizar una capacitación a los operarios para transmitirle la necesidad de compromiso con la limpieza del área.

\section{Estandarización y disciplina}

Para estas 2’S la empresa tiene que asumir la responsabilidad para que la estandarización y disciplina se mantenga en el tiempo. Para ello se conversó con el gerente de producción para la realización de una capacitación, establecimiento de políticas de orden y limpieza, 
asignación de trabajos responsables, seguimientos y control. (Ver Anexo 7. Formato de evaluación para auditorias de 5`S, (Ver anexo 8. Formato de observaciones encontradas en auditorias 5’S), (Ver anexo 9. Formato de control de tarjetas rojas de 5’S), (Ver anexo 10 Formato de control de tarjeta rojas de 5’S herramientas)

\section{Problema 4: Baja productividad}

Alternativa de solución 1: Implementar el indicador OEE.

(Ver Anexo 13 Cálculo del OEE de los meses de junio, julio, agosto y setiembre del 2018, de la línea de planchas de fibrocemento).

\section{Alternativa de solución 2: Implementar la metodología de las 5'S}

Se toma en cuenta la implementación de la metodología de las 5’S en los problemas de retrasos en los mantenimientos programados e incidentes en la línea, ya que, no solo tendrá un impacto positivo en estos dos problemas si no que, tendrá un impacto positivo en el problema de baja productividad. Ya que al implementar la 5’S ayuda a mejorar la baja productividad de línea.

Alternativa de solución 3: "Eliminar el cuello de botella" que es la desalojadora, aplicando ingeniería (Ver Tabla 5. 14 Mejoras en el equipo cuello de botella desalojadora). 
Tabla 5.14

Mejoras en el equipo cuello de botella - desalojadora

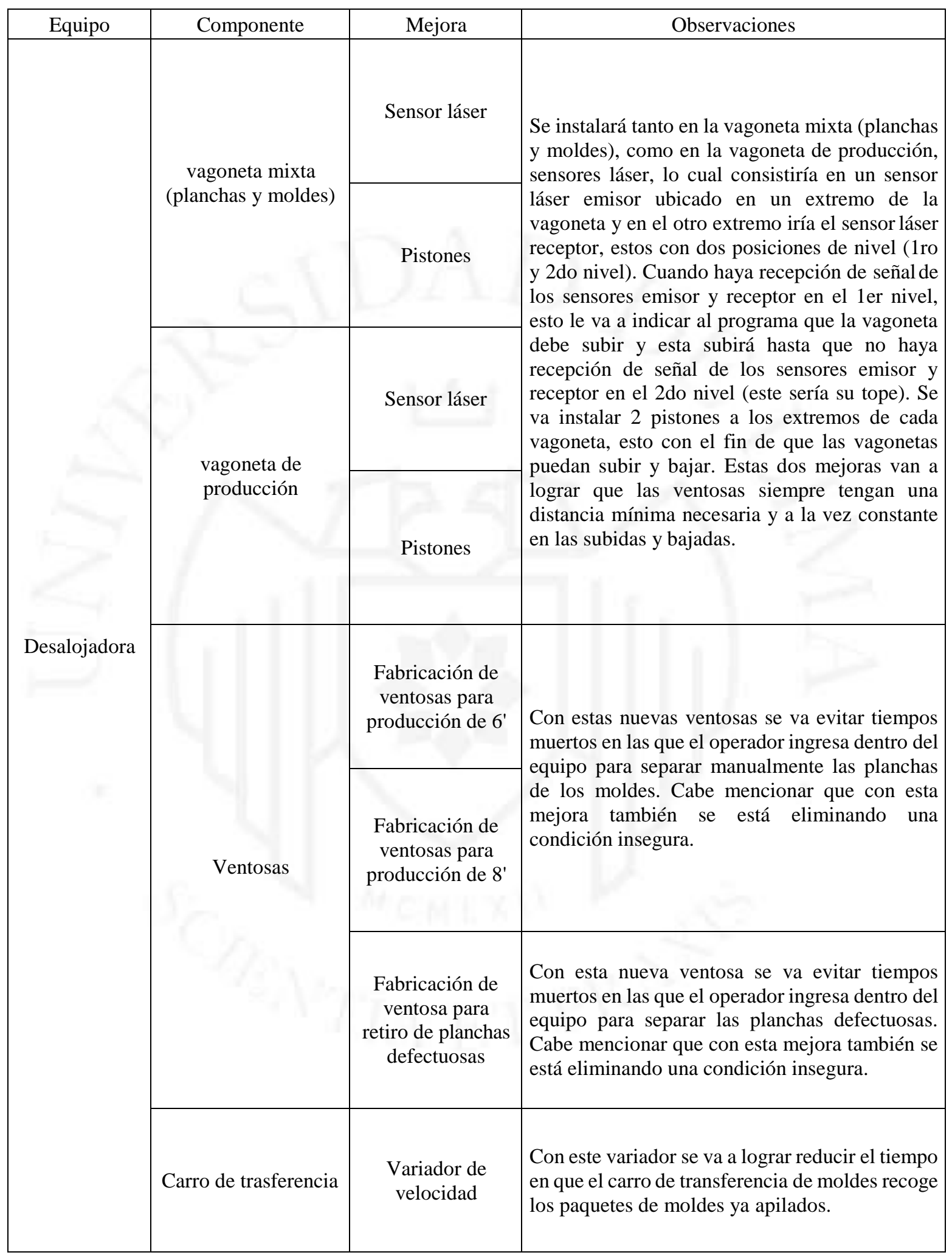

Elaboración Propia 
Alternativa de solución 4: Reducir los tiempos de cambios de producción aplicando SMED

Ver Anexo 14. Análisis SMED para reducción de tiempos de cambio.

\subsection{Plan de implementación de la solución}

\subsubsection{Objetivos y metas}

El objetivo principal de esta investigación es, mejorar el proceso productivo de la línea de plancha de fibrocemento de la Fábrica Peruana Eternit S.A

Tabla 5. 15

Objetivos y metas

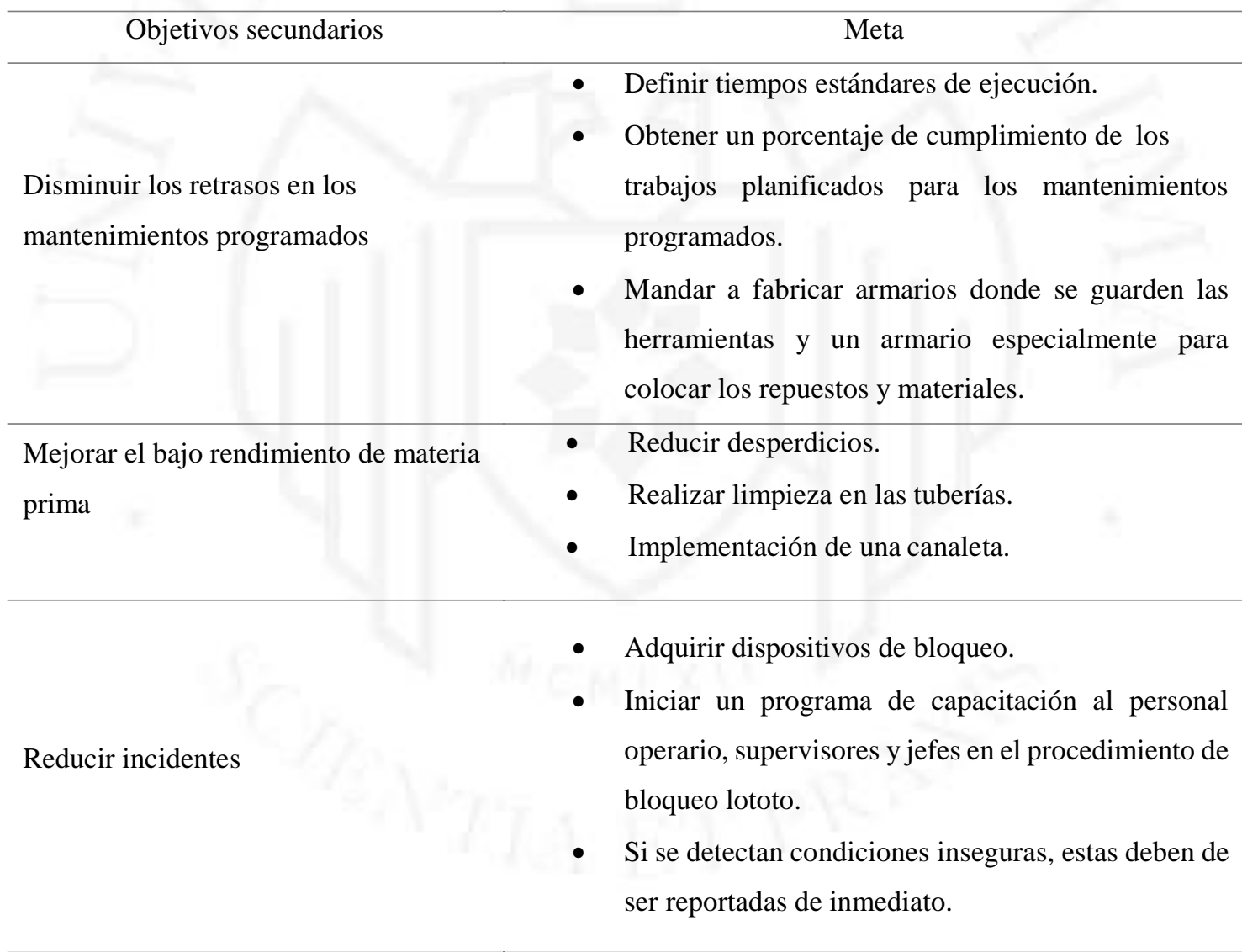

- Cuantificar los procesos

Incrementar productividad

- Adquirir equipos más modernos y automatizados.

Elaboración Propia 


\subsubsection{Elaboración del presupuesto general requerido para la ejecución de la solución}

El presupuesto para la elaboración de la mejora de producción de la línea de fibrocemento de la fábrica peruana Eternit considerando la mano de obra, equipos, servicios y otros costos durante un periodo de 12 meses es el siguiente:

Tabla 5.16

Presupuesto General

\begin{tabular}{lcc}
\hline \multicolumn{1}{c}{ Ítem } & Descripción & Monto \\
\hline Mano de obra & & \\
\hline Supervisor de Proyecto (1) & Responsable del proyecto & S/ 120000 \\
\hline
\end{tabular}

Analistas de Proyecto (4)

Encargados de procesar la información y generar reportes con indicadores para

S/ 240000 proponer oportunidades de mejora.

Practicante (1)

Encargado de recopilar información y ponerla en una base de datos.

S/ 14250

Laptop (6)

Una laptop para cada miembro del equipo.

S/ 12000

Cámara fotográfica

Equipo para capturar imágenes dentro de la línea.

S/ 1000

Consumibles

Papel, tinta para imprimir, cintas adhesivas, pintura, etc.

S/ 3000

Sillas (6)

1 silla para cada integrante del equipo.

S/ 1200

Mesa de trabajo

1 mesa de trabajo para todos los integrantes del equipo

S/ 1000

Equipos de protección al personal 
(continuación)

\begin{tabular}{llll}
\hline & Ítem & Descripción & Monto \\
\hline Servicios & & \\
\hline
\end{tabular}

Servicio de una empresa consultora para

Gestión de Comunicación difundir el proyecto mediante correos, banners y capacitaciones.

\begin{tabular}{|c|c|c|}
\hline Servicio de carpintería & $\begin{array}{l}\text { Servicio para elaborar un armario de } \\
\text { herramientas en una zona delimitada de la } \\
\text { línea por el personal del proyecto }\end{array}$ & S/ 5000 \\
\hline Servicio de pintado & $\begin{array}{l}\text { Servicio para delimitar las zonas con } \\
\text { pintura dentro de la línea de fibrocemento. }\end{array}$ & $\mathrm{S} / 3000$ \\
\hline Implementación de & & \\
\hline capacitaciones y asesorías & $\begin{array}{l}\text { área de la línea de fibrocemento } \\
\text { áresio de capacitaciones al personal del }\end{array}$ & $\mathrm{S} / 15000$ \\
\hline constantes & & \\
\hline \multicolumn{3}{|l|}{ Otros } \\
\hline Transporte & Movilidad para los integrantes del equipo & S/ 8400 \\
\hline Útiles de oficina & Lapiceros, cuadernos, folders, etc. & $\mathrm{S} / 6000$ \\
\hline Seguro de SCTR & $\begin{array}{l}\text { Seguro complementario de trabajo de } \\
\text { riesgo. }\end{array}$ & S/ 8751 \\
\hline
\end{tabular}

Otros gastos

Elaboración Propia

\subsubsection{Actividades y cronograma de implementación de la solución}

A continuación, se presenta el cronograma de implementación del proyecto, que será sustentada frente a la alta dirección de la compañía. 
Figura 5. 5

Cronograma de Implementación

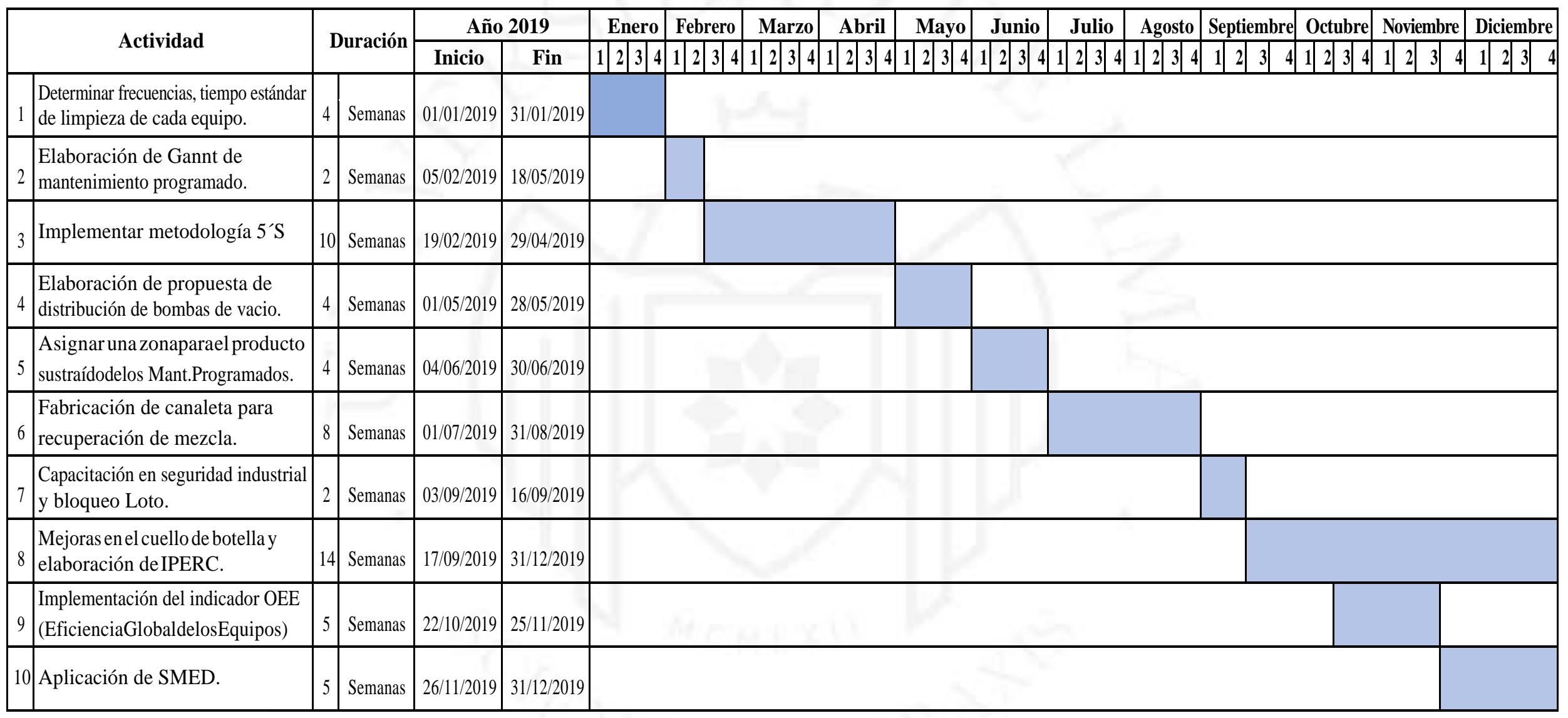

Elaboración Propia 


\section{CAPITULO VI: EVALUACIÓN ECONÓMICA FINANCIERA DE LA SOLUCIÓN}

\subsection{Determinación de escenarios para las soluciones propuestas}

Para la solución de la propuesta se han definido tres escenarios que son el realista, pesimista y optimista. Las variables independientes son las horas de mantenimiento programado y no programado, horas de cambio de producción y material recuperado.

Las variables dependientes son los costos de mantenimiento programado y no programado, costo de cambio de producción y costos por material recuperado.

En un escenario optimista se considera, que el impacto en los costos seria 50\% menor, mientras que en un impacto pesimista seria $50 \%$ mayor.

\subsection{Estimación de los resultados de la implementación}

Se estima que la reducción en las horas de mantenimiento programado, no programado, cambios de producción, así como, la utilización de material recuperado de los mantenimientos programados en la mezcla y recuperación de material que se pierde en la salida de los tamices tendría un impacto positivo en la reducción de costos de la línea, ya que, mejoraría la producción, mantenimiento y seguridad industrial.

Por esta razón, se calculó los costos de la línea del año 2017 versus el tiempo que dura la mejora. Cabe recalcar que las mejoras que se utilizan están en relación con las planteadas anteriormente.

\subsubsection{Costos de la línea antes de la mejora}

A continuación, se puede observar los cálculos para hallar los costos de la línea antes de la mejora (Año 2017). Para el cálculo de los costos de la línea en el año 2017 se consideró lo siguiente: La línea está conformada por 3 mecánicos por turno, 2 electricistas por turno y 10 operarios por turno. El número de trabajo por día son 3 turnos. 
Además la línea cuenta con 1 jefe de producción, 1 coordinador de producción y 1 supervisor por turno.

- En una hora se produce 389 planchas.

- El precio de venta de la plancha es de S/ 34,32.

- El costo de venta de la plancha es de S/ 22.

- La utilidad de la plancha es de S/ 12,32.

- El costo de mano de obra por un operario es de S/ 6,25/hr.

- El costo de mano de obra por un mecánico es S/ 20/hr.

- El costo de mano de obra por un electricista es de $\mathrm{S} / 25 / \mathrm{hr}$.

- El costo de mano de obra por un coordinador es de S/ 30/hr.

- El costo de mano de obra por un supervisor es de S/ 25/hr.

- El costo de sobretiempo de horas extras es $30 \%$ más.

\section{Costo de mantenimiento programado}

El mantenimiento programado dura 12 horas $(1$ turno $=12$ horas $)$ y se realiza 1 vez cada semana.

1 Año= 52 semanas

12 horas X 52 semanas $=624$ horas

semana año año

En todo el año se realizó 624 horas de mantenimiento programado. Cuando hay un mantenimiento programado se considera 15 operarios (10 de turno y 5 por sobretiempo), 5 mecánicos ( 3 de turno y 2 por sobretiempo), 3 electricistas ( 2 de turno y 1 sobretiempo). Así mismo se considera 1 coordinador y 1 supervisor. Para cálculo del costo de mano de obra no se está considerando el gerente y jefe de producción, ya que, ellos tienen a su cargo otras líneas de la planta, por lo que su trabajo no paraliza. También no se considera al asistente y practicante de producción, ya que, su funciónes temas de reportes y gestión de producción. 
$\checkmark$ Costo de mano de obra:

Por turno

$\frac{624 \text { horas }}{\text { año }} \times \frac{\text { S/ } 20}{\text { hora }} \times$ 3 Mecánicos $=\frac{\text { S/ 37 } 440}{\text { año }}$

$\frac{624 \text { horas }}{\text { año }} \times \frac{\text { S/ } 25}{\text { hora }} \times 2$ Electricistas $=\frac{S / 31200}{\text { año }}$

624 horas $\mathrm{X} \quad \mathrm{S} / 6,25 \quad \mathrm{X} \quad 10$ Operarios $=\mathrm{S} / 39000$

\begin{tabular}{|c|c|c|c|c|c|}
\hline año & & hora & & & año \\
\hline 524 horas & $X$ & $\mathrm{~S} / 30$ & $\mathrm{X}$ & 1 Coordinador $=$ & S/ 18720 \\
\hline año & & hora & & & año \\
\hline 524 horas & $\mathrm{X}$ & S/ 25 & $\mathrm{X}$ & 1 Supervisor $=$ & S/ 15600 \\
\hline
\end{tabular}

Por sobretiempo

624 horas $\mathrm{X} \quad \mathrm{S} / 26 \quad \mathrm{X} 2$ Mecánicos $=\mathrm{S} / 32448$

año hora año

624 horas $\mathrm{X} \quad \mathrm{S} / 32,5 \quad \mathrm{X} 1$ Electricistas $=\mathrm{S} / 20280$

año hora año

624 horas $\mathrm{X} \quad \mathrm{S} / 8,13 \quad \mathrm{X} \quad 5$ Operarios $=\mathrm{S} / 25366$

año hora año

El costo de mano de obra por mantenimiento programado en el año 2017 fue de S/. 220054.

Costo por dejar de producir:

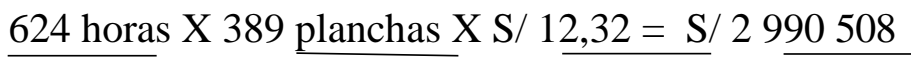

año hora $\frac{1}{\text { planchas año }}$

Costo de materiales:

El costo de materiales por cada mantenimiento programado es de S/ 295. Este costo incluye grasa, pegamento, trapos industriales, silicona líquida. Para el cálculo de este costo se ha considerado 52 mantenimientos al año. 


$\frac{\mathrm{S} / 295}{\text { mantenimiento }} \times \frac{52 \text { mantenimientos }}{\text { año }}=\frac{\mathrm{S} / 15340}{\text { año }}$

$\checkmark$ Costos de reparación

Los costos de reparación del año 2017 fueron de S/ 648959 el cual incluye los costos de repuestos. Para el cálculo del costo de mano de obra se consideró las horas de mantenimiento programado que están líneas arriba.

$\checkmark$ Los costos de repuestos del año 2017 fue lo siguiente:

Tabla 6. 1

Costos de repuestos de mantenimiento programado

\begin{tabular}{lc}
\hline Repuestos & Costos S/ \\
\hline Motor de maquina Hatsheck & S/ 238560 \\
\hline Rolos prensapastas & S/ 90000 \\
\hline Bomba de rebose de batea & S/ 85000 \\
\hline Bomba de alta presión de lavado de fieltro & S/ 30000 \\
\hline Rolo motriz & S/ 85399 \\
\hline Bomba de vacío & S/ 50000 \\
\hline Bomba de recuperación & S/ 50000 \\
\hline Desintegrados de recortes & S/ 20000 \\
\hline Total & S/ 648959 \\
\hline Elaboración Propia &
\end{tabular}

Elaboración Propia

El costo de mantenimiento programado total en el año 2017 fue de S/ 3874861.

\section{Costos en los cambios de producción (SMED)}

Los cambios de producción (C.Producción) en el año 2017 fue de 1,5 horas y el objetivo de la propuesta de mejora es reducir el cambio de producción a 1 hora.

Se realiza 36 cambios de producción al año. Para los cambios de producción se toma en cuenta 2 mecánicos, 1 electricista, 4 operarios. 
$\checkmark$ Costo por dejar de producir:

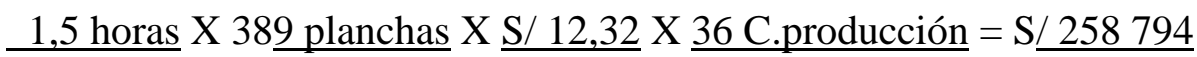

C.producción hora planchas año año

El costo de oportunidad por dejar de producir en los cambios de producción en el año 2017 fue de S/ 258794.

Costo de mano de obra:

$\underline{1,5 \text { horas } X \quad \underline{36} \text { C.producción X } \underline{\mathrm{S} / 20} \times \quad \text { X } 2 \text { Mecánicos }=\mathrm{S} / 2160}$

C.producción año hora año

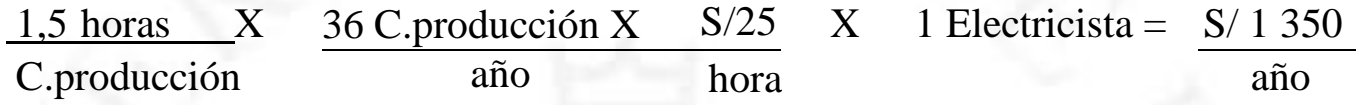

$\frac{1,5 \text { horas }}{\text { C.producción }} X \quad \frac{36 \text { C.producción }}{\text { año }} X \quad \frac{S / 6,25}{\text { hora }} \quad X \quad$ 4 Operarios $=\frac{S / 1350}{\text { año }}$

El costo de mano de obra por cambios de producción en el año 2017 fue de S/ 4860.

El costo por cambios de producción (SMED) en el año 2017 fue de S/ 263654.

Pérdidas por material que se pierde en la salida de los tamices.

Para hallar el equivalente en dinero del material que se pierde en la salida de los tamices se tomó en cuenta lo siguiente:

- El costo de material es de S/ 15,4 por plancha.

- En una hora se produce 389 planchas.

- En un turno (8 horas) se producen 3112 planchas.

- En promedio por cada turno se preparan 33 mezclas.

- En una mezcla se producen 94 planchas.

- Una mezcla contiene $1529 \mathrm{~kg}$.

3112 planchas $=94$ planchas

33 mezclas mezcla


Por cada kilogramo hay S/ 0,947 de costo.

$$
\frac{94 \text { planchas }}{\text { mezcla }} \times \frac{\mathrm{S} / 15,4}{\text { planchas }} \times \frac{1 \text { mezcla }}{1529 \mathrm{~kg}}=\frac{\mathrm{S} / 0,947}{\mathrm{~kg}}
$$

El material que recoge el tamiz es del 53\%, el cual es transferido al producto en su totalidad. Lo que se va por el fondo de la salida del tamiz es de $47 \%$, del cual el $37 \%$ retorna a la máquina (se recupera) y el otro $10 \%$ se pierde en el camino, se adhiere a las tuberías y a los equipos.

Queda en la máquina $\quad 53 \% \quad 0,53 \times 1529 \mathrm{~kg}=810,37 \mathrm{~kg}$

Lo que van en fondo de

La salida de los tamices $\quad 47 \% \quad 0,47$ X $1529 \mathrm{Kg}=718,63 \mathrm{Kg}$

Lo que se pierde

$10 \% \quad 0,1 \times 718,63 \mathrm{Kg}=71,86 \mathrm{Kg}$

El 10\% que se pierde por el fondo de la salida de los tamices es de 71,86 Kg. Con este dato se puede hallar el costo de pérdida.

33 mezclas X 3 turnos X 365 días X 71,86 Kg X S/ 0,947= S/ 2459038

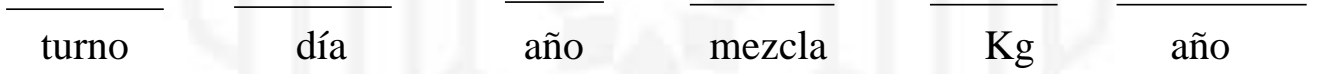

El costo de pérdida de material que se va por el fondo de la salida de los tamices y que no se recupera, en el año 2017 fue de S/ 2459038.

\section{Costo por accidentes}

En el año 2017 hubo 2 accidentes. Uno fue por fractura de hombro y el otro por corte profundo de mano derecha. Para el cálculo de los costos se tomó en cuenta lo siguiente:

- El descanso médico para la fractura de hombro fue por 4 meses.

- El descanso médico para el corte profundo fue de 1 mes.

- El costo por hora extra de trabajo es $30 \%$ más.

- El costo por hora de cada operario es de S/ 6,25.

- El costo por hora extra de cada operario es de S/ 8,125.

- El sueldo mensual de un operario es de S/1 200. 
Costo de descanso médico por fractura de hombro:

4 meses X S/ $1200 /$ mes $=$ S/ 4800

Costo de horas extras por fractura de hombro.

$$
192 \text { horas } X \text { S/ } \frac{8,125 X}{\text { hora }} \underset{\text { año }}{4} \frac{\text { meses }}{\text { año }}
$$

Costo de descanso médico por corte profundo de mano derecha.

1 mes X S/. $1200 /$ mes = S/ 1200.

Costo de horas extras por corte profundo de mano derecha.

$$
\underline{192 \text { horas }} X \frac{\mathrm{S} / 8,125 \mathrm{X}}{\text { hora }} \frac{1 \mathrm{mes}=\mathrm{S} / \mathrm{1}}{\text { año }} \frac{560 \mathrm{mes}}{\text { año }}
$$

Costo de materiales dañados en accidente fue de S/. 500. El costo total por accidentes en el año 2017 fue de S/ 14300.

Nota: Los costos por atención en el centro médico y rehabilitación son pagados por el seguro SCTR (Seguro complementario de trabajo de riesgo), que la empresa adquirió para todos los trabajadores de la planta.

\section{Costos por capacitación en seguridad industrial.}

Los costos en capacitación en seguridad industrial antes de la mejora es de S/ 0.00 ya que, las capacitaciones eran dictadas por el mismo personal de la línea.

Líneas abajo se encuentra un cuadro resumen de los costos de mantenimiento y seguridad industrial de la línea de plancha de fibrocemento en el año 2017. 
Tabla 6. 2

Costos de mantenimiento y seguridad en la línea de planchas de fibrocemento antes de la mejora

\begin{tabular}{lr}
\hline \multicolumn{2}{c}{ Costos de mantenimiento y seguridad de la línea del año 2017} \\
\hline Costo de la línea & Costos en soles \\
\hline Mantenimiento programado & S/ 3874861 \\
\hline Cambio de producción (SMED) & S/ 263654 \\
\hline
\end{tabular}

Recuperación de material que se pierde en la salida de los tamices

S/ 2459038

\begin{tabular}{lc} 
& \\
\hline Accidentes & S/ 14300 \\
\hline Capacitación y seguridad industrial & S/ 0,00 \\
\hline Total & \\
\hline
\end{tabular}

Elaboración Propia

\subsubsection{Costos de la línea después de la mejora}

A continuación, se puede observar los cálculos que se hallaron para mostrar la reducción de costos de la línea durante la mejora planteada.

Se toma en cuenta los siguientes datos para los cálculos utilizando la mejora planteada.

- En una hora se produce 389 planchas.

- El precio de venta de la plancha es de S/ 34,32.

- El costo de venta de la plancha es de S/ 22.

- La utilidad de la plancha es de S/12,32.

- El costo de mano de obra por un operario es de S/ 6,25/hr. 
- El costo de mano de obra por un mecánico es S/ 20/hr.

- El costo de mano de obra por un electricista es de $\mathrm{S} / 25 / \mathrm{hr}$.

- El costo de mano de obra por un coordinador es de S/ 30/hr.

- El costo de mano de obra por un supervisor es de S/ 25/hr.

- El costo de sobretiempo de horas extras es $30 \%$ más.

\section{Mantenimiento programado}

Costo de mantenimiento programado:

Actualmente el mantenimiento programado dura 12 horas debido a la mala planificación y organización de los trabajos, tiempos muertos, demora en la búsqueda de herramientas, ineficiente asignación de los recursos de mano de obra y desorden en la línea.

Con la mejora planteada el mantenimiento programado va a durar 8 horas y se realiza una vez cada semana. Tomando en cuenta estos datos hay 416 horas en todo el año de mantenimiento programado. (Ver Anexo 3 Determinación del tiempo estándar de las actividades de mantenimiento programado y Ver anexo 4 Sustento de reducción de horas de mantenimiento programado)

Cuando hay un mantenimiento programado se considera 15 operarios (10 de turno y 5 por sobretiempo), 5 mecánicos ( 3 de turno y 2 por sobretiempo), 3 electricistas ( 2 de turno y 1 sobretiempo). Así mismo se considera 1 coordinador y 1 supervisor. Para cálculo del costo de mano de obra no se está considerando el gerente y jefe de producción, ya que, ellos tienen a su cargo otras líneas de la planta, por lo que su trabajo no paraliza. También no se considera al asistente y practicante de producción, ya que, su función es temas de reportes y gestión de producción.

Durante el tiempo que dura la mejora (1 año) las horas de mantenimiento programado es de 416 horas. Líneas abajo está el cálculo.

$\frac{8 \text { horas }}{\text { Mant. Programado }} \times \frac{52 \text { Mant. Programado }}{\text { año }}=\frac{416 \text { horas }}{\text { año }}$


Costo de mano de obra:

Por turno

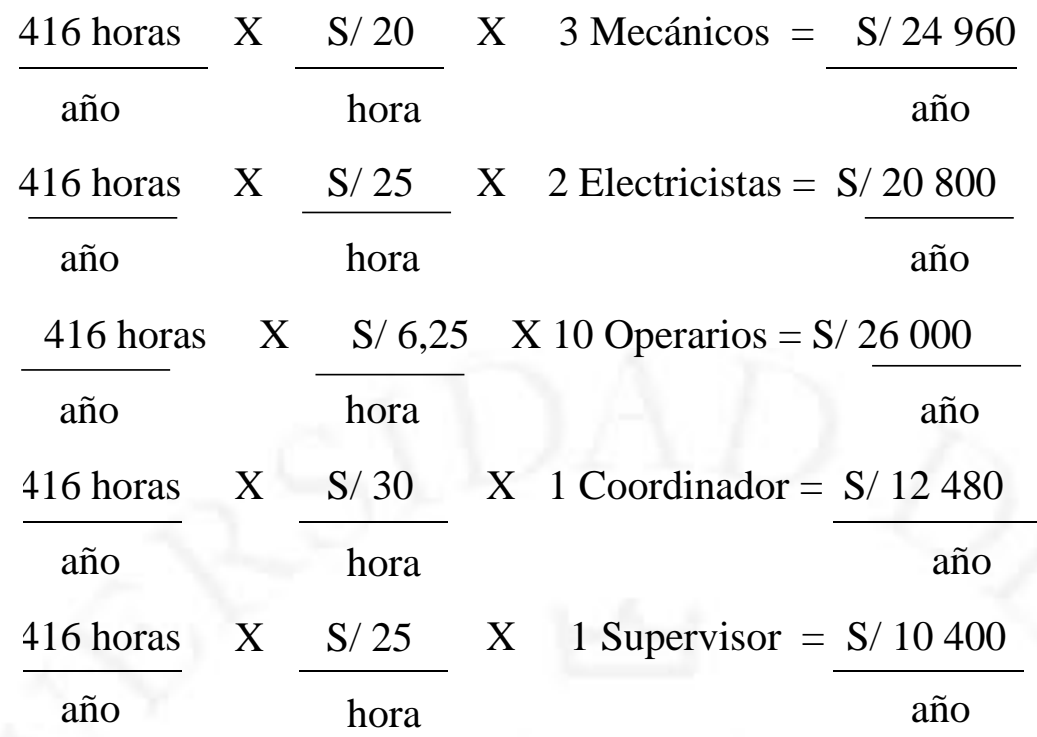

Por sobretiempo

$\begin{array}{llllll}\frac{416 \text { horas }}{\text { año }} & X & \frac{S / 26}{\text { hora }} & & \text { 2 Mecánicos }= & \frac{S / 21632}{\text { año }} \\ \frac{416 \text { horas }}{\text { año }} & X & \frac{S / 32,5}{\text { hora }} & X & 1 \text { Electricistas }=S / 13520 \\ \frac{416 \text { horas }}{\text { año }} & X & \frac{S / 8,13}{\text { hora }} \times & 5 \text { Operarios }=S / 16910 \\ \text { año }\end{array}$

El costo de mano de obra durante el tiempo que dura la mejora es de S/. 146702

$\checkmark$ Costo por dejar de producir :

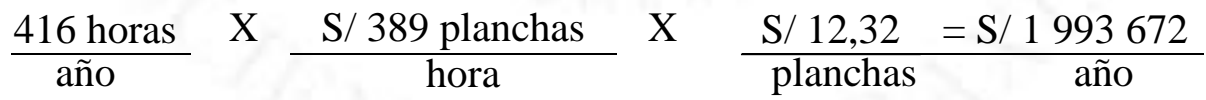

Costo de materiales de mantenimiento programado:

El costo de materiales por cada mantenimiento programado es de S/ 295. Este costo incluye grasa, pegamento, trapos industrial, silicona líquida, etc. Para el cálculo de este costo se ha considerado 52 mantenimientos al año.

$\frac{\mathrm{S} / 295}{\text { mantenimiento }} \times \frac{52 \text { mantenimientos }}{\text { año }} \frac{=\mathrm{S} / 15340}{\text { año }}$ 
$\checkmark$ Costo de reparación y costos de materiales que se necesitan para la mejora

El costo de reparación y materiales que se necesitan durante el tiempo que dura la mejora es de S/ 454 269. Se considera un eficiente programa de mantenimiento programado que se viene reflejado en la disminución de costos, ya que, al tener un correcto mantenimiento programado los equipos tendrán una vida útil mayor y con ellos la cantidad de repuestos a comprar será menor. Para el cálculo del costo de mano de obra se consideró las horas de mantenimiento programado que están líneas arriba. Además, el costo de materiales que se necesitan para la mejora es de S/ 1 026. Líneas abajo está el detalle.

Tabla 6. 3

Materiales adicionales que se necesitan para la mejora

\begin{tabular}{lc}
\hline Materiales & Costos S/ \\
\hline Llave de boca ( 15 unid) & S/ 140 \\
\hline Pistola neumática (3 unid) & S/ 228 \\
\hline $\begin{array}{l}\text { Rotomartillo neumático (2 } \\
\text { unid) }\end{array}$ & S/ 158 \\
\hline $\begin{array}{l}\text { Armario } \\
\text { Total }\end{array}$ & S/ 500 \\
\hline
\end{tabular}

Elaboración Propia

Tabla 6.4

Costos de repuestos con la mejora planteada

\begin{tabular}{lc}
\hline Repuestos & Costos S/ \\
\hline Motor de maquina Hatsheck & S/ 238560 \\
\hline Rolos prensapastas & S/ 90000 \\
\hline Bomba de rebose de batea & S/ 85000 \\
\hline $\begin{array}{l}\text { Bomba de alta presión de } \\
\text { lavado de fieltro }\end{array}$ \\
\hline Total & \\
\hline Elaboración Propia & S/ 4532483 \\
\hline
\end{tabular}


El costo de mantenimiento programado total es de S/ 2609983

\section{Reducción en tiempos de cambios de producción (SMED)}

Con la implementación de la mejora se pretende reducir el tiempo de cambios de producción a 1 hora. Ver anexo 23 (Análisis SMED para reducción de tiempos de cambios)

$\checkmark$ Costo de lo que se deja de producir por cambios de producción (C.Producción) :

$\frac{1 \text { hora }}{\text { C.producción }} X \frac{389 \text { planchas }}{\text { hora }} X \frac{\mathrm{S} / 12,32}{\text { planchas }} \times \frac{36 \text { C.producción }}{\text { año }}=S / \frac{172529}{\text { año }}$

$\checkmark$ Costo de mano de obra por cambios de producción:

\begin{tabular}{|c|c|c|c|c|c|c|c|}
\hline 1 hora & \multirow[t]{2}{*}{$X$} & 36 C.producción & $X$ & $\mathrm{~S} / 20$ & $X$ & 3 Mecánicos = & S/ 2160 \\
\hline C.producción & & año & & hora & & & año \\
\hline 1 hora & $\mathrm{X}$ & 36 C.producción & $X$ & S/ 25 & $X$ & 2 Electricistas $=$ & S/ 1800 \\
\hline C.producción & & año & & hora & & & año \\
\hline 1 hora $Y$ & $X$ & 36 C.producción X & & S/ 6,25 & $\mathrm{X}$ & 6 Operarios $=$ & S/ 1350 \\
\hline .producción & & año & & hora & & & año \\
\hline
\end{tabular}

El costo de mano de obra por cambio de producción es de S/ 5310 .El costo por cambios de producción tomando en cuenta la mejora es de S/ 177839.

\section{Recuperación de material que se pierde en la salida de los tamices}

El costo por fabricar la canaleta por donde se va a recuperar el material es de $\mathrm{S} / 0,00$ ya que se va a fabricar con material en desuso (chatarra) y con los mismos mecánicos de la compañía.

\section{Costos que incurre la empresa cuando ocurre un accidente.}

El objetivo de la mejora es que no haya ningún accidente en la línea, por lo que el costo es de $\mathrm{S} / 0,00$.

\section{Costo por eliminar el cuello de botella}

El costo para eliminar o el cuello de botella es de S/ 265 716. Líneas abajo está el detalle del costo. 
Tabla 6.5

Costo para eliminar el cuello de botella

\begin{tabular}{|l|c|}
\hline \multicolumn{1}{|c|}{ Mejora a implementarse } & Costo S/ \\
\hline Sensor láser & 1780 \\
\hline Pistones & 9540 \\
\hline Sensor láser & 1780 \\
\hline Pistones & 9540 \\
\hline Fabricación de ventosas para producción de 6' & 75650 \\
\hline Fabricación de ventosas para producción de 8' & 90870 \\
\hline Fabricación de ventosa para retiro de planchas defectuosas & 70652 \\
\hline Variador de velocidad & 5904 \\
\hline Total & 265716 \\
\hline
\end{tabular}

Elaboración Propia

\section{Costo de capacitación de bloqueo Loto y seguridad industrial}

Durante la mejora se consideró los costos en capacitación de bloqueo loto, 3 kits de bloqueo loto y capacitación en SST. El costo de cada kit es de S/ 2000 y se considera 3 kits, por lo que el costo total es de S/ 6000.

En el capítulo V en la parte de alternativa de solución está el detalle de la compra del Kit, así como el detalle de las capacitaciones.

Para la capacitación de la línea se considera las siguientes personas:

- 3 mecánicos

- 2 electricistas

- 10 operarios por turno. El número de trabajo por día son 3 turnos.

- 1 jefe de producción.

- 1 coordinador de producción.

- 3 supervisores de producción.

La cantidad a capacitar es de 40 personas, por esta razón, el costo de bloqueo loto es de S/ 32000 y el costo en seguridad industrial es de S/ 112 000. Como se dijo líneas arriba el detalle de los costos de estas capacitaciones se encuentra en el capítulo $\mathrm{V}$ en la parte de alternativas de solución por lo que, aquí se ha optado por poner el costo final. El costo total de capacitación y kit de bloque loto durante el tiempo que dura la mejora es de S/ 150000. 
Líneas abajo están los costos de mantenimiento y seguridad industrial durante el tiempo que dura la mejora.

Tabla 6.6

Costos de la línea de plancha de fibrocemento con las mejoras planteadas

\begin{tabular}{lc}
\hline \multicolumn{2}{c}{ Costos de mantenimiento y seguridad de la línea con las mejoras planteadas } \\
\hline Costo de la línea & Monto en soles \\
\hline Mantenimiento programado & S/ 2609983 \\
\hline Cambio de producción (SMED) & S/ 177839 \\
\hline Mejora de cuello de botella & S/ 265716 \\
\hline Capacitación y seguridad Industrial & S/ 144000 \\
\hline Kit Loto & S/ 6000 \\
\hline
\end{tabular}

Total

S/ 3203538

Elaboración Propia

Tabla 6.7

Costos de antes y después de la mejora

Costo antes de la mejora (2017)

S/ 6611853
Costo después de la mejora

S/ 3203538
Beneficio en soles

\section{Elaboración Propia}

Se presenta un cuadro resumen en el cual se especifica el costo total de la línea antes de la mejora (2017) y después de la mejora, así como, la reducción de costos lo cual se tomará como un beneficio para Eternit. Con la mejora planteada se obtiene una reducción de costos en la línea de S/ 3408315.

Se analizó el VANE (Valor actual neto económico) en base a los escenarios planteados. El impacto en los costos en el escenario optimista seria 50\% menor, mientras que en un escenario pesimista $50 \%$ mayor. 
- Realista:

Aquí se considera el costo después de las mejoras planteadas.

S/ 3203538

- Optimista:

En un impacto optimista los costos serían 50\% menor.

S/. $3203538 \times 0,5=$ S/ 1601769

- Pesimista:

En un impacto pesimista los costos serian 50\% mayor.

S/. $3203538 \times 1,5=$ S/ 4805307

Tabla 6.8

Variable dependiente del análisis de sensibilidad

\begin{tabular}{cccc}
\hline Impacto & Realista & Optimista & Pesimista \\
\hline Costos de la línea (en soles) & S/ 3 203538 & S/ 1 601769 & S/ 4 805 307
\end{tabular}

Elaboración Propia

Además se analizó el VANE (Valor actual neto económico) y el TIRE (Tasa interna de retorno económico), obteniendo los siguientes resultados.

Tabla 6.9

Resultado del análisis

\begin{tabular}{cccc}
\hline Escenario & Realista & Optimista & Pesimista \\
\hline VANE & S/9 935 929 & S/10953 126 & S/8 918 731 \\
\hline TIRE & $205 \%$ & $226 \%$ & $185 \%$ \\
\hline
\end{tabular}

Elaboración Propia

A continuación, se verá a detalle el análisis económico de los escenarios

planteados. Para hallar el flujo económico se tomó en cuenta los siguientes cálculos: 
Tabla 6.10

Ventas de las planchas de fibrocemento

\begin{tabular}{|c|c|c|c|c|c|c|c|c|c|c|c|c|}
\hline & Enero & Febrero & Marzo & Abril & Mayo & Junio & Julio & Agosto & Setiembre & Octubre & Noviembre & Diciembre \\
\hline $\begin{array}{l}\text { Cantidad } \\
\text { de Pastas }\end{array}$ & 128491 & 129491 & 127371 & 125714 & 129721 & 133814 & 140587 & 147492 & 145848 & 141840 & 135529 & 101764 \\
\hline $\begin{array}{l}\text { Precio } \\
\text { unitario S/ }\end{array}$ & 34.32 & 34.32 & 34.32 & 34.32 & 34.32 & 34.32 & 34.32 & 34.32 & 34.32 & 34.32 & 34.32 & 34.32 \\
\hline Ventas S/ & 4409811 & 4444131 & 4371373 & 4314504 & 4452025 & 4592496 & 4824946 & 5061925 & 5005503 & 4867949 & 4651355 & 3492540 \\
\hline
\end{tabular}

Elaboración Propia

Tabla 6. 11

Costo de venta de las planchas de fibrocemento

\begin{tabular}{|c|c|c|c|c|c|c|c|c|c|c|c|c|}
\hline & Enero & Febrero & Marzo & Abril & Mayo & Junio & Julio & Agosto & Setiembre & Octubre & Noviembre & Diciembre \\
\hline $\begin{array}{l}\text { Cantidad } \\
\text { de Pastas }\end{array}$ & 128491 & 129491 & 127371 & 125714 & 129721 & 133814 & 140587 & 147492 & 145848 & 141840 & 135529 & 101764 \\
\hline $\begin{array}{l}\text { Costo } \\
\text { unitario S/ }\end{array}$ & 22 & 22 & 22 & 22 & 22 & 22 & 22 & 22 & 22 & 22 & 22 & 22 \\
\hline $\begin{array}{l}\text { Costo de } \\
\text { Venta S/ }\end{array}$ & 2826802 & 2848802 & 2802162 & 2765708 & 2853862 & 2943908 & 3092914 & 3244824 & 3208656 & 3120480 & 2981638 & 2238808 \\
\hline
\end{tabular}

Elaboración Propia 
Costos de mano de obra de la línea:

Operarios $\quad \mathrm{S} / 6,25 \mathrm{X} \quad 8$ horas X 3 turnos X 30 días X 10 Operarios = S/ 45000 hora 1 turno 1 día mes

Mecánicos $\frac{\mathrm{S} / 20}{\text { hora }} \frac{\mathrm{X} \text { horas }}{1 \text { turno }} \frac{30 \text { días X }}{\text { mes }} \frac{3 \text { turno X }}{1 \text { día }} 3$ Mecánicos $=$ S/ 43200

Electricista $\mathrm{S} / 25$ X 8 horas X 30 días X 3 turno X 2 Electricistas = S/ 36000

hora $\overline{1 \text { turno }} \overline{1 \text { mes }}$

Supervisor $\quad$ S/ $4800 \times 3$ Supervisores $=$ S/ 14400 mes

Asistente $\quad$ S/ $2500 \times 1$ Asistente $=S / 2500$

mes

Practicante S/ $1200 \times 1$ Practicante $=$ S/ 1200 mes

Coordinador S/ $5760 \times 1$ Coordinador $=$ S/ 5760 mes

Jefe de Producción

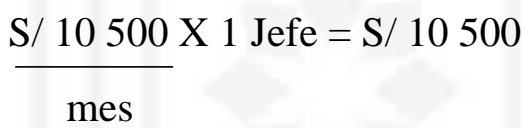

Gerente de producción S/ 15000 X 1 Gerente = S/ 15000 mes

Ingeniero de automatización S/ 4000 X 1 Ingeniero = S/ 4000 mes

El gerente de producción, jefe de producción y ingeniero de automatización están a cargo de las 5 lineas que tiene la empresa. Por esta razón, sus sueldos se van a dividir entre 5 para obtener el sueldo correspondiente a la línea de plancha. El costo de mano de obra mensual es de S/ 153 960. A esto se le suma las dos gratificaciones al año que perciben los trabajadores. 
Tabla 6.12

Costo de venta total realista

\begin{tabular}{|c|c|c|c|c|c|c|c|c|c|c|c|c|}
\hline & Enero & Febrero & Marzo & Abril & Mayo & Junio & Julio & Agosto & Setiembre & Octubre & Noviembre & Diciembre \\
\hline Costo de Venta S/ & 2826802 & 2848802 & 2802162 & 2765708 & 2853862 & 2943908 & 3092914 & 3244824 & 3208656 & 3120480 & 2981638 & 2238808 \\
\hline \multicolumn{13}{|l|}{$\begin{array}{l}\text { Costos de ventas Adicionales y } \\
\text { otros costos }\end{array}$} \\
\hline Mantenimiento Programado & 217499 & 217499 & 217499 & 217499 & 217499 & 217499 & 217499 & 217499 & 217499 & 217499 & 217499 & 217499 \\
\hline SMED & 14820 & 14820 & 14820 & 14820 & 14820 & 14820 & 14820 & 14820 & 14820 & 14820 & 14820 & 14820 \\
\hline Mejora de cuello de botella & 22143 & 22143 & 22143 & 22143 & 22143 & 22143 & 22143 & 22143 & 22143 & 22143 & 22143 & 22143 \\
\hline Capacitación & 12000 & 12000 & 12000 & 12000 & 12000 & 12000 & 12000 & 12000 & 12000 & 12000 & 12000 & 12000 \\
\hline Kit Loto & 500 & 500 & 500 & 500 & 500 & 500 & 500 & 500 & 500 & 500 & 500 & 500 \\
\hline Costo de venta total S/ & 3093764 & 3115764 & 3069124 & 3032670 & 3120824 & 3210870 & 3359876 & 3511786 & 3475618 & 3387442 & 3248600 & 2505770 \\
\hline
\end{tabular}

Elaboración Propia

Tabla 6.13

Utilidad Bruta

\begin{tabular}{|c|c|c|c|c|c|c|c|c|c|c|c|c|}
\hline & Enero & Febrero & Marzo & Abril & Мayo & Junio & Julio & Agosto & Setiembre & Octubre & Noviembre & Diciembre \\
\hline Ventas S/ & 4409811 & 4444131 & 4371373 & 4314504 & 4452025 & 4592496 & 4824946 & 5061925 & 5005503 & 4867949 & 4651355 & 3492540 \\
\hline $\begin{array}{l}\text { Costo de venta } \\
\text { total S/ }\end{array}$ & 3093764 & 3115764 & 3069124 & 3032670 & 3120824 & 3210870 & 3359876 & 3511786 & 3475618 & 3387442 & 3248600 & 2505770 \\
\hline Utilidad Bruta S/ & 1316048 & 1328368 & 1302249 & 1281835 & 1331201 & 1381627 & 1465070 & 1550140 & 1529886 & 1480507 & 1402756 & 986771 \\
\hline
\end{tabular}

Elaboración Propia

Para los costos de ventas adicionales y otros costos se ha realizado un calculo proporcional en base a su costo total del escenario. 
Tabla 6. 14

Análisis Económico en el escenario realista

\begin{tabular}{|c|c|c|c|c|c|c|c|c|c|c|c|c|c|}
\hline & Mes 0 & Enero & Febrero & Marzo & Abril & Mayo & Junio & Julio & Agosto & Setiembre & Octubre & Noviembre & Diciembre \\
\hline Ventas S/ & & 4409811 & 4444131 & 4371373 & 4314504 & 4452025 & 4592496 & 4824946 & 5061925 & 5005503 & 4867949 & 4651355 & 3492540 \\
\hline $\begin{array}{l}\text { Costo de } \\
\text { Venta total } \\
\text { S/ }\end{array}$ & & 3093764 & 3115764 & 3069124 & 3032670 & 3120824 & 3210870 & 3359876 & 3511786 & 3475618 & 3387442 & 3248600 & 2505770 \\
\hline $\begin{array}{l}\text { Utilidad } \\
\text { Bruta S/ }\end{array}$ & & 1316048 & 1328368 & 1302249 & 1281835 & 1331201 & 1381627 & 1465070 & 1550140 & 1529886 & 1480507 & 1402756 & 986771 \\
\hline U.A.I & & 1316048 & 1328368 & 1302249 & 1281835 & 1331201 & 1381627 & 1465070 & 1550140 & 1529886 & 1480507 & 1402756 & 986771 \\
\hline $\begin{array}{l}\text { Imp. Renta } \\
30 \%\end{array}$ & & 394814 & 398510 & 390675 & 384550 & 399360 & 414488 & 439521 & 465042 & 458966 & 444152 & 420827 & 296031 \\
\hline $\begin{array}{l}\text { Utilidad } \\
\text { Neta S/ }\end{array}$ & & 921233 & 929857 & 911574 & 897284 & 931841 & 967139 & 1025549 & 1085098 & 1070920 & 1036355 & 981929 & 690740 \\
\hline $\begin{array}{l}\text { Inversión } \\
\text { S/ }\end{array}$ & $(-) 449051$ & & & & & & & & & & & & \\
\hline $\begin{array}{l}\text { Flujo } \\
\text { económico } \\
\text { S/ }\end{array}$ & $(-) 449051$ & 921233 & 929857 & 911574 & 897284 & 931841 & 967139 & 1025549 & 1085098 & 1070920 & 1036355 & 981929 & 690740 \\
\hline
\end{tabular}

\begin{tabular}{ll}
\hline TASA & $20 \%$ \\
\hline VANE & S/ 9935929 \\
\hline TIRE & $205 \%$
\end{tabular}

Elaboración Propia

Como el proyecto tiene una duracion de 12 meses para el calculo del VAN se considero una tasa mensual de 1,53\% que es el resultado de pasar la tasa de $20 \%$ anual a mensual. 
Tabla 6.15

Costo de venta total optimista

\begin{tabular}{|c|c|c|c|c|c|c|c|c|c|c|c|c|}
\hline & Enero & Febrero & Marzo & Abril & Mayo & Junio & Julio & Agosto & Setiembre & Octubre & Noviembre & Diciembre \\
\hline Costo de Venta S/ & 2826802 & 2848802 & 2802162 & 2765708 & 2853862 & 2943908 & 3092914 & 3244824 & 3208656 & 3120480 & 2981638 & 2238808 \\
\hline \multicolumn{13}{|l|}{$\begin{array}{l}\text { Costos de ventas Adicionales y } \\
\text { otros costos }\end{array}$} \\
\hline Mantenimiento Programado & 108749 & 108749 & 108749 & 108749 & 108749 & 108749 & 108749 & 108749 & 108749 & 108749 & 108749 & 108749 \\
\hline SMED & 7410 & 7410 & 7410 & 7410 & 7410 & 7410 & 7410 & 7410 & 7410 & 7410 & 7410 & 7410 \\
\hline Mejora de cuello de botella & 11072 & 11072 & 11072 & 11072 & 11072 & 11072 & 11072 & 11072 & 11072 & 11072 & 11072 & 11072 \\
\hline Capacitación & 6000 & 6000 & 6000 & 6000 & 6000 & 6000 & 6000 & 6000 & 6000 & 6000 & 6000 & 6000 \\
\hline Kit Loto & 250 & 250 & 250 & 250 & 250 & 250 & 250 & 250 & 250 & 250 & 250 & 250 \\
\hline Costo de venta total S/ & 2960283 & 2960283 & 2960283 & 2960283 & 2960283 & 2960283 & 2960283 & 2960283 & 2960283 & 2960283 & 2960283 & 2960283 \\
\hline
\end{tabular}

Para los costos de ventas adicionales y otros costos se ha realizado un cálculo proporcional en base a su costo total del escenario. 
Tabla 6.16

Análisis Económico en el escenario optimista

\begin{tabular}{|c|c|c|c|c|c|c|c|c|c|c|c|c|c|}
\hline & Mes 0 & Enero & Febrero & Marzo & Abril & Mayo & Junio & Julio & Agosto & Setiembre & Octubre & Noviembre & Diciembre \\
\hline Ventas S/ & & 4409811 & 4444131 & 4371373 & 4314504 & 4452025 & 4592496 & 4824946 & 5061925 & 5005503 & 4867949 & 4651355 & 3492540 \\
\hline $\begin{array}{l}\text { Costo de } \\
\text { Venta S/ }\end{array}$ & & 2960283 & 2982283 & 2935643 & 2899189 & 2987343 & 3077389 & 3226395 & 3378305 & 3342137 & 3253961 & 3115119 & 2372289 \\
\hline $\begin{array}{l}\text { Utilidad } \\
\text { Bruta S/ }\end{array}$ & & 1449528 & 1461848 & 1435730 & 1415316 & 1464682 & 1515108 & 1598551 & 1683621 & 1663367 & 1613988 & 1536237 & 1120252 \\
\hline U.A.I & & 1449528 & 1461848 & 1435730 & 1415316 & 1464682 & 1515108 & 1598551 & 1683621 & 1663367 & 1613988 & 1536237 & 1120252 \\
\hline $\begin{array}{l}\text { Imp. } \\
\text { Renta } \\
30 \%\end{array}$ & & 434859 & 438555 & 430719 & 424595 & 439405 & 454532 & 479565 & 505086 & 499010 & 484196 & 460871 & 336076 \\
\hline $\begin{array}{l}\text { Utilidad } \\
\text { Neta S/ }\end{array}$ & & 1014670 & 1023294 & 1005011 & 990721 & 1025277 & 1060575 & 1118986 & 1178534 & 1164357 & 1129792 & 1075366 & 784176 \\
\hline $\begin{array}{l}\text { Inversión } \\
\text { S/ }\end{array}$ & $(-) 449051$ & & & & & & & & & & & & \\
\hline $\begin{array}{l}\text { Flujo } \\
\text { económico } \\
\text { S/ }\end{array}$ & $(-) 449051$ & 1014670 & 1023294 & 1005011 & 990721 & 1025277 & 1060575 & 1118986 & 1178534 & 1164357 & 1129792 & 1075366 & 784176 \\
\hline
\end{tabular}

\begin{tabular}{cc}
\hline TASA & $20 \%$ \\
\hline VANE & S/10953 126 \\
\hline TIRE & $226 \%$ \\
\hline
\end{tabular}

Elaboración Propia

Para el cálculo del VAN se considero una tasa mensual de 1,53\%, ya que el proyecto dura 12 meses. 
Tabla 6. 17

Costo de venta total pesimista

\begin{tabular}{|c|c|c|c|c|c|c|c|c|c|c|c|c|}
\hline & Enero & Febrero & Marzo & Abril & Mayo & Junio & Julio & Agosto & Setiembre & Octubre & Noviembre & Diciembre \\
\hline Costo de Venta S/ & 2826802 & 2848802 & 2802162 & 2765708 & 2853862 & 2943908 & 3092914 & 3244824 & 3208656 & 3120480 & 2981638 & 2238808 \\
\hline \multicolumn{13}{|l|}{$\begin{array}{l}\text { Costos de ventas Adicionales y } \\
\text { otros costos }\end{array}$} \\
\hline Mantenimiento Programado & 326248 & 326248 & 326248 & 326248 & 326248 & 326248 & 326248 & 326248 & 326248 & 326248 & 326248 & 326248 \\
\hline SMED & 22230 & 22230 & 22230 & 22230 & 22230 & 22230 & 22230 & 22230 & 22230 & 22230 & 22230 & 22230 \\
\hline Mejora de cuello de botella & 33215 & 33215 & 33215 & 33215 & 33215 & 33215 & 33215 & 33215 & 33215 & 33215 & 33215 & 33215 \\
\hline Capacitación & 18000 & 18000 & 18000 & 18000 & 18000 & 18000 & 18000 & 18000 & 18000 & 18000 & 18000 & 18000 \\
\hline Kit Loto & 750 & 750 & 750 & 750 & 750 & 750 & 750 & 750 & 750 & 750 & 750 & 750 \\
\hline Costo de venta total S/ & 3227244 & 3249244 & 3202604 & 3166150 & 3254304 & 3344350 & 3493356 & 3645266 & 3609098 & 3520922 & 3382080 & 2639250 \\
\hline
\end{tabular}

Para los costos de ventas adicionales y otros costos se ha realizado un cálculo proporcional en base a su costo total del escenario. 
Tabla 6.18

Análisis Económico en el escenario pesimista

\begin{tabular}{|c|c|c|c|c|c|c|c|c|c|c|c|c|c|}
\hline & Mes 0 & Enero & Febrero & Marzo & Abril & Mayo & Junio & Julio & Agosto & Setiembre & Octubre & Noviembre & Diciembre \\
\hline Ventas S/ & & 4409811 & 4444131 & 4371373 & 4314504 & 4452025 & 4592496 & 4824946 & 5061925 & 5005503 & 4867949 & 4651355 & 3492540 \\
\hline $\begin{array}{l}\text { Costo de } \\
\text { Venta S/ }\end{array}$ & & 3227244 & 3249244 & 3202604 & 3166150 & 3254304 & 3344350 & 3493356 & 3645266 & 3609098 & 3520922 & 3382080 & 2639250 \\
\hline $\begin{array}{l}\text { Utilidad } \\
\text { Bruta S/ }\end{array}$ & & 1182567 & 1194887 & 1168768 & 1148354 & 1197720 & 1248146 & 1331590 & 1416659 & 1396405 & 1347027 & 1269275 & 853290 \\
\hline U.A.I & & 1182567 & 1194887 & 1168768 & 1148354 & 1197720 & 1248146 & 1331590 & 1416659 & 1396405 & 1347027 & 1269275 & 853290 \\
\hline $\begin{array}{l}\text { Imp. } \\
\text { Renta } \\
30 \%\end{array}$ & & 354770 & 358466 & 350631 & 344506 & 359316 & 374444 & 399477 & 424998 & 418922 & 404108 & 380783 & 255987 \\
\hline $\begin{array}{l}\text { Utilidad } \\
\text { Neta S/ }\end{array}$ & & 827797 & 836421 & 818138 & 803848 & 838404 & 873702 & 932113 & 991661 & 977484 & 942919 & 888493 & 597303 \\
\hline $\begin{array}{l}\text { Inversión } \\
\text { S/ }\end{array}$ & $(-) 449051$ & & & & & & & & & & & & \\
\hline $\begin{array}{l}\text { Flujo } \\
\text { económico } \\
\text { S/ }\end{array}$ & (-)449051 & 827797 & 836421 & 818138 & 803848 & 838404 & 873702 & 932113 & 991661 & 977484 & 942919 & 888493 & 597303 \\
\hline
\end{tabular}

\begin{tabular}{cc}
\hline TASA & $20 \%$ \\
\hline VANE & S/ 8918731 \\
\hline TIRE & $185 \%$ \\
\hline
\end{tabular}

Elaboración Propia

Para el cálculo del VAN se considero una tasa mensual de 1,53\%, ya que el proyecto dura 12 meses. 


\section{Análisis económico y financiero de la propuesta}

La inversión requerida para implementar las mejoras será realizada por la empresa. No se utilizará financiamiento externo. Por esta razón, el análisis es solo económico más no financiero.

Para el análisis económico del proyecto se ha considerado una tasa de $20 \%$ fijado por la alta dirección de la empresa y un impuesto a la renta de $30 \%$, por indicación de la compañía.

Tabla 6. 19

Resultado del análisis económico realista

\begin{tabular}{cc}
\hline VANE & S/ 9935929 \\
\hline TIRE & $205 \%$ \\
\hline Elaboración Propia &
\end{tabular}

En la Tabla 6.19, el VAN (Valor actual neto) y TIR (Tasa interna de retorno) realista es de S/ 9935929 y 205\%. Tales resultados hace que el proyecto tenga impactos positivos en la empresa como para la sociedad, ya que el VAN>0 y el TIR $>1,53 \%$.

\section{Impacto de la solución propuesta}

- Impacto social

A continuación, se calculó los principales indicadores sociales que se tomó en cuenta en la mejora.

Valor Agregado:

Este indicador mide la evaluación socio económica de un proyecto. Para el cálculo de este indicador en la mejora se tomó en cuenta los sueldos y la utilidad antes de impuestos y después se calculó el VANE utilizando una tasa mensual de 1,53\% que equivale a 20 $\%$ anual el cual fue fijado por la empresa.

Con todos estos datos el valor agregado a lo largo del proyecto es de S/17 091872. Líneas abajo, se puede el observar el cálculo de este indicador. 
Tabla 6. 20

Valor agregado acumulado

\begin{tabular}{|c|c|c|c|c|c|c|c|c|c|c|c|c|}
\hline & Enero & Febrero & Marzo & Abril & Mayo & Junio & Julio & Agosto & Setiembre & Octubre & Noviembre & Diciembre \\
\hline Sueldos S/ & 179620 & 179620 & 179620 & 179620 & 179620 & 179620 & 179620 & 179620 & 179620 & 179620 & 179620 & 179620 \\
\hline U.A.I & 1316048 & 1328368 & 1302249 & 1281835 & 1331201 & 1381627 & 1465070 & 1550140 & 1529886 & 1480507 & 1402756 & 986771 \\
\hline $\begin{array}{l}\text { Valor } \\
\text { Agregado }\end{array}$ & 1495668 & 1507988 & 1481869 & 1461455 & 1510821 & 1561247 & 1644690 & 1729760 & 1709506 & 1660127 & 1582376 & 1166391 \\
\hline
\end{tabular}

Valor Agregado

S/ 16792112

Acumulado

Elaboración Propia 
- Relación producto/capital:

Este indicador mide la relación entre el valor agregado y la inversión total del proyecto.

$$
\text { Producto }- \text { Capital }=\frac{\text { Valor agregado }}{\text { Inversión Total }}
$$

Producto - Capital $=\underline{\mathrm{S} / 16792112}$

$$
\text { S/ } 449051
$$

La relación Producto - Capital es 37,39 veces la inversión.

En base al resultado, la relación de este indicador es positiva, ya que, el valor agregado es 37,39 veces más que la inversión total del proyecto.

- Intensidad de capital:

Este indicador mide la capacidad de una empresa para utilizar eficazmente sus activos.

Para la mejora, se tomó en cuenta la relación de la inversión total del proyecto versus el valor agregado del proyecto.

$$
\begin{aligned}
& \text { Intensidad de Capital }=\frac{\text { Inversión Total }}{\text { Valor agregado }} \\
& \text { Intensidad de Capital }=\frac{\mathrm{S} / 449051}{\mathrm{~S} / 16792112}
\end{aligned}
$$

La intensidad de capital es 0,02 . Este resultado indica que se invierte menos y se obtiene mayor valor agregado.

- Densidad de capital:

Este indicador se utiliza para estimar la inversión necesaria para crear un puesto de trabajo. En la mejora se tomó en cuenta 6 puestos de trabajo (1 supervisor, 4 analistas, 1 practicante).

Densidad de Capital $=\frac{\text { Inversión Total }}{\mathrm{N}^{\circ} \text { de empleos }}$ 
Densidad de Capital $=\quad \mathrm{S} / 449051$

Densidad de capital $=$ S/ 74841

El resultado obtenido indica que se ha invertido S/ 74841 por cada empleo generado en el proyecto.

- Impacto ambiental

En base al análisis de la matriz de Leopold, que se muestra líneas abajo se puede afirmar que el proyecto de mejora propuesto en la línea no tiene impacto significativo en las características del agua, aire, suelo y en lo que respecta a la salud del trabajador. Además no afecta la flora y fauna del medio ambiente donde se encuentra la planta. Sin embargo, tiene un efecto importante en los factores culturales como empleo y educación, que genera una mejor calidad de vida y educación profesional. 
Figura 6. 1

Matriz Leopold

\begin{tabular}{|c|c|c|c|c|c|c|c|c|}
\hline \multirow{3}{*}{\multicolumn{2}{|c|}{$\begin{array}{l}\text { Componentes ambientales } \\
\text { (Factores ambientales) }\end{array}$}} & \multirow{2}{*}{\multicolumn{7}{|c|}{$\begin{array}{c}\text { Mejora en la línea de planchas de fibrocemento de la Fabrica Peruana Eternit S.A: Realizar plan de } \\
\text { mantenimiento preventivo,planificar y priorizar los trabajos de mantenimiento preventivo, implementar } \\
5 \text { S elaborar control estadístico, asignar zona de producto sustráído de los mantenimientos, fabricación de } \\
\text { canaletas, creación de una matriz de clasificación de condiciones inseguras, capacitaciones, implementación de } \\
\text { OEE y aplicación de SMED. } \\
\text { Ospectos generales del proyecto }\end{array}$}} \\
\hline & & & & & & & & \\
\hline & & \multirow{2}{*}{$\begin{array}{c}\begin{array}{c}\text { Limpieza de } \\
\text { equipos }\end{array} \\
\end{array}$} & \multirow[t]{2}{*}{ Ruido } & \multirow[t]{2}{*}{$\begin{array}{c}\text { Agua } \\
\text { Residual } \\
\text { Industrial } \\
\end{array}$} & \multirow[t]{2}{*}{ Accidentes } & \multirow[t]{2}{*}{$\begin{array}{l}\text { Residuos } \\
\text { Sólidos }\end{array}$} & \multirow[t]{2}{*}{ Capacitaciones } & Total Magnitud \\
\hline 1 & Aire & & & & & & & -1 \\
\hline 2 & Suelo & -1 & & $-2>$ & & -2 & & -5 \\
\hline 3 & Agua & -1 & & -1 & & & & -2 \\
\hline \multirow{2}{*}{4} & Flora & & & & & & & \\
\hline & Fauna & & & & & & & \\
\hline \multirow{5}{*}{5} & Salud trabajador & & & -1 & -2 & -1 & 3 & -2 \\
\hline & Educación y cultura & & & & 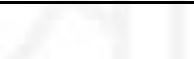 & & 2 & 2 \\
\hline & Vivienda & & & & & & & \\
\hline & Alimentación & & & & & & & \\
\hline & Empleo & & & & -1 & & 4 & 3 \\
\hline
\end{tabular}

Total de importancia

4

2

5

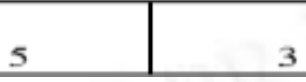

Elaboración Propia 


\section{CONCLUSIONES}

- Con el uso de las herramientas de ingeniería industrial se mejoró el proceso productivo de la línea de planchas de fibrocemento tales como: diagrama de Ishikawa, Pareto, SMED, 5 S' Y OEE obteniendo resultados positivos en la reducción de costos.

- A través de la implementación de las $5 \mathrm{~S}^{\prime}$ y de un correcto mantenimiento programado se logró disminuir las horas de mantenimiento a 8 horas.

- Mediante la implementación de las 5S', un programa de limpieza y fabricación de una canaleta de recuperación de material se logró mejorar el rendimiento de materia prima.

- Mediante capacitaciones en seguridad industrial, elaboración de matriz IPERC y procedimientos contra todo tipo de emergencia se logró reducir los incidentes de la línea de plancha de fibrocemento ya que uno de los objetivos es que no se presente ningún accidente.

- Mediante un correcto mantenimiento programado, adecuada limpieza, buen rendimiento de materia prima, reducción en las horas de cambios de producción se logró mejorar la productividad de la línea de plancha de fibrocemento.

- Después de la mejora el costo de mantenimiento de la línea fue de S/3 203538 , así mismo; se analizó el valor actual neto económico cuyo resultado fue S/ 9935 929 y un tasa interna de retorno económico de $205 \%$. 


\section{RECOMENDACIONES}

- El personal de la línea no mantiene limpia y ordenada su zona de trabajo, las herramientas están todas desordenadas y sin rotular, hay cosas en desuso que aún se mantienen en la línea, por lo que se recomienda que si se desea que las 5’S sean sostenibles en el tiempo, el personal debe saber con exactitud que son las 5’S, para que sirven y cuáles son los beneficios que se esperan obtener. El operador como parte de sus funciones diarias, al terminar su turno deberá dejar limpio y ordenado su zona de trabajo, se debe adquirir armarios amplios y con subdivisiones para que los operarios puedan guardar sus herramientas y se debe ubicar una zona para trasladar las cosas en desuso que se encuentran en la línea. Cabe mencionar que una de las variables claves son los jefes y supervisores de la línea y el compromiso que tienen en cuanto a las $5^{`} \mathrm{~S}$, ya que, si el personal que tienen a su cargo, que son los operarios, no ven que ellos están comprometidos con las 5’S y no los motivan a mantener la línea, ordena y limpia, entonces lo que se pudo lograr en un inicio con la implementación de las 5’S se perderá.

- Con el SMED se logra reducir los tiempos que toman los cambios de producción pero siempre se tiene que apuntar a reducir cada vez más el tiempo del cambio de producción anterior.

- Todos los días en las mañanas se debe tener una reunión, donde asistan los responsables del área de mantenimiento y de producción, para analizar y encontrar las causas raíces de las paradas no programadas del día anterior, proponiendo acciones para que no vuelvan a ocurrir.

- Se recomienda publicar los indicadores más relevantes de la línea de cada turno (Eficiencia de máquina consumida, eficiencia de máquina efectiva, rendimiento de materia prima, porcentaje de paradas, porcentaje de rechazo, índice de frecuencia, índice de gravedad) para que el personal operario tenga conocimiento de cómo terminó su turno y de esta manera este más comprometido con los objetivos de la línea.

- Las capacitaciones en cuanto a temas de seguridad deben de ser constantes para que de esta manera el personal sienta que la empresa se preocupa por la seguridad.

- No se puede mejorar lo que no se puede medir. Se tiene que llevar un control de las variables de los procesos para poder detectar cualquier desviación, 
encontrando la causa raíz y presentando planes de acción para corregir estas desviaciones.

- Se debe incluir dentro de las funciones de los supervisores, proponer e implementar mejoras en la línea. 


\section{REFERENCIAS}

Bonilla, E.; Diaz, B.; Kleeberg, F.; Noriega, M. (2014). Mejora continua de los procesos: herramientas y técnicas. Lima: Universidad de Lima, Fondo Editorial.

Cabrejos, D. y Mejia, K. (2013). Mejora de la Productividad en el área de Confecciones de la empresa Best Group Textil S.A.C mediante la aplicación de la metodología PHVA. Tesis para Obtener el título de Ingeniería Industrial. Recuperado el 18 de Setiembre de 2017, de http://www.usmp.edu.pe/PFII/pdf/20131_3.pdf

Cámara Peruana de la Construcción. (20 de Marzo de 2019). Recuperado de https://www.capeco.org/

El diario de Economía y Negocios del Perú. (Octubre de 01 de 2017). INEI: Construcción sigue en racha positiva y logra su crecimiento más alto en agosto. Recuperado de https://gestion.pe/economia/inei-construccion-sigue-racha-positiva-y-logra-sucrecimiento-mas-alto-agosto-2201296

Eternit. (01 de Abril de 2019). Recuperado de https://www.eternit.com.pe/eses/productos/todos-productos\#Productos

Eternit Construimos Confianza. (18 de Diciembre de 2017). Recuperado de http://www.eternit.com.pe/es-es/sobre-nosotros

Jaca García, M. C. y Santos García, J. (2009). La mejora continua en las organizaciones. Análisis de su implantación en 30 empresas. DYNA, 134-141.

Mejía Carrera. (Setiembre de 2013). Análisis y propuesta de mejora del proceso productivo de una línea de confecciones de ropa interior en una empresa textil mediante el uso de herramientas de manufactura esbelta. Tesis para optar el Título de Ingeniero Industrial. Lima, Perú. Recuperado el 18 de Setiembre de 2017, de http://tesis.pucp.edu.pe/repositorio/bitstream/handle/123456789/4922/MEJIA_S AMIR_ANALISIS_MEJORA_PROCESO_CONFECCIONES_ROPA.pdf

Pastor, E. (2010). Mejora Continua de los procesos: herramientas y técnicas. Lima: Universidad de Lima.

PBI de Construcción. (01 de Abril de 2019). Recuperado de http://www3.vivienda.gob.pe/Destacados/estadistica/62_PBICONSTRUCCION.pdf. 


\section{BIBLIOGRAFIA}

Frey Morote, Juan Carlos y Vela Ruiz, Jessica Paola. (09 de 05 de 2016). Relevancia del proceso de abastecimiento en empresas grandes del sector construcción : estudio de caso comparado entre empresas familiares peruanas. Pontificia Universidad Católica del Perú. Lima, Perú. Recuperado el 2017, de http://tesis.pucp.edu.pe/repositorio/handle/123456789/6847

García, A. (2013). Estrategias empresariales: Una visión holística. Bilineata Publishing.

Hansen, R. (2001). Overall Equipment Effectiveness: A Powerful Production/maintenance Tool for Increased Profits. Industrial Press Inc.

Méndez, M. (2003). El proceso de cambio de útiles. FC Editorial.

Porter, M. (2017). Ser competitivo: Edición actualizada y aumentada. Grupo Planeta.

Zacarias, H. (2014). Administración Estratégica. Grupo Patria. 
ANEXOS 


\section{Anexo 1:Organigrama}

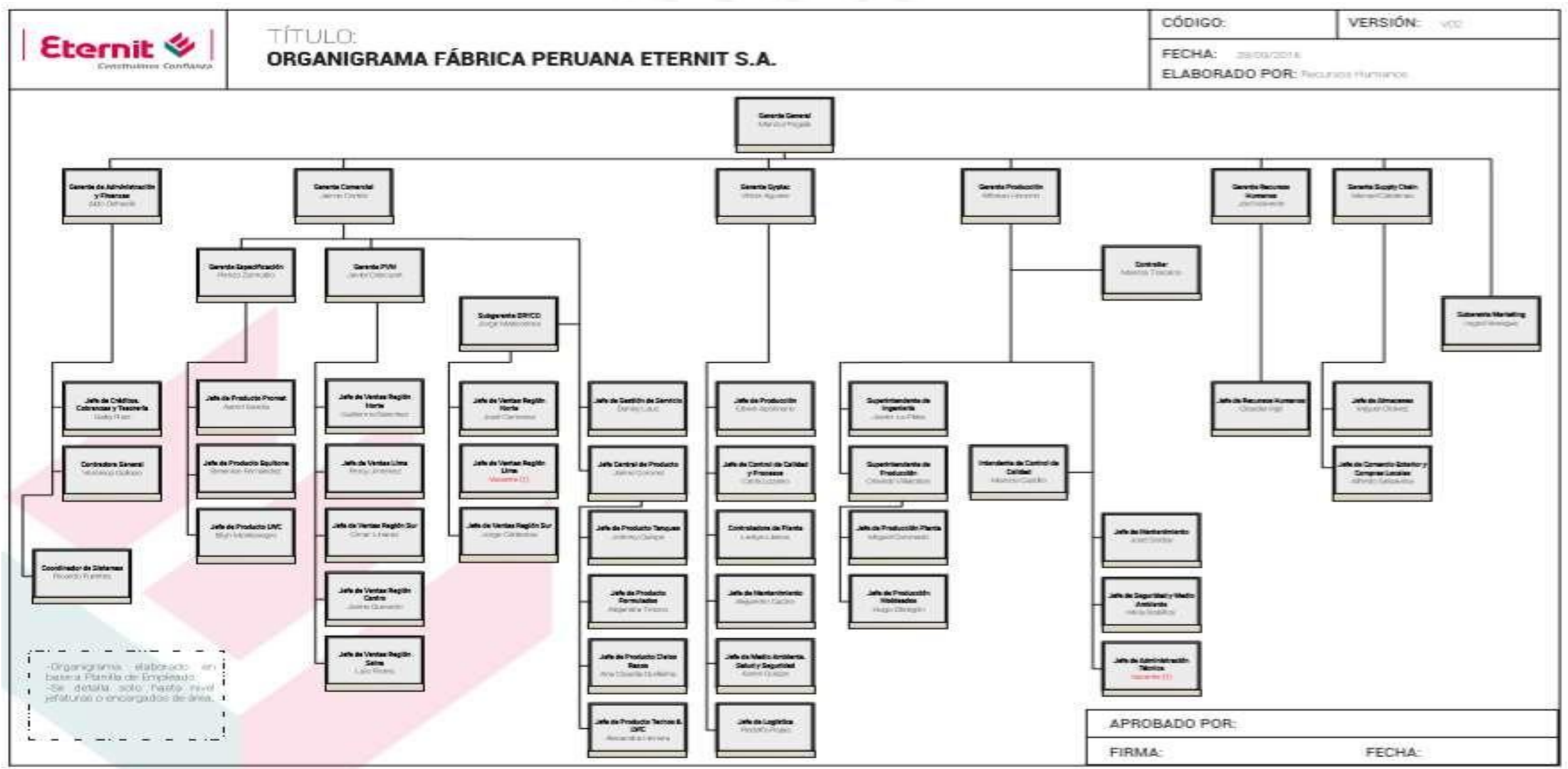

Fuente: Fabrica Peruana Eternit (2018) 


\section{Anexo 2:Plano general de la Fabrica Peruana Eternit S.A}

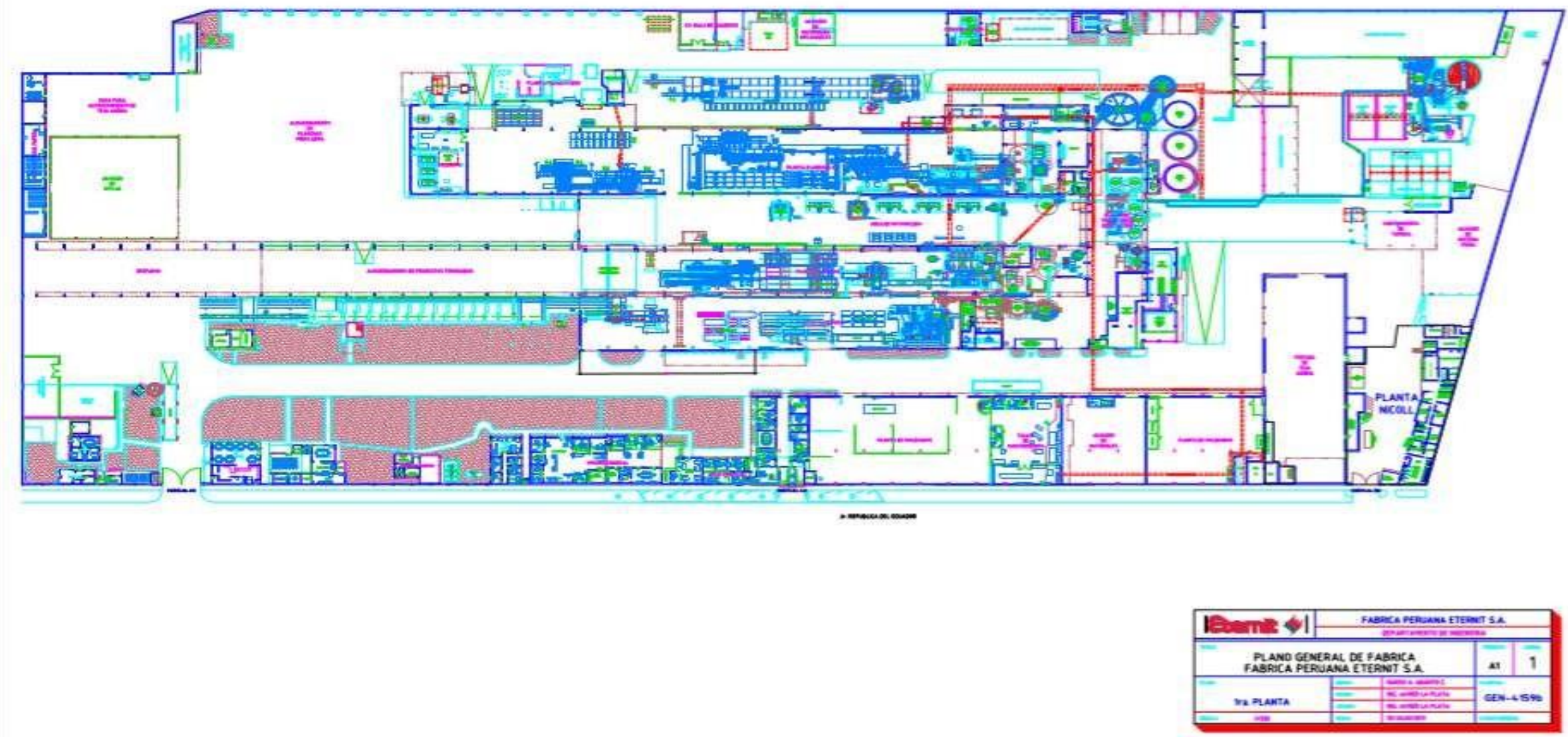

Fuente: Fabrica Peruana Eternit (2018) 


\section{Anexo 3:Determinación del tiempo estándar de las actividades de mantenimiento programado}

\begin{tabular}{|c|c|}
\hline $\begin{array}{l}\mathrm{N}^{\circ} \text { de } \\
\text { elementos }\end{array}$ & Elementos \\
\hline E1 & Limpieza de Cisterna Principal \\
\hline E2 & Limpieza de Línea de Agua de Arrastre \\
\hline E3 & Limpieza de Línea de recuperación de 6' \\
\hline E4 & Limpieza de Mezclador \\
\hline E5 & Limpieza de canaletas de rebose de bateas + Caja rebose \\
\hline E6 & Limpieza de Premixer + Timones reguladores de alimentación a bateas \\
\hline E7 & Limpieza de Selectifier + Caja de desconche \\
\hline E8 & Limpieza de Canaletas de alimentación a bateas \\
\hline E9 & Limpieza de Kanaflex’s de succión de vacíos \\
\hline E10 & Limpieza de Bateas 1, 2 y 3 \\
\hline E11 & Limpieza de Mesas de lavado y secado de Fieltro \\
\hline E12 & Limpieza de Mesas principales de vacío \\
\hline E13 & Limpieza de Mesas tubulares de fijación \\
\hline E14 & Limpieza de Desintegrador de recortes \\
\hline E15 & $\begin{array}{l}\text { Limpieza de Línea "Y" y Codo adyacente al desintegrador de pasta+ caída a cisterna } \\
\text { principal }\end{array}$ \\
\hline E16 & Limpieza de Línea de subida a torre de enfriamiento \\
\hline E17 & Limpieza de poza de agua de sello \\
\hline E18 & Lubricación de la caja de rodamientos de la bomba de descarga de mezclador \\
\hline E19 & Lubricar de los rodamientos del motor de la bomba de descarga de la cisterna principal \\
\hline E20 & Mantenimiento de los ejes de los agitadores de la hatschek \\
\hline E21 & Mantenimiento de los orientadores de la hatschek \\
\hline E22 & Lubricación de chumaceras de los rolos prensapastas \\
\hline E23 & Lubricación de chumaceras de los tamices \\
\hline E24 & Lubricación de chumaceras del rolo templador de fieltro \\
\hline E25 & Lubricar los rodamientos del motor de la bomba del sistema de traslación de la onduladora \\
\hline E26 & Lubricar los rodamientos del motor del agitador del mezclador \\
\hline E27 & Lubricación de chumaceras de los rodillos de las fajas transportadoras \\
\hline E28 & Mantenimiento a los tableros eléctricos \\
\hline E29 & Limpieza de Cono \\
\hline E30 & Limpieza de Poza de recuperación \\
\hline E31 & Limpieza de Canaletas alrededor de máquina \\
\hline E32 & Limpieza de Línea de recuperación de 8' \\
\hline E33 & Limpieza de Línea de bajada a torre de enfriamiento \\
\hline E34 & Limpieza de Línea de fluidores alrededor de máquina \\
\hline E35 & Limpieza de Línea de Cisterna principal a Desintegrador de recortes \\
\hline
\end{tabular}

(continúa) 
(continuación)

\begin{tabular}{|c|c|c|c|c|c|c|c|c|c|c|c|c|c|c|c|}
\hline & \multicolumn{10}{|c|}{$\mathrm{N}^{\circ}$ de observaciones (Segundos) } & & & & \multicolumn{2}{|c|}{ Rango $(+20 \%)$} \\
\hline $\begin{array}{l}N^{\circ} \text { de } \\
\text { elementos }\end{array}$ & 1 & 2 & 3 & 4 & 5 & 6 & 7 & 8 & 9 & 10 & Promedio & $\begin{array}{l}\text { Desv. } \\
\text { Estandar }\end{array}$ & $\begin{array}{c}\mathbf{N}^{\circ} \\
\text { Muestras }\end{array}$ & Min & Max \\
\hline E1 & 617 & 620 & 610 & 615 & 820 & 816 & 819 & 606 & 608 & 609 & 674 & 99,70 & 7 & 539 & 809 \\
\hline E2 & 690 & 681 & 917 & 655 & 670 & 664 & 680 & 670 & 900 & 680 & 721 & 99,55 & 6 & 577 & 865 \\
\hline E3 & 690 & 688 & 677 & 940 & 694 & 927 & 690 & 958 & 674 & 682 & 762 & 124,35 & 9 & 610 & 914 \\
\hline E4 & 501 & 505 & 693 & 748 & 493 & 847 & 503 & 483 & 480 & 488 & 574 & 135,47 & 19 & 459 & 689 \\
\hline E5 & 543 & 548 & 783 & 530 & 540 & 772 & 535 & 738 & 555 & 545 & 609 & 108,04 & 11 & 487 & 731 \\
\hline E6 & 493 & 490 & 510 & 500 & $\begin{array}{l}499 \\
585\end{array}$ & 485 & 480 & 500 & 493 & 490 & 494 & 8,59 & $\mathrm{O}$ & 395 & 593 \\
\hline E7 & 377 & 388 & 593 & 601 & 585 & 378 & 390 & 388 & 395 & 385 & 448 & 100,27 & 17 & 358 & 538 \\
\hline E8 & $\begin{array}{l}335 \\
775\end{array}$ & 340 & 339 & 345 & 329 & 347 & 333 & 341 & 336 & 330 & 338 & 6,00 & $\mathrm{O}$ & 270 & 405 \\
\hline E9 & $\frac{745}{503}$ & $\frac{1002}{500}$ & 740 & 728 & 1010 & 734 & 750 & 999 & 745 & 740 & 819 & 127,40 & 8 & 655 & 983 \\
\hline E10 & $\frac{503}{580}$ & $\frac{500}{550}$ & 690 & 500 & 700 & 510 & 500 & 699 & 482 & $\frac{490}{502}$ & 557 & 96,20 & 10 & 446 & \\
\hline E11 & 580 & $\frac{550}{589}$ & $\frac{600}{583}$ & $\begin{array}{l}570 \\
783\end{array}$ & $\frac{806}{507}$ & $\frac{555}{589}$ & 610 & 768 & 581 & $\frac{593}{580}$ & 621 & 89,73 & 7 & 497 & 746 \\
\hline $\begin{array}{l}\text { E12 } \\
\text { E13 }\end{array}$ & $\frac{600}{600}$ & $\frac{589}{600}$ & $\frac{583}{630}$ & 783 & $\frac{592}{645}$ & 589 & 804 & 591 & 799 & 582 & 651 & $\frac{99,72}{22,42}$ & 8 & 521 & 781 \\
\hline$\frac{\mathrm{E}}{\mathrm{E} 13}$ & $\frac{600}{800}$ & $\frac{600}{800}$ & $\frac{630}{750}$ & $\frac{610}{750}$ & $\frac{645}{750}$ & $\frac{649}{750}$ & $\frac{600}{800}$ & 600 & 650 & $\frac{600}{800}$ & $\frac{618}{780}$ & $\frac{22,46}{2582}$ & 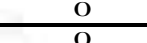 & $\frac{495}{624}$ & 742 \\
\hline E15 & 190 & $\frac{800}{210}$ & 200 & 300 & $\frac{750}{240}$ & $\frac{750}{188}$ & $\frac{800}{305}$ & $\frac{800}{190}$ & $\frac{800}{240}$ & $\frac{800}{200}$ & $\frac{780}{226}$ & $\frac{25,82}{44,41}$ & $\frac{0}{13}$ & $\frac{624}{181}$ & $\frac{936}{272}$ \\
\hline E16 & 480 & 470 & 460 & 683 & 488 & 700 & 695 & 468 & 479 & 500 & 542 & 104,42 & 12 & 434 & 651 \\
\hline E17 & 730 & 1060 & 749 & 1081 & 1090 & 725 & 738 & 1085 & 750 & 739 & 875 & 176,16 & 14 & 700 & 1050 \\
\hline E18 & 366 & 551 & 359 & 582 & 392 & 560 & 573 & 388 & 385 & 390 & 455 & 97,19 & 15 & 364 & 546 \\
\hline E19 & 348 & 488 & 345 & 500 & 338 & 348 & 494 & 336 & 335 & 330 & 386 & 74,66 & 13 & 309 & 463 \\
\hline E2O & 3500 & 2500 & 3472 & 2500 & 2300 & 3508 & 2000 & 3400 & 2500 & 2200 & 2788 & 607,49 & 16 & 2230 & 3346 \\
\hline E21 & 2200 & 2400 & 3063 & 3055 & 2371 & 3070 & 2200 & 2251 & 2350 & 2400 & 2536 & 370,90 & 7 & 2029 & 3043 \\
\hline E22 & 410 & 568 & 413 & 572 & 414 & 592 & 449 & 421 & 401 & 410 & 465 & 78,76 & 10 & 372 & 558 \\
\hline E23 & 401 & 420 & 415 & 555 & 400 & 420 & 590 & 418 & 583 & 410 & 461 & 80,01 & 10 & 369 & 553 \\
\hline E24 & 211 & 207 & 310 & 210 & 219 & 320 & 220 & 220 & 330 & 220 & 247 & 51,01 & 14 & 197 & 296 \\
\hline E25 & 599 & 581 & 850 & 591 & 800 & 583 & 596 & 810 & 550 & 591 & 655 & 115,26 & 10 & 524 & 786 \\
\hline E26 & 244 & 243 & 293 & 220 & 272 & 340 & 245 & 340 & 250 & 250 & 270 & 41,72 & 8 & 216 & 324 \\
\hline E27 & 1500 & 1500 & 1980 & 1500 & 1979 & 1500 & 1200 & 1980 & 1983 & 1250 & 1637 & 314,08 & 12 & 1310 & 1965 \\
\hline E28 & 2600 & 2600 & 3598 & 2600 & 3600 & 2600 & 3650 & 2600 & 2600 & 2600 & 2905 & 490,97 & 10 & 2324 & 3486 \\
\hline E29 & 700 & 700 & 700 & 929 & 700 & 930 & 700 & 925 & 700 & 700 & 768 & 110,14 & 7 & 615 & 922 \\
\hline E30 & 789 & 1100 & 780 & 1080 & 791 & 790 & 1088 & 800 & 799 & 790 & 881 & 144,15 & 9 & 705 & 1057 \\
\hline E31 & 300 & 400 & 250 & 410 & 300 & 399 & 259 & 300 & 220 & 260 & 310 & 69,22 & 17 & 248 & 372 \\
\hline E32 & 833 & 845 & 620 & 859 & 620 & 619 & 625 & 629 & 635 & 630 & 692 & 106,68 & 8 & 553 & 830 \\
\hline E33 & 519 & 528 & 530 & 550 & 721 & 542 & 700 & 527 & 530 & 530 & 568 & 75,90 & 6 & 454 & 681 \\
\hline E34 & 450 & 450 & 620 & 489 & 450 & 610 & 423 & 481 & 611 & 444 & 503 & 78,73 & -2 & 402 & 603 \\
\hline E35 & 500 & 480 & 635 & 470 & 462 & 633 & 450 & 450 & 450 & 620 & 515 & 80,49 & 8 & 412 & 618 \\
\hline
\end{tabular}

(continúa) 
(continuación)

\begin{tabular}{|c|c|c|c|c|c|c|c|c|c|c|c|c|c|c|c|c|c|}
\hline \multicolumn{18}{|c|}{$\mathrm{N}^{\circ}$ de observaciones (Segundos) } \\
\hline $\begin{array}{c}\mathrm{N}^{\circ} \mathrm{de} \\
\text { elementos }\end{array}$ & 1 & 2 & 3 & 4 & 5 & 6 & 7 & 8 & 9 & 10 & Promedio & Valorizacion & $\begin{array}{l}\text { Tiempo } \\
\text { normal }\end{array}$ & Suplementos & Frecuencia & $\begin{array}{c}\text { Tiempo } \\
\text { estandar en } \\
\text { sg } \\
\end{array}$ & $\begin{array}{c}\text { Tiempo } \\
\text { estandar } \\
\text { en hr. } \\
\end{array}$ \\
\hline E1 & 617 & 620 & 610 & 615 & & & & 606 & 608 & 609 & 476 & 1,1 & 524 & $17 \%$ & 15 & 9191 & 2,6 \\
\hline$\overline{E 2}$ & 690 & 681 & & 655 & 670 & 664 & 680 & 670 & & 680 & 539 & 1,2 & 647 & $17 \%$ & 15 & 11351 & 3,2 \\
\hline E3 & 690 & 688 & 677 & & 694 & & 690 & & 674 & 682 & 533 & 1,1 & 586 & $17 \%$ & 15 & 10285 & 2,9 \\
\hline E4 & 501 & 505 & & & 493 & & 503 & 483 & 480 & 488 & 493 & 1,1 & 543 & $17 \%$ & 15 & 9523 & 2,6 \\
\hline E5 & 543 & 548 & & 530 & 540 & & 535 & & 555 & 545 & 542 & 1,1 & 597 & $17 \%$ & 7 & 4885 & 1,4 \\
\hline E6 & 493 & 490 & 510 & 500 & 499 & 485 & 480 & 500 & 493 & 490 & 494 & 1,2 & 593 & $17 \%$ & 7 & 4855 & 1,3 \\
\hline E7 & 377 & 388 & & & & 378 & 390 & 388 & 395 & 385 & 386 & 1,2 & 463 & $17 \%$ & 7 & 3792 & 1,1 \\
\hline E8 & 335 & 340 & 339 & 345 & 329 & 347 & 333 & 341 & 336 & 330 & 338 & 1,1 & 371 & $17 \%$ & 7 & 3041 & 0,8 \\
\hline E9 & 745 & & 740 & 728 & & 734 & 750 & & 745 & 740 & 740 & 1,1 & 814 & $17 \%$ & 7 & 6669 & 1,9 \\
\hline E10 & 503 & 500 & & 500 & & 510 & 500 & & 482 & 490 & 498 & 1,1 & 548 & $17 \%$ & 7 & 4485 & 1,2 \\
\hline$\overline{E 11}$ & 580 & 550 & 600 & 570 & & 555 & 610 & & 581 & 593 & 580 & 1,1 & 638 & $17 \%$ & 7 & 5224 & 1,5 \\
\hline$\overline{E 12}$ & 600 & 589 & 583 & & 592 & 589 & & 591 & & 582 & 589 & 1,1 & 648 & $17 \%$ & 7 & 5310 & 1,5 \\
\hline E13 & 600 & 600 & 630 & 610 & 645 & 649 & 600 & 600 & 650 & 600 & 618 & 1,1 & 680 & $17 \%$ & 7 & 5571 & 1,5 \\
\hline E14 & 800 & 800 & 750 & 750 & 750 & 750 & 800 & 800 & 800 & 800 & 780 & 1,1 & 858 & $17 \%$ & 15 & 15058 & 4,2 \\
\hline E15 & 190 & 210 & 200 & & 240 & 188 & & 190 & 240 & 200 & 207 & 1,1 & 228 & $17 \%$ & 15 & 4001 & 1,1 \\
\hline E16 & 480 & 470 & 460 & & 488 & & & 468 & 479 & 500 & 478 & 1,1 & 526 & $17 \%$ & 15 & 9225 & 2,6 \\
\hline E17 & 730 & & 749 & & & 725 & 738 & & 750 & 739 & 739 & 1,1 & 812 & $17 \%$ & 15 & 14257 & 4,0 \\
\hline E18 & 366 & & 359 & & 392 & & & 388 & 385 & 390 & 380 & 1,1 & 418 & $17 \%$ & 7 & 3423 & 1,0 \\
\hline E19 & 348 & & 345 & & 338 & 348 & & 336 & 335 & 330 & 340 & 1,1 & 374 & $17 \%$ & 7 & 3063 & 0,9 \\
\hline$\overline{E 20}$ & & 2500 & & 2500 & 2300 & & 2000 & & 2500 & 2200 & 2333 & 1,1 & 2567 & $17 \%$ & 7 & 21021 & 5,8 \\
\hline $\bar{E} 21$ & 2200 & 2400 & & & 2371 & & 2200 & 2251 & 2350 & 2400 & 2310 & 1,1 & 2541 & $17 \%$ & 7 & 20813 & 5,8 \\
\hline E22 & 410 & & 413 & & 414 & & 449 & 421 & 401 & 410 & 417 & 1,1 & 459 & $17 \%$ & 7 & 3755 & 1,0 \\
\hline$\overline{E 23}$ & 401 & 420 & 415 & & 400 & 420 & & 418 & & 410 & 412 & 1,1 & 453 & $17 \%$ & 7 & 3712 & 1,0 \\
\hline$\overline{E 24}$ & 211 & 207 & & 210 & 219 & & 220 & 220 & & 220 & 215 & 1,1 & 237 & $17 \%$ & 7 & 1940 & 0,5 \\
\hline $\bar{E} 25$ & 599 & 581 & & 591 & & 583 & 596 & & 550 & 591 & 584 & 1,1 & 643 & $17 \%$ & 7 & 5265 & 1,5 \\
\hline E26 & 244 & 243 & 293 & 220 & 272 & & 245 & & 250 & 250 & 252 & 1,1 & 277 & $17 \%$ & 7 & 2271 & 0,6 \\
\hline$\overline{E 27}$ & 1500 & 1500 & & 1500 & & 1500 & 1200 & & & 1250 & 1408 & 1,1 & 1549 & $17 \%$ & 7 & 12688 & 3,5 \\
\hline $\bar{E} 28$ & 2600 & 2600 & & 2600 & & 2600 & & 2600 & 2600 & 2600 & 2600 & 1,1 & 2860 & $17 \%$ & 7 & 23423 & 6,5 \\
\hline $\bar{E} 29$ & 700 & 700 & 700 & & 700 & & 700 & & 700 & 700 & 700 & 1,1 & 770 & $17 \%$ & 15 & 13514 & 3,8 \\
\hline$\overline{E 30}$ & 789 & & 780 & & 791 & 790 & & 800 & 799 & 790 & 791 & 1,1 & 870 & $17 \%$ & 15 & 15276 & 4,2 \\
\hline $\bar{E} 31$ & 300 & & 250 & & 300 & & 259 & 300 & 220 & 260 & 270 & 1,1 & 297 & $17 \%$ & 15 & 5210 & 1,4 \\
\hline E32 & & & 620 & & 620 & 619 & 625 & 629 & 635 & 630 & 625 & 1,1 & 688 & $17 \%$ & 15 & 12074 & 3,4 \\
\hline E33 & 519 & 528 & 530 & 550 & & 542 & & 527 & 530 & 530 & 532 & 1,1 & 585 & $17 \%$ & 15 & 10270 & 2,9 \\
\hline E34 & 450 & 450 & & 489 & 450 & & 423 & 481 & & 444 & 455 & 1,3 & 592 & $17 \%$ & 15 & 10387 & 2,9 \\
\hline E35 & 500 & 480 & & 470 & 462 & & 450 & 450 & 450 & & 466 & 1,3 & 606 & $17 \%$ & 15 & 10632 & 3,0 \\
\hline
\end{tabular}

Elaboración Propia 
Para los cálculos del anexo 3 se consideró las siguientes variables:

\begin{tabular}{|l|c|}
\hline \multicolumn{2}{|c|}{ Variables } \\
\hline Nivel de confianza & $90 \%$ \\
\hline Error & $10 \%$ \\
\hline & \\
Tamaño de la muestra & 10 \\
\hline Ajuste & $20 \%$ \\
\hline 1 - alfa $(\infty)$ & 0,9 \\
\hline Alfa & 0,1 \\
\hline $\mathrm{T}$ & 1,833 \\
\hline
\end{tabular}

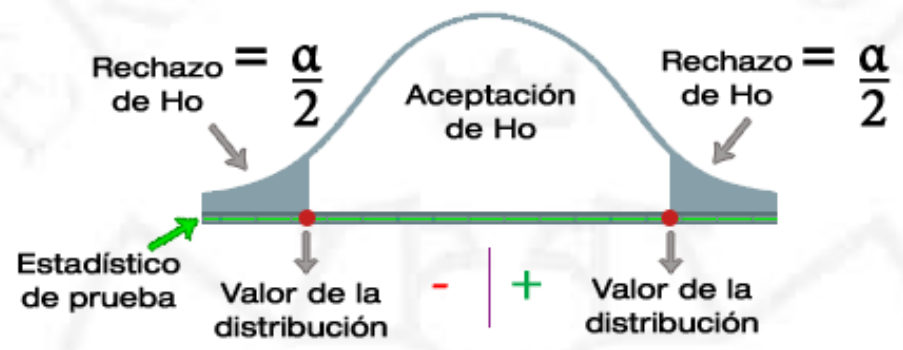

Para el cálculo del $\mathrm{N}^{\circ}$ de muestras se utilizó la siguiente fórmula para $\mathrm{N}^{\circ}<30$

$$
N=\frac{t_{\left(\frac{\alpha}{2}, n-1\right)}^{2} * S^{2}}{E_{r}^{2} * \bar{X}^{2}}
$$




\section{Anexo 4: Check list de condiciones insegura}

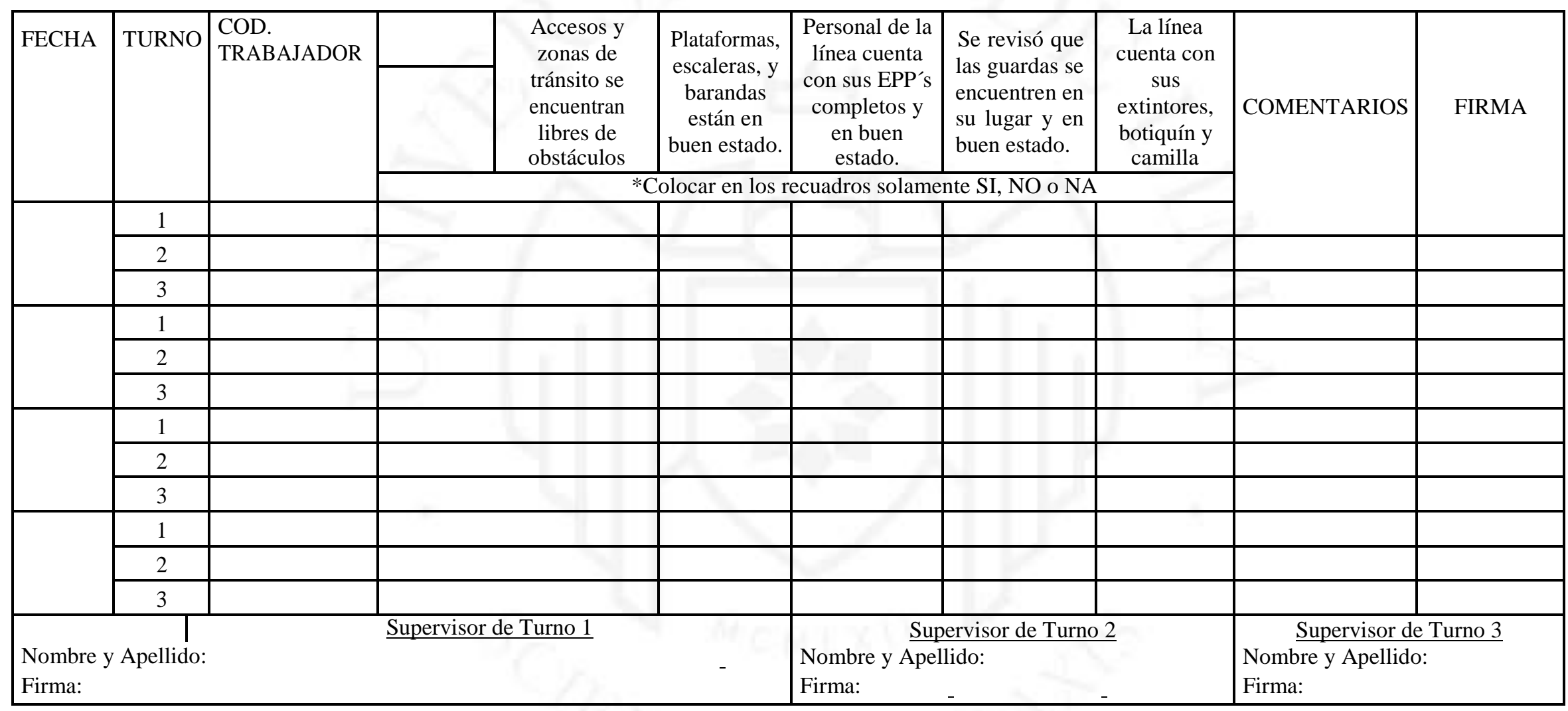

Elaboración Propia 


\section{Anexo 5: Criterios de evaluación para la clasificación de condiciones inseguras por prioridad}

\section{GRAVEDAD}

\begin{tabular}{|l|l|l|l|l|}
\hline INDICE & \multicolumn{1}{|c|}{ DAÑO PERSONAL } & $\begin{array}{l}\text { DAÑO A LA } \\
\text { PROPIEDAD }\end{array}$ & IMPACTO AMBIENTAL & \multicolumn{1}{|c|}{ CRITERIOS } \\
\hline 40 & $\begin{array}{l}\text { Accidente que resulta en la } \\
\text { muerte }\end{array}$ & $>1000.000$ & Impacto externo mayor & Fatalidad \\
\hline 15 & $\begin{array}{l}\text { Accidente con lesión muy } \\
\text { seria }\end{array}$ & $>250.000$ & $\begin{array}{l}\text { impacto fuera del sitio / } \\
\text { instalación }\end{array}$ & $\begin{array}{l}\text { Accidente que genera una } \\
\text { incapacidad permanente }\end{array}$ \\
\hline 7 & Accidente con lesión seria & $>50.000$ & $\begin{array}{l}\text { Gran impacto en en el sitio / } \\
\text { instalación }\end{array}$ & $\begin{array}{l}\text { Accidente que genera mayor a } 3 \\
\text { días de descanso médico sin } \\
\text { incapacidad permanente }\end{array}$ \\
\hline 3 & Accidente con lesión & $>10.000$ & $\begin{array}{l}\text { impacto en el área de } \\
\text { construcción / producción }\end{array}$ & $\begin{array}{l}\text { Accidente con hasta 3 días con } \\
\text { tiempo perdido }\end{array}$ \\
\hline 2 & $\begin{array}{l}\text { Accidente con lesiones } \\
\text { menores }\end{array}$ & $>5.000$ & $\begin{array}{l}\text { Impacto solamente en la } \\
\text { instalación }\end{array}$ & $\begin{array}{l}\text { Atenciones médicas sin tiempo } \\
\text { perdido }\end{array}$ \\
\hline 1 & $\begin{array}{l}\text { Accidente sin tiempo } \\
\text { perdido, primeros auxilios }\end{array}$ & $>=250$ & $\begin{array}{l}\text { Impacto en el lugar del } \\
\text { incidente }\end{array}$ & $\begin{array}{l}\text { Atención de primeros auxilios o casi } \\
\text { accidente }\end{array}$ \\
\hline
\end{tabular}

\section{FRECUENCIA}

\begin{tabular}{|l|c|c|l|}
\hline 1 & Continuo & Diario, varias veces & \multicolumn{1}{|c|}{ Ocurre con frecuencia en nuestro sitio } \\
\hline 2 & Frecuente & $>1 \times$ semana & Ya sucedió en nuestro sitio \\
\hline 3 & A menudo & $1 \times$ semana & Ya sucedió en nuestra empresa \\
\hline 4 & Ocasionalmente & $1 \times$ mes & Ya sucedió en nuestra rama \\
\hline 5 & Raramente & $1 \times$ año & Ya he oído hablar de eso \\
\hline 6 & Muy Raramente & $1 \times 5$ años & Nunca lo oí \\
\hline
\end{tabular}

Elaboración Propia
PROBABILIDAD

\begin{tabular}{|c|c|c|}
\hline INDICE & SITUACION & $\begin{array}{c}\text { CONTROL } \\
\text { ACTUAL }\end{array}$ \\
\hline 10 & Probable & $\begin{array}{c}\text { No hay forma de } \\
\text { controlarlo }\end{array}$ \\
\hline 6 & Muy posible & $\begin{array}{c}\text { Solo se tiene EPP/ } \\
\text { Programa de } \\
\text { comportamiento }\end{array}$ \\
\hline 3 & Inusual & $\begin{array}{c}\text { Entrenamiento en } \\
\text { procedimiento }\end{array}$ \\
\hline 1 & Improbable & $\begin{array}{c}\text { Sustitución / } \\
\text { Ingeniería }\end{array}$ \\
\hline 0.2 & $\begin{array}{c}\text { Prácticamente } \\
\text { imposible }\end{array}$ & Eliminación \\
\hline
\end{tabular}

NIVEL DE RIESGO

\begin{tabular}{|c|c|}
\hline INDICE & RIESGO \\
\hline A & $101-400$ \\
\hline B & $41-100$ \\
\hline C & $21-40$ \\
\hline D & $7-20$ \\
\hline E & $4-6$ \\
\hline F & $0-3$ \\
\hline
\end{tabular}


Anexo 6: Matriz de clasificación de condiciones inseguras por prioridad

\begin{tabular}{|c|c|c|c|c|c|c|}
\hline A & 600115 & $28 D$ DWS & 7DIAS & 3DISS & $101 \mathrm{~A}$ & $I D / A$ \\
\hline B & 90 DIAS & 60DAAS & 15 Dis & 10:A5 & 20115 & IOIA \\
\hline c & 1200DIAS & 900iAs & 15 DIAS & 10.25 & $301 / 5$ & 201As \\
\hline D & 180DIAS & 1200iAs & 20 DiAs & 10 diss & 5 dilus & soliss \\
\hline E & 300DIAS & 150Dias & 28 DiAS & 15 DiAS & 10 Diss & TDIAS \\
\hline F & 365 DIAS & 180DiAs & 60DIAS & 45 DiAS & 28 DiAs & 15 DiNS \\
\hline & 6 & 5 & 4 & 3 & 2 & 1 \\
\hline
\end{tabular}

Nivel de riesgo: Probabilidad x Gravedad

Nivel de priorización: [Nivel de riesgo - Frecuencia]

Elaboración Propia 


\section{Anexo 7: Formato de evaluación para auditorias de 5'S}

FORMATO DE EVALUACIÓN

Calif.

Cuentan con implementos de seguridad en su área

2 Las herramientas de trabajo se encuentran en buen estado para su uso (solo se tiene lo necesario)

Los equipos, escaleras, guardas se encuentran en buen estado (en su sitio, no roto, sin óxido,

pintado)

4 Existen objetos sin uso en los últimos 6 meses

5 Pasillos libres de obstáculos

6 Las cajas o gabinetes de herramientas están libres de objetos sin uso

7 En el área, se cuenta con solo lo necesario para trabajar

8 Las áreas se encuentran debidamente señalizadas

Se ven materiales en otras áreas o lugares diferentes a su lugar asignado

10 Los miembros del equipo conocen el proceso de selección y se esfuerzan por sostenerlo por turno

\begin{tabular}{|l|l|l|}
\cline { 2 - 4 } \multicolumn{1}{l|}{ Ordenar } & \multicolumn{2}{|c|}{ Or áreas están debidamente identificadas, es fácil encontrar lo que se busca inmediatamente } \\
12 & Existen lugares asignados para las herramientas y materiales (se encuentra identificado) & \\
13 & Los tachos de basura están en el lugar adecuado, y asignado para su fin & \\
14 & Apilamiento adecuado de materiales y herramientas para el trabajo & \\
15 & Es posible diferenciar, producto conforme, no conforme y en proceso & \\
16 & Es fácil saber el inventario de las herramientas, materiales y equipos empleados. \\
17 & Todas las identificaciones en gabinetes, zonas están actualizadas y se respetan & \\
18 & Los residuos son correctamente segregados según tipo. (Se cumple programa de segregación) & \\
\hline 19 & Los pisos se encuentran claramente señalizados, así como los sectores de equipos. & \\
20 & Los miembros del equipo conocen el proceso de orden y se esfuerzan por sostenerlos por turno. & \\
\hline
\end{tabular}

\begin{tabular}{|l|l|l|}
\cline { 2 - 4 } \multicolumn{1}{c|}{} & \multicolumn{1}{c|}{ Limpia } \\
\hline 21 & EPP's en buen estado (Epp's cumplen su función) & \\
22 & Los equipos, escaleras y guardas se encuentran limpios. & \\
23 & Las herramientas de trabajo, cajas y gabinetes se encuentran limpias & \\
24 & Piso está libre de polvo, basura, componentes y manchas (se evita la acumulación de material) & \\
25 & Las paredes y columnas se encuentran limpias & \\
26 & Se cumplen los planes de limpieza & \\
27 & Se cuenta con disponibilidad de materiales e instrumentos de limpieza (señalizada y ordenada) & \\
28 & Ausencia de puntos de contaminación o fuga de material & \\
29 & Los miembros del equipo conocen el proceso de limpieza y se esfuerzan por sostenerlos por turno. & \\
\hline
\end{tabular}

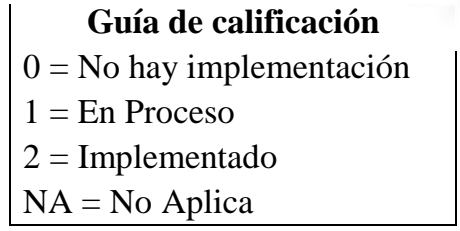

Elaboración Propia

\begin{tabular}{|r|r|}
\hline Puntos obtenidos & \\
\hline Puntos posibles & 58 \\
Resultado & \\
\hline
\end{tabular}




\section{Anexo 8: Formato de observaciones encontradas en auditorias de 5'S}

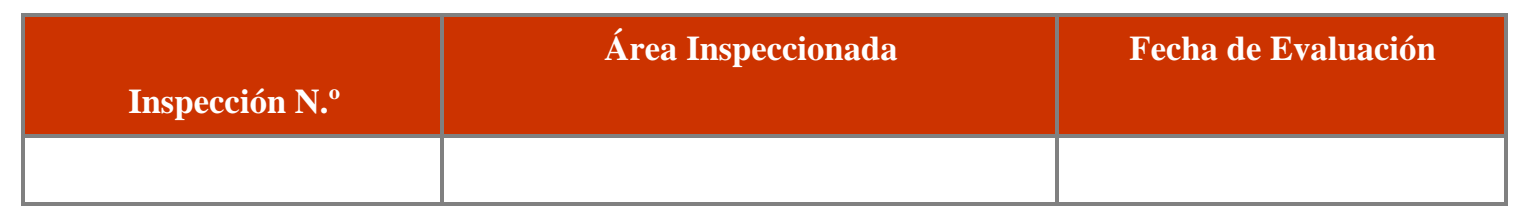

Inspección realizada por:

Responsable de área:

Observador (operario):

Evolución de la Aplicación de las 5's (Doce últimas evaluaciones) - En Porcentaje (\%)

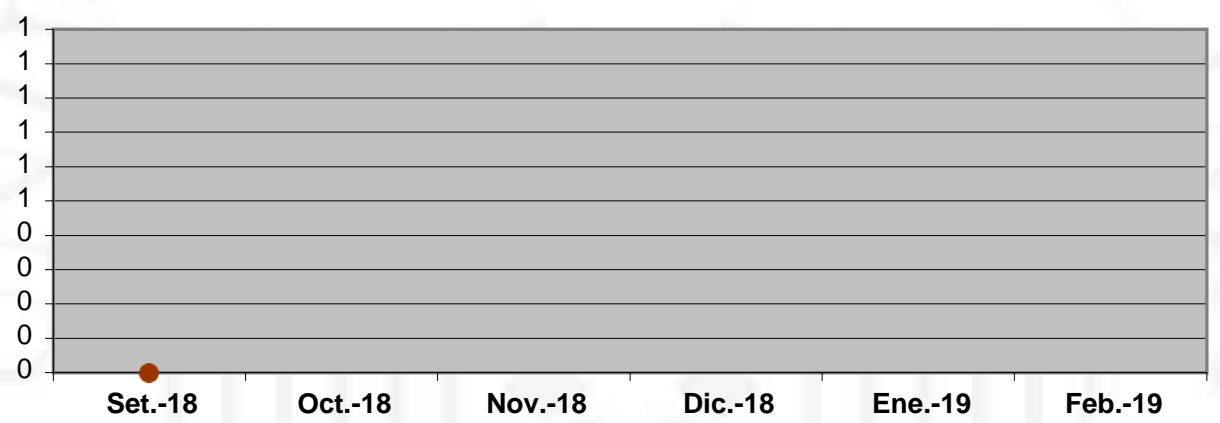

Registro de Incidencias

Incidencias de Seguridad:

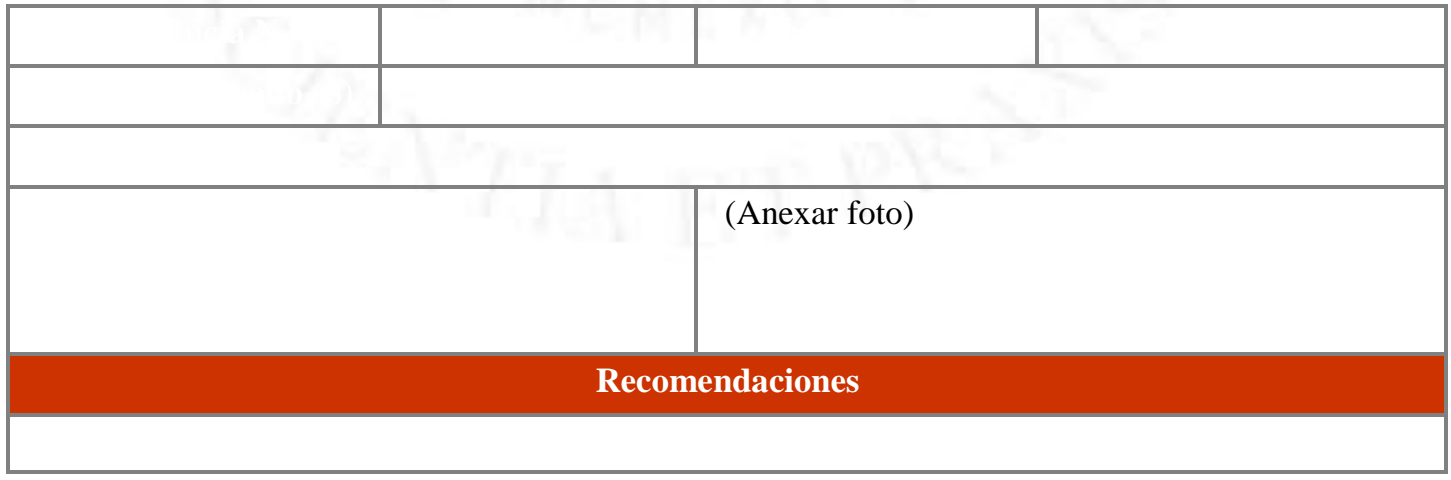

(continúa) 
(continuación)

\section{Incidencias Clasificación / Orden / Limpieza:}

\begin{tabular}{|l|l|}
\hline \multicolumn{1}{|c|}{ Incidencia N. $^{0}$} & \multicolumn{1}{|c|}{ Área } \\
\hline Aspecto Evaluado & \multicolumn{2}{|c|}{} \\
\hline Descripción & \\
\hline & \\
\hline & \\
\hline
\end{tabular}

\begin{tabular}{|l|l|l|l|}
\hline & $\mathbf{2}$ & & \\
\hline & \multicolumn{2}{|c|}{} \\
\hline \multicolumn{2}{|c|}{} \\
\hline & & \\
\hline & \\
\hline
\end{tabular}

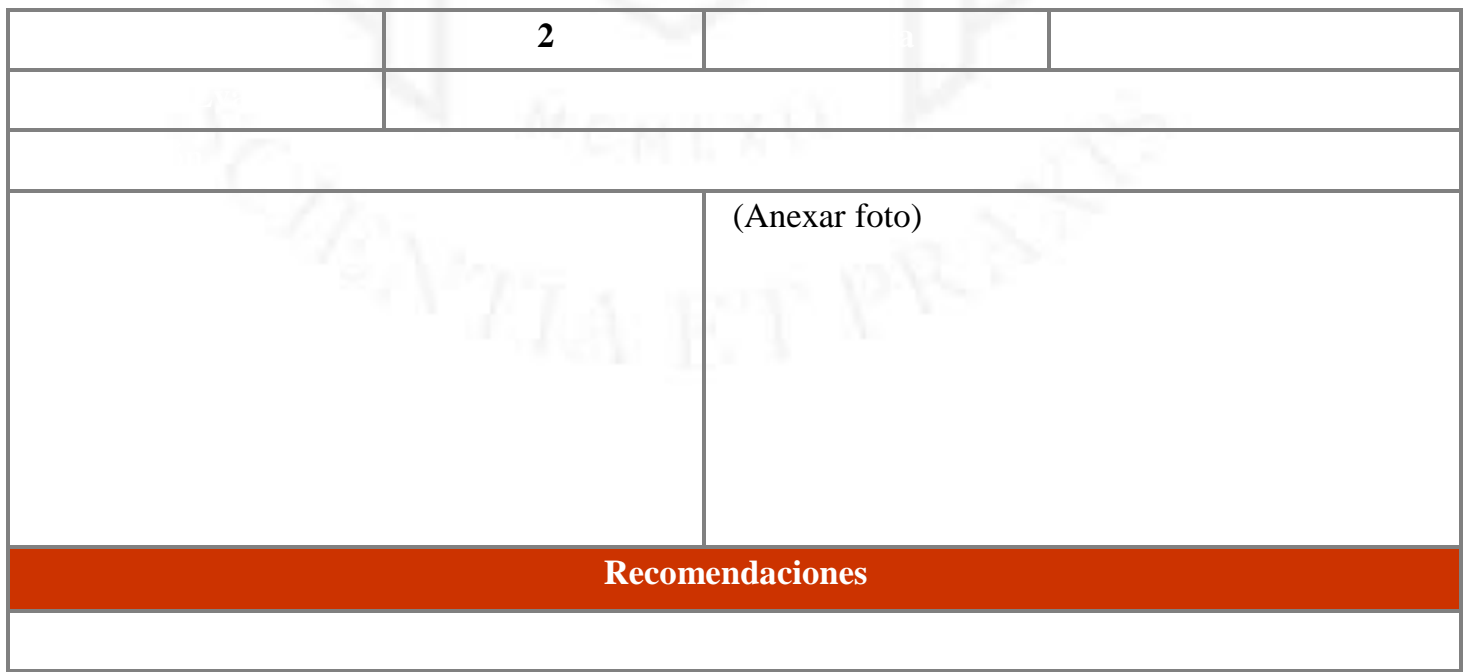

Elaboración Propia 
Anexo 9:Formato de control de tarjetas rojas de 5'S

\begin{tabular}{|c|c|c|c|c|c|c|c|c|c|c|}
\hline $\begin{array}{c}\mathbf{N}^{\circ} \\
\text { Tarjeta }\end{array}$ & Fecha & $\begin{array}{l}\text { Nombre } \\
\text { del } \\
\text { artículo }\end{array}$ & Cantidad & $\begin{array}{l}\text { Plan de } \\
\text { acción }\end{array}$ & Estatus & Comentarios & Responsable & Fecha de cierre & Foto & Foto después \\
\hline 1 & & & & & & & & & & \\
\hline 2 & & & & & & & & & & \\
\hline 3 & & & & & & & 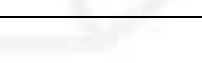 & & & \\
\hline 4 & & & & & & & & & & \\
\hline 5 & & & & & & & & & & \\
\hline 6 & & & & & & & & & & \\
\hline 7 & & & & & & & & & & \\
\hline & & & & & & & & & & \\
\hline
\end{tabular}

Elaboración Propia 
Anexo 10:Formato de control de tarjetas rojas de 5'S-Herramientas

\begin{tabular}{|c|c|c|c|c|c|c|c|}
\hline \multirow[b]{2}{*}{$\mathbf{N}^{\circ}$} & \multicolumn{7}{|c|}{ INVENTARIO DE HERRAMIENTAS } \\
\hline & $\begin{array}{l}\text { Herramienta } \\
\text { (Descripción de } \\
\text { herramienta) }\end{array}$ & Cantidad & $\begin{array}{c}\text { Condición } \\
\text { (1=Bien; } \\
\text { 2=Regular; } \\
\text { 3=Mala) }\end{array}$ & Observaciones & $\begin{array}{c}\text { Uso } \\
\text { (Aplicación de la } \\
\text { herramienta) }\end{array}$ & $\begin{array}{c}\text { ¿Es apropiada? } \\
\text { (En caso NO sea } \\
\text { apropiada sugerir una } \\
\text { herramienta) } \\
\end{array}$ & Foto referencial \\
\hline 1 & & & & & & & \\
\hline 2 & & & & & & & \\
\hline 3 & & & & & & & \\
\hline 4 & & & & & & & \\
\hline 5 & & & & & & & \\
\hline 6 & & & & & & & \\
\hline 7 & & & & & & & \\
\hline 8 & & & & & & & \\
\hline
\end{tabular}

Elaboración Propia 
Anexo 11: Tarjeta roja identificatoria - 5'S

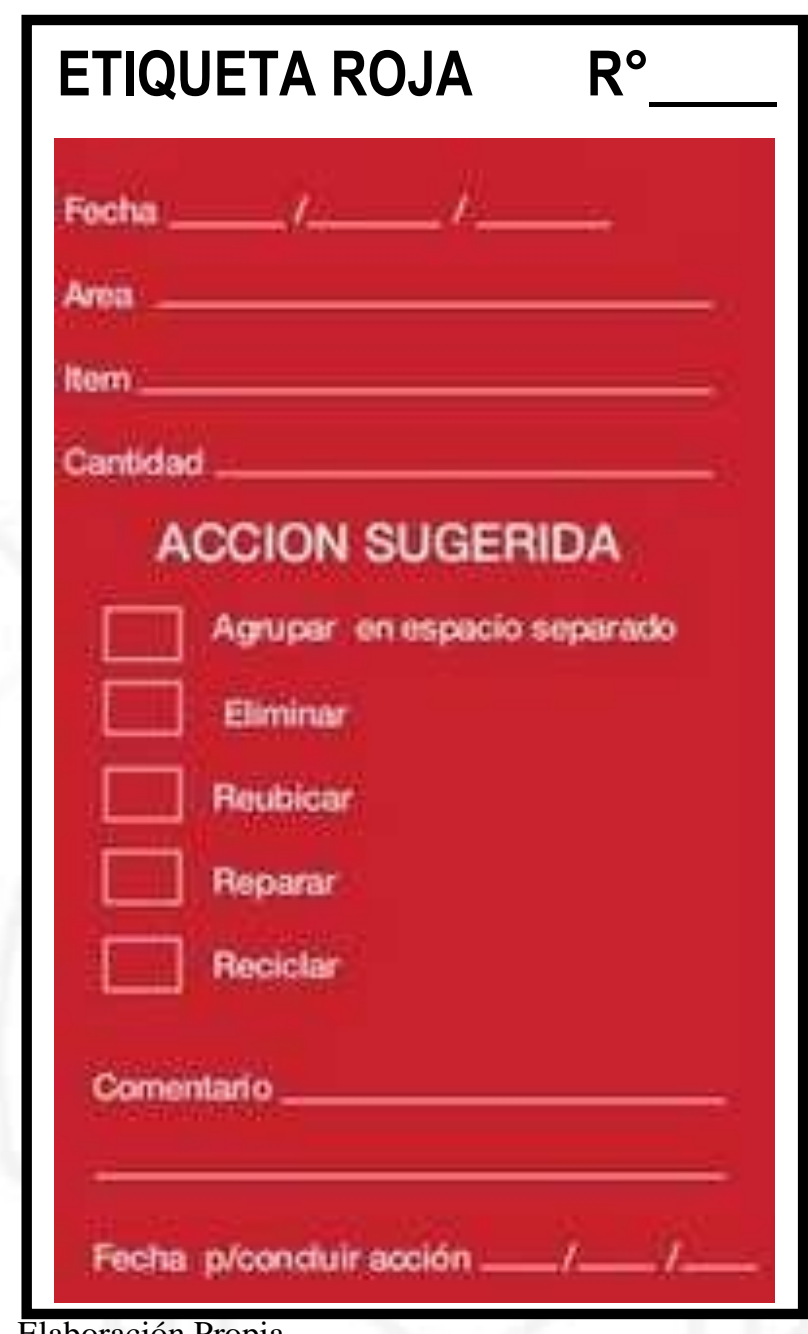

Elaboración Propia 
Anexo 12: Zona de acopio del material sustraído de los mantenimientos programados

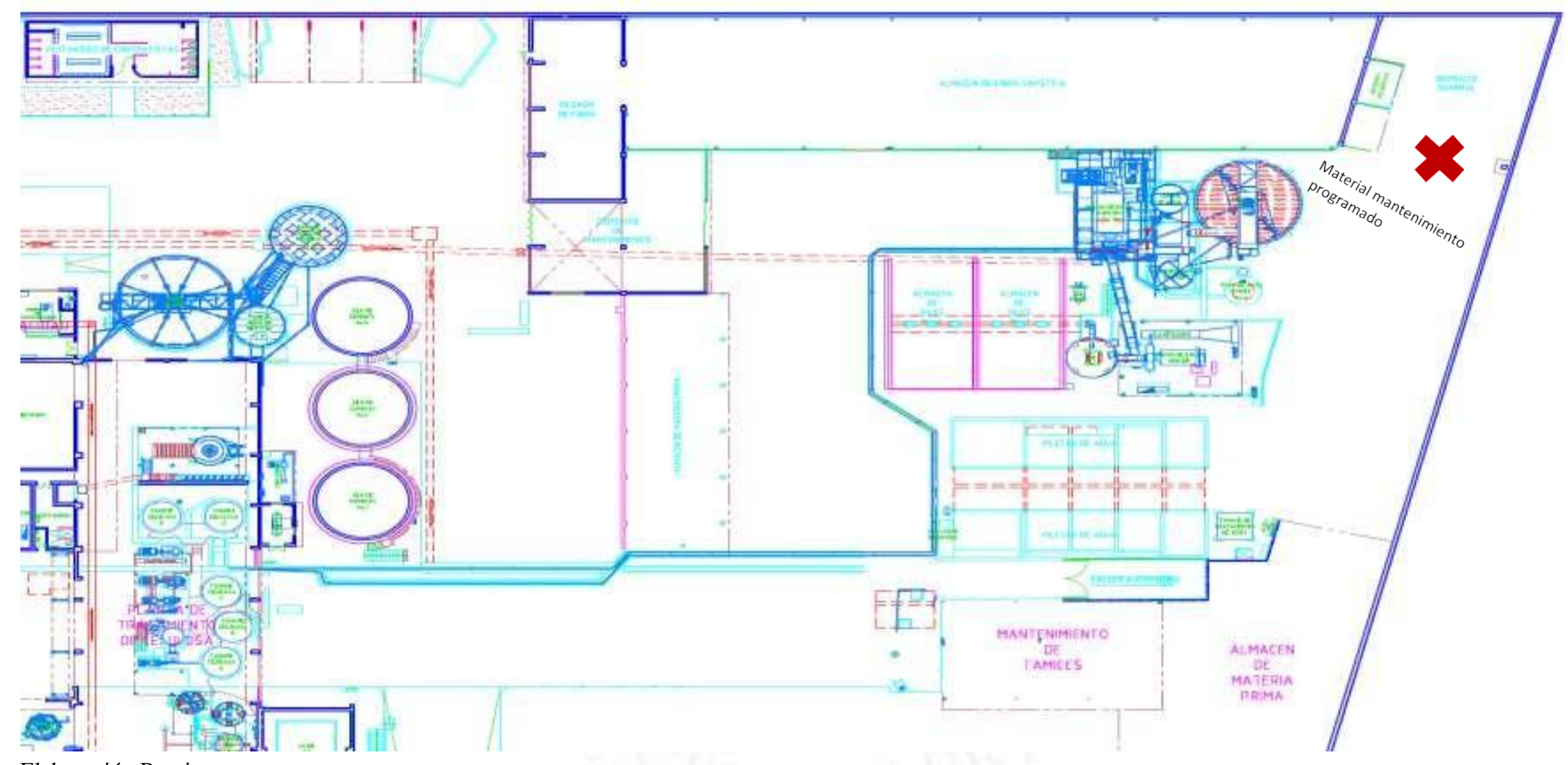

Elaboración Propia 


\section{Anexo 13: Cálculo del OEE de los meses de junio, julio, agosto y setiembre del 2018, de la línea de}

planchas de fibrocemento

\begin{tabular}{|c|c|c|c|c|}
\hline jun-18 & Disp (\%) & Rend (\%) & Calid (\%) & OEE \\
\hline 01 -jun & $90 \%$ & $95 \%$ & $99 \%$ & $85 \%$ \\
\hline 02 -jun & $90 \%$ & $95 \%$ & $99 \%$ & $85 \%$ \\
\hline 03 -jun & $88 \%$ & $94 \%$ & $80 \%$ & $66 \%$ \\
\hline $04-$ jun & $87 \%$ & $92 \%$ & $88 \%$ & $70 \%$ \\
\hline 05 -jun & $90 \%$ & $94 \%$ & $85 \%$ & $72 \%$ \\
\hline 06 -jun & $93 \%$ & $91 \%$ & $70 \%$ & $59 \%$ \\
\hline 07 -jun & $91 \%$ & $94 \%$ & $70 \%$ & $60 \%$ \\
\hline 08 -jun & $90 \%$ & $95 \%$ & $99 \%$ & $85 \%$ \\
\hline 09 -jun & $90 \%$ & $92 \%$ & $98 \%$ & $81 \%$ \\
\hline 10 -jun & $91 \%$ & $95 \%$ & $90 \%$ & $78 \%$ \\
\hline 11 -jun & $88 \%$ & $91 \%$ & $93 \%$ & $74 \%$ \\
\hline 12 -jun & $89 \%$ & $94 \%$ & $96 \%$ & $80 \%$ \\
\hline 13 -jun & $90 \%$ & $95 \%$ & $99 \%$ & $85 \%$ \\
\hline 14 -jun & $90 \%$ & $95 \%$ & $99 \%$ & $85 \%$ \\
\hline 15 -jun & $87 \%$ & $90 \%$ & $92 \%$ & $72 \%$ \\
\hline $16-$ jun & $90 \%$ & $91 \%$ & $88 \%$ & $72 \%$ \\
\hline 17 -jun & $90 \%$ & $95 \%$ & $99 \%$ & $85 \%$ \\
\hline 18 -jun & $90 \%$ & $95 \%$ & $99 \%$ & $85 \%$ \\
\hline 19 -jun & $86 \%$ & $90 \%$ & $99 \%$ & $77 \%$ \\
\hline 20 -jun & $90 \%$ & $95 \%$ & $99 \%$ & $85 \%$ \\
\hline 21 -jun & $90 \%$ & $95 \%$ & $99 \%$ & $85 \%$ \\
\hline $22-$ jun & $90 \%$ & $95 \%$ & $99 \%$ & $85 \%$ \\
\hline 23 -jun & $90 \%$ & $95 \%$ & $99 \%$ & $85 \%$ \\
\hline $24-$ jun & $90 \%$ & $95 \%$ & $99 \%$ & $85 \%$ \\
\hline 25 -jun & $90 \%$ & $95 \%$ & $99 \%$ & $85 \%$ \\
\hline 26 -jun & $90 \%$ & $95 \%$ & $99 \%$ & $85 \%$ \\
\hline $27-$ jun & $90 \%$ & $95 \%$ & $99 \%$ & $85 \%$ \\
\hline 28 -jun & $90 \%$ & $95 \%$ & $99 \%$ & $85 \%$ \\
\hline 29 -jun & $86 \%$ & $90 \%$ & $99 \%$ & $77 \%$ \\
\hline 30 -jun & $88 \%$ & $90 \%$ & $99 \%$ & $78 \%$ \\
\hline Total & $\mathbf{8 9 \%}$ & $\mathbf{9 4 \%}$ & $\mathbf{9 4 \%}$ & $\mathbf{7 9 \%}$ \\
\hline
\end{tabular}

\begin{tabular}{|c|c|c|c|c|}
\hline jul-18 & Disp (\%) & Rend (\%) & Calid (\%) & OEE \\
\hline 01 -jul & $91 \%$ & $95 \%$ & $99 \%$ & $86 \%$ \\
\hline 02 -jul & $91 \%$ & $95 \%$ & $99 \%$ & $86 \%$ \\
\hline 03 -jul & $95 \%$ & $94 \%$ & $80 \%$ & $71 \%$ \\
\hline $04-$ jul & $95 \%$ & $92 \%$ & $88 \%$ & $77 \%$ \\
\hline 05 -jul & $91 \%$ & $94 \%$ & $85 \%$ & $73 \%$ \\
\hline 06 -jul & $94 \%$ & $91 \%$ & $70 \%$ & $60 \%$ \\
\hline 07 -jul & $92 \%$ & $94 \%$ & $70 \%$ & $61 \%$ \\
\hline 08 -jul & $91 \%$ & $95 \%$ & $99 \%$ & $86 \%$ \\
\hline 09 -jul & $91 \%$ & $92 \%$ & $98 \%$ & $82 \%$ \\
\hline 10 -jul & $92 \%$ & $95 \%$ & $90 \%$ & $79 \%$ \\
\hline 11 -jul & $95 \%$ & $88 \%$ & $93 \%$ & $78 \%$ \\
\hline 12 -jul & $95 \%$ & $94 \%$ & $96 \%$ & $86 \%$ \\
\hline 13 -jul & $91 \%$ & $95 \%$ & $99 \%$ & $86 \%$ \\
\hline $14-$ jul & $95 \%$ & $95 \%$ & $99 \%$ & $89 \%$ \\
\hline 15 -jul & $95 \%$ & $95 \%$ & $92 \%$ & $83 \%$ \\
\hline 16 -jul & $95 \%$ & $91 \%$ & $88 \%$ & $76 \%$ \\
\hline 17 -jul & $95 \%$ & $95 \%$ & $99 \%$ & $89 \%$ \\
\hline 18 -jul & $95 \%$ & $95 \%$ & $99 \%$ & $89 \%$ \\
\hline $19-$ jul & $95 \%$ & $95 \%$ & $99 \%$ & $89 \%$ \\
\hline 20 -jul & $95 \%$ & $95 \%$ & $99 \%$ & $89 \%$ \\
\hline 21 -jul & $95 \%$ & $88 \%$ & $99 \%$ & $83 \%$ \\
\hline 22 -jul & $95 \%$ & $95 \%$ & $99 \%$ & $89 \%$ \\
\hline 23 -jul & $95 \%$ & $95 \%$ & $99 \%$ & $89 \%$ \\
\hline $24-$-jul & $95 \%$ & $95 \%$ & $90 \%$ & $81 \%$ \\
\hline 25 -jul & $95 \%$ & $88 \%$ & $99 \%$ & $83 \%$ \\
\hline 26 -jul & $95 \%$ & $95 \%$ & $99 \%$ & $89 \%$ \\
\hline 27 -jul & $95 \%$ & $90 \%$ & $90 \%$ & $77 \%$ \\
\hline 28 -jul & $95 \%$ & $95 \%$ & $99 \%$ & $89 \%$ \\
\hline 29 -jul & $95 \%$ & $95 \%$ & $99 \%$ & $89 \%$ \\
\hline $30-$ jul & $95 \%$ & $95 \%$ & $99 \%$ & $89 \%$ \\
\hline Total & $\mathbf{9 4 \%}$ & $\mathbf{9 4 \%}$ & $\mathbf{9 4 \%}$ & $\mathbf{8 2 \%}$ \\
\hline & & & & \\
\hline
\end{tabular}

\begin{tabular}{|c|c|c|c|c|}
\hline ago-18 & Disp (\%) & Rend (\%) & Calid(\%) & OEE \\
\hline 01-ago & $92 \%$ & $95 \%$ & $99 \%$ & $87 \%$ \\
\hline 02-ago & $92 \%$ & $95 \%$ & $99 \%$ & $87 \%$ \\
\hline 03-ago & $95 \%$ & $94 \%$ & $80 \%$ & $71 \%$ \\
\hline 04-ago & $95 \%$ & $92 \%$ & $88 \%$ & $77 \%$ \\
\hline 05-ago & $92 \%$ & $94 \%$ & $85 \%$ & $74 \%$ \\
\hline 06-ago & $95 \%$ & $91 \%$ & $70 \%$ & $61 \%$ \\
\hline 07-ago & $93 \%$ & $94 \%$ & $70 \%$ & $61 \%$ \\
\hline 08-ago & $92 \%$ & $95 \%$ & $99 \%$ & $87 \%$ \\
\hline 09-ago & $92 \%$ & $92 \%$ & $98 \%$ & $83 \%$ \\
\hline 10-ago & $93 \%$ & $95 \%$ & $98 \%$ & $87 \%$ \\
\hline 11-ago & $95 \%$ & $91 \%$ & $93 \%$ & $80 \%$ \\
\hline 12-ago & $95 \%$ & $94 \%$ & $96 \%$ & $86 \%$ \\
\hline 13-ago & $92 \%$ & $95 \%$ & $99 \%$ & $87 \%$ \\
\hline 14-ago & $95 \%$ & $95 \%$ & $99 \%$ & $89 \%$ \\
\hline 15-ago & $96 \%$ & $95 \%$ & $92 \%$ & $84 \%$ \\
\hline 16-ago & $96 \%$ & $91 \%$ & $88 \%$ & $77 \%$ \\
\hline 17-ago & $96 \%$ & $95 \%$ & $99 \%$ & $90 \%$ \\
\hline 18-ago & $96 \%$ & $95 \%$ & $99 \%$ & $90 \%$ \\
\hline 19-ago & $96 \%$ & $95 \%$ & $99 \%$ & $90 \%$ \\
\hline 20-ago & $96 \%$ & $95 \%$ & $99 \%$ & $90 \%$ \\
\hline 21-ago & $96 \%$ & $95 \%$ & $99 \%$ & $90 \%$ \\
\hline 22-ago & $96 \%$ & $95 \%$ & $99 \%$ & $90 \%$ \\
\hline 23-ago & $96 \%$ & $95 \%$ & $99 \%$ & $90 \%$ \\
\hline 24-ago & $96 \%$ & $95 \%$ & $99 \%$ & $90 \%$ \\
\hline 25-ago & $96 \%$ & $95 \%$ & $99 \%$ & $90 \%$ \\
\hline 26-ago & $96 \%$ & $95 \%$ & $99 \%$ & $90 \%$ \\
\hline 27-ago & $96 \%$ & $95 \%$ & $99 \%$ & $90 \%$ \\
\hline 28-ago & $96 \%$ & $95 \%$ & $99 \%$ & $90 \%$ \\
\hline 29-ago & $96 \%$ & $95 \%$ & $99 \%$ & $90 \%$ \\
\hline 30-ago & $96 \%$ & $95 \%$ & $99 \%$ & $90 \%$ \\
\hline Total & $\mathbf{9 5 \%}$ & $\mathbf{9 4 \%}$ & $\mathbf{9 5 \%}$ & $\mathbf{8 5 \%}$ \\
\hline & & & & \\
\hline
\end{tabular}

\begin{tabular}{|c|c|c|c|c|}
\hline sep-18 & Disp (\% & Rend (\%) & Calid (\%) & OEE \\
\hline 01 -sep & $93 \%$ & \begin{tabular}{|l|}
$95 \%$ \\
\end{tabular} & $99 \%$ & $87 \%$ \\
\hline 02 -sep & $93 \%$ & $95 \%$ & $99 \%$ & $87 \%$ \\
\hline 03 -sep & $95 \%$ & $94 \%$ & $80 \%$ & $71 \%$ \\
\hline 04-sep & $95 \%$ & $92 \%$ & $88 \%$ & $77 \%$ \\
\hline 05 -sep & $93 \%$ & $94 \%$ & $85 \%$ & $74 \%$ \\
\hline 06 -sep & $96 \%$ & $91 \%$ & $88 \%$ & $77 \%$ \\
\hline 07 -sep & $95 \%$ & $94 \%$ & $88 \%$ & $79 \%$ \\
\hline 08 -sep & $93 \%$ & $95 \%$ & $99 \%$ & $87 \%$ \\
\hline 09 -sep & $93 \%$ & $92 \%$ & $98 \%$ & $84 \%$ \\
\hline 10 -sep & $94 \%$ & $95 \%$ & $98 \%$ & $88 \%$ \\
\hline 11-sep & $95 \%$ & $91 \%$ & $93 \%$ & $80 \%$ \\
\hline 12-sep & $95 \%$ & $94 \%$ & $96 \%$ & $86 \%$ \\
\hline 13-sep & $93 \%$ & $95 \%$ & $99 \%$ & $87 \%$ \\
\hline 14-sep & $95 \%$ & $95 \%$ & $99 \%$ & $89 \%$ \\
\hline 15 -sep & $97 \%$ & $95 \%$ & $92 \%$ & $85 \%$ \\
\hline 16-sep & $97 \%$ & $91 \%$ & $88 \%$ & $78 \%$ \\
\hline 17 -sep & $97 \%$ & $95 \%$ & $99 \%$ & $91 \%$ \\
\hline 18 -sep & $97 \%$ & $94 \%$ & $99 \%$ & $90 \%$ \\
\hline 19-sep & $97 \%$ & $95 \%$ & $99 \%$ & $91 \%$ \\
\hline 20 -sep & $97 \%$ & $95 \%$ & $99 \%$ & $91 \%$ \\
\hline 21 -sep & $97 \%$ & $95 \%$ & $99 \%$ & $91 \%$ \\
\hline 22 -sep & $97 \%$ & $95 \%$ & $99 \%$ & $91 \%$ \\
\hline 23-sep & $97 \%$ & $95 \%$ & $90 \%$ & $83 \%$ \\
\hline 24-sep & $97 \%$ & $90 \%$ & $99 \%$ & $86 \%$ \\
\hline 25 -sep & $97 \%$ & $95 \%$ & $99 \%$ & $91 \%$ \\
\hline 26-sep & $97 \%$ & $95 \%$ & $90 \%$ & $83 \%$ \\
\hline 27 -sep & $97 \%$ & $95 \%$ & $99 \%$ & $91 \%$ \\
\hline 28 -sep & $97 \%$ & $95 \%$ & $90 \%$ & $83 \%$ \\
\hline 29 -sep & $97 \%$ & $95 \%$ & $99 \%$ & $91 \%$ \\
\hline 30 -sep & $97 \%$ & $95 \%$ & $99 \%$ & $91 \%$ \\
\hline Total & $96 \%$ & $94 \%$ & $95 \%$ & $85 \%$ \\
\hline
\end{tabular}

Elaboración Propia 


\section{Anexo 14: Análisis SMED para reducción de tiempos de cambios}

\begin{tabular}{|c|c|c|c|c|c|c|c|c|c|c|c|c|}
\hline \multirow{2}{*}{\multicolumn{2}{|c|}{$\mathrm{N}^{\circ} . \quad$ Operación de cambio }} & \multicolumn{4}{|c|}{ Personas } & & & \multicolumn{3}{|c|}{ Clasificación del cambio } & \multirow{2}{*}{\multicolumn{2}{|c|}{ Comentario }} \\
\hline & & 1 & 2 & 3 & 4 & Tiempo Acumulado & Tiempo & Tiempo con SMED & Interno & Externo & & \\
\hline 1 & Parar máquina & $\mathrm{x}$ & $\mathrm{x}$ & & & $07: 15$ & & & & & & \\
\hline 2 & Bloquear equipos & $\mathrm{x}$ & & & & $07: 18$ & 00:03:00 & 00:03:00 & & & & \\
\hline 3 & Recoger Herramientas & $\mathrm{x}$ & & & & $07: 29$ & 00:11:00 & $00: 00: 00$ & & & Transporte & 5'S, kit de herramientas a la mano \\
\hline 4 & Cambiar tela de la ventosa de producción & $\mathrm{x}$ & $\mathrm{x}$ & $\mathrm{x}$ & & $07: 45$ & 00:16:00 & 00:12:00 & & & Transporte & 5'S, zona de telas al costado del equipo \\
\hline 5 & Ajustes de tela de la ventosa de producción & $\mathrm{x}$ & $\mathrm{x}$ & & & $07: 50$ & 00:05:00 & 00:05:00 & & & 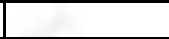 & \\
\hline 6 & Afilado de discos de corte & $\mathrm{x}$ & & & & 07:52 & 00:02:00 & 00:00:00 & & & Afilado & Tener previamente los discos de corte afilados \\
\hline 7 & Cambio de discos de corte transversales & $\mathrm{x}$ & $\mathrm{x}$ & & & 08:10 & 00:18:00 & 00:14:00 & & & Cambio & $\begin{array}{l}\text { Instalar sistemas de corte adicionales tan solo } \\
\text { para subir y/o bajar }\end{array}$ \\
\hline 8 & Posicionamiento de los discos de corte transversa & $\mathrm{x}$ & $\mathrm{x}$ & & & 08:17 & 00:07:00 & 00:04:00 & & & Medición & $\begin{array}{l}\text { Colocar marcas referenciales para el } \\
\text { posicionamiento de los discos de corte }\end{array}$ \\
\hline 9 & Cambio de discos de corte longitudinales & $\mathrm{x}$ & & & & 08:25 & 00:08:00 & 00:05:00 & & & Cambio & $\begin{array}{l}\text { Instalar sistemas de corte adicionales tan solo } \\
\text { para subir y/o bajar }\end{array}$ \\
\hline 10 & Desbloqueo de equipos & $\mathrm{x}$ & & & & 08:28 & 00:03:00 & 00:03:00 & & & & \\
\hline 11 & Arrancar máquina & $\mathrm{x}$ & $\mathrm{x}$ & & & 08:36 & 00:08:00 & 00:05:00 & & & $\begin{array}{c}\text { Falta de } \\
\text { comunicación }\end{array}$ & $\begin{array}{l}\text { Comunicación entre los responsables del } \\
\text { cambio y el operador responsable de preparar } \\
\text { las mezclas }\end{array}$ \\
\hline 12 & Ajustes de máquina & $\mathrm{x}$ & $\mathrm{x}$ & & & $08: 42$ & 00:06:00 & 00:06:00 & & & & \\
\hline 13 & Medición de planchas & $\mathrm{x}$ & & & & $08: 45$ & 00:03:00 & 00:03:00 & & & & \\
\hline & Tiempo Total & & & & & & $1: 30: 00$ & 1:00:00 & & & & Sin cambio \\
\hline & Desperdicio Total & & & & & & 0:30:00 & & & & & Area de oportunidad inmediata \\
\hline & & & & & & & & & & & & Area de oportunidad (mediano plazo) \\
\hline Obs & servaciones: & & & & & & & & & & & Area de oportunidad (largo plazo) \\
\hline
\end{tabular}

\begin{tabular}{|l|}
\hline Integrantes del equipo: \\
Líder: \\
\hline Elaboración Propia
\end{tabular}

Elaboración Propia 
Anexo 15:Trabajo de mantenimiento programado

\begin{tabular}{|c|c|c|c|c|c|c|c|c|c|c|}
\hline \multirow[b]{2}{*}{ \# } & \multirow[b]{2}{*}{ Actividades } & \multirow[b]{2}{*}{$\begin{array}{c}\text { Cantidad de } \\
\text { personas }\end{array}$} & \multirow[b]{2}{*}{ Tipo de trabajo } & \multirow[b]{2}{*}{$\begin{array}{c}\text { Frecuencia de } \\
\text { intervención } \\
\text { (días) }\end{array}$} & \multirow[b]{2}{*}{$\begin{array}{c}\text { Tiempo } \\
\text { muerto (hrs.) }\end{array}$} & \multirow[b]{2}{*}{$\begin{array}{c}\text { Tiempo } \\
\text { estándar } \\
\text { (Hrs.) }\end{array}$} & \multicolumn{4}{|c|}{ Causas de tiempos muertos } \\
\hline & & & & & & & $\begin{array}{l}\text { Busqueda de } \\
\text { herramientas }\end{array}$ & $\begin{array}{l}\text { Busqueda de } \\
\text { repuestos } y \\
\text { materiales }\end{array}$ & $\begin{array}{l}\text { Desorden en } \\
\text { la línea }\end{array}$ & $\begin{array}{c}\text { Mala planificación, } \\
\text { organización y } \\
\text { supervisión de los } \\
\text { trabajos }\end{array}$ \\
\hline E1 & Limpieza de Cisterna Principal & 3 & Operacional & 15 & 0,7 & 2,60 & $\bar{x}$ & $\mathrm{x}$ & $\mathrm{x}$ & \\
\hline E2 & Limpieza de Línea de Agua de Arrastre & 4 & Operacional & 15 & 0,5 & 3,20 & $\mathrm{x}$ & $\mathrm{x}$ & & \\
\hline E3 & ${\text { Limpieza de Línea de recuperación de } 6^{\prime}}^{\prime}$ & 4 & Operacional & 15 & 0,8 & 2,90 & $\mathrm{x}$ & $\mathrm{x}$ & & \\
\hline E4 & \begin{tabular}{|l|} 
Limpieza de Mezclador \\
\end{tabular} & 1 & Operacional & 15 & 0,6 & 2,60 & $\mathrm{x}$ & $\mathrm{x}$ & & \\
\hline E5 & Limpieza de canaletas de rebose de bateas + Caja rebose & 1 & Operacional & 7 & 0,6 & 1,40 & $\mathrm{x}$ & $\bar{x}$ & & \\
\hline E6 & Limpieza de Premixer + Timones reguladores de alimentación a bateas & 1 & Operacional & 7 & 0,0 & 1,30 & $\mathrm{x}$ & $\mathrm{x}$ & $\mathrm{x}$ & \\
\hline E7 & Limpieza de Selectifier + Caja de desconche & 1 & Operacional & 7 & 0,5 & 1,10 & $\mathrm{x}$ & $\mathrm{x}$ & $\mathrm{x}$ & \\
\hline E8 & Limpieza de Canaletas de alimentación a bateas & $\frac{1}{1}$ & Operacional & 7 & 0,0 & 0,80 & $\mathrm{x}$ & $\mathrm{x}$ & & \\
\hline E9 & Limpieza de Kanaflex's de succión de vacíos & 2 & Operacional & 7 & 0,8 & 1,90 & $\mathrm{x}$ & $\mathrm{x}$ & & \\
\hline E10 & Limpieza de Bateas 1,2 y 3 & 3 & Operacional & 7 & 0,6 & 1,20 & $\mathrm{x}$ & $\mathrm{x}$ & & \\
\hline E11 & Limpieza de Mesas de lavado y secado de Fieltro & 1 & Operacional & 7 & 0,4 & 1,50 & $\mathrm{x}$ & $\mathrm{x}$ & & \\
\hline E12 & Limpieza de Mesas principales de vacío & 1 & Operacional & 7 & 0,7 & 1,50 & $\mathrm{x}$ & $\mathrm{x}$ & & \\
\hline $\mathrm{E} 13$ & \begin{tabular}{|l|} 
Limpieza de Mesas tubulares de fijación \\
\end{tabular} & $\frac{2}{2}$ & Operacional & 7 & 0,0 & $\frac{1,50}{3}$ & $\mathrm{x}$ & $\mathrm{x}$ & & \\
\hline$\overline{E 14}$ & Limpieza de Desintegrador de recortes & 2 & Operacional & 15 & 0,0 & 4,20 & $\mathrm{x}$ & $\mathrm{x}$ & & \\
\hline E15 & Limpieza de Linea " $\mathrm{Y}$ " y Codo adyacente al desintegrador de pasta+ caída a cisterna principal & 2 & Operacional & 15 & 0,2 & 1,10 & $\mathrm{x}$ & $\mathrm{x}$ & & \\
\hline$\overline{E 16}$ & Limpieza de Línea de subida a torre de enfriamiento & 3 & Operacional & 15 & 0,6 & 2,59 & $\mathrm{x}$ & $\mathrm{x}$ & & \\
\hline E17 & \begin{tabular}{|l} 
Limpieza de poza de agua de sello \\
\end{tabular} & 6 & Operacional & 15 & 1,2 & 3,96 & & & & \\
\hline E18 & Lubricación de la caja de rodamientos de la bomba de descarga de mezclador & 1 & Mecánico & 7 & 0,6 & 1,00 & & & $\mathrm{x}$ & $\mathrm{x}$ \\
\hline E19 & Lubricar de los rodamientos del motor de la bomba de descarga de la cisterna principal & 1 & Mecánico & 7 & 0,4 & 0,93 & & & $\mathrm{x}$ & $\mathrm{x}$ \\
\hline $\mathrm{E} 20$ & Mantenimiento de los ejes de los agitadores de la hatschek & 2 & Mecánico & 7 & 2,9 & 5,83 & & $\mathrm{x}$ & & $\mathrm{x}$ \\
\hline E21 & Mantenimiento de los orientadores de la hatschek & 1 & Mecánico & 7 & 2,6 & 5,83 & & $\mathrm{x}$ & & $\mathrm{x}$ \\
\hline E22 & Lubricación de chumaceras de los rolos prensapastas & 1 & Mecánico & 7 & 0,5 & 1,00 & & & $\mathrm{x}$ & $\mathrm{x}$ \\
\hline E23 & Lubricación de chumaceras de los tamices & 1 & Mecánico & 7 & 0,5 & 1,00 & & & & $\mathrm{x}$ \\
\hline E24 & Lubricación de chumaceras del rolo templador de fieltro & 1 & Mecánico & 7 & 0,3 & 0,50 & & $\mathrm{x}$ & $\mathrm{x}$ & $\mathrm{x}$ \\
\hline E25 & Lubricar los rodamientos del motor de la bomba del sistema de traslación de la onduladora & 1 & Mecánico & 7 & 0,7 & 1,51 & & & $\mathrm{x}$ & $\mathrm{x}$ \\
\hline E26 & Lubricar los rodamientos del motor del agitador del mezclador & 1 & Mecánico & 7 & 0,2 & 0,55 & & & $\mathrm{x}$ & $\mathrm{x}$ \\
\hline E27 & \begin{tabular}{|l} 
Lubricación de chumaceras de los rodillos de las fajas transportadoras \\
\end{tabular} & 2 & Mecánico & 7 & 2,2 & 3,47 & & & $\mathrm{x}$ & $\mathrm{x}$ \\
\hline E28 & Mantenimiento a los tableros eléctricos & 3 & Eléctrico & 7 & 3,0 & 6,50 & & & $\mathrm{x}$ & $\mathrm{x}$ \\
\hline E29 & Limpieza de Cono & 2 & Operacional & 15 & 0,8 & 3,83 & $\mathrm{x}$ & $\mathrm{x}$ & $\mathrm{x}$ & \\
\hline E30 & \begin{tabular}{|l} 
Limpieza de Poza de recuperación \\
\end{tabular} & 3 & Operacional & 15 & 0,9 & 4,15 & $\mathrm{x}$ & $\mathrm{x}$ & $\mathrm{x}$ & \\
\hline E31 & Limpieza de Canaletas alrededor de máquina & 2 & Operacional & 15 & 0,3 & 1,42 & $\mathrm{x}$ & $\mathrm{x}$ & $\mathrm{x}$ & \\
\hline E32 & \begin{tabular}{|l|} 
Limpieza de Línea de recuperación de $8^{\prime}$ \\
\end{tabular} & 4 & Operacional & 15 & 0,5 & 3,43 & $\mathrm{x}$ & $\mathrm{x}$ & & \\
\hline E33 & Limpieza de Línea de bajada a torre de enfriamiento & 3 & Operacional & 15 & 0,4 & 2,87 & $\mathrm{x}$ & $\mathrm{x}$ & & \\
\hline E34 & Limpieza de Línea de fluidores alrededor de máquina & 4 & Operacional & 15 & 0,5 & 2,92 & $\mathrm{x}$ & $\bar{x}$ & & \\
\hline E35 & Limpieza de Línea de Cisterna principal a Desintegrador de recortes & 5 & Operacional & 15 & 0,5 & 2,96 & $\bar{x}$ & $\mathrm{X}$ & & $\mathrm{x}$ \\
\hline
\end{tabular}

Elaboración Propia 
Anexo 16:Check list de limpieza

\begin{tabular}{|c|c|c|c|c|c|c|c|}
\hline \multirow{2}{*}{ Zona } & \multirow{2}{*}{ equipos y líneas } & \multicolumn{2}{|c|}{ ¿ Está limpio y ordenado? } & \multicolumn{2}{|c|}{ ¿ Existen fugas? } & \multirow{2}{*}{ Observaciones } & \multirow{2}{*}{$\begin{array}{r}\text { Firma del } \\
\text { responsable }\end{array}$} \\
\hline & & $\mathrm{Si}$ & No & $\mathbf{S i}$ & No & & \\
\hline \multirow{5}{*}{ Mezclador } & Mezclador & & & & & & \\
\hline & Cono & & & & & & \\
\hline & Cisterna principal & & & & & & \\
\hline & Cisterna Auxiliar & & & & & & \\
\hline & Sala de control & 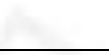 & 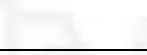 & & 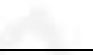 & 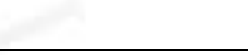 & \\
\hline \multirow{3}{*}{ Formato } & Fajas transportadoras \#1 y \#2 & 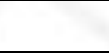 & & & & t & \\
\hline & Formato & & & & & 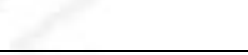 & \\
\hline & Tablero de control & & & & & 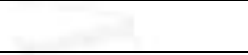 & \\
\hline \multirow{2}{*}{ Máquina } & Máquina Hatschek & & & & & & \\
\hline & Zona bombas de vacío & & & & & & \\
\hline \multirow{4}{*}{ Onduladora } & Fajas transportadoras \#3 & & & & & & \\
\hline & Desintegrador de recortes & & & & & & \\
\hline & Tablero de control & & & & & & \\
\hline & ventosas y vagonetas & & & 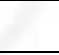 & 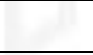 & & \\
\hline \multirow{2}{*}{$\begin{array}{l}\text { Cabinas de pre } \\
\quad \text { - curado }\end{array}$} & Cabinas de pre - curado & & & & & & \\
\hline & $\begin{array}{l}\text { Zona de válvulas reguladoras de } \\
\text { vapor }\end{array}$ & & 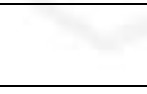 & & & & \\
\hline \multirow{3}{*}{ Desalojadora } & Sistema de lubricación de moldes & & & & & & \\
\hline & Tablero de control & & & & & & \\
\hline & ventosas y vagonetas & & & & & & \\
\hline
\end{tabular}

Elaboración Propia 


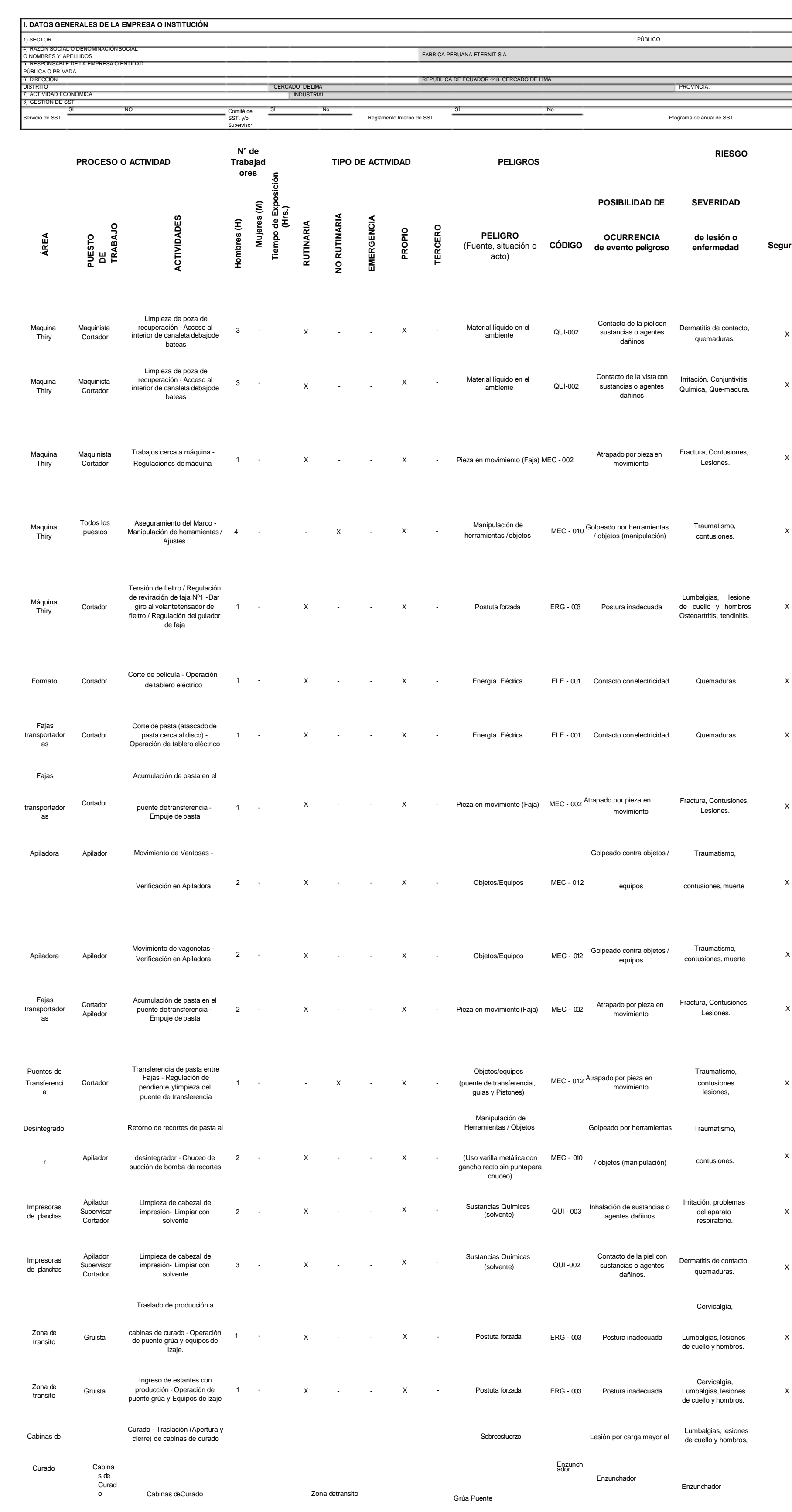




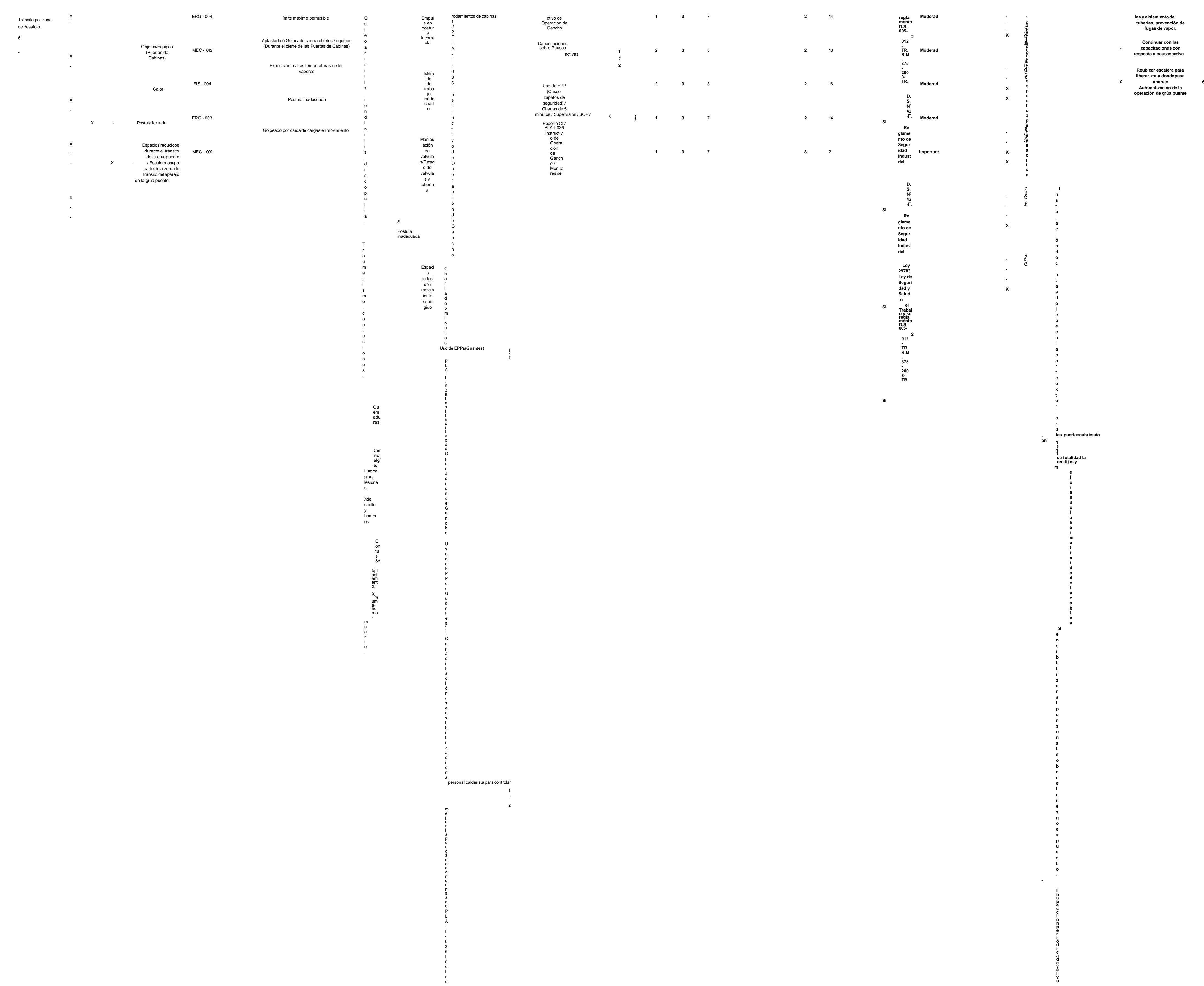




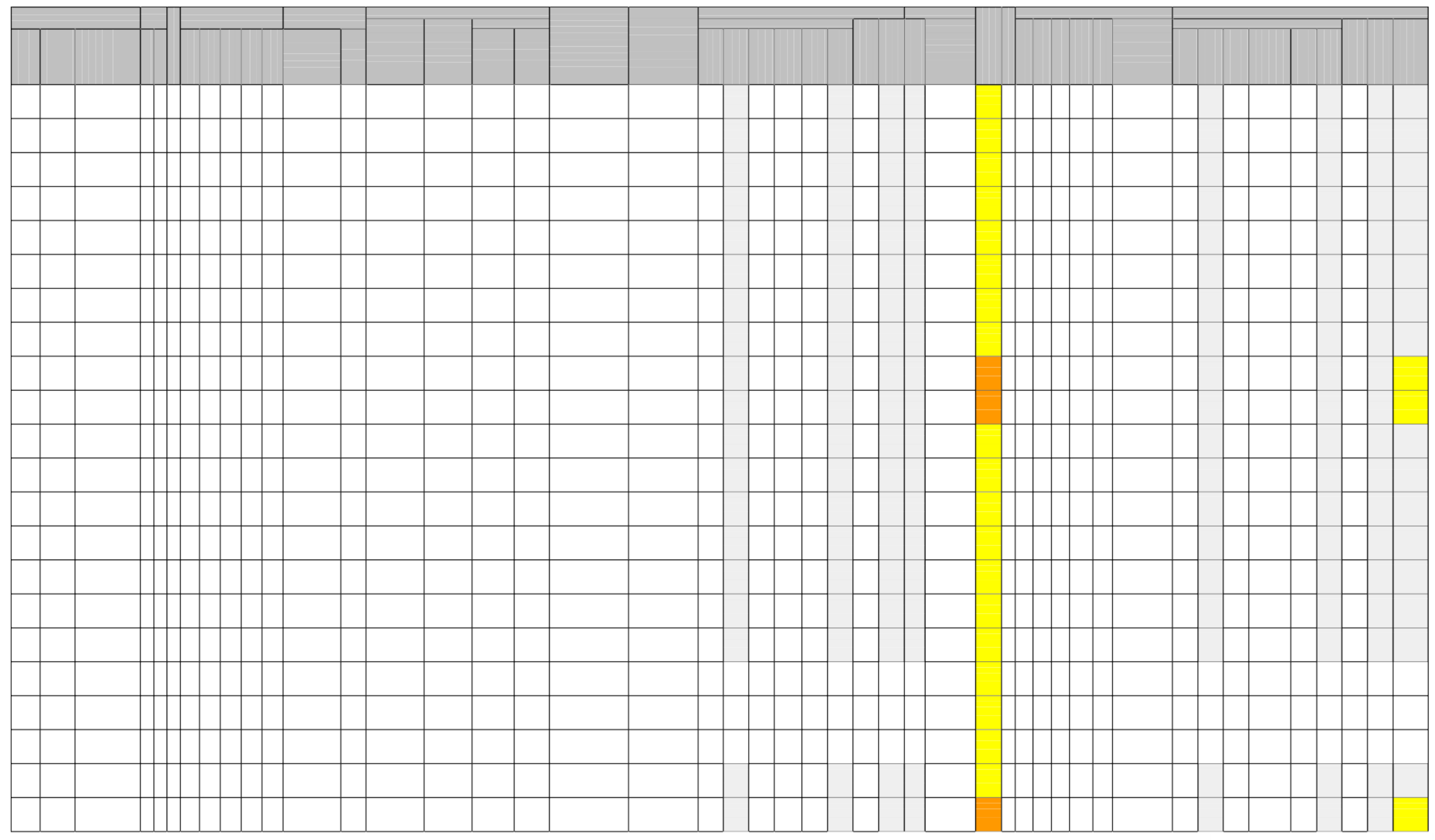




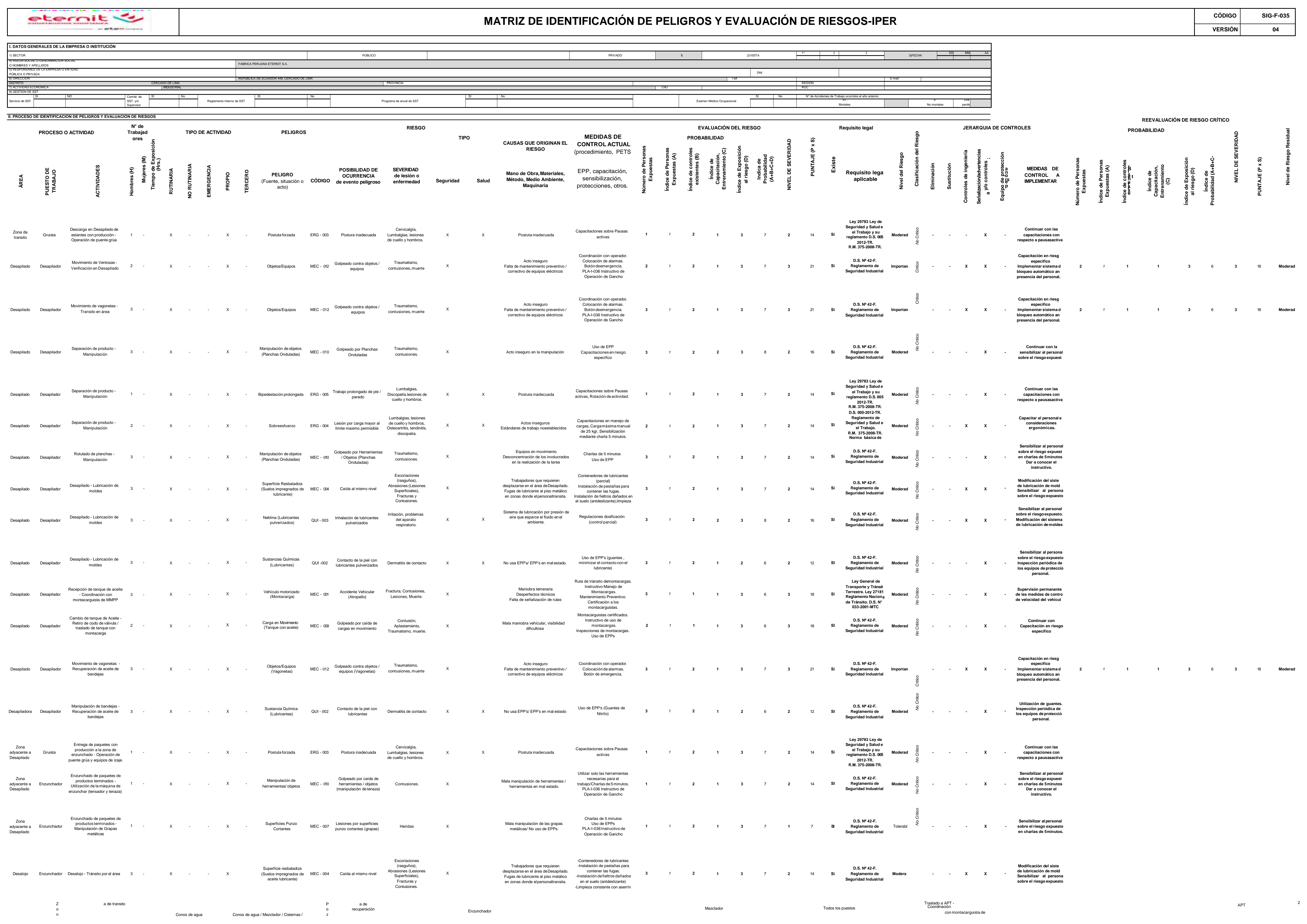



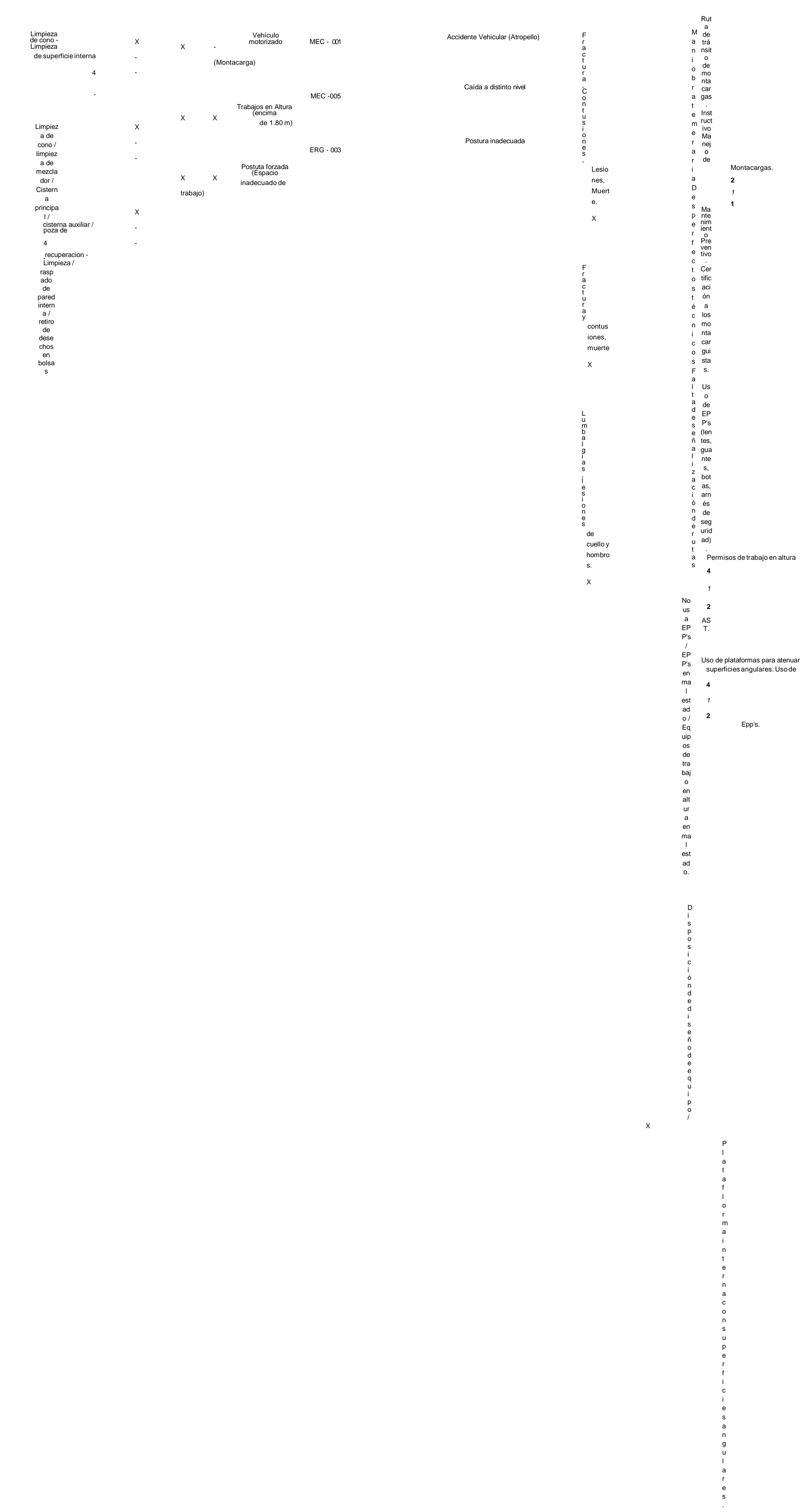

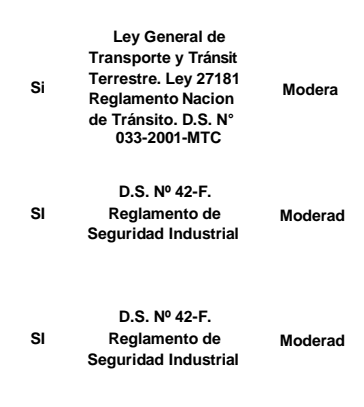

Fecha aprobación del formato:23/04/13 


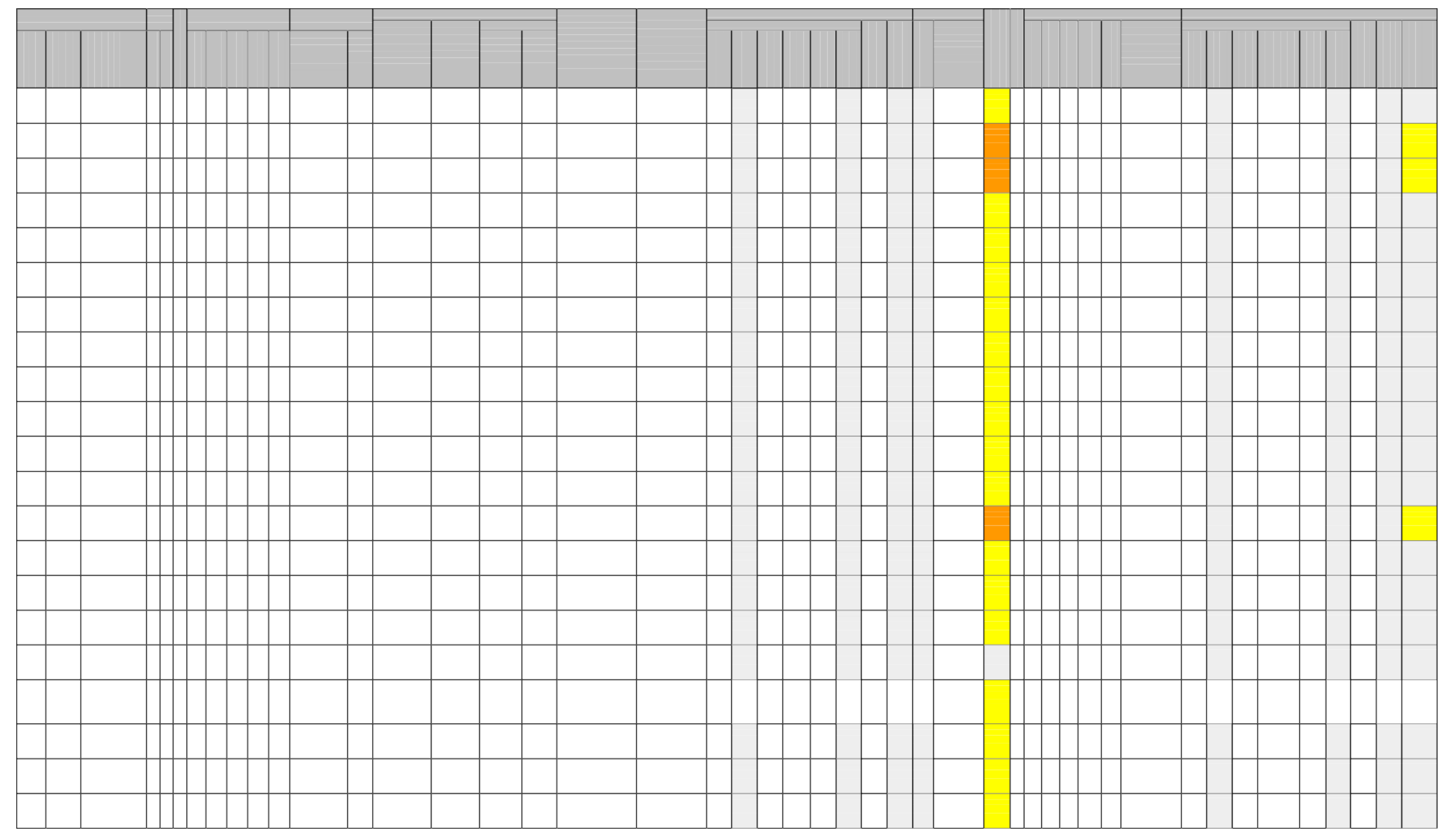




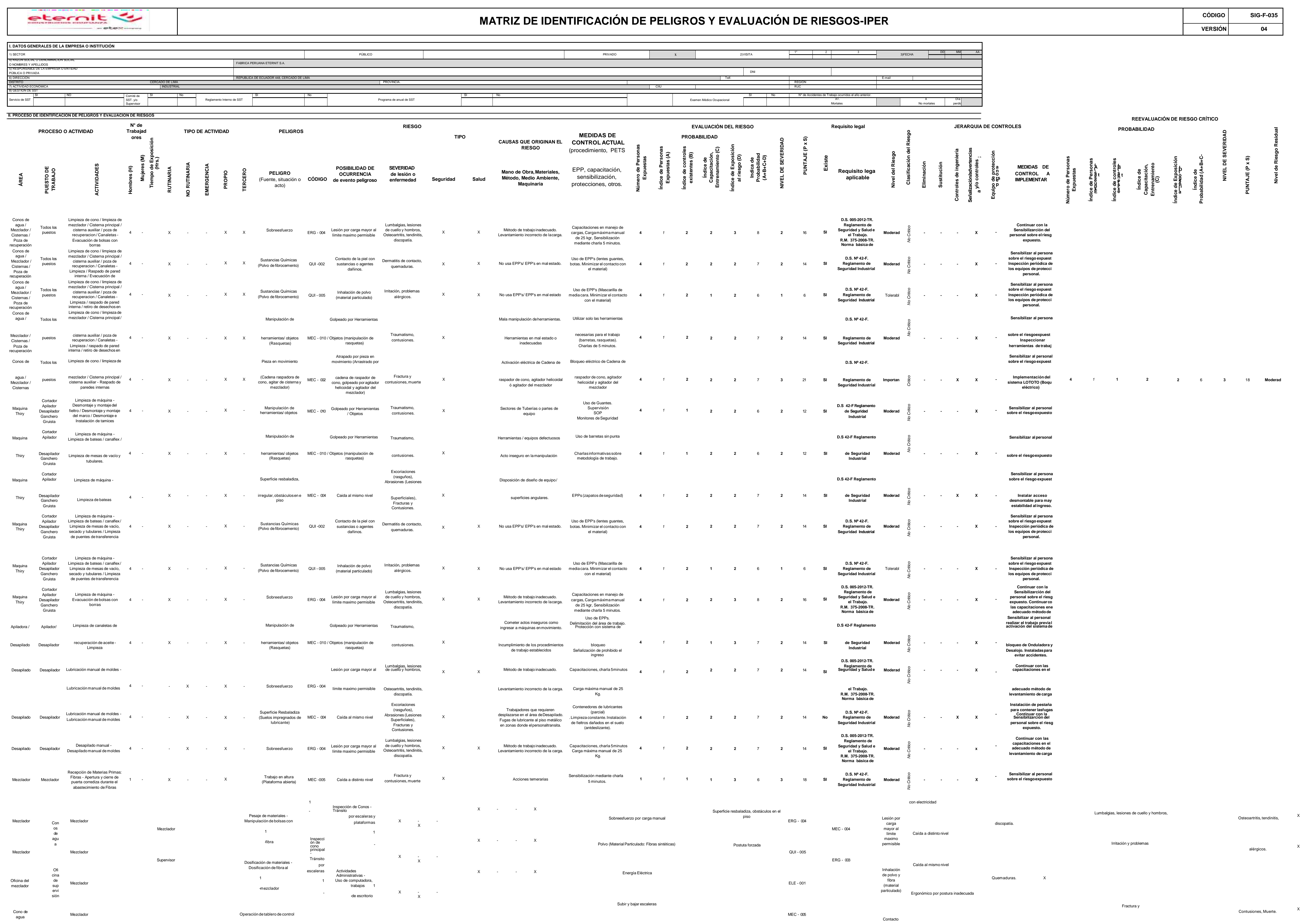




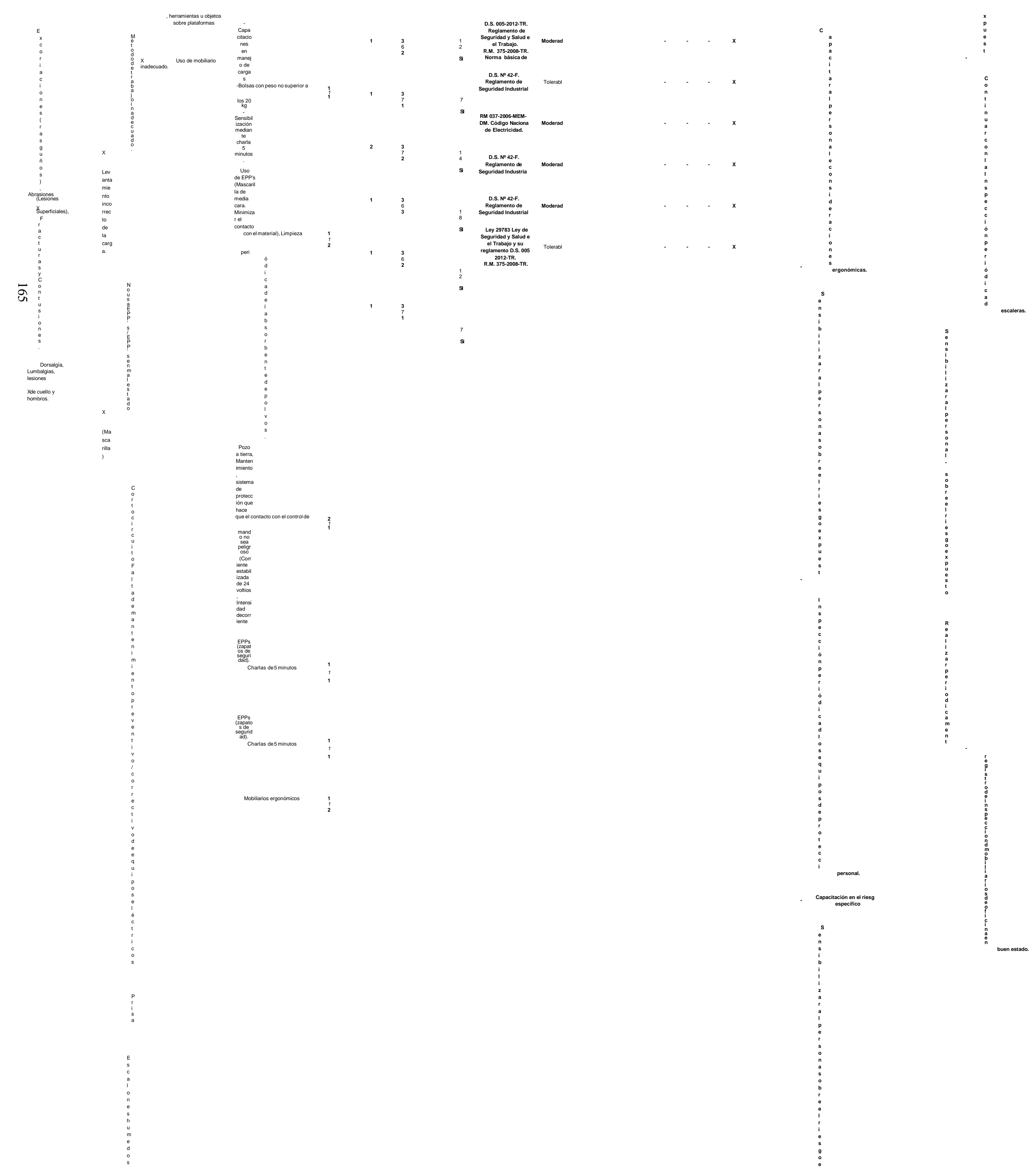




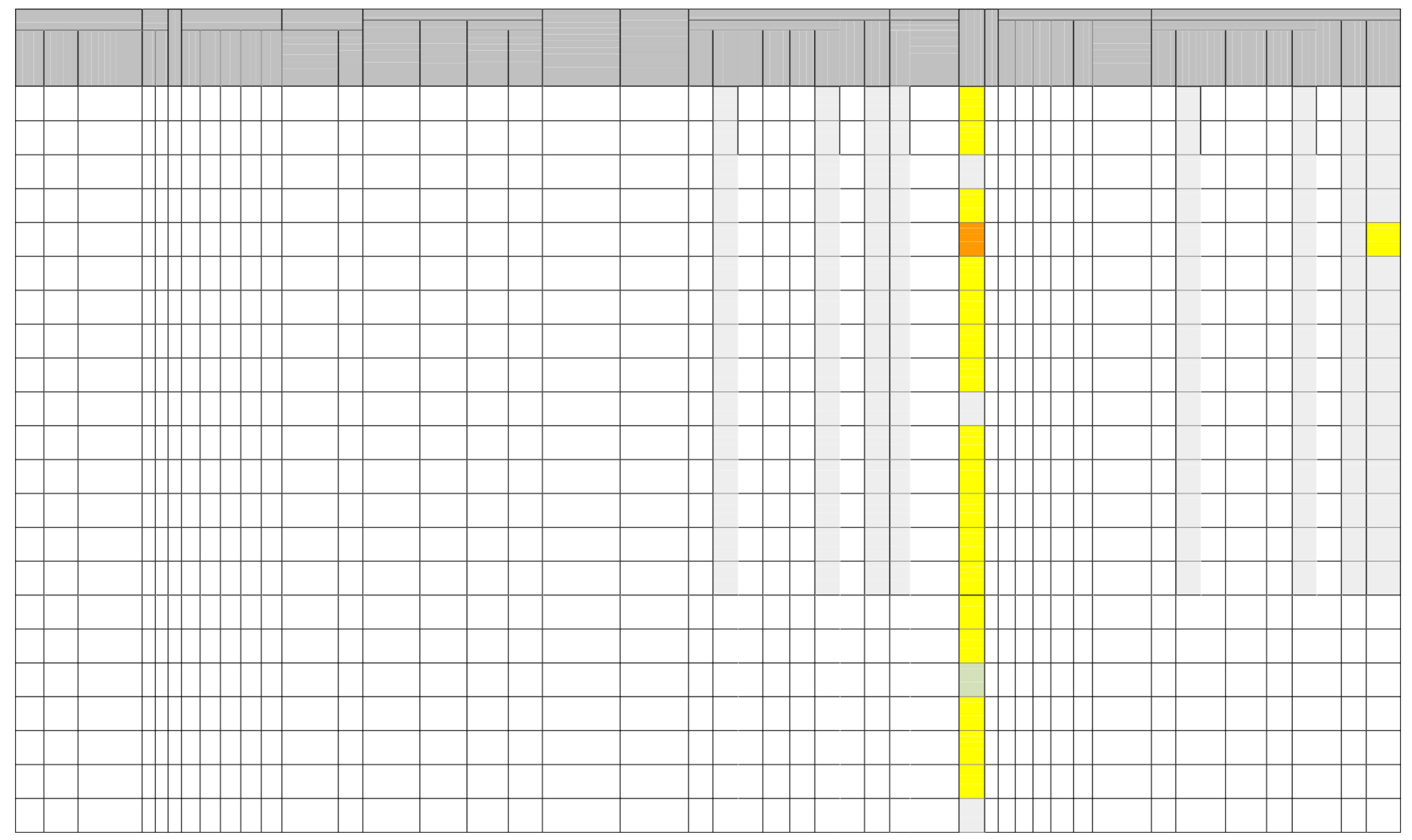




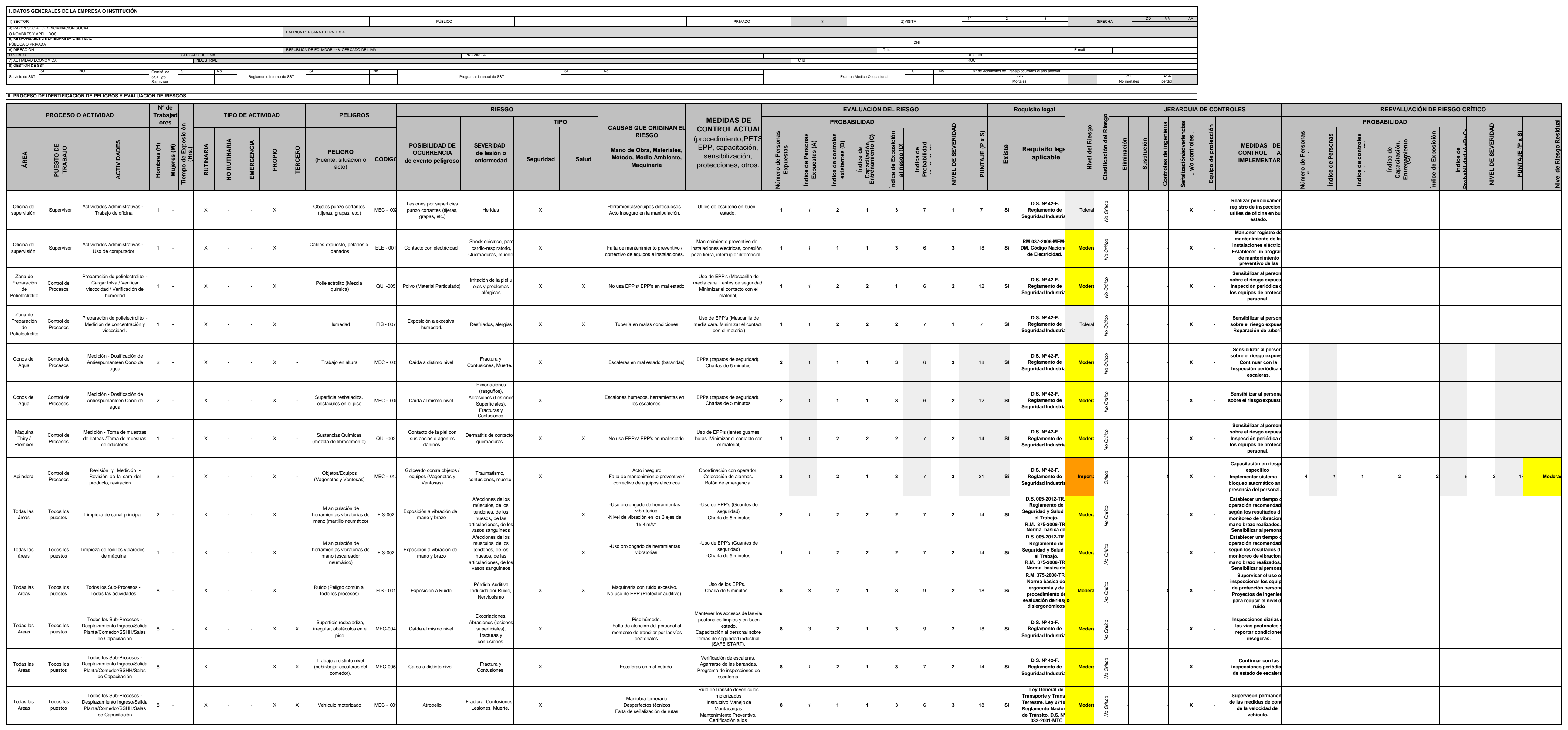

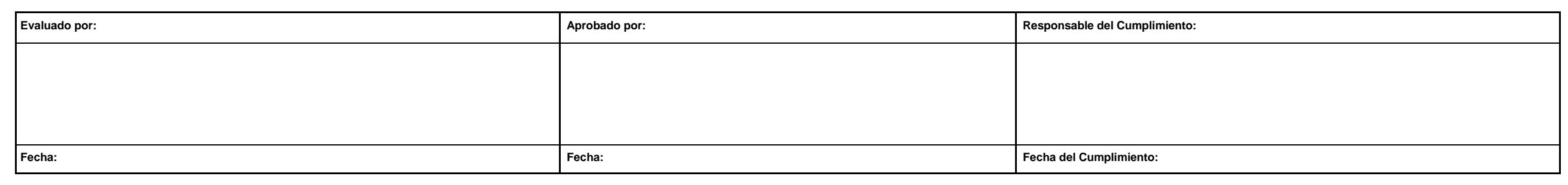




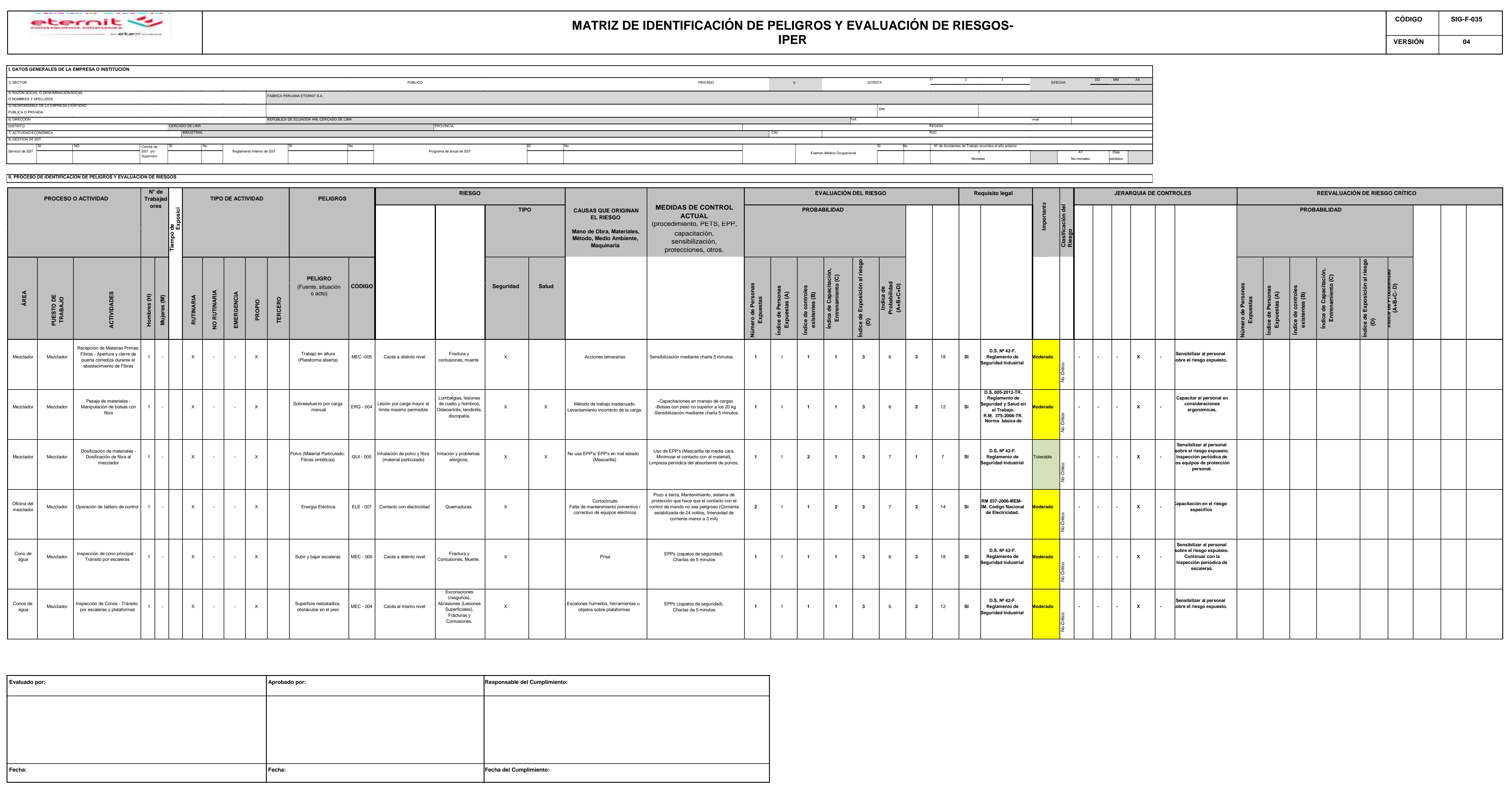


